\title{
IMAGE : an integrated model to assess the greenhouse effect
}

Citation for published version (APA):

Rotmans, J. (1990). IMAGE : an integrated model to assess the greenhouse effect. [Doctoral Thesis, Maastricht University]. Rijksuniversiteit Limburg. https://doi.org/10.26481/dis.19900920jr

Document status and date:

Published: 01/01/1990

DOI:

10.26481/dis.19900920jr

Document Version:

Publisher's PDF, also known as Version of record

\section{Please check the document version of this publication:}

- A submitted manuscript is the version of the article upon submission and before peer-review. There can be important differences between the submitted version and the official published version of record.

People interested in the research are advised to contact the author for the final version of the publication, or visit the DOI to the publisher's website.

- The final author version and the galley proof are versions of the publication after peer review.

- The final published version features the final layout of the paper including the volume, issue and page numbers.

Link to publication

\footnotetext{
General rights rights.

- You may freely distribute the URL identifying the publication in the public portal. please follow below link for the End User Agreement:

www.umlib.nl/taverne-license

Take down policy

If you believe that this document breaches copyright please contact us at:

repository@maastrichtuniversity.nl

providing details and we will investigate your claim.
}

Copyright and moral rights for the publications made accessible in the public portal are retained by the authors and/or other copyright owners and it is a condition of accessing publications that users recognise and abide by the legal requirements associated with these

- Users may download and print one copy of any publication from the public portal for the purpose of private study or research.

- You may not further distribute the material or use it for any profit-making activity or commercial gain

If the publication is distributed under the terms of Article $25 \mathrm{fa}$ of the Dutch Copyright Act, indicated by the "Taverne" license above, 
IMAGE:

AN INTEGRATED MODEL TO

ASSESS THE GREENHOUSE EFFECT 
Promotor : Prof.dr.ir.drs. O.J. Vrieze

Co-promotor: Dr.ir. B.C.J. Zoeteman

Leden van de beoordelingscommissie:

Prof.dr. H.J. van den Herik

Prof.dr. J.P.C. Kleijnen

Dr. J. Kleinjans

Prof.dr. C.J.E. Schuurmans

Prof.dr.ir. H.G. Wind 


\section{IMAGE:}

\section{AN INTEGRATED MODEL TO ASSESS THE GREENHOUSE EFFECT}

\section{PROEFSCHRIFT}

ter verkrijging van de graad van doctor aan de Rijksuniversiteit Limburg te Maastricht op gezag van de Rector Magnificus, Prof.dr. F.I.M. Bonke, volgens het besluit van het College van Decanen, in het openbaar te verdedigen op donderdag, 20 september 1990, om 14.00 uur

door

Jan Rotmans

geboren te Rotterdam in 1961 
3.3 Emissions Module . . . . . . . . . . . . . . . . . . 32

3.4 Atmospheric Concentrations Module ... . . . . . . 34

3.5 Ocean Module . . . . . . . . . . . . . . . . . 35

3.6 Terrestrial Biosphere Module ... . . . . . . . . . . 40

3.7 Deforestation Module . . . . . . . . . . . . . 45

3.7 .1 Introduction . . . . . . . . . . . 45

3.7.2 Description of the Deforestation Model . . . . . 47

3.7 .3 Description of the Processes . . . . . . . . 53

3.8 Validation and Uncertainty . . . . . . . . . . . 62

3.9 Results . . . . . . . . . . . . . . . . . . 62

3.10 Conchusions . . . . . . . . . . . . . . . 72

3.11 Appendix ...................... 74

4 The Methane Module $\quad \mathbf{8 1}$

4.1 Introduction . . . . . . . . . . . . . . . . 81

4.2 Model Description . . . . . . . . . . . . . . . 82

4.2 .1 Structure . . . . . . . . . . . . . 82

4.2 .2 Calculation Procedure . . . . . . . . . 82

4.2 .3 Notation . . . . . . . . . . . . . . . . . . . . . 84

4.3 Emissions . . . . . . . . . . . . . . . . . . . . 84

4.4 Concentrations . . . . . . . . . . . . . . . . 90

4.5 Results . . . . . . . . . . . . . . . . . . 93

4.6 Conclusions . . . . . . . . . . . . . . . . 100

5 The $\mathrm{N}_{2} \mathrm{O}$ Module 103

5.1 Introduction . . . . . . . . . . . . . . . . 103

$5.2 \mathrm{~N}_{2} \mathrm{O}$ Emissions Module . . . . . . . . . . . . . 103

$5.3 \mathrm{~N}_{2} \mathrm{O}$ Concentration Module . . . . . . . . . . . 106

5.4 Results . . . . . . . . . . . . . . . . . 107

5.5 Conclusions . . . . . . . . . . . . . 108

6 The CFCs Module 111

6.1 Introduction . . . . . . . . . . . . . . 111

6.2 CFCs Emissions Module . . . . . . . . . . . . . . . . 112

6.3 CFCs Concentrations Module . . . . . . . . . . . . 116

6.4 Results . . . . . . . . . . . . . . . . . 117

6.5 Conclusions . . . . . . . . . . . . . . . . 121 
7 The Climate Module $\quad 123$

7.1 Introduction . . . . . . . . . . . . . . 123

7.2 Model Description . . . . . . . . . . . . . 125

7.2 .1 Equilibrium Response . . . . . . . . . . . 125

7.2 .2 Transient Response . . . . . . . . . . . . . 129

7.2 .3 Climate Feedbacks . . . . . . . . . . . 133

7.3 Results . . . . . . . . . . . . . . . . . . 134

7.4 Conclusions ...................... 146

8 The Sea Level Rise Module $\quad 149$

8.1 Basic Trend . . . . . . . . . . . . . . . . 150

8.2 Thermal Expansion . . . . . . . . . . . . . . . 150

8.3 Glaciers and Small Ice Caps . . . . . . . . . . . . . . 151

8.4 Greenland Ice Cap . . . . . . . . . . . . . . . . 152

8.5 Antarctic Ice Cap . . . . . . . . . . . . . . . . 154

8.6 Uncertainties . . . . . . . . . . . . . . . . 155

8.7 Sea Level Rise Potential . . . . . . . . . . . . . . . . 156

8.8 Results . . . . . . . . . . . . . . . . 157

8.9 Conclusion . . . . . . . . . . . . . . 161

9 Socio-Economic Impact 163

9.1 Introduction . . . . . . . . . . . . . . . . . . . 163

9.2 General Model Description . . . . . . . . . . . . . 164

9.3 Quantification of Impacts for Various Sectors . . . . . . . 171

9.3.1 Introduction . . . . . . . . . . . 171

9.3.2 Coastal Defence . . . . . . . . . . . . . 171

9.3.3 Water Management and Water Supply . . . . . 178

9.3 .4 Agriculture . . . . . . . . . . . . . 180

9.3 .5 Energy Use . . . . . . . . . . . . . . . 181

9.4 Results . . . . . . . . . . . . . . . . . . . 182

9.5 Conclusions . . . . . . . . . . . . . . . . . 191

10 Policy Analysis $\quad 193$

10.1 Introduction . . . . . . . . . . . . . . . . . 193

10.2 Scenario Calculations . . . . . . . . . . . . . . . 194

10.3 Low Climate Risk Scenario . . . . . . . . . . . . . . . 195

10.4 Results . . . . . . . . . . . . . . . . . . 196

10.5 Delayed Response . . . . . . . . . . . . . . . 198

10.6 Future Worlds . . . . . . . . . . . . . . . . . . 200 
10.7 Conclusions $\ldots \ldots 203$

11 Temperature Increasing Potential 205

11.1 Introduction . . . . . . . . . . . . . . . 205

11.2 Relation between Temperature and Emissions . . . . . . 205

11.3 Methodology . . . . . . . . . . . . . . . . . . . . . . . . . . 206

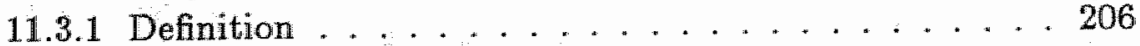

11.3.2 Modelling Approach . . . . . . . . . . . . . . 208

11.3.3 Analytical Approach . . . . . . . . . . . . . 211

11.4 Results. . . . . . . . . . . . . . . . . . . 215

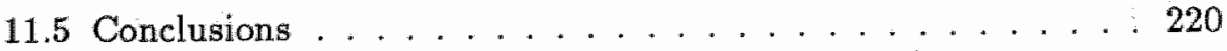

11.6 Appendix . . . . . . . . . . . . . . . . 222

12 Sensitivity Analysis $\quad \mathbf{2 2 5}$

12.1 Introduction . . . . . . . . . . . . . . 225

12.2 Metamodelling . . . . . . . . . . . . . 226

12.3 Experimental Design . . . . . . . . . . . . . . . 228

12.4 A Metamodel for the Costs of Dike Raising . . . . . . . 230

12.4.1 Introduction . . . . . . . . . . . 230

12.4.2 Input and output variables ......... 230

12.4.3 Specification of the First Metamodel for the Costs of Dike Raising . . . . . . . . . . . . 230

12.4.4 Experimental Design for the First Metamodel . . . . 232

12.4.5 Results of the First Metamodel . . . . . . . . 233

12.4.6 Further Analysis after the First Metamodel . . . . . 233

12.4.7 Specification of the Final Metamodel for the Costs of Dike Raising

12.4.8 Validation of the Final Metamodel . . . . . . . 236

12.4 .9 Scaling Effects . . . . . . . . . . . . . 239

12.4.10 Conclusions . . . . . . . . . . . . . . 240

12.5 A Metamodel for the Ocean Module .......... 241

12.5.1 Introduction . . . . . . . . . . . . . 241

12.5.2 First Metamodel for the Ocean Module . . . . . . . 242

12.5.3 Further Analysis after the First Metamodel . . . . . 245

12.5.4 Final Metamodel for the Ocean Module . . . . . . 245

12.5 .5 Conclusions . . . . . . . . . . . . . . 249

12.6 A Terrestrial Biosphere Metamodel . . . . . . . . . . 249

12.6.1 Introduction . . . . . . . . . . . . . 249 
12.6.2 Various Metamodels for the Terrestrial Biosphere Module . . . . . . . . . . . . . . 250

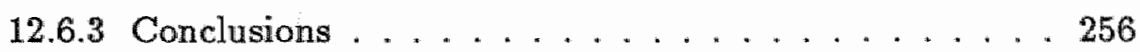

12.7 General Conclusions . . . . . . . . . . . . . . 257

$\begin{array}{lr}13 \text { Discussion } & 259\end{array}$

$\begin{array}{ll}\text { References } & 263\end{array}$

$\begin{array}{ll}\text { Samenvatting } & 291\end{array}$

$\begin{array}{lr}\text { Curriculum vitae } & 295\end{array}$ 


\section{Preface}

This book is the result of a research project entitled "Reference function for Global Air Pollution $/ \mathrm{CO}_{2}$ " initiated by RIVM. It deals with the description of a computer simulation model of the greenhouse effect. This model, IMAGE, tries to capture the fundamentals of the complex problem of climate change in a simplified way. The model is a multidisciplinary product and is based on knowledge from disciplines as economics, atmospheric chemistry, marine and terrestrial biogeochemistry, ecology, climatology, and glaciology. This book might be of interest for any one working in the broad field of climate change. Furthermore, it can be useful for model builders, simulation experts, mathematicians etc. A PC version of the model will become available free of charge. Requests can be sent to the author.

Although being the only author of this book, I could never have written it without the help of many other people. First of all I would like to thank Koos Vrieze, originally a colleague at RIVM, later my professor. Without his inspiring attitude I would have never finished this thesis. I am also very grateful to RIVM for giving me the opportunity to write this thesis. I owe many thanks to Hans de Boois and Rob Swart for their support and assistance during the research. Furthermore, I would like to thank my trainees who have substantially contributed to the contents of this book. Especially I would like to thank Greet van Ham, who helped me to perform a thorough sensitivity analysis with the computer model. I also want to express my attitude for the help of Michel den Elzen, who assisted me with great devotion in developing and improving parts of the model. Special thanks to Martin Middelburg and André Berends for drawing the great number of pictures. I also wish to thank Marlies Haenen for the many hours she spent on transforming the rough version of the document into a perfect-looking one.

Last, but not least, I would like to thank Inge and my parents for their support and patience throughout. 


\section{Units}

${ }^{\circ} \mathrm{C}$ degrees Celsius

K degrees Kelvin

ppm parts per million by volume

$p p b \quad$ parts per billion by volume

ppt parts per trillion by volume

$G t$ : gigatons (10 $\left.0^{15} \mathrm{gram}\right)$

$G t C$ gigatons of carbon

$T g$ teragram ( $10^{12}$ gram)

$M k g$ million kilogram (10 ${ }^{9}$ gram)

$\lambda$ lambda

$W m^{-2}$ watts per meter square

Mha millions of hectares

$k g \quad$ kilogram

$\operatorname{TgN}$ teragram of nitrogen

Df Dutch florins or guilders

$\mathrm{km}$ kilometer 


\section{Chapter 1}

\section{General Introduction}

\subsection{The Problem}

The earth's energy balance is dominated by atmospheric heat trapping; about $70 \%$ of of the incoming solar energy is absorbed. The absorbed energy is re-emitted at infrared wavelengths by the atmosphere and the earth's surface. Most of the surface radiation is trapped by clouds and greenhouse gases, and returned to the earth. This phenomenon is called the greenhouse effect, inducing an average temperature of the earth at the surface of +15 ${ }^{\circ} \mathrm{C}$ rather than the $-18{ }^{\circ} \mathrm{C}$ it would have without the heat trapping. This greenhouse effect is essential for the existence of life on earth, having made it possible for millions of years.

Through this process of radiative absorption greenhouse gases - of which carbon dioxide $\left(\mathrm{CO}_{2}\right)$, methane $\left(\mathrm{CH}_{4}\right)$, nitrous oxide $\left(\mathrm{N}_{2} \mathrm{O}\right)$, and chlorofluorocarbons (CFCs), together with water vapour $\left(\mathrm{H}_{2} \mathrm{O}\right)$ and ozone $\left(\mathrm{O}_{3}\right)$ are the most important - play a major role in determining the earth's climate.

Since the industrial revolution mankind has caused a considerable increase in the atmospheric content of these greenhouse gases. The primary cause of the increased concentrations is the large-scale and worldwide use of fossil fuels to generate heat, power, and electricity for a growing world population, as well as the changes in land use, especially for agriculture. For more than a century the use of fossil fuels has been on the increase and this development is still continuing. Since the beginning of this century the atmospheric concentration of $\mathrm{CO}_{2}$ has increased by about $25 \%$. The concentrations of some other greenhouse gases have increased by even larger factors.

Dependent on the assumptions and definitions used it can generally be 
said that the energy and industrial sectors cause about $75 \%$ of the enhanced greenhouse problem, while about $25 \%$ is caused by the agricultural sector, including deforestation. In this way mankind has become a dominant factor in the greenhouse effect.

There is virtually no doubt among scientists that increasing concentrations of greenhouse gases will raise the earth's temperature. There is only controversy about the magnitude and the time frame of the temperature increase. Measurements from bubbles of air trapped in ice cores of the Antarctic ice sheets show that, over the past 160,000 years, there is a very close correlation between past climatic changes and fluctuations in the greenhouse gas concentrations of carbon dioxide and methane. It is not clear, however, whether the greenhouse gas variations caused the climatic changes or vice versa.

In the past 100 years the global average surface temperature has increased by about half a degree celsius. Although it seems obvious to account for the temperature increase on the basis of the enhanced greenhouse effect, the evidence is not yet conclusive. One of the things that cannot be explained is the irregular course of the temperature record: a rapid warming until the end of the Second World War, then a slight cooling through the seventies, and a period of rapid warming since then. That does not correspond with the steady warming that might be expected from a steady buildup of the greenhouse gases.

The future temperature curve will depend on the emissions of trace gases, the resulting concentrations, and the climatic effects these concentrations will bring about. Growth in fossil fuel use, the adoption of alternative energy sources, the rate of deforestation, and policy measures will strongly affect future emission pathways. These future emission levels will, together with a whole complex of feedback mechanisms, determine the resulting concentrations, among other things. Increasing concentrations and temperature rise may trigger both positive and negative feedback mechanisms, such as the increased uptake of $\mathrm{CO}_{2}$ by plants and oceans, or increased release of $\mathrm{CO}_{2}$ by organic matter in soils, or increasing $\mathrm{CH}_{4}$ release through methane hydrates and methane locked up in Arctic permafrost. In spite of these uncertainties, a doubling of the $\mathrm{CO}_{2}$ concentration is expected around the middle of the next century. The $\mathrm{CO}_{2}$ equivalent concentration, which expresses the combined total radiative forcing effect of all trace gases compared to $\mathrm{CO}_{2}$ alone, is expected to doubie even sooner.

The climatic implications of a doubling of atmospheric $\mathrm{CO}_{2}$ are computed by mathematical climate models. These models are used because history 
gives us no clear quantitative answer, and the complicated climate system cannot be reproduced in a laboratory. These General Circulation Models (GCM's) consist of mathematical expressions for the ocean-atmosphere system. In such a model the atmosphere is represented as a three-dimensional grid with an average horizontal spacing of several hundred killometers, and an average vertical spacing of several kilometers. The models calculate equilibrium temperature, pressure, wind speed, humidity, soil moisture and other variables, based on an abrupt doubling or quadrupling of atmospheric $\mathrm{CO}_{2}$. Running such GCM's costs immense amounts of computer time even on the fastest supercomputers (Schneider, 1989).

These climate models suggest that the earth is now warmer than the observational record indicates, and are inconsistent in their simulation of regional-scale average temperatures. Simulated precipitation is also geographically inconsistent among the various models. The inconsistencies of the models are due to their coarse resolution and their crude treatment of the oceans. However, smaller-scale portrayals, while desirable, increase model computational requirements exponentially.

Despite their limitations, models are the only means for estimating future climate change. The results of the most recent GCM's are in agreement that a doubling of $\mathrm{CO}_{2}$ in the atmosphere will lead to an average surface temperature increase of $1.5^{\circ} \mathrm{C}$ to $4.5^{\circ} \mathrm{C}$. This estimate for the coming century is comparable with the increase in temperature of rougly $5^{\circ} \mathrm{C}$ since the peak of the last ice age 18,000 years ago, with this difference: it will occur between 10 and 100 times faster (Schneider, 1989).

These predicted temperature increases will be larger at polar latitudes than at temperate latitudes and smallest at tropical latitudes. Additionally, precipitation will increase globally by $7 \%$ to $15 \%$.

In spite of the discrepancy between the model predictions and the measured global temperature trend so far, there is a growing scientific consensus that the enhanced greenhouse warming has already appeared, and that it will be detected within one or more decades.

Obviously the greenhouse phenomenon will have a profound effect on ecological and social structures. One of the major threats is a sea level rise, as a result of the thermal expansion of the oceans, the melting of glaciers, and the net effect of the possible melting of the Greenland ice cap and the accumulation effect in Antarctica. Sea level rise could endanger many low-lying coastal settlements and ecosystems, and might cause erosion, salt intrusion and seepage.

Water resource management, currently a problem in many nations, may 
become even more problematic. Current policies may have to be modified in the areas of water storage, flood and erosion control.

Practically every other important natural resource and need for human welfare, such as agriculture, shipping, forestry, nutrition, health, and natural ecosystems could be affected by the greenhouse effect, with outcomes that are currently uncertain. Some areas may benefit from the greenhouse effect.

Clearly these direct effects of climatic change could have powerful economic, social and political consequences. But the economy and society will also be indirectly affected owing to the effects on the food supply, world timber production and the energy supply. Both for the developed countries, and for the developing countries, especially for the rapidly increasing population of the Thirld World, where ecosystems are often vulnerable the risks are very high. However, even in a highly developed country with a complex social and economic structure, the environmental and economic effects may also be profound. The greenhouse issue may even lead to political instability. In the face of this array of threats, three kinds of responses could be considered: first, technical measures to counteract climatic change; secondly, adaptation, often with little or no attempt to anticipate damages or prevent climatic change. The third category of response is prevention: curtailing the greenhouse gas buildup. Energy conservation measures, alternative energy sources or a switch from coal to natural gas; whatever action we choose to take, the greenhouse effect is a permanent part of living on our fragile planet.

In summary it can be concluded that humanity is performing a largescale geophysical experiment, not in a laboratory or on a computer, but on the planet earth itself. The outcome of the experiment should be evident within decades.

\subsection{The Model}

In 1984, the RIVM initiated a project entitled "Reference Function for Global Air Pollution $/ \mathrm{CO}_{2} "$. Within this framework global modelling was defined as a quintessential activity. As a kind of feasibility study, it was planned to build a prototyping model for the greenhouse problem. During the period from June 1985 to February 1986 I was seconded to RIVM as a student, and in this period I developed this prototype. The main purpose of the prototype was to develop a tool that could give a broad overview of the complex greenhouse problem, by coarsely combining and aggregating diffuse information from various disciplines. The prototype comprised many input-output 
relationships, which underly complex model formulations. This model was mainly based on an extensive study of the literature (Rotmans, 1986), and was implemented on a $\mathrm{PC}$, making use of the simulation language D YNAMO (Pugh, 1983). As a result of the satisfactory results obtained with the prototype, it seemed worth the effort to continue with a globally model of the greenhouse issue. The prototype marked the end of the first phase.

The second phase started in the course of 1986, with the initiation of IMAGE: the Integrated Model to Assess the Greenhouse Effect. The primary objective of IMAGE is to create a comprehensive picture of global climate change, by integrating the separate components into a synthetic framework. Although, in the literature, more abstract definitions of integrated environmental models are given (Hafkamp, 1984, and Brouwer, 1987), here a pragmatic definition of an integrated environmental model is used. According to Olsthoorn (1987) and Aldenberg (1988), an integrated environmental model is defined here as a model that couples air, soil, and water compartments, and integrates the interactions between divers environmental compartments. Such an integrated model considers the whole cause-effect relationship, from the arising of the pollution or the taking of a measure, to the ultimate ecological or socio-economic effect. Such an integrated model adds nothing to the separate compartment models, but is merely a modelling integration of knowledge and expertise from the separate scientific disciplines. (Boois, de, et al., 1989)

IMAGE comprises a concatenation of autonomously functioning models, called modules, each module representing and covering a particular scientific field. Following Hettelingh (1989) a module is interpreted as a set of intra-related variables oriented towards a single discipline, that represent the phenomena of a subsystem and that are interrelated to the variables of another module.

The atmosphere, terrestrial biota, and the ocean are the compartments included in IMAGE. Furthermore, the main interactions between these compartments are integrated. Within these compartments the following processes can be distinguished: emissions, atmospheric chemical processes, ra diative perturbation, and sea level rise. To model these processes, as well as their causes and effects, IMAGE makes use of separate aspect-compartment models in the sphere of such scientific disciplines as the world economy, atmospheric chemistry, marine and terrestrial biogeochemistry, ecology, climatology, hydrology, and glaciology.

These elaborate aspect-compartment models need to be reformulated, and remodelled. Inevitably they have to be simplified, by applying the 
simplification tools of parametrization, omission of minor contributions, and approximation of nonlinear systems. Thissen (1978) has given an elaborate review of useful techniques for simplifying complicated models.

Besides this reformulation and remodelling aspect, the methodology of coupling also involves the definition of one single mathematical concept. Specifically, this means that, from a mathematical viewpoint, the broad collection of models, which can be subdivided into discrete/continuous, deterministic/stochastic, dynamic/steady state, etc., has to be reduced to one, unambiguous mathematical formulation and system (Aldenberg, 1988). Furthermore, a mutual harmonization of such aspects as content is also necessary. This implies one conceptual framework, with uniformity with respect to time and space scales, aggregation levels, use of quantities, time step, data, etc.

With respect to these aspects IMAGE meets the requirements of the definition of an integrated environmental model as given above. Following Aldenberg (1988), these integrated environmental models can in turn be subdivided into: sequentially coupled (asynchronously running models, on a variety of computers using different languages), simultaneously coupled (simultaneously running models, on a variety of computers using different languages) and fully integrated (simultaneously running models, using one computer and one language). IMAGE falls within the last category, and is a fully integrated environmental model. This has the advantage that the full integration aspect allows feedback mechanisms to be implemented rather easily, compared to the other two types of integrated model. IMAGE runs on a SUN 4 SPARC Workstation using the simulation language ACSL (Advanced Continuous Simulation Language), which has the advantage that ACSL computer code resembles the original model formulation. Separate modules are running on an IBM PS2/70 computer, again using ACSL.

In the second half of 1990 the second phase will be completed with the incorporation of a network of feedback mechanisms. Although some feedback loops have already been incorporated into IMAGE, this has been done in a provisional way. It is intended to include as many potential interactions and feedbacks as possible, and to make these into a coherent whole. As a final step of the second phase, IMAGE will be documented and a rough version of IMAGE will become available, free of charge, for any interested person or institute.

The third phase encompasses a further regionalization at every level, and the development of a menu-driven, fully interactive version of IMAGE, with a projected time schedule of five years. 
IMAGE belongs to the class of so-called global models (Soest; van, et al., 1988). Up to 1972, when the Report of the Club of Rome appeared, global modelling was not considered to be a serious activity. Today, more than twenty years after the foundation of the Club of Rome, it is now widely accepted that such global, empirical scen ario models are a powerful tool for analysing long-term decision problems. In spite of this there is still a dense aura of scepticism around global modelling. One of the principal reasons for this scepticism is the complexity and unmanageability of the models, in combination with the accumulation of uncertainties and sensitivities. Pestel (1988) for instance, prefers the use of mental models, instead of building huge and monolithic models, which are extremely difficult to understand.

Generally, the predictive force of these models is rather limited. Rather than prediction tools, global models are neither more nor less than instruments which can amplify our insights into the present and future driving forces behind our complex social structures. In Soest van, et al. (1988) Meadows illustrates this by comparing these models with maps: "They don't tell you where to go, but if you know where to go, you can select the best route, which depends upon your goal. The chart (or equivalently the model) gives you but possibilities (options)."

This sceptical attitude holds particularly for IMAGE, especially since IMAGE is a quantitative concatenation of interacting numerical variables, according to mathematical formulations, about the hypothesis of the greenhouse effect. Consequently, if the greenhouse hypothesis were to be rejected in the future, the fundamentals underlying IMAGE would be tarnished. Therefore, although the integrated approach is conceptually attractive, it is a disputable one, because of the sequence of failures and uncertainties consequent on the modelling of the individual disciplines.

It can be questioned what the use is of such a global integrated environmental model as IMAGE. IMAGE tries to capture as much as possible of the cause-effect relationship with respect to climate change, based on an interdisciplinary approach. This leads to a better understanding of the interrelations between the different scientific skills with respect to global climate change. In this way policy agencies can be offered a concise overview of the quantitative aspects of and insights into the greenhouse problem. Additionally, such an integrating instrument can strongly increase awareness among different societal groups. Thus the educational and instructive value of IMAGE is a key element.

Besides these aspects, uncertainties or crucial gaps in current knowledge in the field of global climate change can be identified, because of the added 
value of the integrated approach, which can yield insights that scattered information cannot offer. Furthermore, such an integrated model reveals weaknesses in discipline-oriented models. Finally, the integrating tool enables the evaluation of long term climate strategies. The prognostic character of IMAGE makes it possible to calculate policy options, by defining scenarios. In the long run it is meant to be an interactive tool for different kinds of users, such as policy makers, investigators, students, etc.

As a matter of course, uncertainty and sensitivity analyses are of vital importance in determining the essential features and revealing the weaknesses of IMAGE. In Jansen et al. (1990) an enumeration of methods and techniques for the performance of such analyses is given. Several analyses on IMAGE have been carried out; sensitivity analyses, making use of the techniques of metamodelling and experimental designs (Rotmans and Vrieze, 1990, Ham van, et al., 1990). According to this method the relationship between the inputs and outputs of the simulation model is modelled through a regression model, also called a metamodel. The use of experimental designs allows experiments to be carried out in an efficient and effective way.

In addition, a preliminary uncertainty analysis has been performed, using the software package PRISM. PRISM incorporates the features of Latin Hypercube Sampling and metamodelling (Gardner et al., 1983, Lammerts, 1989). Finally, the method of group screening has been utilized, by which very many variables can be investigated and, hopefully, a few really important factors can be detected (Bettonvil, 1990, Bettonvil and Rotmans, 1990).

However, only modules of IMAGE have been subjected to these analyses. Unfortunately no overall analysis has been achieved on IMAGE as a whole, primarily because these sensitivity and uncertainty methods are very timeconsuming. Another reason is the continually updating status of IMAGE, which makes it rather difficult to spend much time on analysing the model. For instance, the mere evaluation of the carbon cycle took more than six months.

Another delicate, unsound point which applies to global integrated environmental models, but to IMAGE in particular, is the limited possibility of verification and validation. One of the things that can at least be done is the comparison of historical trends of state variables in the model with measurements. Thus, global atmospheric concentration trends of greenhouse gases, simulated with IMAGE, are compared to measured global concentrations. For $\mathrm{CO}_{2}$, which has been measured since 1958 at Mauna Loa, this verification time-span is more than 30 years. Furthermore, the observed global 
surface temperature increase of about $0.5^{\circ} \mathrm{C}$ during the last century can be verified with the simulated transient temperature response.

In order to partly overcome these drawbacks, a broad range of conceivable scenarios have been generated. Simulations with these scenarios can be interpreted as a kind of uncertainty analysis. The results obtained with these scenarios are only indicative of future pathways; they do not pretend to be future predictions. 


\section{Chapter 2}

\section{General Model description of IMAGE}

\subsection{Introduction}

The Integrated Model to Assess the Greenhouse Effect (IMAGE) is a policy oriented model based on scientific principles. More specifically, it is a parameterized simulation model, developed for the calculation of historical and future emissions of greenhouse gases on global temperature and sea level rise and ecological and socio-economic interests in specific regions. The model is based on a large variety of data derived from both an extensive study of the literature and knowledge transfer resulting from consultations with specialist experts. In this way the problem could be dealt with via a multi-disciplinary approach, combining different fields of research.

The greenhouse problem is modelled as a dynamic system which evolves in time as a non-stationary Markov chain, with discrete time steps of half a year and a simulation time of 200 years, from 1900 to 2100. The year 1900 is chosen as starting year for the simulation, symbolizing the end of the pre-industrial area. The system is split up into a number of different subsystems, which are modelled by linking sub-models, called modules. From a mathematical viewpoint, the model is a sequence of first order differential equations, and ordinary algebraic equations, which are solved using a Runge-Kutta numerical algorithm. The Runge-Kutta method is used as a default algorithm, but more sophisticated methods as Gear's Stiff have also been used to solve this series of equations.

IMAGE is a deterministic computer simulation model, which consists of 
interlinked modules, each of them describing a specific element of climate change. The modules are linked in a simple way: the output of one module serves as input to the next. At the highest aggregation level the framework of IMAGE consists of the following modules: a source module, an emission module, a concentration module, a climate module, a sea level rise module and a socio-economic impact module for the Netherlands, as shown in figure 2.1.

At a lower aggregation level each module is itself modular built-up, which will be described in chapter 3 and in what follows. Figure 2.2 shows the modullar structure of IMAGE in greater detail. Here an arrow from one module (component) to another represents a driving influence from the first component to the second. The modular structure allows improvements to be implemented gradually without affecting the basic structure. At its inception IMAGE was set up primarily as a tool for long term greenhouse policy analysis and demonstration sessions, running on a microcomputer. The original simple parameterized model structure has been expanded with a number of elaborate modules without interfering with the original purpose. Basically IMAGE tries to capture as much as possible of the cause-effect relationship with respect to climate change. The causes are considered at the global level while, so far, impacts beyond global mean temperature and sea level rise have been included for the Netherlands only. Evidently, such a model can never be complete. New insights and additional scientific knowledge demand for continual updating, improvement and extension of the current model. 


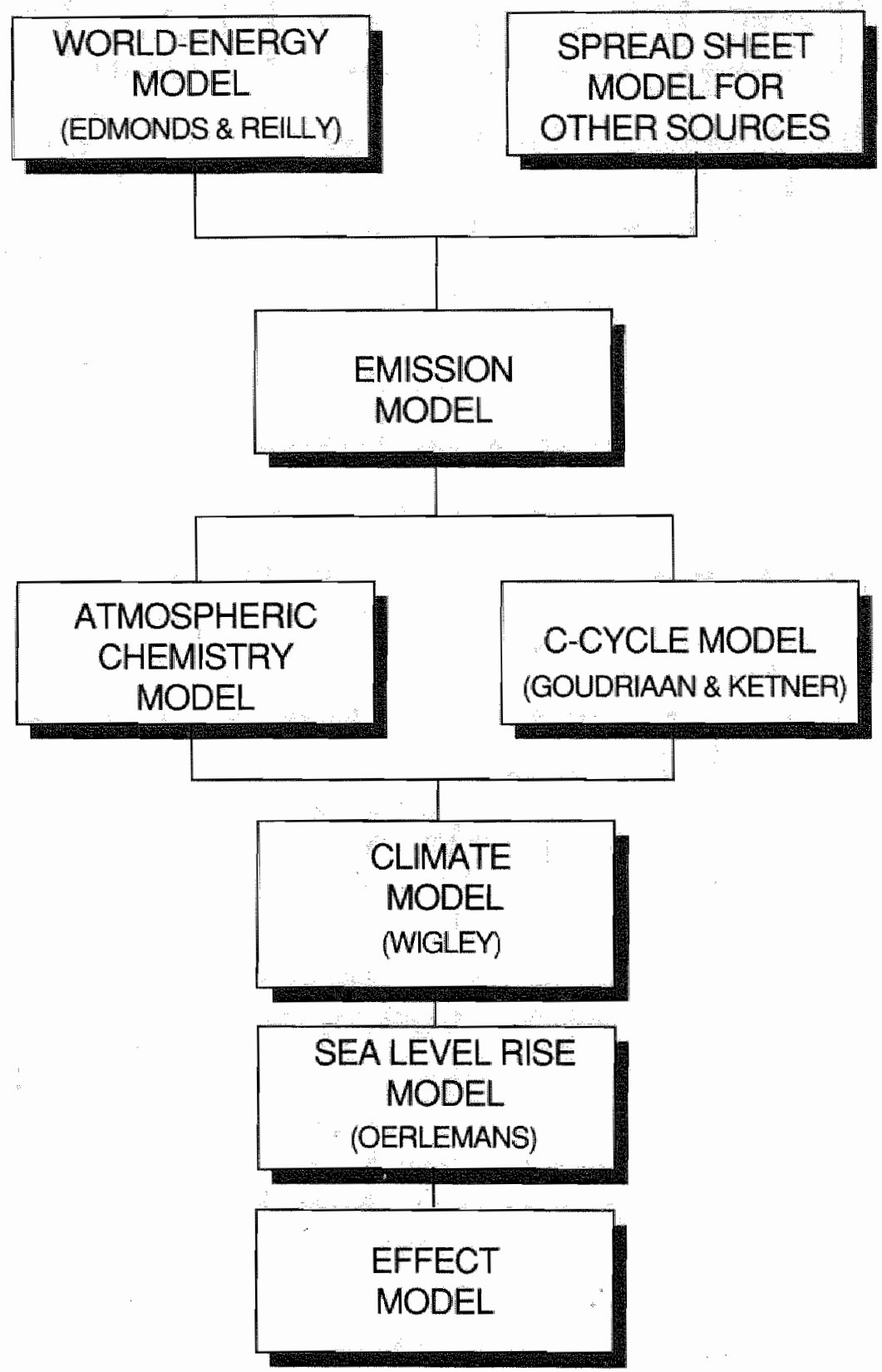

Figure 2.1: Modular construction of IMAGE. 


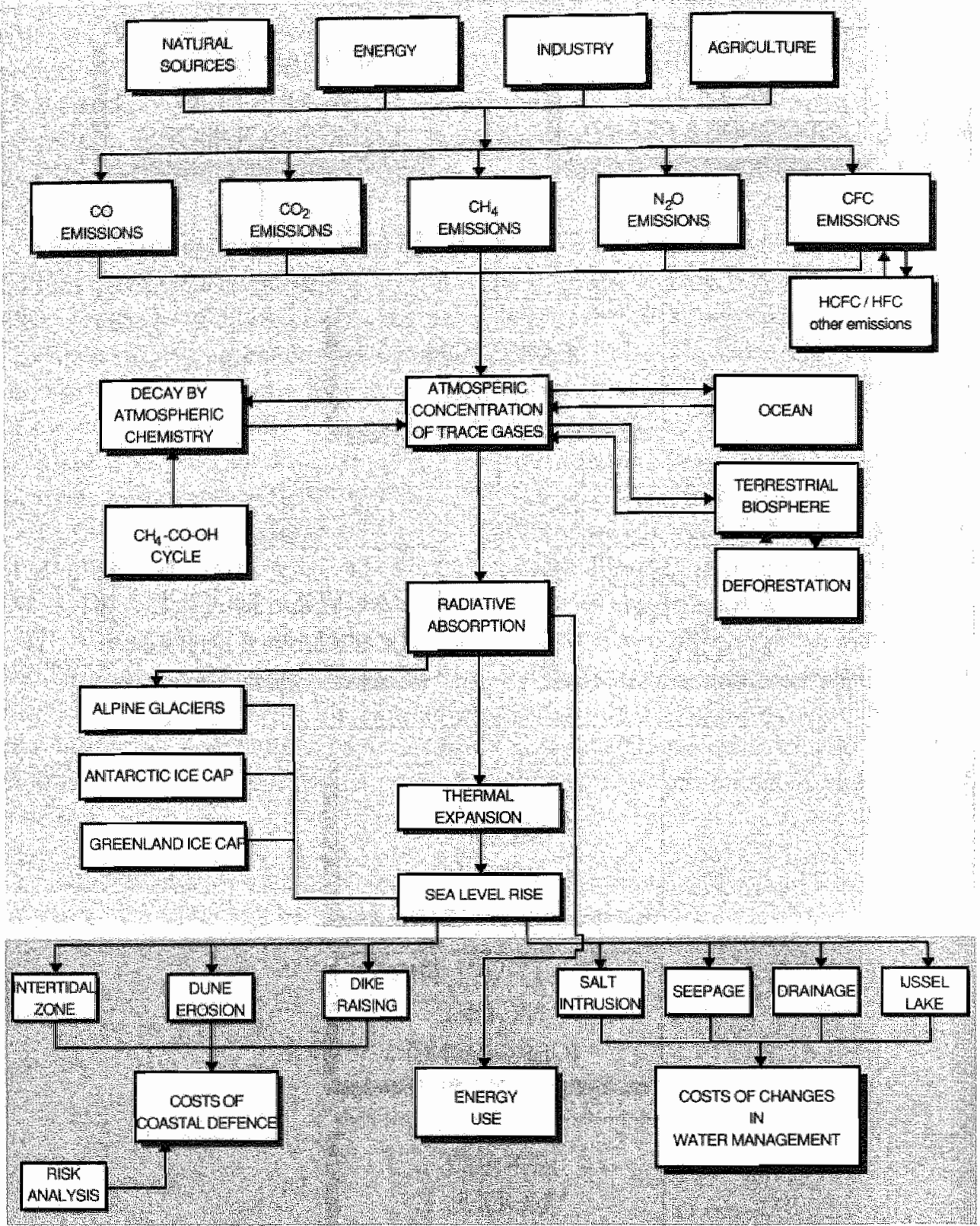

mondial assessment

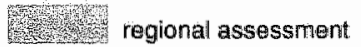

Figure 2.2: "The Integrated Model to Assess the Greenhouse Effect (IMAGE). 


\subsection{Description of the Various Modules}

\subsubsection{Emission Modules}

At present the model includes the trace gases $\mathrm{CO}_{2}, \mathrm{CH}_{4}, \mathrm{CO}, \mathrm{N}_{2} \mathrm{O}, \mathrm{CFC}$ 11 and CFC-12. In the emission modules current global, annual estimates of historical emissions have been incorporated for the period 1900 to 1985 . For the period 1985 to 2100 four sets of scenarios were chosen. An emission scenario is defined as a possible future development, without pretending that any probability is a prediction. Furthermore, we define a set of scenarios as a similar, consistent development for all trace gases. The underlying scenario assumptions, which will be discussed in more detail later, are based on a study of the different sources of trace gas emissions grouped as: nature, energy, agriculture and industry. At present the most detailed emission module is the energy module, for which the PC-version of the Edmonds and Reilly model is used (Edmonds and Reilly, 1986). The IEA/ORAU, longterm, global energy model was developed by Joe Edmonds and John Reilly at the Institute for Energy Analysis from 1980 onwards. The primary goal of the model is to assess long-term energy paths by considering economic, demographic, technical, and policy factors. The model is disaggregated into nine regions: USA, OECD West, OECD Asia, Centrally Planned Europe, Centrally Planned Asia, Middle East, Africa, Latin America, South and East Asia. The model is intended for making long-term projections, from 1975 to 2075 , with time steps of 25 years. In the integrated IMAGE version the results of intervening years are interpolated and, for the period 2075 to 2100 , results are extrapolated.

For each region the supply of and demand for energy is forecasted, as well as world and regional energy prices. Finally, $\mathrm{CO}_{2}$ emissions are calculated by associating the release of carbon with the consumption of oil, gas, and coal. Besides carbon dioxide emissions, methane emissions from coal mining and gas distribution and nitrous oxide emissions from combustion are also related to the results of scenario calculations with this model in a simple way (by spread sheet models). The main parameters that are varied during scenario analysis are population, economic growth (labour productivity), end use and conversion efficiency, cost developments for non-fossil fuel energy sources, environmental costs and carbon taxes. So far the agricultural sources of methane and nitrous oxide have been scaled to developments in the relevant areas (e.g. nitrous oxide emissions proportional to the consumption of nitrogenous fertilizer, which is again a function of arable land 
development). $\mathrm{CO}_{2}$ emissions from deforestation are not an exogenous input, but are calculated in the carbon cycle module, as will be discussed in the next section.

\subsubsection{Concentration Modules}

The emission modules provide the input for the concentration module. The emission and concentration of $\mathrm{CO}_{2}$ is linked to an ocean module, and a deforestation module, together reflecting the carbon cycle. The $\mathrm{CO}_{2}$ emission by deforestation is simulated in a separate deforestation module and integrated in the biosphere component of the carbon cycle module (Swart and Rotmans, 1989b). The $\mathrm{C}$ cycle module is an extended, modified version of the carbon cycle simulation model of Goudriaan and Ketner (1984). According to the present scientific opinion the assumptions with respect to the $\mathrm{CO}_{2}$ fertilization effect have been relaxed (Swart and Rotmans, 1989b).

The structure of the greenhouse trace gas module is quite different from that of $\mathrm{CO}_{2}$. The removal of the greenhouse gases concerned by atmospheric chemical processes is an essential feature. The spatial dimension of the simulated trace gas concentration is zero. Generally, the trace gas concentrations of $\mathrm{CH}_{4}, \mathrm{CO}, \mathrm{N}_{2} \mathrm{O}, \mathrm{CFC}-11$ and $\mathrm{CFC}-12$ are expressed as:

$$
\begin{aligned}
p X(t)= & p X(t-1)+\int_{t-1}^{t}(\operatorname{convf} X * \operatorname{em} X(\tau) \\
& -\operatorname{remvl} X * p X(\tau-\Delta \tau)) d \tau
\end{aligned}
$$

with:

$p X(t)=$ tropospheric concentration of a trace gas at time $t$ (in $p p b$ )

$e m X(t)=$ global emission of a trace gas at time $t$ (in $T_{g} y^{-1}$ )

convf $X=$ conversion factor of trace gas $X$ (in $p p b \mathrm{Tg}^{-1}$ )

remvlX $=$ removal rate of trace gas $X$ (in $y^{-1}$ )

The concentration of methane is derived from the global $\mathrm{CH}_{4}-\mathrm{CO}-\mathrm{OH}$ cycle by simulating the main atmospheric chemical processes influencing the global concentrations of these trace gases. Since a large fraction of the increase of the concentration of methane in the atmosphere is most probably caused by $\mathrm{CO}$ competing for $\mathrm{OH}$ radicals, inefficient combustion in the energy sector also contributes to the greenhouse effect via this route.

The removal rates of $\mathrm{CH}_{4}$ and $\mathrm{CO}$ are determined by the uptake, transport and oxidation rates of these gases, the latter being dependent on the OH concentration (Thompson and Cicerone, 1986, Khalil and Rasmussen, 
1985, Brühl and Crutzen, 1988, Isaksen and Høv, 1987, Logan et al., 1981, Crutzen and Graedel, 1986b, Rotmans and Eggink, 1988, Swart, 1988).

For CFCs the removal rate is supposed to be inversely proportional to the atmospheric lifetime, which is assumed to be constant (Rotmans, 1986). For CFC production, figures are input to the emission module which take account of the delay between production and emission, which is assumed to be different for different applications (Miller and Mintzer, 1986). Finally nitrous oxide concentrations are computed from emissions by taking a constant atmospheric lifetime into account.

\subsubsection{Climate Module}

The calculated trace gas concentrations serve as an input for the climate module. The parameterized radiative convective module, including different feedbacks, is based on Wigley $(1985,1987)$. The total change in radiative forcing $\left(\Delta Q_{t o t}\right)$ resulting from concentration changes of $\mathrm{CO}_{2}, \mathrm{CH}_{4}$, $\mathrm{N}_{2} \mathrm{O}, \mathrm{CFC}-11$ and CFC-12 is modelled according to Wigley (1987) and Ramanathan et al., (1985):

$$
\begin{aligned}
\Delta Q_{\text {tot }}= & 6.23 * \ln \left(p C \mathrm{O}_{2} / p C \mathrm{O}_{2} i n\right) \\
& +0.0398 *\left(\sqrt{p C \bar{H}_{4}}-\sqrt{p C H_{4} i n}\right) \\
& +0.105 *\left(\sqrt{p N_{2} \mathrm{O}}-\sqrt{p N_{2} \mathrm{Oin}}\right) \\
& +0.27 * p C F C-11+0.31 * p C F C-12
\end{aligned}
$$

with:

$\triangle Q_{\text {tot }} \quad=$ total change in radiative forcing

$\mathrm{pCO}_{2}, p \mathrm{CH}_{4}, p \mathrm{~N}_{2} \mathrm{O}, p \mathrm{CFC}=$ concentrations of $\mathrm{CO}_{2}, \mathrm{CH}_{4}, \mathrm{~N}_{2} \mathrm{O}$ and $\mathrm{CFC}$

$p \mathrm{CO}_{2} i n, p C \mathrm{H}_{4} i n, p \mathrm{~N}_{2} \mathrm{Oin}=$ initial concentrations (at time $=1900$ )

The resulting global mean equilibrium surface temperature rise can be calculated from (2.2) by dividing the radiative forcing by a climate feedback factor in which the water vapour factor is explicitly taken into account (Dickinson 1986, Wigley 1985, Tricot and Berger 1987, Ramanathan et al., 1985 and Health Council 1983). Furthermore, the transient temperature response is calculated, taking into account a time lag which suppresses the equilibrium temperature, based on Wigley and Schlesinger (1985). 


\subsubsection{Sea Level Rise Modulle}

The resulting temperature changes form the input to the sea level rise module. The effects of global warming on the potential sea level are determined by five processes: thermal expansion of ocean water, melting of alpine glaciers, and ablation of the Greenland ice caps, accumulation of the Antarctic, and a natural trend:

$$
\begin{aligned}
\Delta Z s p(t)= & \Delta Z s p_{t h e x}(t)+\Delta Z s p_{\text {glac }}(t)+\Delta Z s p_{G r}(t)+\Delta Z s p_{\text {Ant }}(t) \\
& +\Delta Z s p_{n a t}
\end{aligned}
$$

with

$$
\begin{aligned}
\Delta Z s p(t)= & \text { total sea level rise at time } t \text { (in } \mathrm{cm} \text { ) } \\
\Delta Z s p_{\text {thex }}(t)= & \text { sea level rise due to thermal expansion of the ocean } \\
& \text { (in } \mathrm{cm} \text { ) } \\
\Delta Z s p_{\text {glac }}(t)= & \text { sea level rise due to melting of glaciers (in } \mathrm{cm}) \\
\Delta Z s p_{G r}(t)= & \text { sea level rise due to net increase of ablation of } \\
& \text { Greenland (in } \mathrm{cm}) \\
\Delta Z s p_{\text {Ant }}(t)= & \text { sea level rise due to net increase of accumulation of } \\
& \text { Antarctica (in } \mathrm{cm} \text { ) } \\
\Delta Z s p_{\text {nat }}= & \text { natural sea level rise trend. Based on the difference } \\
& \text { between the observed sea level rise and the calculated } \\
& \text { sea level rise (in } \mathrm{cm} \text { ). }
\end{aligned}
$$

The information necessary for the description of the various complicated aspects of the phenomenon sea level rise is derived from Barnett (1983), Gornitz et al. (1982), Meier (1984), Revelle (1983), Robin (1986), United States Department of Energy (1985), Van der Veen (1986), Barth and Titus (1984), Oerlemans (1987), and Oerlemans (1989), and has been integrated and aggregated to a high level of abstraction.

The thermal expansion effect is divided into a uniform expansion for the mixed layer $(0-75 \mathrm{~m})$ of the ocean module of Goudriaan and Ketner (1984) and, by differential equations, a delayed expansion effect for the layers below $(75-1000 \mathrm{~m})$, determined by the transient temperature response calculated in the climate module. For the contributions of the glaciers, Greenland and Antarctica, differential equations have been incorporated, containing inputoutput factors (in $m m / \Delta T *^{\circ} C$ ). 


\subsubsection{Socio-Economic Impact Module}

A socio-economic impact has been developed for the Netherlands, describing the consequences of an accelerated sea level rise for three kinds of coastal defence systems, namely dikes, dunes and intertidal areas (Den Elzen and Rotmans, 1988). Additionally, a risk analysis may be performed, calculating the future theoretical chance of inundation for the western and northern coastal zone of the Netherlands, compared with the present so-called "Delta norm", which involves a risk of inundation once every 10,000 years. Finally, for four elements of inland water management, the impact of sea level rise has been modelled: salt intrusion, seepage, drainage and the management of the IJssel Lake. Given four global scenarios, estimates are made of the regional costs in coastal defence and water management as a result of adaptation to the impacts of regional climate change and sea level rise. For other social sectors, such as agriculture and energy use, only tentative conclusions have been drawn.

\subsection{Description of Scenarios}

\subsubsection{Introduction}

Model calculations have been performed with four sets of scenarios, which are based on consistent assumptions for each trace gas. A general survey of these assumptions is given in Table 2.1. The sets of scenarios are meant to encompass the possible global, socio-economic developments in order to illustrate the impact of different future pathways on the greenhouse effect. The highest scenario, A: unrestricted trends, assumes a continuation of economic growth, not limited by environmental constraints. Scenario B: reduced trends, is meant to include the implementation of environmental measures presently being considered to control other environmental problems, such as acidification and eutrophication, having important side-effects for the greenhouse effect. Scenario C: changed trends, assumes the enforcement of a stricter environmental control, at least partly influenced by international concern about the greenhouse effect as expressed at some recent conferences (see Jäger 1988, Environment Canada 1988). Finally, scenario D: forced trends, assesses the possibilities of maximum efforts towards global sustainable development. World population growth, a factor that is believed not to be influenced by greenhouse policies, is assumed to approach 10.8 billion in 2100 in all scenarios. 


\subsubsection{Energy Supply}

The combustion of fossil fuel is the most important human activity contributing to the emissions of greenhouse gases. The emissions of $\mathrm{CO}_{2}$ can be quantified reasonably well for different energy scenarios. In the literature distinctions between scenarios are usually very similar to those described above. The PC-version of the IEA/ORAU Long-Term Global Energy $\mathrm{CO}_{2}$ Model (Edmonds and Reilly 1985, 1986) has been fully integrated into IMAGE. In this work four Energy $\mathrm{CO}_{2}$ scenarios have been reproduced using this model, using the input data given by Mintzer (1987). His scenario assumptions coincide very. well with the four types of world development described above. Like population growth, labor productivity growth - the main driving factor for economic growth - is assumed to be common for all scenarios and, while varying among the different regions, it averages $1.8 \%$ annually. The energy related emissions of $\mathrm{CH}_{4}$ and $\mathrm{N}_{2} \mathrm{O}$ are less well-defined than those of $\mathrm{CO}_{2}$ but may play an important role in the greenhouse problem. For the purpose of the IMAGE calculations average estimates for the emissions of the different sources of these gases are assumed to be valid for 1985 and future emissions are determined by assessing developments of these sources along the lines described above. Unabated $\mathrm{CH}_{4}$ emissions from the mining of coal and the exploitation of natural gas are assumed to be proportional to the consumption of these fuels. In particular, because of the expected long term increase in the use of coal, better information is needed about the methane emission rates from coal mining (both open pit and deep mining) and the nitrous oxide emission rates from coal combustion.

The most important policy tools are efficiency improvements for supply, conversion and end use, cost assumptions for renewables and synfuels, environmental costs (or taxes) for supply and end use and abatement of energy related emissions of methane and nitrous oxide.

In the high scenario (A: unrestricted trends) economic growth is based on an increase in fossil fuel consumption, especially coal because of the higher prices of the decreasing oil and gas resources. It should be noted that in the results from the Edmonds and Reilly model recent discoveries of major natural gas reserves have not yet been included. In this scenario environmental concerns neither alter ways of life nor lead to substantial efforts to reduce emissions. Introduction of renewable energy is retarded (e.g. solar energy at US $\$ 20 .-/ G J$ ) and production of synfuels is enabled by relatively low prices (e.g. non-energy prices for synoil at US\$3.50/GJ, for syngas at $\mathrm{US} \$ 2.75 / \mathrm{GJ})$. 


\begin{tabular}{|c|c|c|}
\hline $\begin{array}{c}\text { TRACE OAS } \\
\text { SOENARIO }\end{array}$ & $\mathrm{OO}_{2}$ & $\mathrm{OH}_{\mathrm{H}}$ \\
\hline $\begin{array}{c}\text { Womtinued } \\
\text { brends } \\
\text { A }\end{array}$ & 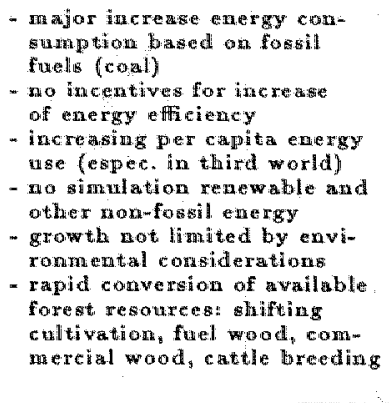 & 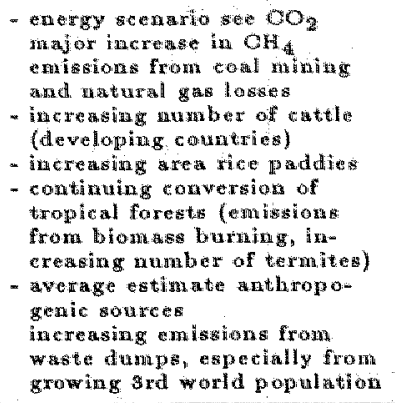 \\
\hline $\begin{array}{l}\text { Reduced } \\
\text { trends }\end{array}$ & 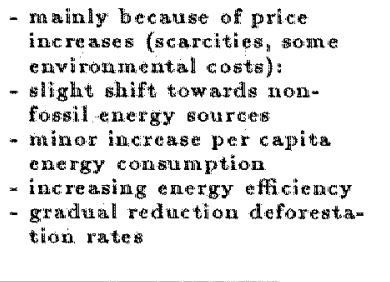 & 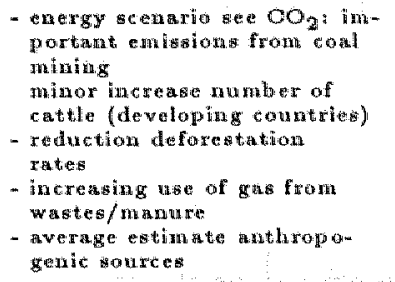 \\
\hline $\begin{array}{l}\text { Changing } \\
\text { trends }\end{array}$ & 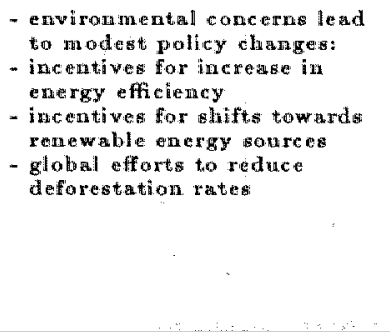 & 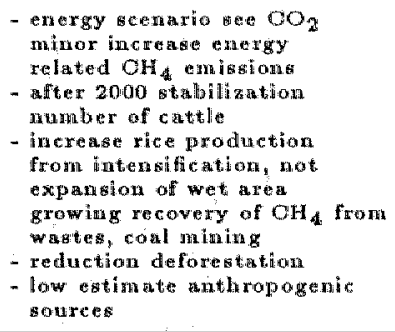 \\
\hline $\begin{array}{l}\text { Forced } \\
\text { treads }\end{array}$ & 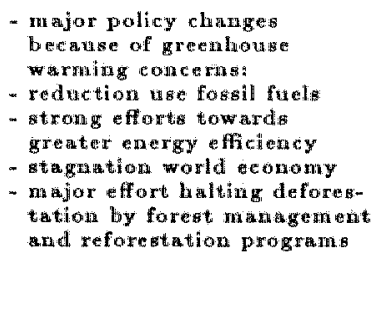 & 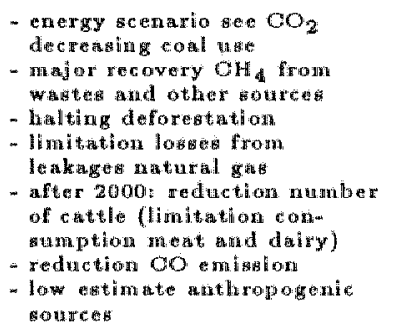 \\
\hline
\end{tabular}

Table 2.1: Policy assumptions in scenario sets. 


\begin{tabular}{|c|c|c|}
\hline $\begin{array}{l}\text { PHACHOA } \\
\text { YCHARIO }\end{array}$ & $\mathrm{N}_{2} \mathrm{O}$ & $\mathrm{CECS}$ \\
\hline 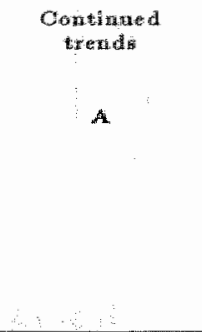 & 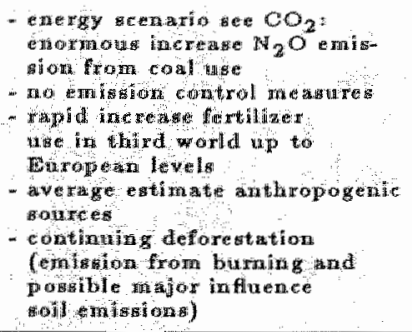 & 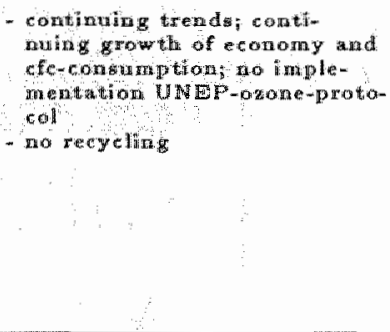 \\
\hline $\begin{array}{c}\text { Roducentu } \\
\text { Hention }\end{array}$ & 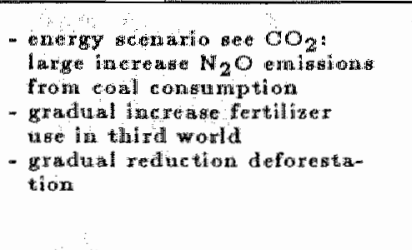 & 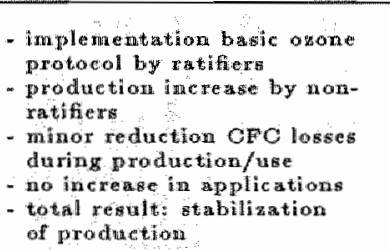 \\
\hline $\begin{array}{l}\text { Clinamging } \\
\text { tretid }\end{array}$ & 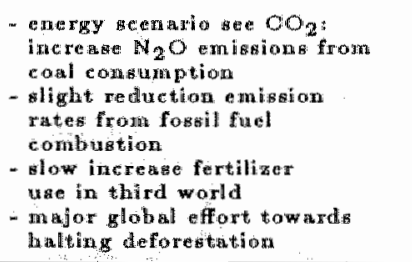 & 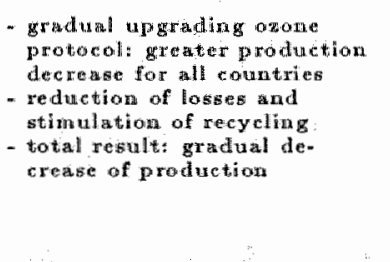 \\
\hline $\begin{array}{l}\text { Hored } \\
\text { trentlod } \\
\text { D }\end{array}$ & 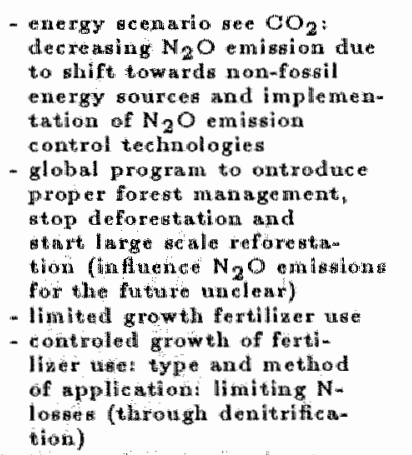 & 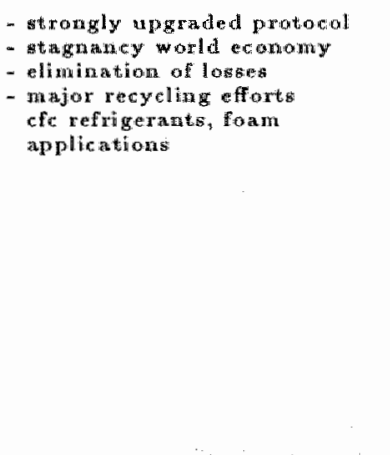 \\
\hline
\end{tabular}

Table 2.1: (continued) 
End use efficiency increases by only $0.2 \%$ annually and the efficiency of coal supply $\left(0.75 \% y^{-1}\right)$ increases more than the efficiency of fuels with lower $\mathrm{CO}_{2}$ emission factors (e.g. $0.3 \% \mathrm{yr}^{-1}$ ). No major environmental costs are assumed. Since coal has the highest emission rates this scenario leads to high $\mathrm{CO}_{2}$ emissions. The effects of these high emissions may even cause a negative feedback in the next century, climatological change affecting economic growth and food production. This has not yet been taken into account. High temperature combustion of coal and other fossil fuels causes increasing $\mathrm{N}_{2} \mathrm{O}$ emissions (Hao et al. 1987, Kavanaugh 1987). The release of methane during the exploitation of coal reserves may cause a sharp increase in $\mathrm{CH}_{4}$ emissions. However, further research into this aspect for different methods of coal mining is needed to confirm this statement. This is particularly interesting, since recent research suggests that the contribution of fossil sources to methane increase may have been underestimated (Lowe et.al., 1988). Because of a rather stable supply of natural gas in all scenarios in absolute terms, $\mathrm{CH}_{4}$ emissions from leakages will not alter much. It may be assumed that efforts to reduce leakages will compensate for emissions caused by possibly increasing transport distances.

In the reduced trends scenario (B) the introduction of non-fossil fuels is accelerated and energy efficiency increased because of higher prices of fossil fuels, influenced by scarcity and environmental measures. The costs of solar energy are assumed to be lower than in scenario A (US\$16.50/GJ) and end use efficiency increases by $0.8 \%$ annually. Supply efficiency for gas and oil are assumed to increase faster $(0.3 \%$ annually) than for coal $(0.2 \%)$. Synfuels are relatively more expensive (US\$ 4.25 non-energy costs for synoil and US\$ 3.15 for syngas). Moderate environmental costs for coal are introduced. Methane is a useful gas and therefore the reduction of losses is not only interesting from the environmental point of view. A graclual increase of the methane recovery from coal mining up to $25 \%$ in 2100 is assumed. This might be a scenario including the implementation of the enwironmental strategies presently being considered. $\mathrm{CO}_{2}$ and $\mathrm{CH}_{4}$ emissions from coal combustion and mining are still high.

In the changed trends scenario (C) environmental strategies will be upgraded. Incentives accelerate the introduction of renewable energy sources (e.g. solar US\$15.00/GJ). End use energy efficiency increases by $1 \%$ annually and supply efficiency increases more for gas $\left(0.4 \% \mathrm{yr}^{-1}\right)$ than for oil $(0.3 \%)$. Higher prices delay the introduction of synfuels (synoil US $\$ 5$.- and syngas US\$ 4.- non-energy prices). Again, $15 \%$ of the methane from coal mining is assumed to be recovered in 2100 . Higher environmental costs are 
introduced for coal. Increased energy consumption, especially in the third world, will still cause a considerable increase of coal consumption.

The onlly scenario showing a continuation of or, in the long run, a return to present day emission rates is the forced trends scenario (D). Concern about the global environment will lead to a change in lifestyle in the developed world, combined with the introduction of very energy efficient technologies using renewable energy sources both in developed and developing countries. This will lead to low per capita energy consumption of fossil fuels rather than the introduction of expensive emission control technologies, enabling a sustainable development of global societies (Mintzer 1987, Goldenberg et al. 1987a and 1987b, Cheng et al. 1986). Costs of solar energy are assumed to arrive at US\$ $12 .-$ GJ in 25 years. End use efficiency increases by $1.5 \%$ animually and supply efficiency for natural gas $\left(1.5 \% \mathrm{yr}^{-1}\right)$ increases much faster than for oil $(0.6 \%)$ and coal $(0.2 \%)$. High prices (synoil US\$ 7.- and syngas US $\$ 5.50$ non-energy costs) and low energy consumption prevent the introduction of synfuels. Environmental costs (taxes) proportional to their carbon content are applied to supplies of the different types of fuel and their consumption. Remaining $\mathrm{N}_{2} \mathrm{O}$ emissions are assumed to be reduced by technological measures. Half of the $\mathrm{CH}_{4}$ emissions from coal mining are finally recovered.

\subsubsection{Agriculture}

Although energy production and consumption are the main contributors to the greenhouse effect, agricultural activities also influence the emission of trace gases: methane from cattle and rice paddies, nitrous oxide from fertilization and probably carbon dioxide from deforestation. Again the preliminary scenarios for methane and nitrous oxide (both anthropogenic and naturall) are based on average base year estimates from a variety of sources, among which are Sheppard et al. (1982), Khalil and Rasmussen (1982, 1984, and 1985), Atmospheric Ozone (1985), Van Ham (1987), Bolle et al. (1986), Holzapfel-Pschorn and Seiler (1986), Bingerner and Crutzen (1987), Crutzen et al. (1986a), Seiler (1984), and Bartlett et al. (1985) for methane, and Keller et al. (1987), Van Ham (1987), Conrad et al. (1980, 1983), Marland and Rotty (1985), Hignett (1985), and Anderson and Levine (1987) for nitrous oxide. Scenario assumptions are rough estimates; in comparison to the figures of the Food and Agricultural Organization (1987) they tend to be low.

In the unrestricted trends scenario it is assumed that food production 
will keep up with population growth through massive intensification of agricultural production by way of fuel or mined mineral-based technologies, including fertilizers and irrigation. The sustainability of such a scenario may be questioned.

Because of an increase of agricultural land and the intensity of fertilizer application the use of nitrogenous fertilizers will increase the still uncertain $\mathrm{N}_{2} \mathrm{O}$ emissions by more than fourfold by the year 2100. For predicting the increase in arable land logistic curves are used, fitted to historical FAO data and consistent with estimates of potential arable land. Although the area available for rice cultivation will probably not be extended very much, since the remaining arable area will become scarce and erosion will cause loss of fertile soil, irrigation of the present rainfed area has been assumed to lead to increases of $\mathrm{CH}_{4}$ emissions by almost $80 \%$ in 2100 . Again logistic curves are applied utilizing FAO data for historical development of rice paddy area. With an increasing number of countries reaching higher levels of prosperity, an increasing consumption of meat and dairy products will lead almost to a doubling of the number of methane producing cattle, mainly in the now developing world.

The unrestricted economic growth in this scenario will further exploit the tropical forests. Cattle breeding, cultivation of export products, production of $\operatorname{logs}$ and fuelwood, mining or infrastructural projects, all force the increasing rural population further into the remaining forests, practising a form of slash and burn agriculture, which is often not sustainable due to shorter rotation times and unsuitable soils (World Resources Institute 1986, 1987, Molofsky et al. 1986). This affects the emissions of several trace gases: more $\mathrm{CO}_{2}$ will be released into the atmosphere. The effects as to $\mathrm{CH}_{4}$ and $\mathrm{N}_{2} \mathrm{O}$ are still unclear. Tropical soils serve as a sink for $\mathrm{CH}_{4}$, higher rates being observed for savannahs than for forest soils. $\mathrm{N}_{2} \mathrm{O}$ emissions from tropical forest soils are important and may increase after forest conversion. As the number of termites increases when tropical forests are being converted, emissions by termites may increase.

In the reduced trends scenario (B) the high costs of agricultural inputs to increase productivity and irrigated areas decrease the present growth rates of fertilizer use and irrigation, thus limiting the agricultural emissions of $\mathrm{CH}_{4}$ and $\mathrm{N}_{2} \mathrm{O}$. The number of cattle gradually increases by $75 \%$ in 2100 , fertilizer use increases by $250 \%$ and rice paddies by about $40 \%$. Deforestation rates are gradually slowing down.

In the changed trends scenario (C) the changes of scenario $\mathrm{B}$ are accelerated: increases in productivity are sought in intensification based on 
agro-ecological practises rather than technological means, although use of fertilizer remains essential in order to meet food demands, causing a $150 \%$ increase in fertilizer consumption globally in 2100. A global effort to control deforestation is initiated. The number of cattle increases by only $50 \%$ compared to a doubling of the human population. Agricultural wastes are increasingly used for energy production.

The forced trends scenario (D) reflects a worldwide change of attitude towards agricultural practices. The use of fertilizers and pesticides is limited to the necessary minimum agricultural development aiming at full sustainability at the local or regional level. This scenario is dependent on the spread of sustainable agro-ecological techniques, as yet to be fully developed (e.g. see Dover and Talbot 1987). Yet a global increase in nitirogen fertilizer ( $80 \%$ in 2100 ) is still assumed to be unavoidable. In order to optimize food efficiency meat consumption is limited, leading to only a small increase ( $10 \%$ in 2100$)$ in the number of cattle and the associated methane emissions.

All agriculturall wastes (crop residues, manure) are used for fertilizers or energy production. An effective global program stops deforestation and stimulates proper forest management and reforestation. All these activities limit emissions of $\mathrm{CO}_{2}, \mathrm{CH}_{4}$ and $\mathrm{N}_{2} \mathrm{O}$, and even change the direction of present trends.

\subsubsection{CFC Use}

In the unrestricted trends scenario it is assumed that the ozone protocol is not fully implemented: production and use will continue to increase, albeit at a moderate rate, and will stabilize in the first half of the 21st century.

In the reduced trends scenario the Montreal protocol (United Nations Environment Program 1987) is supposed to be implemented by linearly decreasing the production towards the limits set for $1993(80 \%)$ and 1998 ( $50 \%)$, making use of the allowance ( $10 \%$ and $15 \%$ respectively) to 'satisfy basic domestic needs' and 'for the purpose of industrial rationalization' followed by stabilization after 1999 . The allowed growth of production planned in the protocol is not taken into account because of lack of data, while no substances other than $\mathrm{CFC}-11$ and CFC-12 are yet being considered in IMAGE. The objectives are reached by turning to substitutes, limiting losses and gradually increasing recycling.

In the changed trends scenario the basic protocol is upgraded to a limit of $15 \%$ of the 1986 production and consumption figures for 1998 , after which annual production and consumption are assumed to stabilize. No additional 
production capacity is built, since this seems to be useless under these circumstances. The efforts towards the development of 'safe' substances, recycling and loss reduction are increased.

In the forced trends scenario a total ban is assumed in 2050 in addition to the $85 \%$ reduction in scenario C. A possibly remaining use for purposes that are considered to be essential is neglected.

\subsubsection{Other Trends}

Methane emissions from waste dumps are increasing with population growth and the increasing level of prosperity. In the scenarios from $A$ to $D$ an increasing percentage of methane recovery from waste is assumed (2100 $0 \%, 20 \%, 30 \%$ and $50 \%$ respectively).

Other factors that may possibly have an influence are kept constant because of lack of even qualitative information. Forest and bush fires may increase with population, and the increasing $\mathrm{CO}_{2}$ concentrations will probably increase the release of $\mathrm{CH}_{4}$ emissions from an aerobic microbiological sources. The reclamation of wetlands may reduce $\mathrm{CH}_{4}$ emissions, but temperature rises may melt the permafrost in the Arctic regions, increasing the 'wetland' areas.

\subsection{Model Deficiencies and Future Developments}

The simulation model is a reflection of the current state of knowledge. Current knowledge being far from complete, the model has structural limitations. An important spin-off of IMAGE is the possibility of recognizing gaps in our knowledge, which is necessary for a better prediction of the effects of the enhanced greenhouse phenomenon. This may lead to the allocation of future research priorities.

Ozone and ozone depleting substances other than CFC-11 and CFC-12 are planned to be added to IMAGE in the near future. Secondly, an integrated energy module will be developed, based on the LEAP model of the Energy and Systems Research Group in Boston (ESRG, 1988). Thirdly, an energy balance module is being developed, including the lag effects between the equilibrium and transient temperature rise, and extended by a pattern of regional differentiation. A number of internal feedback processes will be incorporated (especially biogeochemical feedbacks such as changes in methane emissions, ocean $\mathrm{CO}_{2}$ uptake, and vegetation albedo). Furthermore the atmospheric chemistry within IMAGE will be made more complete, with 
the addition of $\mathrm{NO}_{x}$ and $\mathrm{O}_{3}$. On a European scale the ecological effects of climate change will be added to IMAGE in the near future.

In consequence of the modular structure of IMAGE new information can generally be incorporated without affecting the model structure.

\subsection{Comparison with Other Models}

Recently in Washington IMAGE was compared to the Model of Warming Commitment (MWC) of the World Resource Institute (Mintzer, 1987), and the Atmospheric Stabilization Framework (ASF) of the EPA (EPA, 1989), which are the only comparable integrated greenhouse policy models published to date. Generally the model builders concluded that the frameworks of these models were very similar. However comparing IMAGE with ASF (EPA model) the following major differences should be mentioned (Response Strategies Working Group, 1989a and 1989b):

- The structures differ in aggregation level: the EPA model is more detailed than IMAGE, especially with respect to the energy end use, the industrial (CFCs), and agricultural sectors;

o The ASF atmospheric chemistry is more complete;

o The ASF includes emissions of more trace gases than does IMAGE (i.e. ozone-depleting substances other than CFC-11 and CFC-12, $\mathrm{NO}_{x}$, and ozone as a greenhouse gas);

- IMAGE includes a fully integrated carbon cycle, while ASF uses exogenous variables for the carbon cycle and biogenic emissions;

- IMAGE includes emissions of non-methane hydrocarbons, which are not included in ASF;

- IMAGE covers a timespan between 1900 to 2100 , while ASF simulation time is from 1985 to 2100 ;

- IMAGE includes a number of global (sea level rise) and national impact modules, which are not included in ASF;

- IMAGE has a more flexible structure, allowing alternatives to be implemented easily. 
Comparing IMAGE with MWC (WRI model) the following similarities and differences appear:

- IMAGE and MWC have a comparable aggregation level;

- The present energy end use and CFC modules of MWC are more detailed than in IMAGE;

- IMAGE includes a carbon cycle, while MWC uses exogenous wariables instead of a carbon cycle;

- $\mathrm{CO}_{2}$ emission by deforestation is in IMAGE not an exogenous variable like $\mathrm{MWC}$, but is integrated in the biosphere component of the carbon cycle module;

o For methane, IMAGE includes a $\mathrm{CH}_{4}-\mathrm{CO}-\mathrm{OH}$ cycle incorporating emissions of methane and carbon monoxide, while MWC only takes $\mathrm{CH}_{4}$ concentrations into account;

- The most obvious additional features of IMAGE are the effect modules (for instance the sea level rise module)

IMAGE runs were performed with the same input emission scenarios as used in the EPA model and the WRI model. It appeared that the resulting equivalent $\mathrm{CO}_{2}$ concentrations and temperature changes were not significantly different (Response Strategies Working Group, 1989a, 1989b). Among other things this exercise confirmed the reproducibility of the results. One important reason for the differences appeared to be the different treatment of the biospheric component of the carbon cycle.

\subsection{Discussion}

Over the last few years the utility of an integrated methodology for evaluating different futures with respect to climate change has been proved extensively. IMAGE gives clear, long-term relationships between causes and effects of the enhanced greenhouse effect, based on the latest scientific evidence, but without requiring detailed scientific knowledge from the user. Given that the Edmonds and Reilly model has 25 year time steps, IMAGE is less suitable for the assessment of details of the effects, feasibility and costs of different policy options in the short run. Attention will be given to this drawback over the following years in collaboration with other groups. 


\section{Chapter 3}

\section{The Carbon Cycle Model}

\subsection{Introduction}

Carbon dioxide $\left(\mathrm{CO}_{2}\right)$ occurs naturally in the atmosphere, and plays an important role in almost all living mechanisms. The natural carbon cycle encompasses exchange of $\mathrm{CO}_{2}$ between the atmosphere, oceans and the terrestrial biosphere of hundreds of billions tons of carbon a year. Compared with these tremendous quantities the extra man-made addition through the burning of fossil fuels and changing land use is only a small contribution to the carbon cycle. Nevertheless this minor anthropogenic injection is supposed to account for the imbalance of the carbon cycle and thus for the increase in the $\mathrm{CO}_{2}$ concentration. However, only about $40 \%$ of the manmade $\mathrm{CO}_{2}$ emissions remains in the atmosphere. The remainder is taken up by the oceans and terrestrial ecosystems. The atmospheric $\mathrm{CO}_{2}$ level has increased approximately 25\% from 1900 to 1989 ; additionally, since 1958, the starting year of systematic accurate measurements of atmospheric $\mathrm{CO}_{2}$ at Mauna Loa, the $\mathrm{CO}_{2}$ level has increased by more than $11 \%$. The total anthropogenic $\mathrm{CO}_{2}$ flux to the atmosphere is surrounded by uncertainties (USDOE, 1985a). In fact only the resulting flux from the combustion of fossil fuels is well known, in contrast to the flux from the terrestrial biota to the atmosphere or vice versa, which is still debated. Some argue that the terrestrial biosphere is a net sink of atmospheric $\mathrm{CO}_{2}$ (Lugo and $\mathrm{Brown}$, 1980, Goudriaan and Ketner, 1984, Esser, 1987, Harvey, 1989b), while others argue that it is a net source (Houghton et al., 1983).

IMAGE contains a carbon cycle model which is merely an interpretation of the complex global carbon cycle mechanism and which is described in detail below. 


\subsection{Model Description}

A carbon cycle model has been developed which consists of several linked modules: an emission module, an atmospheric concentration module, an acean module, a terrestrial biota module and a deforestation module. The $\mathrm{CO}_{2}$ emission module provides the input for the concentration module of $\mathrm{CO}_{2}$. Both modules are linked to an ocean module and a terrestrial biota module, together reflecting the carbon cycle. The latter is a modified version of the carbon cycle model of Goudriaan and Ketner (1984). All C cycle models assume that the atmospheric-ocean-terrestrial biosphere system was in steady-state prior to the industrial era (Kohlmaier et al., 1981, Houghton et al., 1983, Emanuel et al., 1984, Esser, 1987), although this is questioned by Lugo and Brown (1986).

In consequence of the coupling of the emission, concentration, ocean and terrestrial biota modules the airborne fraction has been defined in a specific sense: the airborne fraction is the fraction of the total $\mathrm{CO}_{2}$ emissions from fossil fuels and biosphere changes that remains in the atmosphere. In formula form:

$$
\begin{aligned}
\text { Af } & =\frac{\text { net increase of } \mathrm{CO}_{2} \text { in the atmosphere }}{\text { fossil fuel emission }- \text { net terrestrial biota uptake }} \\
& =\frac{\text { fsem }-\Delta \text { ocean }+ \text { bioem }- \text { bioupt }}{\text { fsem }+ \text { bioem }- \text { bioupt }} \\
& =\frac{\text { fsem }-\Delta \text { ocean }-\Delta \text { biota }}{\text { fsem }-\Delta \text { biota }}
\end{aligned}
$$

with:

Af $\quad=$ airborne fraction

fsem $=$ fossil fuel emission (in GtC)

$\Delta$ ocean $=\mathrm{CO}_{2}$ uptake by the ocean (in $G t C$ )

$\Delta$ biota $=$ net biota uptake $=$ bioupt - bioem (in GtC)

bioem = emission released from terrestrial biota by human disturbance (in $G t C$ )

bioupt = uptake by terrestrial biota, equivalent with the total net ecosystem production (in $G t C$ )

\subsection{Emissions Module}

There are three anthropogenic sources of $\mathrm{CO}_{2}$ emission: 1. Fossil fuel combustion, 2. Production of cement, 3. Land use change. 
Only the first two issues will be treated in this section, the third one will be dealt with in the section about the deforestation module. Figures concerning the contribution of fossil fuels to $\mathrm{CO}_{2}$ emission are known from 1860 (Watts, 1982). Marland and Rotty (1984) and later on Rotty and Masters (1985), and Rotty (1987) have adjusted these figures, although the differences are small. Historical fossil fuel emissions figures have been put into IMAGE for the period 1900-1985, involving an uncertainty range of about $5 \%$.

For the period before 1950 no cement production data are on record, whereas the cement production from 1950 is reasonably well known. For the period 1950-1985 cement figures, based on Marland and Rotty (1984) have been implemented.

For the period 1985-2100 four different Energy $\mathrm{CO}_{2}$ scenarios have been introduced (Rotmans et al., 1990a). These scenarios are generated with the PC-version of the IEA/ORAU Long-Term Global Energy $\mathrm{CO}_{2}$ Model (Edmonds and Reilly, 1986), which has now been fully integrated into IMAGE. The IEA/ORAU Long-Term Global Energy $\mathrm{CO}_{2}$ Model was developed by Jae Edmonds and John Reilly to run on a personal computer and was released in 1985. The model calculates alternative long-term energy strategies and the effects on global economic activity and finally estimates the emissions of trace gases resulting from the production, transportation, distribution, and consumption of fossil fuels.

In the unrestricted trends (A) scenario economic growth is based on an increase in fossil fuel consumption, especially coal, because of the higher prices of decreasing oil and gas resources. Environmental concerns neither alter ways of life nor lead to substantial efforts to reduce emissions. Introduction of renewable energy is retarded and production of synfuels is enabled by relatively low prices. No major environmental costs are assumed. Since coal has the highest $\mathrm{CO}_{2}$ emission rates this scenario leads to high $\mathrm{CO}_{2}$ emissions.

In the reduced trends scenario (B) the introduction of non-fossil fuels is accelerated and energy efficiency increased because of higher price of fossil fuels, influenced by scarcity and environmental measures. Moderate environmental costs for coal supply are introduced.

In the changed trends scenario (C) environmental strategies will be upgraded. Incentives accelerate the introduction of renewable energy sources and provides an increase in energy efficiency.

The only scenario showing a continuation of or, in the long run, a return to present day emission rates is the forced trends scenario (D). Concern 
about the global environment will lead to a change in lifestyle in the developed world, combined with the introduction of very energy efficient technologies using renewable energy sources both in developed and developing countries. Environmental costs (taxes) proportional to their carbon content are applied to supply of the different fuel types and their consumption. Figure 3.1 shows the emissions of $\mathrm{CO}_{2}$ for the four scenarios described above.

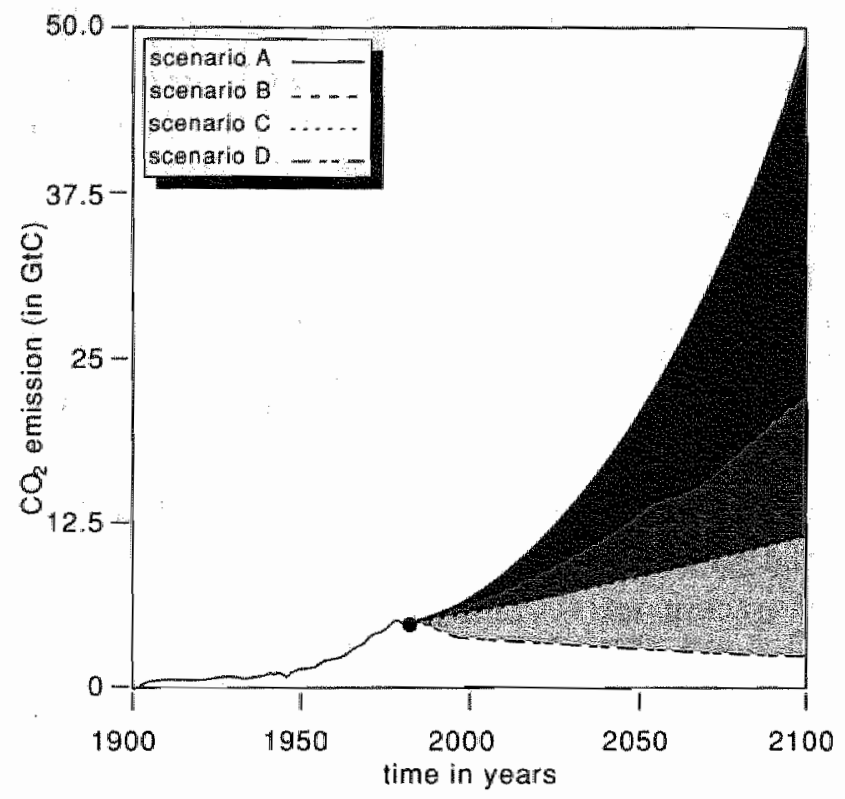

Figure 3.1: Emissions of $\mathrm{CO}_{2}$.

\subsection{Atmospheric Concentrations Module}

The atmosphere is represented as a well-mixed reservoir, with a mixing time of 1 year, although in reality the atmospheric concentration of $\mathrm{CO}_{2}$ is not uniformly mixed. The atmospheric $\mathrm{CO}_{2}$ concentration is determined by the fossil fuel combustion, uptake of $\mathrm{CO}_{2}$ by the oceans, flux of $\mathrm{CO}_{2}$ from the terrestrial biota and the net ecosystem production flux. The driving forces of this system are the fossil fuel combustion and the changing land use, perturbing the global carbon cycle, and causing an imbalance in the $\mathrm{CO}_{2}$ uptake by the oceans, and in the net ecosystem production. The atmospheric 
$\mathrm{CO}_{2}$ concentration is then modelled according to the following equation:

$$
\begin{aligned}
p \mathrm{POO}_{2}(t)= & p \mathrm{CO}_{2}(t-1)+\int_{t-1}^{t}[A T M C F *(F S E M(\tau)+O C E A(\tau) \\
& -T N E P(\tau)+T H D I S T(\tau))] d \tau
\end{aligned}
$$

with:

$p_{\mathrm{CO}}(t)=$ atmospheric $\mathrm{CO}_{2}$ concentration at time $t$ (in ppm)

$p \mathrm{CO}_{2}(0)=$ initial $\mathrm{CO}_{2}$ concentration at time $t=0$, in 1900; (in ppm) is $285 \mathrm{ppm}$, varies from 270-300 ppm (Rotmans, 1986)

$A T M C F=$ factor that converts emissions of $\mathrm{CO}_{2}$ into concentrations; is $0.471 \mathrm{ppm} / \mathrm{GtC}$ according to Brewer (1983) (in $p p m / G t C$ )

$F S \operatorname{EM}(\tau)=$ fossil fuel combustion flux at time $t$ (in $G t C / y r$ )

$O C E A(\tau)=$ Hux from oceanic mixed layers to the atmosphere (in $G t C / y r$ )

$T N E P(\tau)=$ carbon flux by total net ecosystem production (in $G t C / y r$ )

$T H D I S T(\tau)=$ total carbon flux of $\mathrm{CO}_{2}$ due to human disturbance

\subsection{Ocean Module}

The ocean module is a slightly modified version of that given in Goudriaan and Ketner (1984), based on De Haan (1989). It belongs to the class of ocean models which are modified versions of the basic box-diffusion model of Oeschger et al. (1975), of which the model by Björkström (1979) was the first. Emanuel et al. (1985) surveys the different types of ocean models.

In this module the ocean is divided into 12 layers. Two surface layers, a warm mixed layer of 75 meters and a cold mixed layer of 400 meters, one intermediate layer of 1005 meters and nine layers of 680 meters, represented in Figure 3.2 .

Three primary processes are defined, determining the carbon concentration in the ocean: carbon transport by mass flow of water, by turbulent mixing and by gravitation. Refinements that are not yet included in the IMAGE ocean module, but are being developed in the new ocean module to increase its realism, are polar outcrop, mutrient cycling, upwelling and separate boxes for the Atlantic, the Pacific and the Indian ocean. One-dimensional models are available in which most of the refinements cited above are already incorporated (Hoffert et al., 1981, Peng et al., 1983, Bolin et al., 1983). In 
the ocean model of Goudriaan and Ketner (1984) marine photosynthesis was added as a fixed driving force (Goudriaan, 1988b).

It should be noted that although the one-dimensional box-diffusion models are useful for general analysis of the role of the oceans in the global carbon cycle, none of these one-dimensional box-diffusion models gives a realistic representation of the dynamics of the ocean. A realistic reflection of the ocean circulation must account for geometry. However, at present, a realistic, general circulation model of the ocean does not exist (Emanuel et al., 1985).

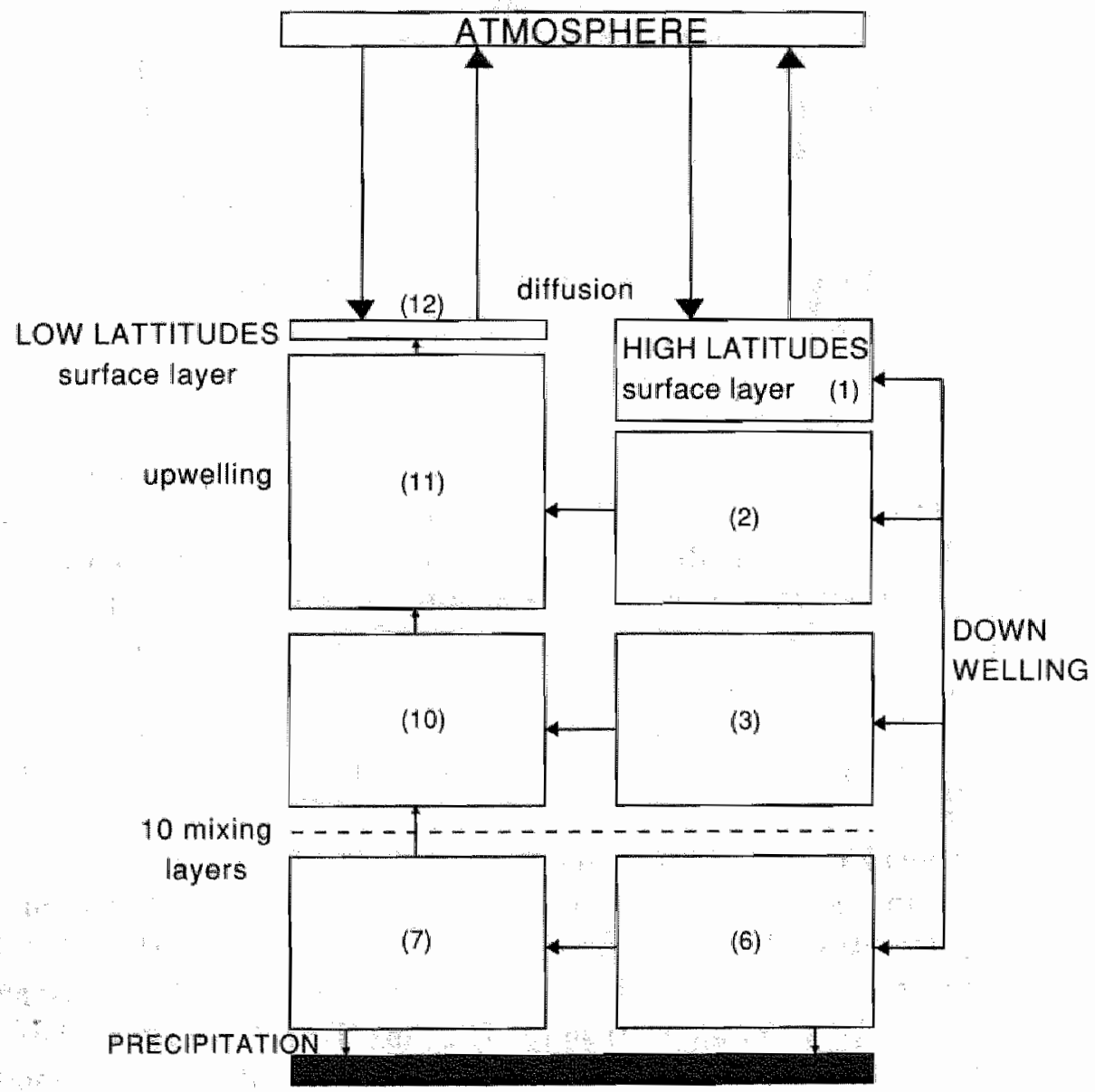

Figure 3.2: Schematic of the IMAGE 12-layer ocean model. 
Two of the prominent processes, mass flow and turbulent mixing, can be represented in a discrete way (De Haan, 1989):

Mass flow:

$$
\frac{C^{t+1}(i)-C^{t}(i)}{\Delta t}=u^{t}(i) * \frac{C^{t}(i)-C^{t}(i-1)}{\Delta D}
$$

with:

$C^{t}(i)=$ carbon concentration in ocean layer $i$ at time $t\left(\right.$ in $\left.t C / \mathrm{m}^{3}\right)$

$\Delta t=$ time interval $t$ (in $y r$ )

$\Delta D=$ depth of an ocean layer (in $m$ )

$u^{t}(i)=$ constant in ocean layer $i$ at time $t$ (in $m / y r$ )

Turbulent mixing:

$$
\frac{C^{t+1}(i)-C^{t}(i)}{\Delta t}=D I F F * \frac{C^{t}(i+1)-2 * C^{t}(i)+C^{t}(i-1)}{\Delta D^{2}}
$$

with:

$\Delta D^{2}=$ square of the ocean layer depth (in $m^{2}$ )

$D I F F=$ diffusion coefficient (see below) (in $m^{2} / y r$ )

These two processes, mathematically defined above, are incorporated in the following equations, together with the process of precipitation of organic material:

$$
\begin{aligned}
\frac{d O(1)}{d t}= & {[M F L *(C(12)-C(1))] } \\
& +\left[D I F F * \frac{V(1)}{D(1)} * \frac{(C(2)-C(1))]}{(D(2)+D(1)) / 2}\right]-[P R C] \\
& \quad[\text { TUREULENT MIXING } \\
\frac{d O(i)}{d t}= & {[1 / 5 * M F L *(C(1)-C(I))] } \\
& +\left[D I F F * \frac{V(I)}{D(I)} * \frac{C(i+1)-C(i)}{D(i)}\right. \\
& \left.-\frac{C(i)-C(i-1)}{(D(i)+D(i-1)) / 2}\right]-[P R C] \quad i=2, \ldots, 5
\end{aligned}
$$




$$
\begin{aligned}
\frac{d O(6)}{d t}= & {[1 / 5 * M F L *(C(1)-C(6))] } \\
& +\left[D I F F * \frac{V(6)}{D(6)} * \frac{(C(5)-C(6))}{D(6)+D(5)) / 2}\right]-[P R C] \\
\frac{d O(7)}{d t}= & {[1 / 5 * M F L *(C(6)-C(7))] } \\
& +\left[D I F F * \frac{V(7)}{D(7)} * \frac{(C(8)-C(7))}{(D(8)+D(7)) / 2}\right]-[P R C] \\
\frac{d O(i)}{d t}= & {[1 / 5 * M F L *(C(13-I)+((I-7) * C(I-1))} \\
& -((I-6) * C(I)))] \\
& +\left[D I F F * \frac{V(I)}{D(I)} * \frac{(C(i+1)-C(i))}{(D(i)+D(i+1)) / 2}\right. \\
& \left.-\frac{(C(i)-C(i-1))]-[P R C] \quad i=8, \ldots 11}{D(i)}\right] \\
\frac{d O(12)}{d t}= & {[M F L *(C(11)-C(12)]} \\
& +\left[D I F F * \frac{V(12)}{D(12)} * \frac{(C(12)-C(11))}{(D(12)+D(11)) / 2}\right]-[P R C)(3.10)
\end{aligned}
$$

with:

$\frac{d O(i)}{d t}=$ change in amount of carbon in ocean layer $i$ (in $G t C / y r$ )

$C(i)=$ carbon concentration in ocean layer $i$ (in $G t C / m^{3}$ )

$D(i)=$ thickness of ocean layer $i$ (in $m)$

$V(i)=$ volume of ocean layer $i$ (in $\left.\mathrm{m}^{3}\right)$

$D I F F=$ diffusion coefficient ; is $4000 \mathrm{~m}^{2} / \mathrm{yr}$, varies in the literature from about 3700 to $6000 \mathrm{~m}^{2} / \mathrm{yr}$ (Hoffman, 1984)

$M F L=$ mass flow of water ; is $2.3 * 10^{15} \mathrm{~m}^{3} / \mathrm{yr}$,

$P R C=$ precipitation flux; is constant according to Goudriaan and Ketner (1984) (in $G t C / y r)$

The $\mathrm{CO}_{2}$ exchange between the surface layers of the ocean and the atmosphere is buffered. The buffer factor is widely used to represent the equilibrium distribution of $\mathrm{CO}_{2}$ between the ocean and the atmosphere. This buffer factor is dependent on the the atmospheric $\mathrm{CO}_{2}$ concentration and the inorganic carbon content in the surface layers of the ocean. Additionally the buffer factor increases with decreasing temperature (Bolin, 1986). 
The following equation reflects the equilibrium phase between $\mathrm{CO}_{2}$ in the atmosphere and in the ocean (Mook and Engelsman, 1983):

$$
B U F F * \frac{d O_{e q}}{0_{e q}}=\frac{d p C O_{2}}{p C O_{2}}
$$

with:

$B U F F=$ buffer factor

$d O_{e q}=$ change in the amount of inorganic carbon in the ocean surface layers, in equilibrium with the atmospheric $\mathrm{CO}_{2}$ concentration (in $\mathrm{GtC}$ )

$O_{e q}=$ amount of inorganic carbon in the ocean surface layers, in equilibrium with the atmospheric $\mathrm{CO}_{2}$ concentration (in $\mathrm{GtC}$ )

$d p C \mathrm{O}_{2}=$ change in atmospheric concentration of $\mathrm{CO}_{2}$ (in ppm) $\mathrm{pCO}_{2}=$ atmospheric $\mathrm{CO}_{2}$ concentration (in ppm)

In modelling the buffer factor the dependence on the inorganic carbon and on temperature is ignored. Only the functional relationship with the atmospheric $\mathrm{CO}_{2}$ relation has been taken into account (Rotmans, 1986, and Health Council, 1983):

$$
B U F F(t)=4.05 * \operatorname{Ln}\left(0.033 * p C \mathrm{O}_{2}(t)\right)
$$

with:

$B U F F(t)=$ buffer factor at time $t$

$p \mathrm{CO}_{2}(\mathrm{t})=$ atmospheric $\mathrm{CO}_{2}$ concentration at time $t$ (in ppm)

In this way the diffusion fluxes between the ocean and the atmosphere can be calculated:

$$
\begin{aligned}
& F L O C 1=\left(O_{1}-O_{1 e q}\right) / R T 1 A \\
& F L O C 2=\left(O_{2}-O_{2 e q}\right) / R T 2 A
\end{aligned}
$$

with:

$F L O C 1=$ flux from the thin surface ocean mixed layer to the atmosphere (in $G t C / y r$ )

FLOC2 $=$ flux from the higher latitude surface ocean layer to the atmosphere (in $G t C / y r$ )

$O_{1}=$ amount of carbon in the thin surface ocean mixed layer (in $G t C$ ) 


$\begin{aligned} O_{1 e q}= & \text { amount of carbon in the thin surface ocean mixed layer in } \\ & \text { equilibrium with atmospherie } \mathrm{CO}_{2} \text { (in } G t C \text { ) } \\ O_{2} & \text { amount of carbon in the higher latitude ocean mixed layer } \\ & (\text { in } G t C) \\ O_{2 e q}= & \text { amount of carbon in the higher latitude ocean mixed layer } \\ & \left.\text { in equilibrium with atmospheric } \mathrm{CO}_{2} \text { (in } G t C\right) \\ R T 1 A= & \text { residence time of carbon in the thin surface ocean layer; } \\ & \text { is } 1 \text { year according to Goudriaan and Ketner (1984) } \\ R T 2 A= & \text { residence time of carbon in the higher latitude surface ocean } \\ & \text { layer; is } 20 \text { year according to Goudriaan and Ketner (1984) }\end{aligned}$

The net flux from the mixed ocean layers to the atmosphere is formed by the addition of FLOC1 and FLOC2, and is used in Equation (3.2), where it is written as OCEA.

\subsection{Terrestrial Biosphere Module}

Various models have been developed to estimate the role of terrestrial biota in the carbon cycle. Wiersum and Ketner (1989) describe three kinds of models: bookkeeping models, evaluating amounts of $\mathrm{CO}_{2}$ release by land-use change (Avenhaus and Hartmann, 1975, Detwiler and Hall, 1988, Houghton et al., 1987); secondly, dynamic global carbon cycle models (Goudriaan and Ketner, 1984, and Esser, 1987); and finally, geochemical models, tracing historic $\mathrm{CO}_{2}$ fossil fuel emissions in the atmospheric $\mathrm{CO}_{2}$ budget (Peng et al., 1983, and Emanuel et al, 1984).

Although the various model estimates of the terrestrial biospheric contribution vary from a net $\mathrm{CO}_{2}$ uptake to a net $\mathrm{CO}_{2}$ release, the differences have been decreasing.

The IMAGE terrestrial biosphere module is an extended version of the Goudriaan and Ketner model (Goudriaan and Ketner, 1984). The terrestrial biosphere is horizontally divided into seven ecosystems (six in the original model of Goudriaan and Ketner). Vertically, the components biomass (subdivided into leaves, branches, stemwood and roots), litter, humus and charcoal have been distinguished. Furthermore, the deforestation process and its underlying causes have been modelled separately. This is described further in the deforestation module section.

The driving force of the carbon cycle model is the net primary production (NPP), being directed by the fertilization effect. This is the increase in accumulation of carbon in terrestrial ecosystems under influence of higher 
$\mathrm{CO}_{2}$ concentrations. In the carbon cycle model this fertilization effect is parameterized by means of a biotic growth factor, even though this factor is ill-known (Goudriaan and Ketner, 1984, Goudriaan, 1987).

The relationship between net primary production and atmospheric $\mathrm{CO}_{2}$ is generally presumed to be logarithmic (Emanuel et al., 1985, Goudriaan and Ketner, 1984):

$$
\frac{d N P P(t)}{N P P(0)}=B \operatorname{IOSTIM} * \frac{d p C O_{2}(t)}{p C O_{2}(t)}
$$

with:

$d N P P(t)=$ change in net primary production at time $t(G t C / y r)$

$N P P(0)=$ initial net primary production, at time $t=0$, in 1900 $(G t C / y r)$

BIOSTIM = biotic growth factor; varies in the literature from 0 to 0.7 ; is 0.4 in IMAGE, whereas Goudriaan and Ketner (1984) take a value of 0.5

$p \mathrm{CO}_{2}(t)=$ atmospheric $\mathrm{CO}_{2}$ concentration at time $t(p p m)$

$d p \mathrm{CO}_{2}(t)=$ change in atmospheric $\mathrm{CO}_{2}$ concentration at time $t(\mathrm{ppm})$

Recently a new relationship has been incorporated, in which, next to the fertilization effect due to the atmospheric $\mathrm{CO}_{2}$ increase, the effect of an increase in temperature has also been taken into account, based on Kohlmaier et al. (1990). Both are considered as negative feedbacks.

The carbon flow throughout the system is given in Figure 3.3. The natural input to the system is the net primary production (NPP), while the carbon released upon the decay of the biomass, litter, humus and charcoal components accounts for the natural output of this system. Man-made processes are on the one hand input sources, by humification and charcoal forming, and on the other they are output flows, by changing land use. Both the natural and anthropogenic input and output processes are modelled according to Goudriaan and Ketner (1984):

$$
\begin{aligned}
B_{j k}(t)= & B_{j k}(0)+\int_{t-1}^{t}\left[f r_{j k} * N P P(\tau)\right. \\
& \left.-\frac{B_{j k}(\tau)}{L F\left(B_{j k}\right)}-s B_{j k}(\tau) * \sum_{i=1}^{7} a_{i j}(\tau) d \tau\right]
\end{aligned}
$$

with:

$B_{j k}(t)=$ carbon in ecosystem $j$ in component $k$ at time $t$ (in GtC) 
$B_{j k}(0)=$ initial carbon in ecosystem $j$ in component $k$ at time $t=0$, 1900 (in GtC)

$f r_{j k}=$ fraction of NPP partitioned to component $k$ in ecosystem $j$

$L F^{\prime}\left(B_{j k}\right)=$ life-span of carbon in ecosystem $j$ of component $k$ (in $y r$ ) $s B_{j k}(t)=$ surface density of carbon in ecosystem $j$ in component $k$ at time $t$ (in $G t C / M h a$ )

$a_{i j}(t)=$ transfer of area from ecosystem $j$ to ecosystem $i$ at time $t$ (in Mha/yr)

$$
\begin{aligned}
L_{j}(t)= & L_{j}(0)+\int_{t-1}^{t}\left[\sum_{k=1}^{3} \frac{B_{j k}(\tau)}{L F\left(B_{j k}\right)}\right. \\
& \left.-\frac{L_{j}(\tau)}{L F\left(L_{j}\right)}-s L_{j}(\tau) * \sum_{i=1}^{7} a_{i j}(\tau) d \tau\right]
\end{aligned}
$$

with:

$L_{j}(t)=$ carbon in litter in ecosystem $j$ at time $t$ (in GtC)

$L_{j}(0)=$ initial carbon in litter in ecosystem $j$ at time $t=0$, in 1900 (in $G t C$ )

$L F\left(L_{j}\right)=$ life-span of litter in ecosystem $j$ (in $y r$ )

$s L_{j}(t)=$ surface density of litter in ecosystem $j$ at time $t$ (in GtC/Mha) 


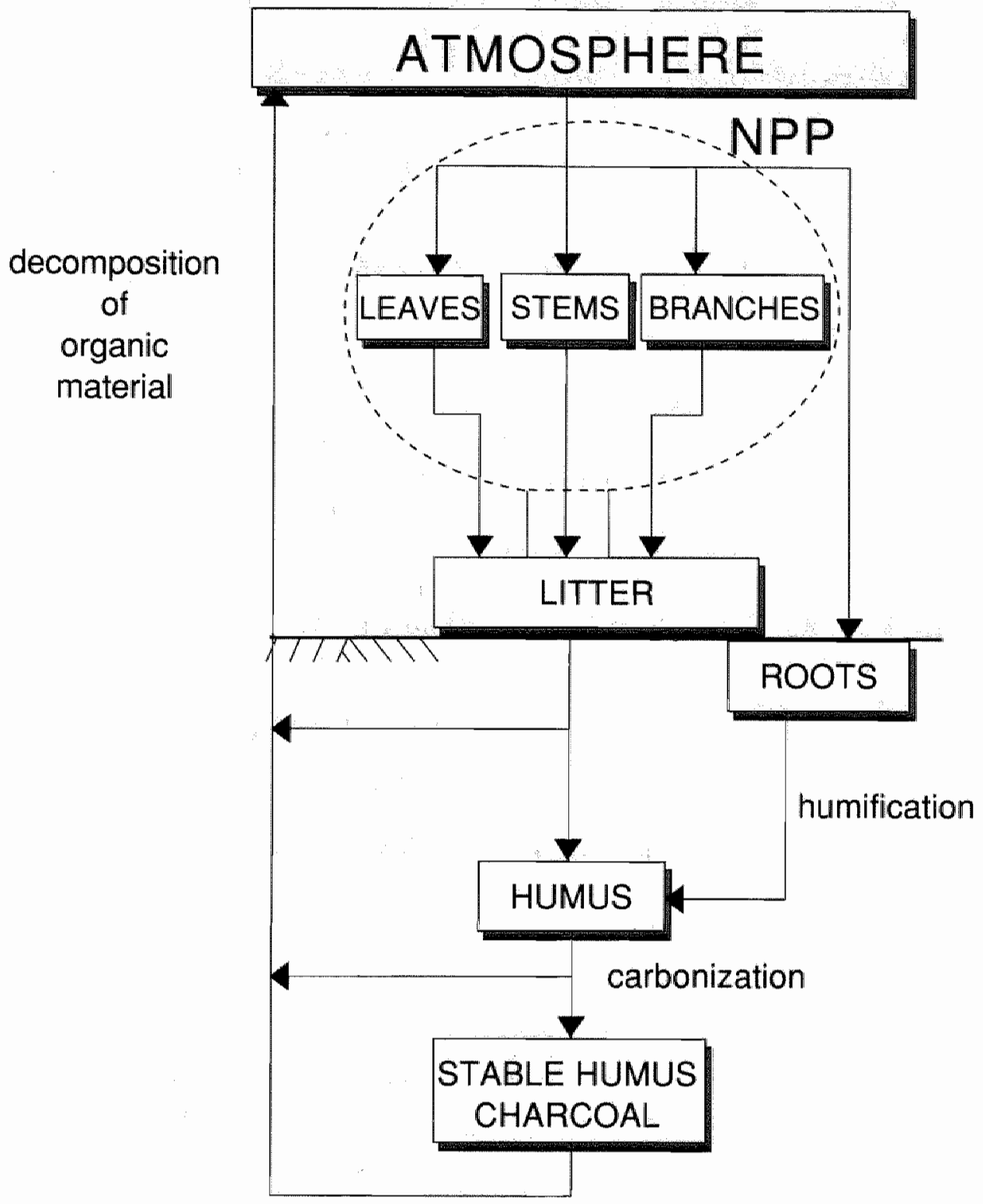

\section{BIOSPHERE}

Figure 3.3: Structure of the terrestrial biota model (Goudriaan and Ketner, 1984). 


$$
\begin{aligned}
H_{j}(t)= & H_{j}(0)+\int_{t-1}^{i}\left[H F _ { j } * \left(\frac{L_{j}(\tau)}{L F^{\prime}\left(L_{j}\right)}\right.\right. \\
& \left.+\frac{B_{j 4}(\tau)}{L F\left(B_{j 4}\right)}\right)-\frac{H_{j}(\tau)}{L F\left(H_{j}\right)}-s H_{j}(\tau) * \sum_{i=1}^{7} a_{i j}(\tau) \\
& \left.+\sum_{i=1}^{7} a_{j i}(\tau) *\left(s H_{i}(\tau)+H F_{j} * s B_{i 4}(\tau)+0.5 * s B_{i 3}(\tau)\right) d \tau\right]
\end{aligned}
$$

with:

$H_{j}(t)=$ humus in ecosystem $j$ at time $t$ (in GtC)

$H F_{j} \quad=$ humification fraction in ecosystem $j$

$B_{j 4}(t)=$ carbon in roots in ecosystem $j$ (in GtC)

$B_{i 3}(t)=$ carbon in stems in ecasystem $i$ (in GtC)

$s H_{j}(t)=$ surface density of humus in ecosystem $j$ (in GtC/Mha)

$L F\left(H_{j}\right)=$ life-span of humus in ecosystem $j$ (in $y r$ )

$$
\begin{aligned}
K_{j}(t)= & K_{j}(0)+\int_{t-1}^{t}\left[\frac{C F H_{j} * H_{j}(\tau)}{L F\left(H_{j}\right)}-\frac{K_{j}(r)}{L F\left(K_{j}\right)}\right. \\
& -s K_{j}(\tau) * \sum_{i=1}^{7} a_{i j}(\tau)+\sum_{i-1}^{7}\left(a _ { j i } ( \tau ) * \left(s K_{i}(\tau)\right.\right. \\
& \left.+\sum_{k=1}^{3}\left(C F B_{k} * s B_{j k}(\tau)+C F L * s L_{i}(\tau)\right) d \tau\right]
\end{aligned}
$$

with:

$K_{j}(t)=$ carbon in charcoal in ecosystem $j$ at time $t$ (in $G t C$ )

$K_{j}(0)=$ initial carbon in charcoal in ecosystem $j$, at time $t=1900$ (in $G t C$ )

$L F\left(K_{j}\right)=$ life-span of charcoal in ecosystem $j$ (in $y r$ )

$s K_{j}(t)=$ surface density of charcoal in ecosystem $j$ at time $t$ (in $G t C / M h a$ )

$C F H_{j} \quad=$ carbonization fraction of humus in ecosystem $j$ upon decomposition

$C F B_{k}=$ carbonization fraction of component $k$ upon burning

$C F L=$ carbonization fraction of litter upon burning 
The land transfer matrix $\left(a_{i j}\right)$ links the terrestrial biota module with the deforestation module. While in Goudriaan and Ketner (1984) the matrix elements are related to the growth of world population, in IMAGE these matrix elements are for the greater part dynamic processes, as will be described in the next section, which deals with the deforestation module.

Finally, with the calculated amounts of carbon in the pools of biomass $\left(B_{j k}\right)$, humus $\left(H_{j}\right)$, litter $\left(L_{j}\right)$ and charcoal $\left(K_{j}\right)$, the fluxes TNEP and THDIST from Equation 3.2 can be simulated according to Goudriaan and Ketner (1984):

$$
\begin{aligned}
N E P_{j}(t)= & N P P_{j}(t)-\left(\frac{L_{j}(t)}{L F\left(L_{j}\right)}+\frac{B_{j 4}(t)}{L F\left(B_{j 4}\right)}\right) *\left(\mathbb{1}-H F_{j}\right) \\
& -\frac{H_{j}(t) *\left(1-C F H_{j}\right)}{L F\left(H_{j}\right)}-\frac{K_{j}(t)}{L F\left(K_{j}(t)\right)}
\end{aligned}
$$

with:

$N E P_{j}(t)=$ net ecosystem production of ecosystem $j$ at time $t$ (in $G t C / y r$ )

$T N E P(t)=$ NEP, summed over all ecosystems at time $t$ (in $G t C / y r$ )

$N P P_{j}(t)=$ net primary production of ecosystem $j$ at time $t$ (in $G t C / y r)$

$$
\begin{aligned}
\operatorname{HDIST}_{j}(t)= & \sum_{j=1}^{7} \sum_{i=1}^{7} a_{i j} *\left[\sum_{k=1}^{3}\left(1-C F B_{k}\right) * s B_{j k}(t)-0.5 * s B_{i 3}(t)\right. \\
& \left.+\left(1-H F_{j}\right) * s B_{i 4}(t)+(1-C F L) * s L_{i}(t)\right]
\end{aligned}
$$

with:

$H D I S T_{j}(t)=$ carbon flux released from biosphere by human disturbance at time $t$ (in GtC/yr)

THDIST $(t)=$ HDIST, summed over all ecosystems at time $t$ (in $G t C / y r$ )

\subsection{Deforestation Module}

\subsubsection{Introduction}

The world's tropical forests presently face tremendous pressures from the increasing demands of increasing populations. More than 10 million hectares of closed tropical rainforests are destroyed annually and an equal amount is 
severely altered. The result of this is the extinction of species, increased erosion, threats to indigenous people, the modification of regional and even global climate and the destruction of a wide variety of possible economically important assets.

Land use change is one of the human activities influencing global change. It can be manipulated in the model by changing the elements of a land use transfer matrix, describing shifts between ecosystems. As a first step towards a global land use change module a tropical forest module was developed to be linked to this matrix in IMAGE. Because the climate effect is only one among several other (possibly more important) effects of deforestation, the module can also be used as a demonstration model on its own. To take other land use changes into account, such as desertification, forest dieback, wetland drainage and extended lowering of groundwater tables, the module has to be upgraded in the future.

Because of the different characteristics of the areas in the module the three major tropical forest areas are considered separately: Latin America, Africa and South-East Asia. It is not intended to present reliable projections of forest resources for the near future, but merely to present long term possibilities for different types of development. In order to calculate long-term deforestation projections, four scenarios were developed: A. unrestricted trends, B. reduced trends, C. changed trends and D. forced trends. From $A$ to $D$ increasing national and international awareness causes the implementation of increasingly protective measures.

In scenario A economic growth is not restricted by environmental concerns. Short time profits prevail over long term assets. For tropical forests this means: a continuing exploitation as if tropical forest were 'mined' as quickly as possible. This means high estimates for logging, agricultural consumption and industrial projects. Because in such a scenario short term economic growth can be considered to generate finances enabling the use of agricultural inputs to increase productivity, the scenario can be expected not to show an exponential trend.

The scenarios $\mathrm{B}$ and $\mathrm{C}$ are meant to describe two levels of developments in which forest destruction is limited by increasing use of long tern economic potential, as for instance planned in some recent initiatives as the International Tropical Timber Agreement (ITTA) and FAO's Tropical Action Plan. Scenario B is assumed to reflect the effect of the ITTA, whereas in scenario $\mathrm{C}$ the Tropical Action Plan of the FAO can be considered to implemented (Food and Agricultural Organization, 1986).

Finally, scenario $D$ is intended to describe the preservation of the forests 
for ecological reasons mainly. Scenario D assumes pure conservation of the forest in their primary state, even if this means, that the economic value of the area would not be used to its full extent. In this scenario, for instance, production of hardwood and meat dairy is limited in the tropical zones and reforestation is important. To simulate scenarios the parameters in the module are varied: demand for wood for construction, fuel wood, energy and minerals, agricultural land and pasture, etc.

Population growth is taken common for all scenarios. Economic development is not included explicitly, since it is assumed that there is no direct easy linkage between economic growth and land use change, and that long term land use change will be driven by the demand for land and products whatever the costs. The details of the different scenarios are described in the Appendix to this chapter.

\subsubsection{Description of the Deforestation Model}

The deforestation module is an independent submodule within the carbon cycle module. The structure of the deforestation module is shown in Figure 3.4. The module distinguishes four types of ecosystems that are important for the areas concerned: tropicall forests, grasslands, arable land and semidesert. In this study the tropical forest system was split into closed and open forest as defined by Lanly (1982). The ecosystems have different carbon densities for their different components (vegetation, litter, soil humus).

Intermediate types of forests (secondary forests, forest fallow) were included in the 'open forest' system. All converted forests are assumed to end up as re-established forests, agricultural or pasture land, or degraded area. Deforestation is triggered by a variety of processes, which are mainly caused by a number of demands driven by growth of population and economy.

Notation:

The ecosystems (in $h a$ ) and processes (in $h a / y r$ ) are denoted as follows: 


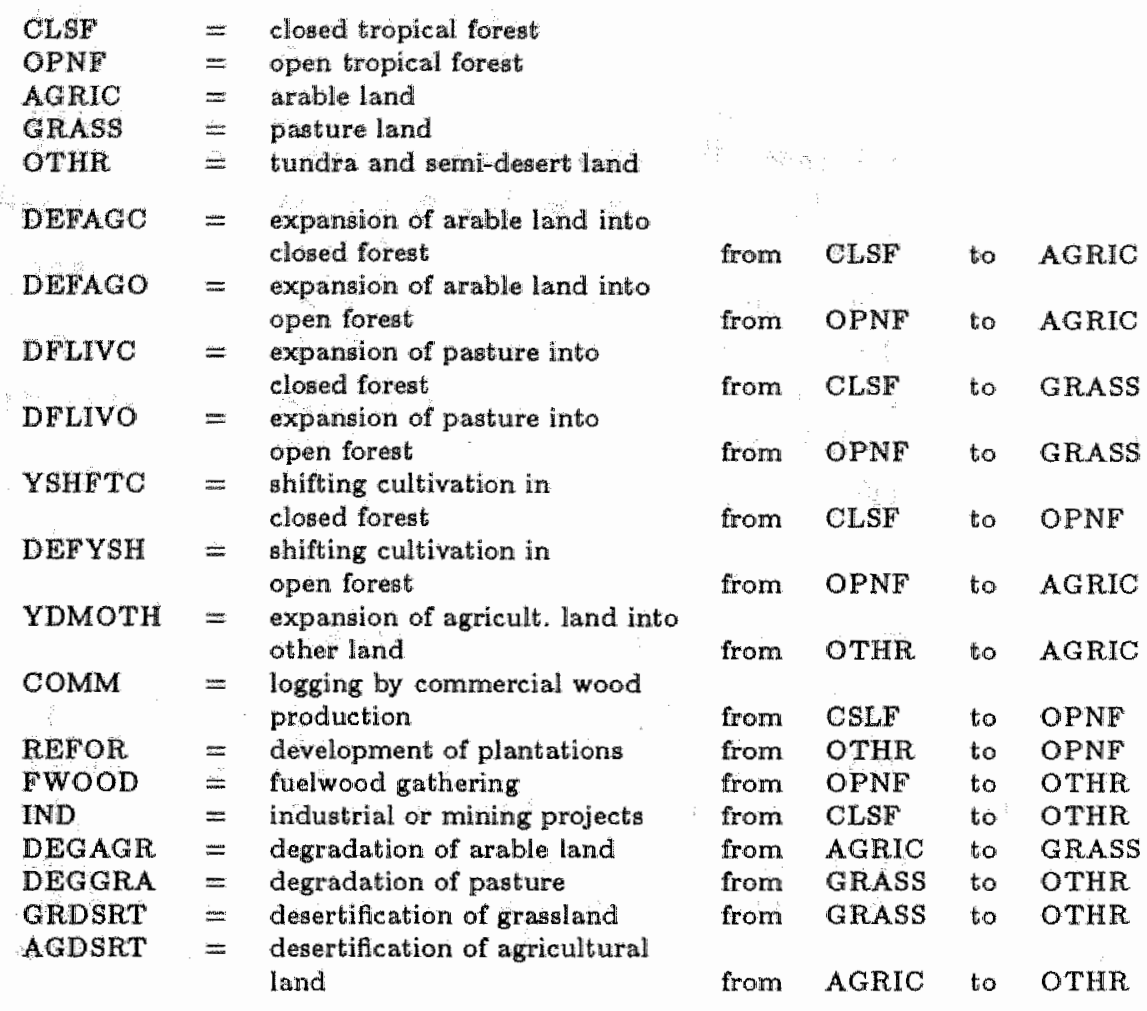

In the deforestation computer model several processes (DFLIVC, DFLIVO, DEFAGC, DEFAGO, DEFYSH and YDMOTH) may become negative. Therefore these processes are defined in such a way that, in case of the occurrence of a negative value, this process is set to 0 and the reverse process is activated. For instance DFLIVO (deforestation of open forest by livestock, from OPNF to GRASS) has an analogously defined reverse process DFLIOR (reversed deforestation, from GRASS to OPNF), which is O if DFLIVC is greater than 0 and receives the absolute value of DFLIVC if DFLIVC is less than 0 . The same holds for the other processes DFLIVO, DEFAGC, DEFAGO, DEFYSH and YDMOTH.

The land use changes resulting from the calculations are represented by the already mentioned processes and are inserted at the relevant places of the transfer matrix as shown in Table 3.1. 


\begin{tabular}{|c|c|c|c|c|c|c|c|}
\hline into from & $\begin{array}{l}\text { closed } \\
\text { forest }\end{array}$ & $\begin{array}{c}\text { open } \\
\text { forest }\end{array}$ & $\begin{array}{l}\text { temperate } \\
\text { forest }\end{array}$ & $\begin{array}{l}\text { giragand } \\
\text { land }\end{array}$ & $\begin{array}{l}\text { aysie. } \\
\text { Isand }\end{array}$ & $\begin{array}{c}\text { humanan } \\
\text { mirea }\end{array}$ & 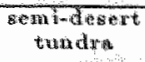 \\
\hline $\begin{array}{l}\text { closed } \\
\text { forest }\end{array}$ & 10 & 0 & 0 & $\theta$ & 0 & 0 & 0 \\
\hline $\begin{array}{l}\text { open } \\
\text { forest }\end{array}$ & 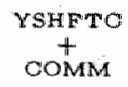 & 6.5 & 0 & 0 & DEFYSH & a & REFOR \\
\hline $\begin{array}{l}\text { tempedate } \\
\text { forest }\end{array}$ & 0 & 0 & 2 & 0 & 0 & a & $a$ \\
\hline grastand & DFLIVO & DELIVO & 1 & 400 & DEOAGR & 0 & 0 \\
\hline $\begin{array}{l}\text { agricult. } \\
\text { area }\end{array}$ & DEFAGC & $\begin{array}{c}\text { DEFAGO } \\
\text { + } \\
\text { DEFYSH }\end{array}$ & 0 & 0 & 400 & 0 & YDMOTH \\
\hline $\begin{array}{l}\text { human } \\
\text { area }\end{array}$ & 0.5 & 0 & 0.5 & 1 & 1 & 0 & 0 \\
\hline $\begin{array}{l}\text { semi- } \\
\text { desert/ } \\
\text { turedra }\end{array}$ & IND & WOOD & 0 & $\begin{array}{c}\text { DEGGRA } \\
\text { A } \\
\text { GRDRT }\end{array}$ & AGDSRT & 0 & 0 \\
\hline
\end{tabular}

Table 3.1: Modified process transfer matrix of area between ecosystems (Mha/yr) in 1980 .

As can be seen in Figure 3.4 some simplifications have been made. Fuelwood gathering is only taken into account for open forests, assuming that in closed forest areas the natural production capacity surpasses local demand (de Montalembert and Clément, 1983). Forest plantations are assumed to develop on other lands rather than on agricultural, grass or forest lands. Logging is assumed to take place in closed forests only, degrading them into secondary (here open) forests. These processes will be discussed in the following sections. To validate the different relationships for the past decades the FAO Production Yearbooks were used as well as a number of literature estimates of present and historical values of important parameters, among which are those cited by the World Resources Reports (World Resources Institute, 1986, 1987, 1988/1989). The most important assumptions and input data are summarized in the Appendix to this chapter.

Land transfers are described by differential equations, while processes are represented by algebraic dynamic functions. The amount of closed tropical forest is determined by the initial amount and the conversion into arable land (process DEFAGC), pasture (process DFLIVC), other land (process IND) and open tropical forest (processes COMM and YSHFTC), respectively. This leads to the following dynamic expression: 


$$
\begin{aligned}
C L S F(t)= & C L S F(t-1)+\int_{t-1}^{t}(-\operatorname{COMM}(\tau)-\operatorname{IND}(\tau) \\
& -Y S H F T C(\tau)-D E F A G C(\tau)-D F L I V C(\tau)) d \tau
\end{aligned}
$$

with:

CLSF $(0)=$ amount of closed forest at time 0 , in 1900 (in $h a$ )

Similar to closed forest, the amount of open tropical forest is determined by the initial amount and the conversion into arable land (processes DEFAGO and DEFYSH), pasture (process DFLIVO), other land (FWOOD) and the re-establishment of open forest (process REFOR); additionally closed forests are converted into open forests (processes COMM and YSHFTC). Hence the dynamic amount of open tropical forest is expressed as:

$$
\begin{aligned}
\operatorname{OPNF}(t)= & \operatorname{OPNF}(t-1)+\int_{t-1}^{t}(\operatorname{COMM}(\tau)+\operatorname{REFOR}(\tau) \\
& +\operatorname{YSHFTC}(\tau)-\operatorname{DEFAGO}(\tau)-\operatorname{DFLIVO}(\tau) \\
& -\operatorname{FWOOD}(\tau)-\operatorname{DEFYSH}(\tau)) d \tau
\end{aligned}
$$

with:

$O P N F(0)=$ amount of open forest at time 0 , in 1900 (in $h a$ )

The penultimate ecosystem to be described is arable land. The amount of arable land is specified by the initial amount and the expansion of agricultural land into closed forest (processes DEFAGC) and open forest (processes DEFAGO and DEFYSH) and into other land (process YDMOTH) minus the degradation of arable land to grassland (process DEGAGR):

$$
\begin{aligned}
A G R I C(t)= & A G R I C(t-1)+\int_{t-1}^{t}(Y \operatorname{DMOTH}(\tau)-D E G A G R(\tau) \\
& +D E F A G C(\tau)+D E F A G O(\tau)+D E F Y S H(\tau)) d \tau
\end{aligned}
$$

with:

$A G R I C(0)=$ amount of agricultural land at time 0, in 1900 (in ha) 


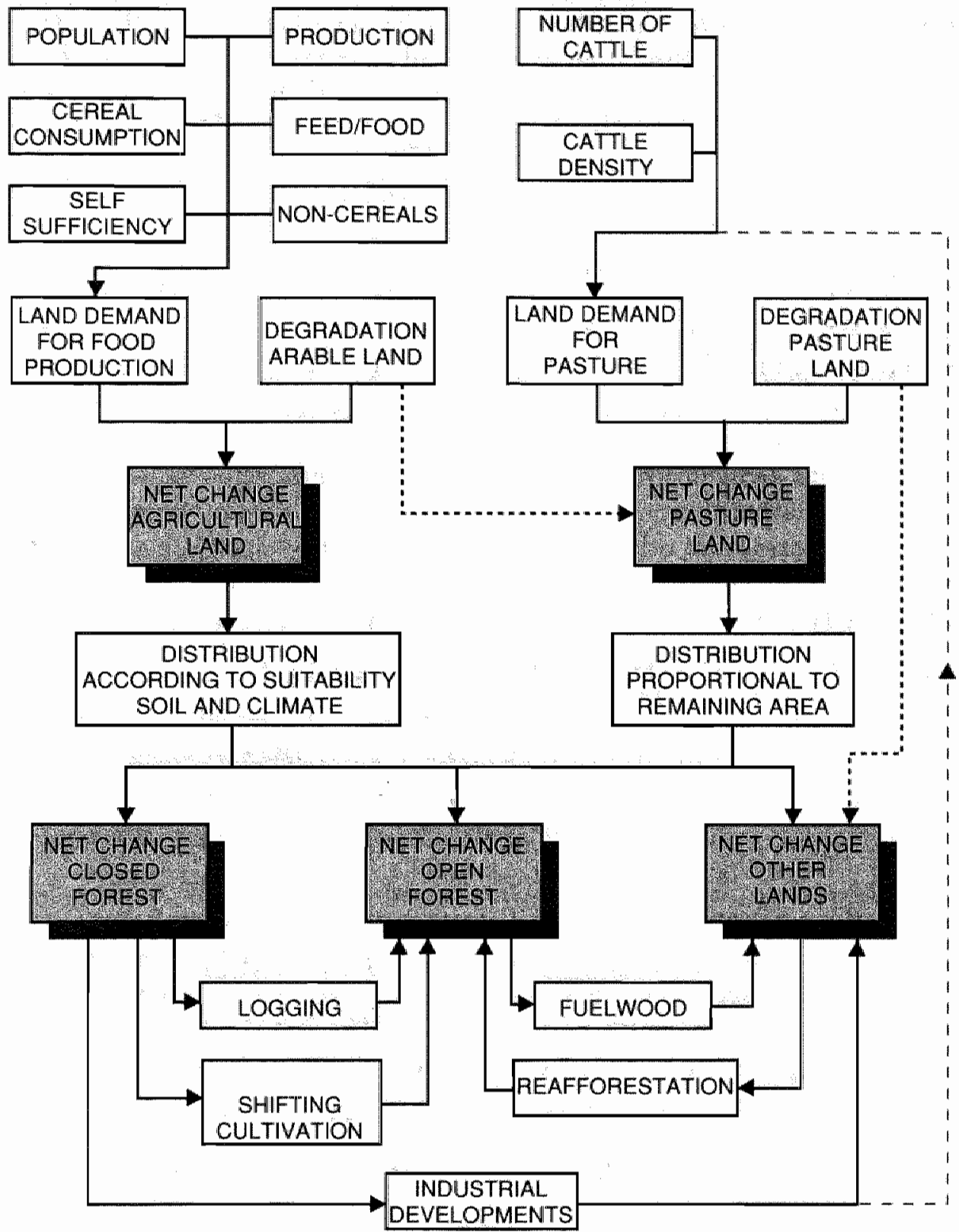

Figure 3.4: Structure of the IMAGE deforestation module 
Finally the ecosystem pasture (grassland) is defined, specified by the initial amount of pasture, the conversion of tropical forest into pasture (processes DFLIVC and DFLIVO) and degradation of arable land to grassland (DEGAGR), minus the degradation of grassland to other land (DEGGRA):

$$
\begin{aligned}
\operatorname{GRASS}(t)= & \operatorname{GRASS}(t-1)+\int_{t-1}^{t}(D E G A G R(\tau)-D E G G R A(\tau) \\
& +D F L I V C(\tau)+D F L I V O(\tau)) d \tau
\end{aligned}
$$

with:

GRASS (0) = amount of pasture (grassland) at time 0, in 1900 (in ha)

A few of the most important processes are elucidated below. These processes are represented by algebraic equations. The other processes are expounded in Swart and Rotmans (1989a,b).

The expansion of agricultural land into closed tropical forest is represented by the demand for arable land and the degradation of arable land, multiplied by a suitability factor, representing the proportion between closed forest, open forest and other land within a suitability class (for an explanation of the term suitability class see $\S 3.7 .3)$ ). This agricultural expansion is defined by the following algebraic equation:

$$
D E F A G C(t)=(Y D M A G R(t)+D E G A G R(t)) * A L F C L F(t)
$$

with:

YDMAGR $(t)=$ yearly demand for arable land at time $t$ (in $h a / y r$ )

$A L F C L F(t)=$ ratio of current amount of closed tropical forest to the current amount of closed forest, open forest and other land according to suitability distribution at time $t$

Exactly the same kind of equation holds for the expansion of open tropical forest into agricultural land (Swart and Rotmans, 1989a,b). Analagous to the agricultural expansion, the expansion of pasture into closed forest is determined by the demand for grassland, the degradation of both grassland and arable land, multiplied by a ratio, reflected in the following expression:

$$
\begin{aligned}
D F L I V C(t)= & (Y D M G R(t)+D E G G R A(t) \\
& -D E G G R A(t)) * A L F G R C(t)
\end{aligned}
$$

with:

$Y D M G R(t)=$ yearly demand for pasture at time $t$ (in $h a / y r)$ $A L F G R C(t)=$ ratio of current amount of closed tropical forest to the initial amount of closed tropical forest. 
The same applies to the expansion of pasture into open forest. The expansion of agricultural land into other land is defined as a function of the yearly demand for agricultural land multiplied by a ratio:

$$
Y D M O T H(t)=Y D M A G R(t) * A L F O T H
$$

with:

$Y D M O T H(t)=$ colonization (yearly expansion of agricultural land into other land) at time $t$ (in $h a / y r$ )

$Y D M A G R(t)=$ yearly demand for agricultural land at time $t$ (in $h a / y r$ )

$A L F O T H(t)=$ ratio of the current amount of other land to the current amount of closed forest, open forest and other land in the current suitability class at time $t$

For an exhaustive and more detailed description of the other driving forces and processes of the deforestation module is referred to Swart and Rotmans (1989b).

\subsubsection{Description of the Processes}

The following processes will be described: permanent agriculture, shifting or pioneer cultivation, cattle breeding, logging, fuelwood gathering, industrial projects, and reforestation.

\section{Permanent agriculture}

Mankind has always transformed the face of the earth since prehistoric times. The scope of this transformation has accelerated since man's lifestyle changed from nomadic to sedentary, culminating in the spectacular population growth after the industrial revolution (Wolman and Fournier, 1987). Expansion of permanent agriculture has always been the most important factor in deforestation at all latitudes. Presently the demand for agricultural land in the tropical regions is primarily caused by five factors:

- an increasing number of people

- higher levels of consumption of food, fiber and forest products due to economic growth

- area and productivity loss by land degradation 
- inaccessibility of intensive agriculture for poor farmers

- production for export (often for debt relief).

Many studies have indicated that, theoretically, present and future world populations can be amply fed by increases in arable land and productivity (e.g. Buringh et al., 1975). Other studies have indicated that this is not so for individual countries (FAO, 1984). Unfortunately, in past studies on population carrying capacities the present vegetation has not been taken into account. In this study it is. To determine the net demand for additional agricultural land for each region the following parameters have been taken into account: population, cereal demand per capita, cereal productivity per hectare, present arable land, fraction of land used for non-cereals and other products, fraction of cerals used for feed, the self-sufficiency ratio to allow for food imports or aid.

$$
D M A G R(t)=\frac{P O P(t) * C E(t) * S S R(t)}{Y(t) * \alpha(t) *(1-\beta(t)-\gamma(t))}
$$

with:

$D M A G R(t)=$ cumulative demand for agricultural land at time $t$ (in $h a$ ) $\operatorname{POP}(t)=$ population at time $t$

$C E(t) \quad=$ cereal consumption at time $t$ (in $\mathrm{kg} / \mathrm{cap}$ )

$S S R(t) \quad=$ self sufficiency ratio at time $t$

$Y(t)$

$\alpha(t)$

$\beta(t)$

$=$ yield at time $t$ (in $\mathrm{kg} / \mathrm{ha}$ )

$\gamma(t)$

$=$ fraction of cereals used for food at time $t$

$=$ fraction of area for food from non-cereals at time $t$

= fraction of area for other other agricultural products at time $t$

To determine the total demand for agricultural land finally degraded lands are added. For lack of quantitative information degradation is simulated by a negative exponential function, which encompasses the assumption that every newly converted hectare will be more susceptible to erosion than the previous one. High inputs are not only assumed to increase agricultural productivity, but also to decrease erosion rates. Additional effort is necessary for a better quantitative estimate of land degradation.

The demand for agricultural land has to be distributed over the different ecosystems. The following procedure has been followed. First, those areas are converted which have been altered by logging or shifting cultivation the year before. Then the land is assumed to be colonized according to its 
suitability for agriculture. For this project, estimates of the suitability of areas have been made by Bouwman $(1989 \mathrm{a}, \mathrm{b})$, taking into account the soil types, the climate, the topography and the input level, see Table 3.2. For scenarios A and B high input levels have been assumed, and low levels for $\mathrm{C}$ and D.

\begin{tabular}{|c|c|c|c|c|c|c|c|c|c|}
\hline \multirow[t]{2}{*}{ min ha } & \multicolumn{9}{|c|}{ enitabillity aldsesti) } \\
\hline & \multicolumn{4}{|c|}{ low imput } & \multicolumn{4}{|c|}{ high loppot } & \\
\hline Africa & I & II & $\mathrm{III}$ & IV & 1 & II & IIII & IV & totan \\
\hline closed Forest & .7 & 27.8 & 1510 & 41.7 & S. & 149.8 & 5 & 22.7 & 221.1 \\
\hline open forest ${ }^{2}$ & d. .0 & 136. & 165 & 19.8 & 162.5 & 227.5 & 80.0 & $7 \%, 6$ & 498.5 \\
\hline gethond & 6.6 & 186.09 & 170.0 & 415.7 & $221+8$ & 2330 & 35,1 & $28 \mathrm{~B}$ & 778.2 \\
\hline arable land & 1.1 & 519.5 & 64.4 & 67.1 & $6 \pi 7$ & 76.1 & 12,4 & 27.0 & 189.1 \\
\hline $\operatorname{sen} x^{4}-d^{4} \sec t^{3}$ & 2.8 & 82.7 & 937 & 1008.0 & 111.7 & 110.4 & 21.0 & 102.4 .2 & 1277.2 \\
\hline total & 12.1 & 483.8 & 6447 & 1817.3 & 606.9 & 2053 & 105.1 & 1440.7 & 2050.0 \\
\hline \multicolumn{10}{|l|}{ Lin tin A merica } \\
\hline closed forest & 0.0 & 53.11 & $509 \cdots 4$ & 130.7 & 403,4 & 170.2 & 66.6 & 4.0 & 690.2 \\
\hline open forest ${ }^{2}$ & 0.0 & 46.3 & 87.3 & 106,0 & 86.01 & 106.2 & 9.65 & 36,6 & 230.5 \\
\hline temperate forest & 0.0 & 22.0 & $01 . \overline{19}$ & 14.7 & 22.7 & 0.0 & i.1.1 & 2.0 & 36.7 \\
\hline prassland & $5 . \overline{3}$ & 97.8 & $202: \pi$ & 245.2 & 179.1 & 201.2 & 87,2 & 118.3 & 350,4 \\
\hline arable land & 0.0 & 81.2 & 85.8 & 38.5 & $1,08.3$ & 38.3 & 16.7 & 12.2 & 175.8 \\
\hline semindesentions & 0.6 & 57.6 & 18.3 & $2.15,8$ & 58.4 & 30,5 & 20.9 & 175.3 & 201.6 \\
\hline total & 5.9 & 327.9 & 902.8 & 750.8 & $8 B 2 . T$ & 556.7 & 190.0 & $38 \pi .5$ & 1989.9 \\
\hline \multicolumn{10}{|l|}{ Soutineast Asia } \\
\hline clased foriest & 7.8 & 62.2 & 170.6 & 55.0 & 220,0 & 20.6 & 35.9 & 10.4 & 305.5 \\
\hline open forest ${ }^{2}$ & 0.0 & 15.6 & 35 & 11.9 & 25.0 & 1.5 & 3.4 & 1,1 & 31.0 \\
\hline grassland & 0.0 & 4.3 & Q. & 16.0 & 12.5 & 3.5 & 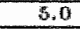 & 9.2 & 30.2 \\
\hline arabel land & 0.8 & 07.5 & 55.0 & 103.9 & 166.6 & 20.5 & 25,8 & 44,5 & 257.2 \\
\hline semi-desert ${ }^{3}$ & 1.7 & 153.8 & 58.2 & 71.5 & 119.8 & 15.1 & 22.0 & 28.9 & 185.0 \\
\hline total & 10.2 & 23.3 & 306.2 & 250.1 & $5,4,4$ & 70.2 & 221 & 102.2 & 808,8 \\
\hline
\end{tabular}

1 Imhigh, II=moderate, III=low and IV=marginal suitability

2 including forest fallow, logged forest, forest plantations

3 üncluding human area. Shifting or pioncer cultivation

Table 3.2: Agricultural suitability classes (derived from Bouwman, 1989a,b).

\section{Shifting or pioneer cultivation}

Much controversy exists on the subject of shifting cultivation. According to Lanly (1982) shifting cultivation is increasing because of increasing numbers of people; according to Myers (1984) it is decreasing, because landless farmers from other areas convert traditional shifting cultivation areas into permanent cropland. For the carbon cycle a sustainable traditional form of shifting cultivation is not very important. Without entering the discussion on the definition of 'shifting' or 'pioneer' cultivation the following approach is chosen: expanding traditional shifting cultivation in closed forest areas is 
considered as a catalysing agent for further forest destruction in later years, degrading them initially into open forests. First the expansion into closed forests is calculated as a function of the fraction of the rural population involved in this type of agriculture, the fallow period and the conversion per familly (Detwiler et al., 1985).

$$
\begin{aligned}
S H F T C L(t)= & P O P(t) * R U R(t) * S W F C(t) \\
& *(C L F(t) / N F M(t)) * F C(t)
\end{aligned}
$$

with:

$S H F T C L(t)=$ area under shifting cultivation at time $t$ (in $h a$ )

$P O P(t)=$ population number at time $t$

$R U R(t) \quad=$ rural fraction at time $t$

$S W F C(t)=$ rural fraction shifting cultivation (swidden farmers) at time $t$

$C L F(t)=$ amount of land cleared per family per year at time $t$ (in $h a / f m . y r$ )

$N F M(t) \quad=$ number of people per family at time $t$ (in $c a p / f m$ )

$F C(t) \quad=$ fallow cycle at time $t$ (in $y r$ )

In the computer program this converted area is memorized and in the next timestep it is first used for expansion of permanent agricultural area.

\section{Cattle breeding}

In all developing countries the number of cattle has gradually increased along with the population. Only in Latin America has this growth taken place at the expense of tropical forests. In Asia and Africa meat and dairy products form a less important part of the diet, while no major export markets are near at hand. The troublesome situation in Latin America, where cattle breeding is expanding, originally triggered by beef demands in the USA and maintained by a complex of socio-economic factors, is discussed extensively in the literature (Hecht, 1988, Fearnside, 1987 or Repetto, 1988). In Asia, cattle are integrated in the agricultural system and in general do not require separate grazing lands. They feed on agricultural wastes and off-season feed products.

At this point in time it is not clear whether this situation might change in the future. When economies surpass a certain welfare level, the demand for luxury products like meat and dairy may jump to a much higher level, which might not be served by the present integrated situation, but might 
require additional land for grazing and feed production. In Africa a different situation exists. Many areas are less suitable for agriculture than for cattle breeding. Therefore livestock is an important source of income for many people. Although the extensive cattle breeding has expanded in Africa, it appears that the most important problem is the land degradation by overgrazing rather than forest destruction. More study on livestock in these two regions is needed. For the different scenarios different growth rates of numbers were taken and different levels of intensity (numbers per hectare):

$$
D M G R S=G R S S I N * C A T / C T 1900 * C A T P R D P R 1900
$$

with:

$D M G R S(t)=$ cumulative demand for grassland (in $h a$ )

$\operatorname{GRSSIN}(t)=$ initial amount of grassland (in $h a$ )

$C A T(t) \quad=$ number of cattle

$C T 1900(t)=$ number of cattle at time $t=0$, in 1900

$C A T P R D(t)=$ cattle productivity (in $h a / h d$ )

$P R 1900(t)=$ cattle productivity at time $t=0$, in 1900 (in $h a / h d)$

\section{Logging}

In public discussions on tropical deforestation in the developed world production of commercial tropical hardwood is often pointed at as the most important cause of deforestation. The wood traders then reply that they do not cause more than a few percent of the total. Both may be right. Directly, commercial logging may not contribute much in comparison with other causes. But indirectly, logging activities open up the forests by road construction, taking poor farmers in their wake to finish the job. In this model this effect is simulated in a similar way to shifting cultivation: after logging in the next timestep the logged area is converted into agricultural area. This assumption is not valid everywhere, for instance in parts of Indonesia, where logs are transported by river. Generally logging can be considered as the mining of a non-renewable resource. Commercially preferred species need 40 to 100 years for full regrowth, were they to be replanted, which does not happen yet.

The per capita demand for wood and wood products is more or less proportional to economic growth. This means that, in the future, an increasing portion of the wood production of the tropical forest areas will be used internally. Even now some tropical forest countries are wood importers. Supplies 
in the developed world will be restricted by the applied principle of sustained yield and maybe by the effects of acidification. Now that the forest resources of Southeast Asia and West Africa are becoming depleted, attention will be focused on hitherto relatively unexploited regions like Amazonia and the Congo basin. There are a number of ways to reduce the stress on wood resources. First, more species have to be utilized. This does not stop the "mining" aspect of tropical wood production, however. More efficient end use or the use of alternative materials is needed. Then the development of tropical hardwood plantations has to be stimulated. In the model scenarios two parameters are varied: the growth rate of hardwood production and the productivity per hectare. The simulated logging for the three regions is plotted in Figure 3.5.

\section{Fuelwood gathering}

Combustion of fuelwood only contributes to the greenhouse effect when extraction is larger than regrowth. This is the case in many regions; where fuelwood scarcities occur (de Montalembert and Clément, 1983). Usually these areas lie outside the major forest areas. Lanly (1982) considers fuelwood gathering in forests as a less important degradation factor rather than a cause of total forest destruction. Fuelwood is the primary source of energy in rural areas. Since scarcities arise in the rural areas and wood is transported over ever longer distances, commercial fuelwood extraction from forests may increase, leaving large areas of forest severely damaged. According to Myers (1984) the demand for fuelwood already causes major deforestation (25,000 $\mathrm{km}^{2}$ annually). For this study it is assumed that closed forests are not affected because of natural regrowth. Only open forests are taken to be deforested, at a rate which is chosen proportional to rural population growth in the area. No allowance for decreasing withdrawal because of plantation wood or increased combustion efficiency has yet been taken into account. 

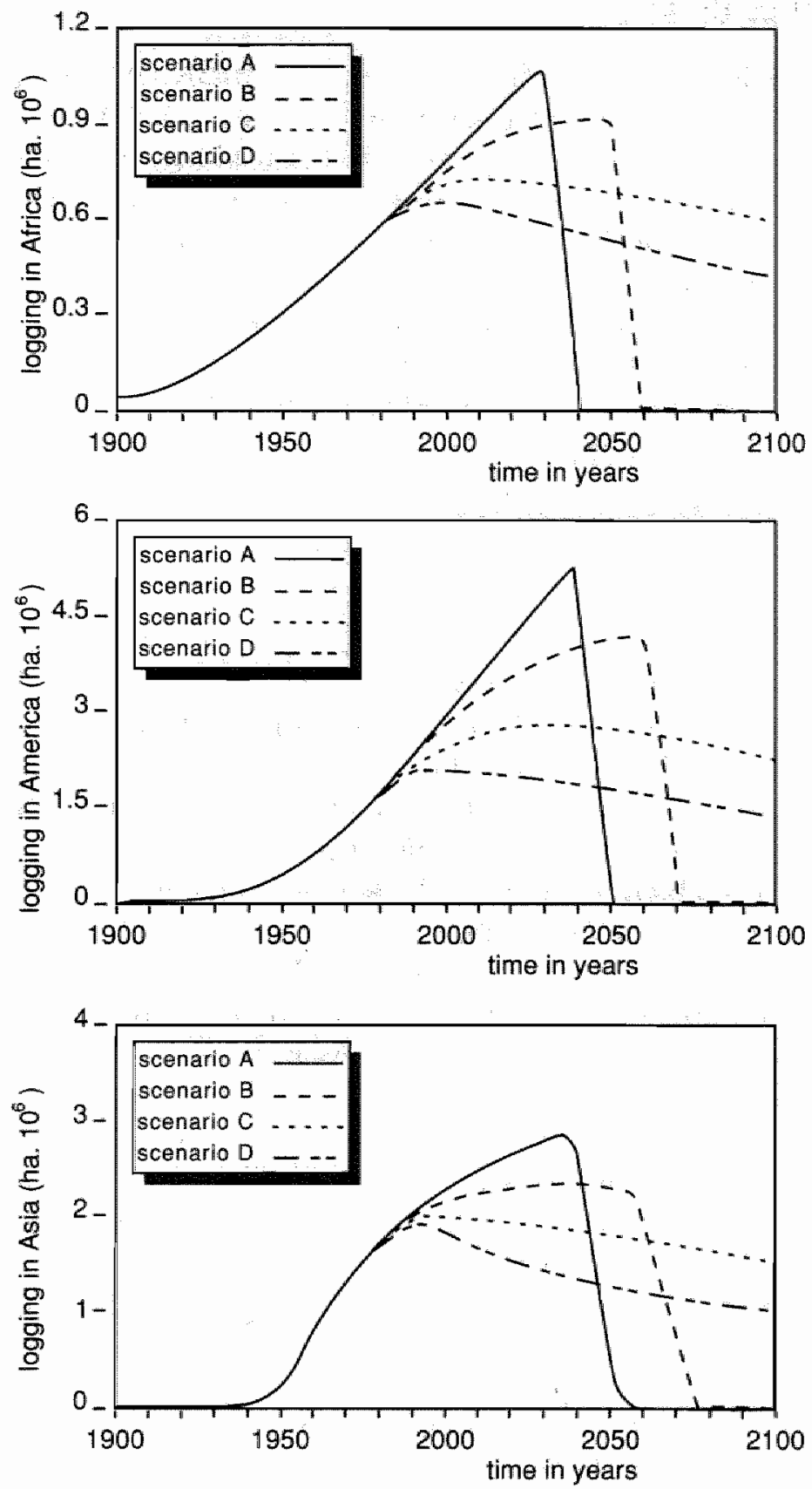

Figure 3.5: Simulated logging for the three regions. 


\section{Industrial projects}

Industrial projects are seldom considered in systems studies on deforestation. The implementation of projects is primarily steered by political and financial aspects. Although the direct effect is usually rather small in terms of hectares of forests cleared, the opening up of virgin land and possible employment opportunities draw vast amounts of people to the project area. Although in all three regions these projects play a role, only the massive plans for Amazonia have been included, aiming at the exploitation of the mineral resources and hydropower potential. The planned size of the projects depends very much on government changes and opportunities for external financing, and changes rapidly. In order to illustrate the potential importance of these projects, different rates of forest conversion are included for the different scenarios for Latin America.

\section{Forest plantations}

Next to the abatement of deforestation, re-afforestation is often brought forward as a possible instrument to combat climate change. The calculated areas necessary to balance fossil fuel emissions depend very much on the assessment of the productivity of forest plantations. Optimists use figures taken from relatively small, well-managed plots, while pessimists argue that the associated productivities cannot be applied to the large-scale plantations necessary to have a significant impact on the carbon cycle.

Furthermore, in the developing countries forest plantations will be established for more pressing needs than carbon sequestering, such as fuelwood supply or erosion control. Re-afforestation of abandoned agricultural lands or other lands in the developed countries may have significant potential but is not covered by this module. In the most optimistic scenario present plantation rates as given by Lanly (1982) are used and the areas increase logistically to 345 million hectares in Africa, 310 million hectares in Latin America and 100 million hectares in Southeast Asia. In the other scenarios only 75,50 and $25 \%$, respectively, of these areas would be afforested, see Figure 3.6.. Since this variable is not integrated with the energy module, the positive contribution to the greenhouse effect stops when the final forest areas are reached. Theoretically, forest plantations could have a longer-lasting effect when short rotation plantations are used to provide fuelwood as a replacement for fossil fuels. 

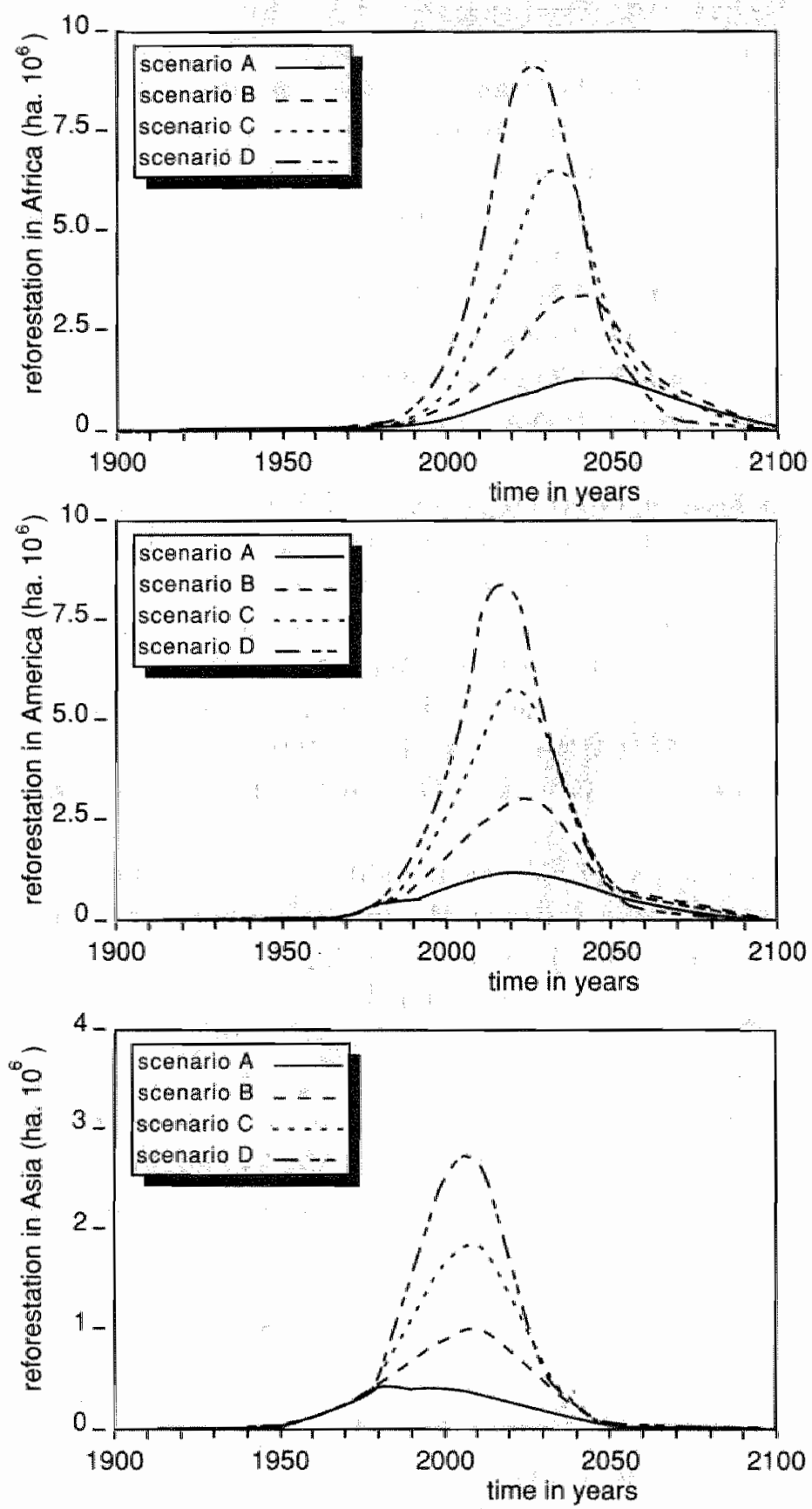

Figure 3.6: Simulated reforestation by plantations for three areas. 


\subsection{Validation and Uncertainty}

There are two ways of validating the model results. First, to compare the simulated $\mathrm{CO}_{2}$ concentrations with measured concentrations at Mauna-Loa, for the known series of measurements from the year 1960 to 1985 (Keeling et al., 1982). A comparison of the simulated concentrations with measured concentrations yields a maximum relative difference of $1.4 \%$ in the year 1960 and a minimum relative difference of $0.05 \%$ in 1985 . Analying the simulation pattern of historical $\mathrm{CO}_{2}$ concentration shows a slightly more rapid increase in the calculated $\mathrm{CO}_{2}$ concentration compared with the increase in the Mauna-Loa concentration series.

Secondly, for validation of the different ecosystem areas and rates of conversion the statistical information of the FAO was used, together with a limited number of estimates from the literature. With the present deforestation system dynamics it was difficult to simulate values for conversion of tropical forests below $20 \%$. Therefore estimates below $10 \%$ seem to be improbable, especially for Southeast Asia. More historical evidence of land use changes will improve these insights. Simulation results with the deforestation module of IMAGE for the period 1900 to 1985 show a decline in the tropical forest areas of 20 to $25 \%$, which is higher than some estimates in the literature.

Uncertainties in this carbon cycle model arise from the choice of vegetation types, being rather arbitrary, the biotic feedback on atmospheric $\mathrm{CO}_{2}$ increase (fertilization effect), represented by the biotic growth factor, and the role of charcoal production by burning. The role of the latter in the carbon cycle is especially controversial (Jansen, 1987).

In view of these uncertainties it is of crucial importance to perform sensitivity and uncertainty analyses with these carbon cycle models. Examples of such analyses are presented in USDOE $(1985 \mathrm{a}, \mathrm{b})$ and Yearsley and Letitenmaier (1987). A description of a sensitivity analysis applied to the carbon cycle module is described in Chapter 12 .

\subsection{Results}

The airborne fraction, as defined in (3.1), is represented in Figure 3.7. In scenario D a continuous decrease takes place, down to about $25 \%$ in 2100 , while for scenario $A$ an increasing value is reached of about $70 \%$. The near equilibrium between the uptake of $\mathrm{CO}_{2}$ (by oceans and terrestrial biota) and the release of $\mathrm{CO}_{2}$ (by fossil fuels and land use change) in scenario $\mathrm{D}$, 
causes a low airborne fraction. From the results of the calculations with the carbon cycle module the biosphere appears to have been an important carbon source in the past, but a minor sink at present. Although still resulting in a positive carbon flux from the biosphere, estimates of other authors also show a declining trend (Houghton et al., 1983, 1985 and 1987, Detwiler and Hall, 1985, 1988).

Concerning the greenhouse problem the items referred to most are the time at which a doubling of the initial atmospheric $\mathrm{CO}_{2}$ concentration will occur and the consequent temperature increase. Figure 3.8 shows that doubling of the $\mathrm{CO}_{2}$ concentration will be reached in about 2060 (scenario A), 2075 (scenario B), 2100 (scenario C) or even after 2100 (scenario D).

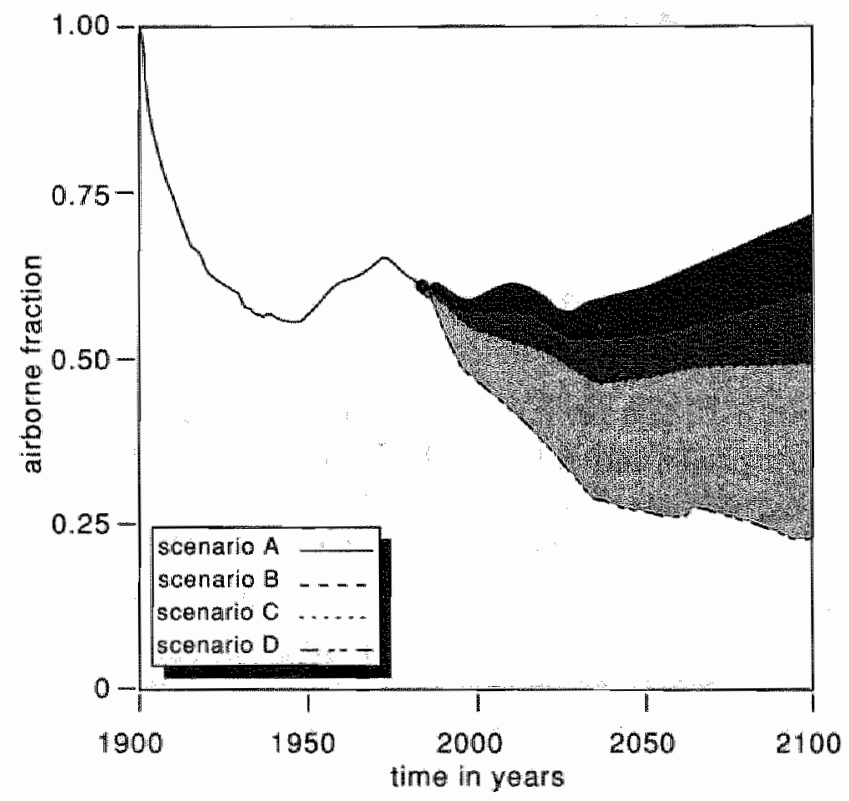

Figure 3.7: Airborne fraction. 


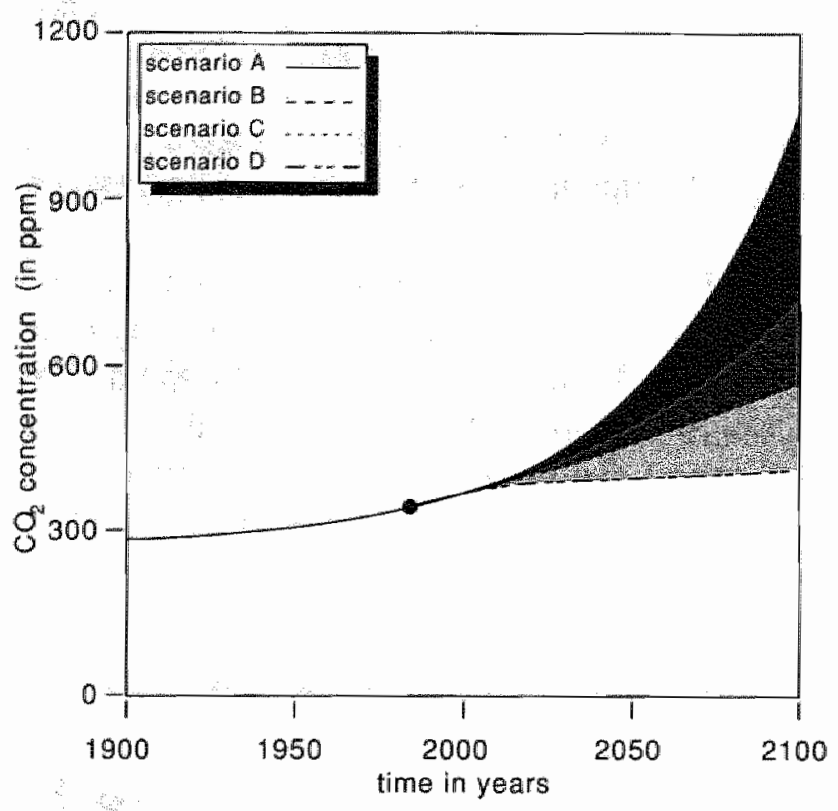

Figure 3.8: Concentration of $\mathrm{CO}_{2}$.

In Figures 3.9 and 3.10 the remaining amounts of closed and open forests for four scenarios are presented for the three regions. In the most pessimistic scenario the closed tropical forests would disappear before the middle of the next century. Although one may expect the forests in the remote Amazon and Congo basin to last the longest, we find that they may disappear at least as fast as the Asian forests. This result can partly be explained by the fact that we used estimates of past land use changes by Houghton et al. (1983) to validate our results for the period 1900-1980. This source suggests that in Asia only a small percentage of the tropical forests would have been destroyed. Very likely this finding is not correct, taking into account that in several Southeast Asian countries 30 to $40 \%$ of the forests have disappeared (World Resources Institute, 1988). In this model this also affects the future deforestation rates. The curves for open forests show upward trends for some scenarios, which is primarily caused by the inclusion of forest plantations in this category.

Figures 3.11 and 3.12 show the causes of deforestation as simulated in 1980 and one particular future year, namely 2020. For closed forests the demand for agricultural land, pasture and commercial wood are of similar importance, while for open forests both agriculture and fuel wood demand 
play a dominant role. The demand for agricultural land and pasture is partly driven by increasing loss of land by erosion. To avoid the large increases in agricultural land in forest area dramatic increases in productivity in other areas is necessary.

In Figure 3.13 the interesting increases for agricultural land are shown as simulated by the model. In the higher scenarios increases in demand driven by growth of economy and population exceed the effect of increasing yields. In scenario A the demand for agriculture and pasture not only requires the conversion of all forests but also a significant fraction of the 'other lands'. Further elaboration of these results will be useful.

The important role of soil degradation is emphasized by Figure 3.14, showing the degradation of arable land. The simulated loss of arable land increases in both absolute and relative terms. This is caused by the fact that in the degradation relation the increase of degradation by expansion of land dominates over the decrease of degradation by input increases.

In Figures 3.15 and 3.16 the impact of different deforestation scenarios on the atmospheric $\mathrm{CO}_{2}$ concentration is shown. In Figure 3.16 a common forced trend energy scenario is taken for both lines. The difference between deforestation scenario $\mathrm{A}$ and $\mathrm{D}$ is limited to about $50 \mathrm{ppm}$, or roughly $10 \%$. For the higher energy scenarios the relative differences are slightly smaller, as Figure 3.15 shows for an unrestricted trends energy scenario. For this scenario the difference between deforestation scenario $\mathrm{A}$ and $\mathrm{D}$ is limited to about $50 \mathrm{ppm} \mathrm{CO}_{2}$, which is about $5 \%$. Earlier, around 2050 , the relative difference is larger because the logistic approach for afforestation leads to the higher rates of carbon sequestering in the first half of the next century. These findings indicate that deforestation is important, but small in comparison to the contribution of fossil fuel combustion to the greenhouse effect, see Swart and Rotmans (1990). It is important to note that this result is not the separate and direct effect of the destruction of tropical forests alone, but the net impact of all changes of land use and atmospheric composition. In the dynamics of the carbon cycle by Goudriaan and Ketner (1984) the $\mathrm{CO}_{2}$ release by deforestation is counteracted by other factors like the $\mathrm{CO}_{2}$ fertilization effect and charcoal formation after burning of vegetation. An elaborate sensitivity analysis shows that in the $\mathrm{C}$ cycle model the factors concerning land use change are of moderate importance in comparison with dominating factors as the fertilization factor or the grassland humification factor (Swart and Rotmans, 1989b). This accounts to a large extent for the limited impact of deforestation in the Goudriaan and Ketner carbon cycle module. 

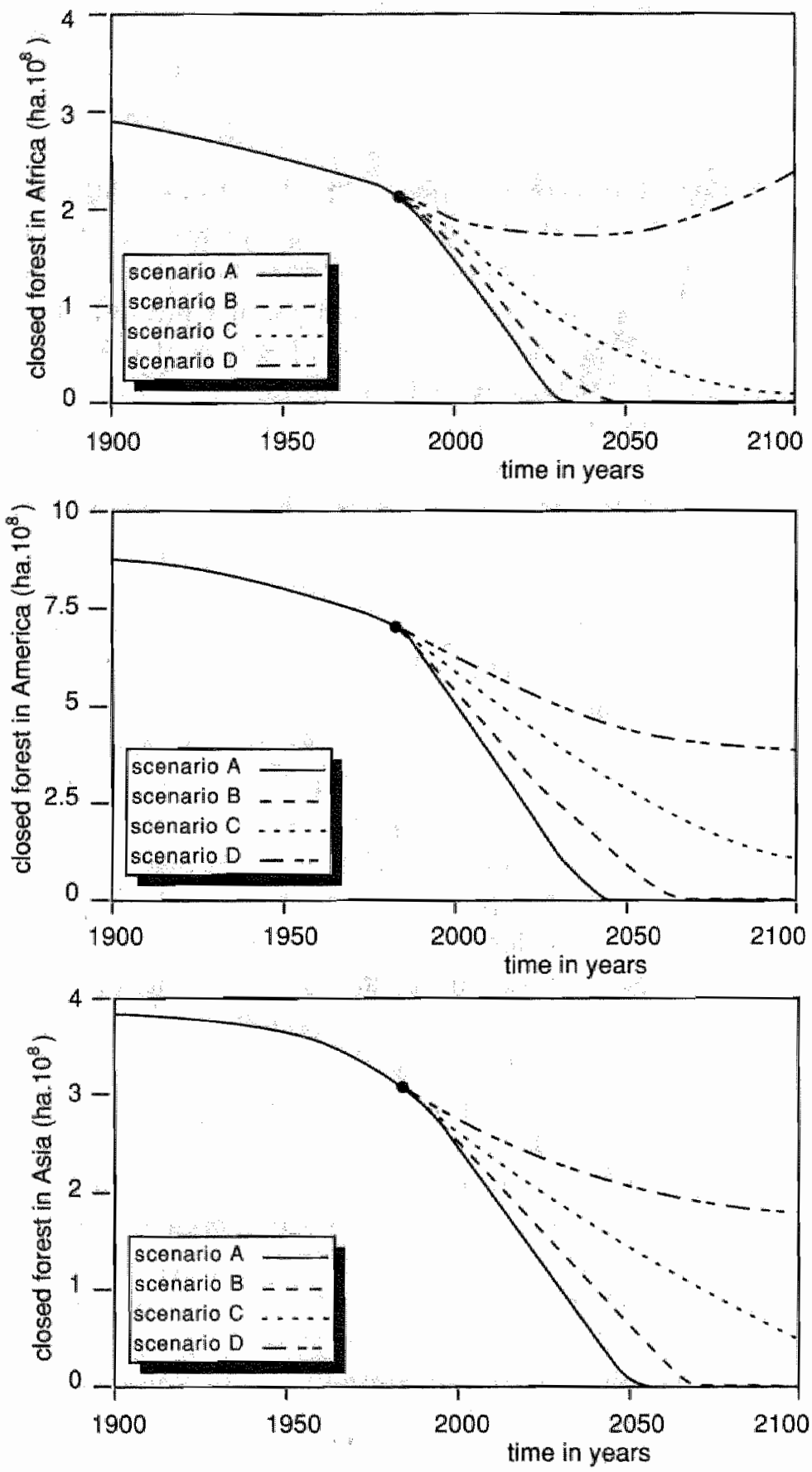

Figure 3.9: Simulated areas of closed tropical forests for three regions. 

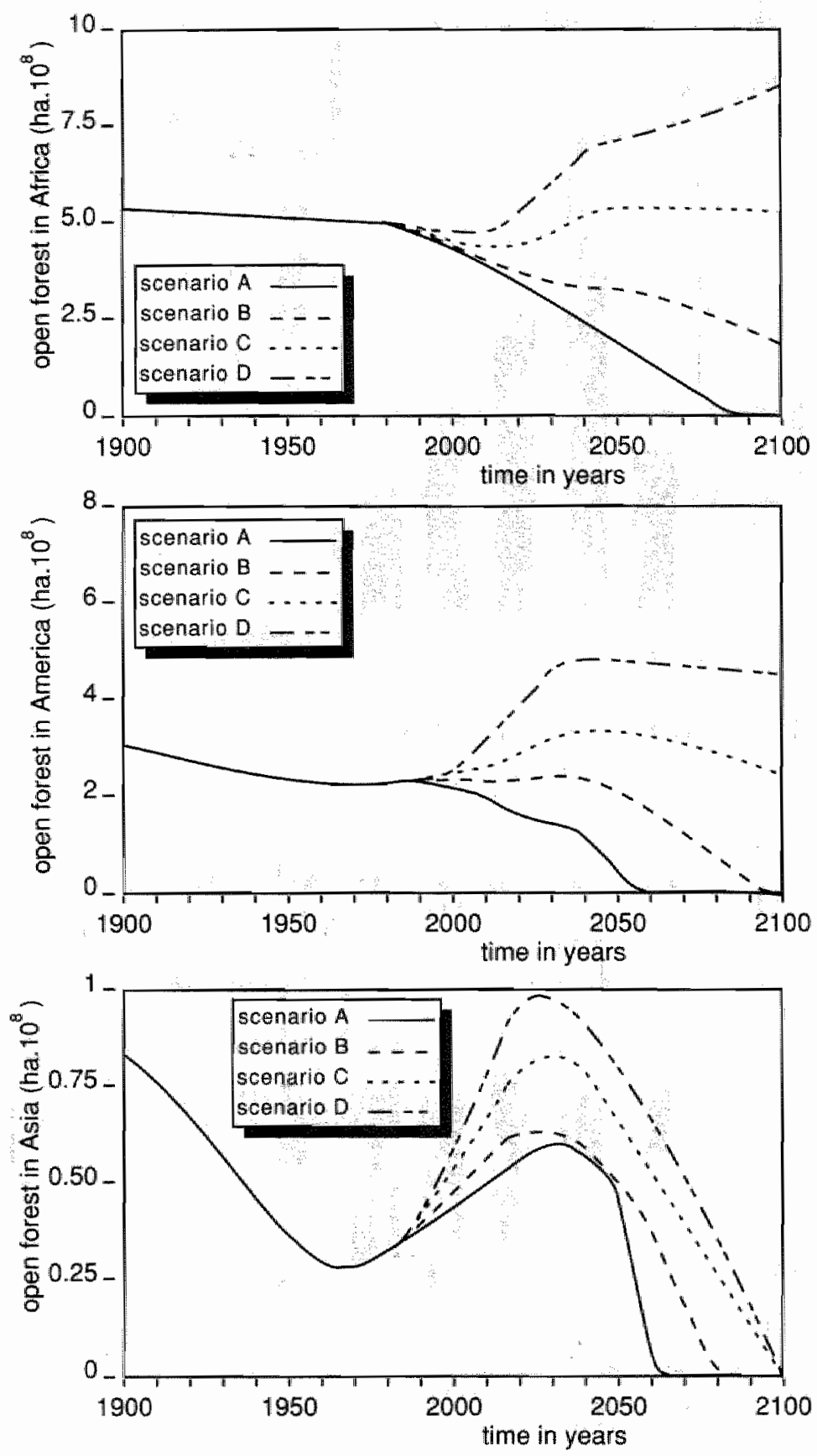

Figure 3.10: Simulated areas of open tropical forests for three regions. 


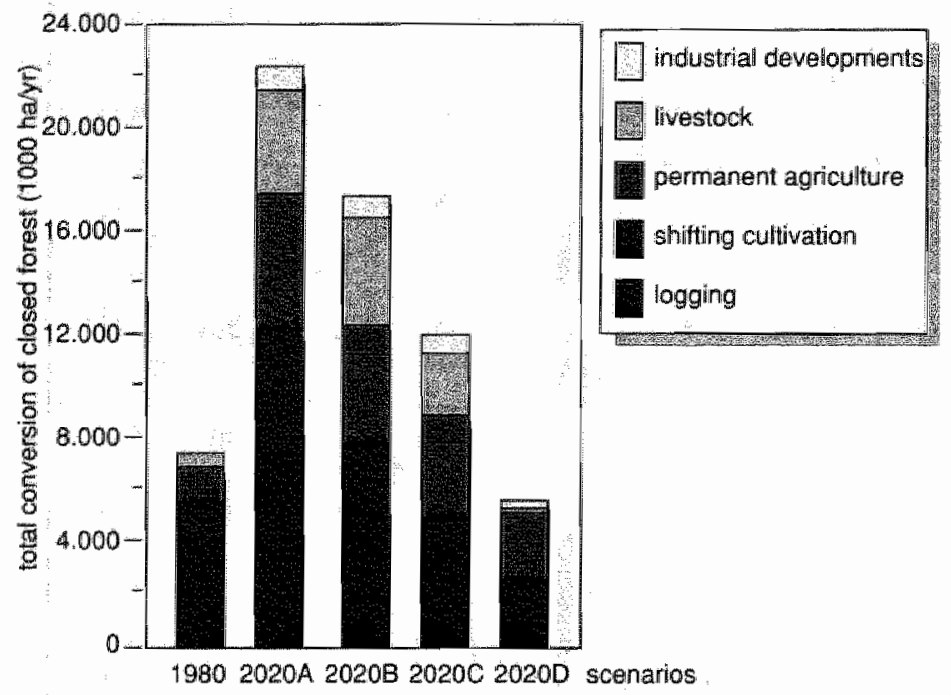

Figure 3.11: Conversion of closed tropical forests by cause for selected years.

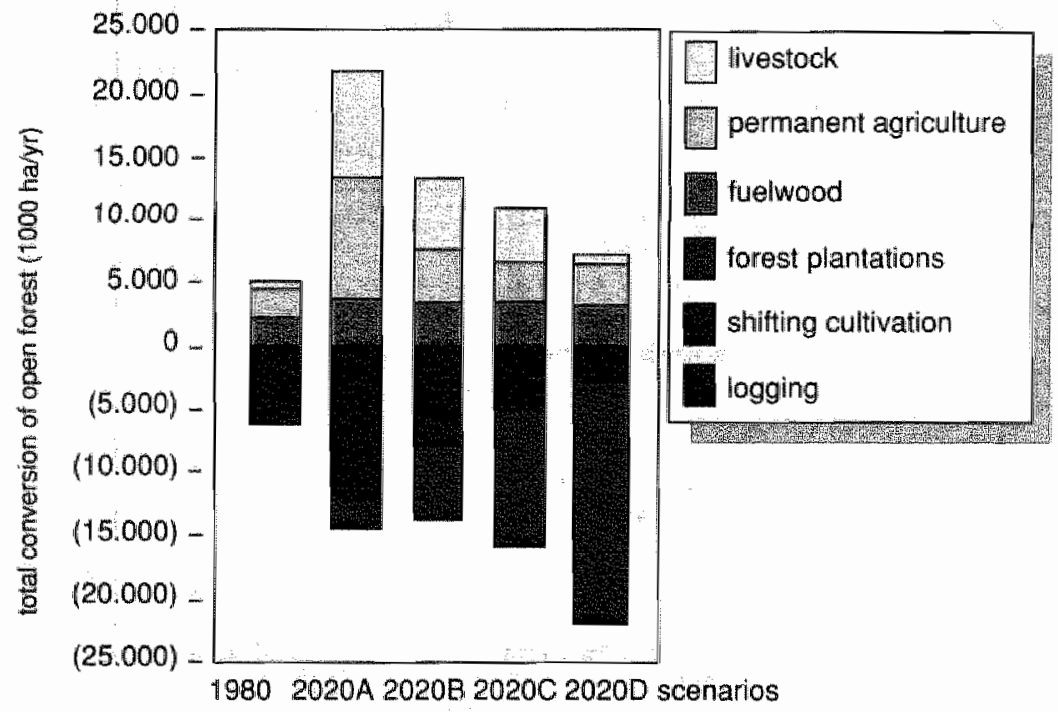

Figure 3.12: Conversion of open tropical forests by cause for selected years. 

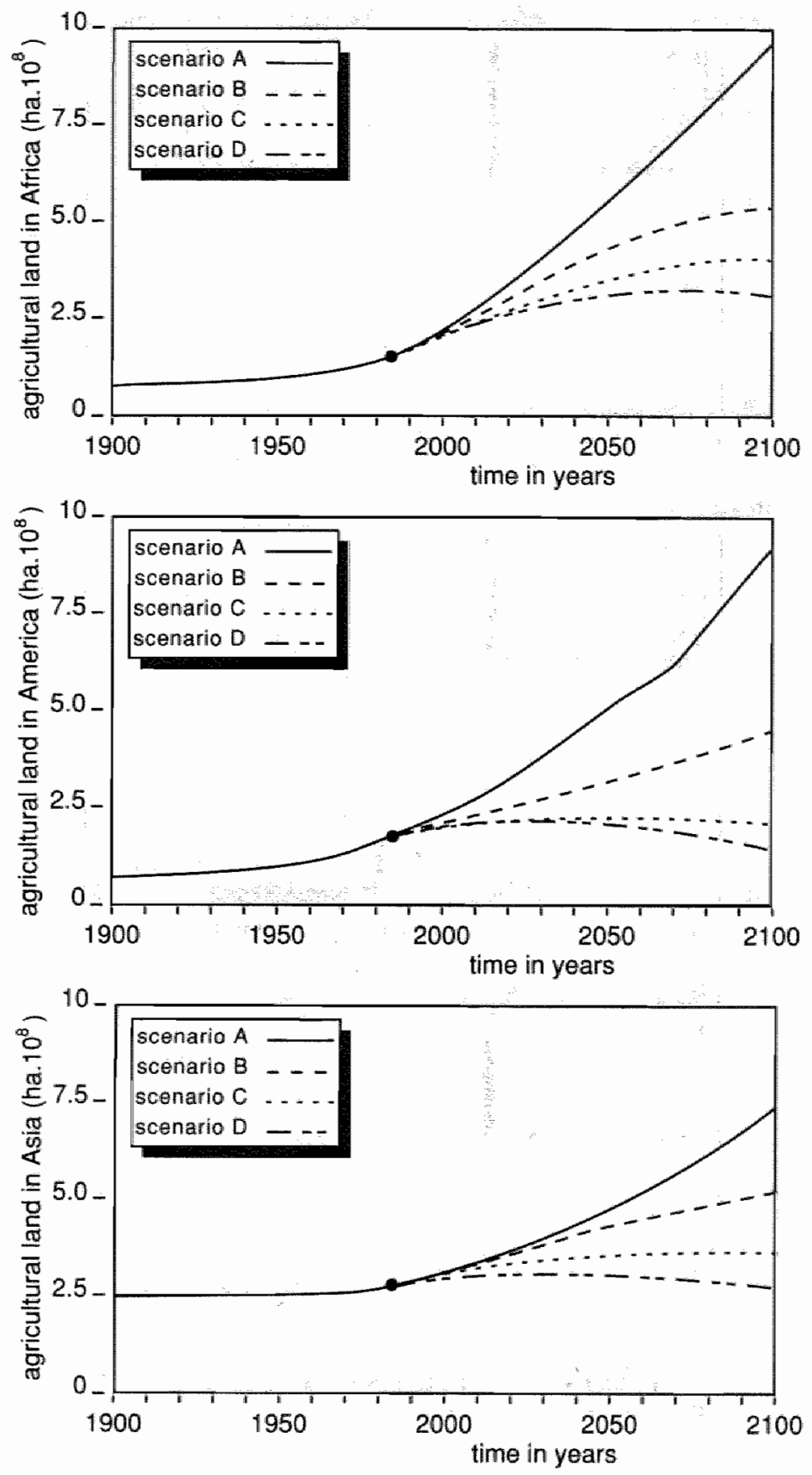

Figure 3.13: Simulated areas of agricultural land for three regions. 

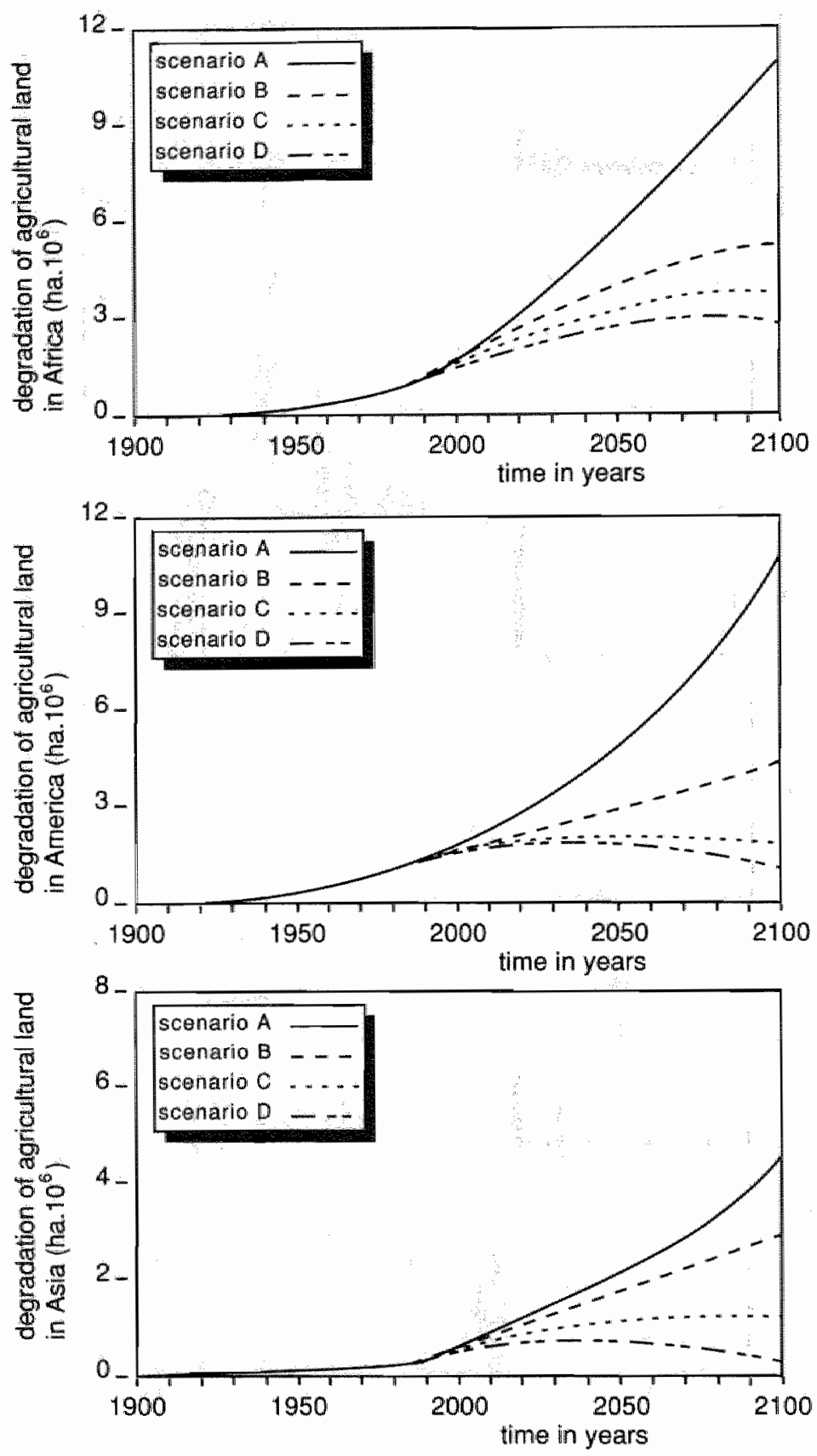

Figure 3.14: Simulated degradation of agricultural land for three areas. 


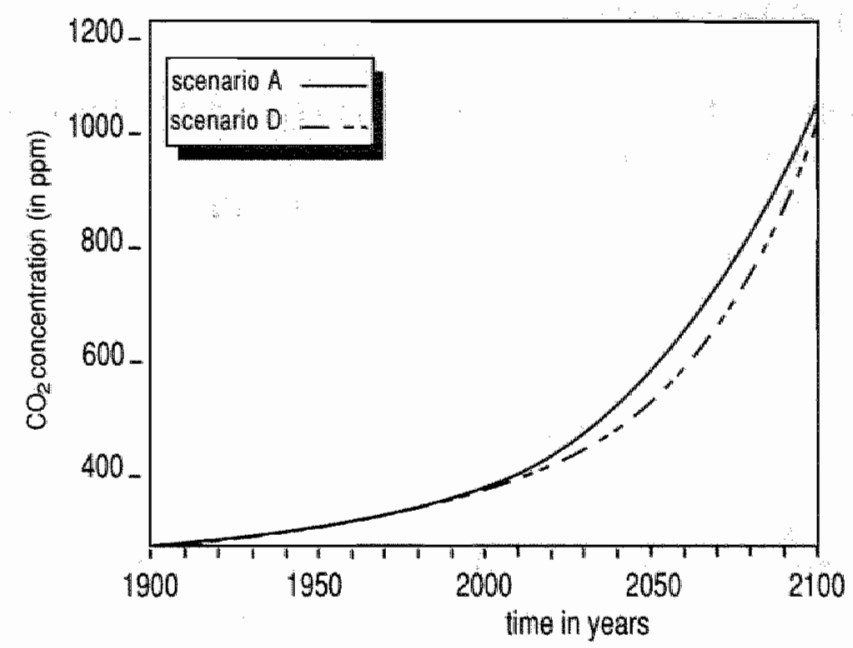

Figure 3.15: Simulated atmospheric $\mathrm{CO}_{2}$ concentrations for the highest and lowest deforestation scenario combined with an unrestricted trends energy scenario

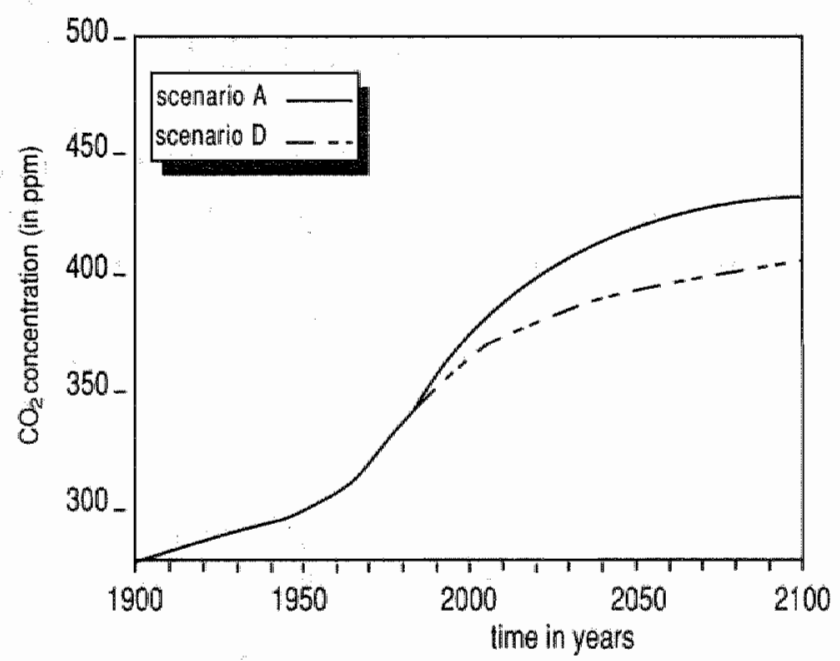

Figure 3.16: Simulated atmospheric $\mathrm{CO}_{2}$ concentrations for the highest and lowest deforestation scenario combined with forced trend trends energy scenario 


\subsection{Conclusions}

- Continuation of the recent trend of emissions of $\mathrm{CO}_{2}$ leads to a rapid rise of the atmospheric $\mathrm{CO}_{2}$ concentration. Even radical measures (scenario $\mathrm{D}$ : forced trends scenario) cannot prevent the $\mathrm{CO}_{2}$ concentration from increasing, although in this case a $\mathrm{CO}_{2}$ doubling is not reached before 2100 .

- The contribution of biospheric changes to the greenhouse effect is important but small as compared to that of fossil fuel combustion. Model simulations with IMAGE show a difference of a maximum of $10 \%$ in $\mathrm{CO}_{2}$ concentrations over the next century between optimistic and pessimistic deforestation cases. If not for reasons of global climate change, then deforestation should be stopped for other reasons, including the combat of erosion, the conservation of species diversity, safety of indigenous people and avoidance of local and regional climate changes.

- The most important direct cause of deforestation is the demand for agricultural land to satisfy demand for food, feed or debt-resolving export products. The combination of growth of population and their consumption level will increase the pressure on the forests if no drastic corrective measures are taken.

- Simulation results with IMAGE show that if present deforestation rates continue a total destruction of the tropical forests will occur halfway through the next century. This would be disastrous although its effect on global climate is only one reason to stop tropical deforestation. Other possibly more important reasons are the inefficient use of the resource leading to erosion, the loss of species, the threat to the indigenous population and the effects on local and regional climate.

o Although it is difficult to give quantified estimates, IMAGE simulations show that soil degradation is a process that, while seldom mentioned in this connection, contributes considerably to the rate of tropical deforestation by decreasing the availability of land for agriculture and pasture.

"o The result that even rapid deforestation has only a moderate net effect on the carbon cycle is in IMAGE primarily caused by an increasing soil carbon pool due to the conversion of organic matter into charcoal during burning, by $\mathrm{CO}_{2}$ fertilization and to possible underestimation 
of soil losses after conversion. To some extent the biospheric $\mathrm{CO}_{2}$ emissions by deforestion will be counteracted by a $\mathrm{CO}_{2}$ fertilization effect. However, the less vegetation that remains, the less potential there is for this effect.

o The IMAGE deforestation module shows that the development of a global land use change model is feasible and can provide valuable insights into the interactions between human activities and the earth system. Such a model, possibly in combination with a long term energy model, could not only be used to study the impact of land use changes on climate, but also on other important biogeochemical cycles.

- Although reforestation can play a significant role in a transition period, a gradual shift towards a world energy system based on renewables away from fossil fuels is a more effective strategy for the mitigation of climatic change.

- Large scale industrial, infrastructural, mining or livestock projects have an enormous potential for accelerating the deforestation process, which is, however, difficult to quantify. Integrated economic and ecological evaluation is crucial to avoid unnecessary ecological disasters.

o Decrease of agricultural area and productivity by land degradation is an important factor, catalysing deforestation. Erosion control and conversion of soils less susceptible to erosion should have priority. The importance of this factor warrants a more thorough analysis of this process than has been applied in this study. 


\subsection{Appendix}

IMAGE DEFORESTATION MODULE DATA SHEET

\begin{tabular}{|c|c|c|c|}
\hline \multirow{2}{*}{ Africa } & \multicolumn{3}{|c|}{ in 2100 scenario to } \\
\hline & unit & 1900 & 1985 \\
\hline remainuing closed forest & $1000 h a$ & 294000 & 221079 \\
\hline remaining open forest & $1000 \mathrm{ha}$ & 539000 & 498479 \\
\hline fallow tot. AT closed & $1000 \mathrm{ha}$ & & 61646 \\
\hline swidden cycle closed & years: & 10 & 10 \\
\hline fallow tot. AF open & $1000 h a$ & & 104335 \\
\hline fallow period open & years. & & 15 \\
\hline population function ${ }^{2}$ & $\mathrm{mln}$ & & 555 \\
\hline percentage rural & $\%$ & 70 & 70 \\
\hline swidden farmers closed & $\%$ & 2.5 & 4 \\
\hline swidden farmers open & $\%$ & 10 & 10 \\
\hline number in family & $\operatorname{cap} / \mathrm{fm}$ & 8 & 7 \\
\hline cleared per family & $h a / y r$ & 1.3 & 1.3 \\
\hline human area $(0.05 h a / c a p)$ & $1000 \mathrm{ha}$ & & 27750 \\
\hline yield tot cereals $\& c . A^{1}$ & $\mathrm{~kg} / \mathrm{ha}$ & & 800 \\
\hline yield tot. cereals $\$ c . B^{1}$ & $\mathrm{~kg} / \mathrm{ha}$ & & 800 \\
\hline yield tot. cereals sc. $C^{1}$ & $\mathrm{~kg} / \mathrm{ha}$ & & 800 \\
\hline yield tot. cereals $s c . D^{1}$ & $\mathrm{~kg} / \mathrm{ha}$ & & 800 \\
\hline consumption food cereals & $\mathrm{kg} / \mathrm{cap}$ & 110 & 110 \\
\hline percentiage food (vs. feed) & $\%$ & 100 & 84 \\
\hline area non-cereals & $\%$ & 61 & 61 \\
\hline self-sufficiency ratio & $\%$ & 100 & 79 \\
\hline forest plantations sc. $\mathbb{A}^{1}$ & $1000 h a$ & 1 & 2411 \\
\hline forest plantations sc. $B^{1}$ & $1000 h a$ & 1 & 2411 \\
\hline forest plantations sc. $C^{1}$ & $1000 \mathrm{ha}$ & 1 & 2411 \\
\hline forest plantations sc. $D^{1}$ & $1000 h a$ & 1 & 2411 \\
\hline cattle number scen. $A^{1}$ & 1000 & 60000 & 140000 \\
\hline cattle number scen. $B^{11}$ & 1000 & 60000 & 140000 \\
\hline cattle number scen. $O^{1}$ & 1000 & 60000 & 140000 \\
\hline cattle number scen. $D^{1}$ & 1000 & 60000 & 140000 \\
\hline cattle productivity & $h a / h d$ & 8.0 & 4.5 \\
\hline comm. wood prod. index $x^{1,4}$ & $h a / y r$ & 50400 & 639000 \\
\hline comm. wood prod. index ${ }^{1,4} \mathrm{~B}$ & $h a / y r$ & 50400 & 639000 \\
\hline comm. wood prod. index ${ }^{1,4} \mathrm{C}$ & $h a / y r$ & 50400 & 639000 \\
\hline comm. wood prod. index ${ }^{1,4} \mathrm{D}$ & $h a / y r$ & 50400 & 639000 \\
\hline wood prod. int. index & & 0.09 & 1 \\
\hline affectied by fuelwood & $h a / y r$ & & 700000 \\
\hline
\end{tabular}

For notes see page 80 
IMAGE DEFORESTATION MODULE DATA SHEET

\begin{tabular}{|c|c|c|c|c|}
\hline \multirow[t]{2}{*}{ Africa } & \multicolumn{4}{|c|}{ in 2100 scenario to } \\
\hline & $\mathbf{A}$ & $\mathrm{B}$ & $\mathrm{C}$ & $\mathrm{D}$ \\
\hline remaining closed forest & \multirow{3}{*}{\multicolumn{4}{|c|}{$\begin{array}{l}\text { to be calculated } \\
\text { to be calculated } \\
\qquad(+1.4 \% / a)\end{array}$}} \\
\hline remaining open forest & & & & \\
\hline fallow tot. AF closed & & & & \\
\hline swidden cycle closed & 20 & 15 & 10 & 5 \\
\hline fallow tot. AF open & & & & \\
\hline fallow period open & & & & \\
\hline population function ${ }^{1}$ & 21525 & 0.0073 & 0.0410 & 2935 \\
\hline percentage rural & 80 & 70 & 60 & 50 \\
\hline swidden farmers closed & 3.5 & 2.5 & 2.0 & 1.0 \\
\hline swidden farmers open & 10 & 8 & 6 & 4 \\
\hline number in family & 6 & 7 & 8 & 9 \\
\hline cleared per family & 1.3 & 1.1 & 0.9 & 0.7 \\
\hline human area $(0.05 \mathrm{ha} / \mathrm{cap})$ & \multicolumn{4}{|c|}{ proportional to population growth } \\
\hline yield tot. cereals sc. $A^{1}$ & 306 & 0.087 & 0.018 & 3500 \\
\hline yield tot. cereals sc. $B^{1}$ & 297 & 0.119 & 0.020 & 2500 \\
\hline yield tot. cereals sc. $C^{1}$ & 241 & 0.161 & 0.029 & 1500 \\
\hline yield tot. cereals sc. $D^{1}$ & 153 & 0.135 & 0.047 & 1150 \\
\hline consumption food cereals & 170 & 150 & 120 & 110 \\
\hline percentage food (vs. feed) & 65 & 75 & 85 & 95 \\
\hline area non-cereals & 80 & 70 & 60 & 50 \\
\hline self-sufficiency ratio ${ }^{2}$ & 90 & 80 & 70 & 60 \\
\hline forest plantations sc. $A^{1}$ & 15.1 & $1.8 \mathrm{E}-4$ & 0.06 & \\
\hline forest plantiations sc. $B^{1}$ & 2.72 & $1.6 \mathbb{E}-5$ & 0.08 & \\
\hline forest plantations sc. $C^{1}$ & 0.50 & $1.9 \mathrm{E}-6$ & 0.10 & \\
\hline forest plantations sc. $D^{1}$ & 0.09 & $2.7 \mathrm{E}-7$ & 0.12 & \\
\hline cattle number scen. $A^{1}$ & 59100 & 0.118 & 0.014 & 500000 \\
\hline cattle number scen. $B^{1}$ & 55000 & 0.157 & 0.017 & 350000 \\
\hline catitle number scen. $C^{1}$ & 58130 & 0.233 & 0.020 & 250000 \\
\hline cattle number scen. $D^{1}$ & 55700 & 0.279 & 0.025 & 200000 \\
\hline cattle productivity & 4 & 3.5 & 3.0 & 2.5 \\
\hline comm. wood prod. index ${ }^{1 / 4}$ A & 0.2001 & 0.0801 & 0.0265 & 2.50 \\
\hline comm. wood prod. index ${ }^{1,4}$ B & 0.1572 & 0.0786 & 0.0318 & 2.00 \\
\hline comm. wood prod. index ${ }^{1,4} \mathrm{C}$ & 0.0898 & 0.0561 & 0.0424 & 1.60 \\
\hline comm. wood prod. index ${ }^{1,4} \mathrm{D}$ & 0.0408 & 0.0292 & 0.0556 & $\mathbb{1} .40$ \\
\hline wood prod. int. index & 1.0 & 1.3 & 1.6 & 2.0 \\
\hline affected by fuelwood & \multicolumn{4}{|c|}{ prop. to rural population growth } \\
\hline
\end{tabular}

For notes see page 80 
IMAGE DEFORESTATION MODULE DATA SHEET

\begin{tabular}{|c|c|c|c|}
\hline Latin America & \multicolumn{3}{|c|}{ in 2100 scenario to } \\
\hline & anit & 1900 & 1985 \\
\hline remaining closed forest & $1000 \mathrm{ha}$ & 873000 & 693155 \\
\hline remaining open forest & 1000 ha & 307000 & 239520 \\
\hline fallow tot. AM closed & $1000 \mathrm{ha}$ & & 108612 \\
\hline swidden cycle closed & years & 10 & 10 \\
\hline fallow tot. AM open & $1000 \mathrm{ha}$ & & 61650 \\
\hline swidden cycle open & years & 15 & 15 \\
\hline population function ${ }^{1}$ & $\mathrm{~min}$ & & 406 \\
\hline percentage rural & $\%$ & 40 & 40 \\
\hline swidden farmers closed & $\%$ & 9 & 9 \\
\hline swidden farmers open & $\%$ & 8 & 8 \\
\hline number in family & $\operatorname{cap} / f m$ & 7 & 7 \\
\hline cleared per family & $h a / y r$ & 1.0 & 1.0 \\
\hline human area $(.05 h a / c a p)$ & $1000 \mathrm{ha}$ & & 20300 \\
\hline yield tot. cereals sc. $A^{1}$ & $k g / h a$ & & 1800 \\
\hline yield tot. cereals sc. $B^{1}$ & $k g / h a$ & & 1800 \\
\hline yield tot. cereals sc. $C^{1}$ & $k g / h a$ & & 1800 \\
\hline yield tot. cereals sc. $D^{1}$ & $\mathrm{~kg} / \mathrm{ha}$ & & 1800 \\
\hline consumption food cereals & $\mathrm{kg} / \mathrm{cap}$ & 140 & 140 \\
\hline percentage food (vs. feed) & $\%$ & 95 & 60 \\
\hline area non-cereals & $\%$ & 50 & 50 \\
\hline irrigated area & $1000 \mathrm{ha}$ & & \\
\hline self-sufficiency ratio ${ }^{2}$ & $\%$ & 125 & 90 \\
\hline forest plantations sc. $A^{1}$ & $1000 h a$ & 1.5 & 7303 \\
\hline forest plantations sc. $B^{1}$ & $1000 h a$ & 1.5 & 7303 \\
\hline forest plantations sc. $C^{1}$ & $1000 h a$ & 1.5 & 7303 \\
\hline forest plantations sc. $D^{1}$ & $1000 \mathrm{ha}$ & 1.5 & 7303 \\
\hline cattle number scen. $A^{1}$ & 1000 & 100000 & 250000 \\
\hline cattle number scen. $B^{1}$ & 1000 & 100000 & 250000 \\
\hline cattle number scen. $C^{1}$ & 1000 & 100000 & 250000 \\
\hline cattle number scen. $D^{1}$ & 1000 & 100000 & 250000 \\
\hline cattle productivity & ha/hd & 4.4 & 2.4 \\
\hline other deforestation & $1000 \mathrm{ha}$ & & 1000 \\
\hline comm. wood prod, index ${ }^{1,4}$ A & $h a / y r$ & 48400 & 2003000 \\
\hline comm. wood prod. index ${ }^{1,4} B$ & $h a / y r$ & 48400 & 2003000 \\
\hline comm. wood prod. index ${ }^{1,4} \mathrm{C}$ & $h a / y r$ & 48400 & 2003000 \\
\hline comm. wood prod. index ${ }^{1,4} \mathrm{D}$ & $h a / y r$ & 48400 & 2003000 \\
\hline wood prod. int. index & & 0.03 & 1 \\
\hline affected by fuelwood & ha/yr & & 300000 \\
\hline
\end{tabular}

For notes see page 80 
IMAGE DEFORESTATION MODULE DATA SHEET

\begin{tabular}{|c|c|c|c|c|}
\hline Latin America & \multicolumn{4}{|c|}{ in 2100 scenario to } \\
\hline & A & $\mathrm{B}$ & $\mathrm{C}$ & $\bar{D}$ \\
\hline $\begin{array}{l}\text { remaining closed forest } \\
\text { remaining open forest } \\
\text { fallow tot. AM closed }\end{array}$ & \multicolumn{4}{|c|}{$\begin{array}{l}\text { to be calculated } \\
\text { to be calculated } \\
(+1.1 \% / a)\end{array}$} \\
\hline $\begin{array}{l}\text { swidden cycle closed } \\
\text { fallow tot. AM open } \\
\text { swidden cycle open }\end{array}$ & 200 & 15 & 10 & 5 \\
\hline population function ${ }^{\mathbb{1}}$ & 31836 & 0.025 & 0.0346 & 1259 \\
\hline percentage rural & 60 & 55 & 50 & 45 \\
\hline swidden farmers closed & 8.0 & 6.0 & 4.0 & 3.0 \\
\hline swidden farmers open & 8 & 6 & 4 & 2 \\
\hline number in family & 7 & 7 & 7 & 7 \\
\hline cleared per family & $\mathbb{1 . 3}$ & 1.1 & 1.0 & 0.8 \\
\hline human area $(.05 h a / c a p)$ & \multicolumn{4}{|c|}{ proportional to population growth } \\
\hline yield tot. cereals sc. $A^{1}$ & 628 & 0.150 & 0.019 & 4200 \\
\hline yield tot. cereals sc. $B^{1}$ & 546 & 0.162 & 0.023 & 3400 \\
\hline yield tot. cereals sc. $C^{1}$ & 394 & 0.141 & 0.030 & 2800 \\
\hline yield tot. cereals sc. $D^{1}$ & 355 & 0.158 & 0.038 & 2250 \\
\hline consumption food cereals & 200 & 170 & 150 & 130 \\
\hline percentiage food (vs. feed) & 50 & 60 & 70 & 80 \\
\hline $\begin{array}{l}\text { area non-cereals } \\
\text { irrigated area }\end{array}$ & 75 & 65 & 55 & 45 \\
\hline self-sufficiency ratio ${ }^{2}$ & 115 & 105 & 90 & 85 \\
\hline forest plantations sc. $A^{1}$ & 49.2 & $6.3 \mathrm{E}-4$ & 0.06 & 79000 \\
\hline forest plantations sc. $B^{1}$ & 8.54 & $5.5 \mathrm{E}-5$ & 0.08 & 155000 \\
\hline forest plantations $s c . C^{1}$ & 1.53 & $6.6 \mathrm{E}-6$ & 0.10 & 235000 \\
\hline forest plantations sc. $D^{1}$ & 0.28 & $9.0 \mathrm{E}-7$ & 0.12 & 310000 \\
\hline cattle number scen. $A^{1}$ & 52000 & 0.041 & 0.021 & 1270000 \\
\hline cattle number scen. $B^{1}$ & 53600 & 0.071 & 0.023 & 755000 \\
\hline cattle number scen. $C^{1}$ & 52060 & 0.116 & 0.028 & 450000 \\
\hline cattile number scen. $D^{1}$ & 58300 & 0.167 & 0.032 & 350000 \\
\hline cattle productivity & 3.5 & 3.25 & 3.0 & 2.5 \\
\hline other deforestation & 750 & 500 & 250 & $* 0$ \\
\hline comm. wood prod. index ${ }^{1,4} A$ & 0.0770 & 0.0193 & 0.0356 & 4.00 \\
\hline comm. wood prod. index ${ }^{1,4} \mathbb{B}$ & 0.0607 & 0.0202 & 0.0401 & 3.00 \\
\hline comm. wood prod. index ${ }^{1,4} \mathrm{C}$ & 0.0278 & 0.0139 & 0.0535 & 2.00 \\
\hline comm. wood prod. index ${ }^{1,4} \mathrm{D}$ & 0.0049 & 0.0033 & 0.0802 & 1.50 \\
\hline wood prod. int. index & 1.0 & 1.3 & 1.6 & 2.0 \\
\hline affected by fuelwood & \multicolumn{4}{|c|}{ prop. to rural population growth } \\
\hline
\end{tabular}

For notes see page 80 
IMAGE DEFORESTATION MODULE DATA SHEET

\begin{tabular}{|c|c|c|c|}
\hline Tropical Asia & \multicolumn{3}{|c|}{ in 2100 scenario to } \\
\hline 13 countries $^{1}$ & unit & 1900 & 1985 \\
\hline remaining closed forest & $1000 \mathrm{ha}$ & 381000 & 301344 \\
\hline remaining open forest & $1000 \mathrm{ha}$ & 85000 & 30653 \\
\hline closed 9 countries & $\%$ & & 92 \\
\hline open 9 countries & $\%$ & & 98 \\
\hline fallow tot. AS closed & $1000 \mathrm{ha}$ & & 69225 \\
\hline swidden cycle closed & years & 10 & 10 \\
\hline fallow tot. AS open & $1000 \mathrm{ha}$ & & 3990 \\
\hline swidden cycle open & years & 9 & 9 \\
\hline population function ${ }^{2}$ & $\operatorname{mln}$ & & 1274 \\
\hline percentage rural & $\%$ & 50 & 50 \\
\hline$\%$ swidden farmers closed & $\%$ & 2 & 2 \\
\hline$\%$ swidden farmers open & $\%$ & 0.4 & 0.4 \\
\hline number in family & $\operatorname{cop} / f m$ & 9 & 9 \\
\hline cleared per family & $h a / y r$ & 0.7 & 0.7 \\
\hline human area $(0.05 \mathrm{ha} / \mathrm{cap})$ & 1000 ho & & 63700 \\
\hline yield tot. cereals sc. $A^{2}$ & $k g / h a$ & & 2500 \\
\hline yield tot. cereals sc. $B^{2}$ & $\mathrm{~kg} / \mathrm{ha}$ & & 2500 \\
\hline yield tot. cereals sc. $C^{2}$ & $\mathrm{~kg} / \mathrm{ha}$ & & 2500 \\
\hline yield tot. cereals sc. $D^{2}$ & $\mathrm{~kg} / \mathrm{ha}$ & & 2500 \\
\hline consumption food cereals & $\mathrm{kg} / \mathrm{cap}$ & 170 & 170 \\
\hline percentage food (vs. feed) & $\%$ & 95 & 80 \\
\hline area non-cereals & $\%$ & 50 & 50 \\
\hline irrigated area & $1000 \mathrm{ha}$ & & 62000 \\
\hline self-sufficiency ratio ${ }^{3}$ & $\%$ & 100 & 95 \\
\hline forest plantations sc. $A^{2}$ & $1000 \mathrm{ha}$ & 2 & 7320 \\
\hline forest plantations ac. $B^{2}$ & $1000 h a$ & 2 & 7320 \\
\hline forest plantations sc. $C^{2}$ & $1000 h a$ & 2 & 7320 \\
\hline forest plantations sc. $D^{2}$ & $1000 \mathrm{ha}$ & 2 & 7320 \\
\hline caltle number scen. $A^{2}$ & 1000 & 135000 & 303000 \\
\hline cattle number scen. $B^{2}$ & 1000 & 135000 & 303000 \\
\hline cattle number scen. $C^{2}$ & 1000 & 135000 & 303000 \\
\hline cattle number scen. $D^{2}$ & 1000 & 135000 & 303000 \\
\hline cattle productivity & ha/hd & 0.10 & 0.10 \\
\hline comm. wood prod. inde $x^{2,5} \mathrm{~A}$ & $h a / y r$ & 68160 & 1755000 \\
\hline comm. wood prod. index ${ }^{2,5} \mathrm{~B}$ & $h a / y r$ & 68160 & 1755000 \\
\hline comm. wood prod. index $x^{2,5} \mathrm{C}$ & $h a / y r$ & 68160 & 1755000 \\
\hline comm. wood prod. index ${ }^{2,5} \mathrm{D}$ & $h a / y r$ & 68160 & 1755000 \\
\hline wood prod. int. index & & 0.04 & 1 \\
\hline affected by fuelwood & $h a / y^{r}$ & & 1700000 \\
\hline
\end{tabular}

For notes see page 80 
IMAGE DEFORESTATION MODULE DATA SHEET

\begin{tabular}{|c|c|c|c|c|}
\hline Tropical Asia & \multicolumn{4}{|c|}{ in 2100 scenario to } \\
\hline 13 countries $^{1}$ & A & B & $\mathrm{C}$ & $\mathrm{D}$ \\
\hline remaining closed forest & \multirow{4}{*}{\multicolumn{4}{|c|}{$\begin{array}{l}\text { to be calculated } \\
\text { to be calculated } \\
\text { to be calculated } \\
\text { to be calculated }\end{array}$}} \\
\hline remaining open forest & & & & \\
\hline closed 9 countries & & & & \\
\hline open 9 countries & & & & \\
\hline fallow tot. AS closed & $(+1.25 \% / a)$ & & & \\
\hline swidden cycle closed & 20 & 15 & 10 & 5 \\
\hline fallow tot. AS open & & & & \\
\hline swidden cycle open & & & & \\
\hline population function ${ }^{2}$ & 138988 & 0.0433 & 0.0320 & 3206 \\
\hline percentage rural & 70 & 65 & 55 & 50 \\
\hline$\%$ swidden farmers closed & 4.0 & 3.0 & 2.0 & 1.0 \\
\hline$\%$ swidden farmers open & 0.4 & 0.3 & 0.2 & 0.1 \\
\hline number in family & 7 & 7 & 8 & 8 \\
\hline cleared per family & 1.0 & 0.8 & 0.7 & 0.6 \\
\hline human area $(0.05 h a / c a p)$ & \multicolumn{4}{|c|}{ proportional to population growth } \\
\hline yield tot. cereals sc. $A^{2}$ & 563 & 0.095 & 0.024 & 6000 \\
\hline yield tot. cereals sc. $B^{2}$ & 348 & 0.088 & 0.035 & 4000 \\
\hline yield tot. cereals sc. $C^{2}$ & 279 & 0.081 & 0.041 & 3500 \\
\hline yield tot. cereals sc. $D^{2}$ & 226 & 0.075 & 0.049 & 3000 \\
\hline consumption food cereals & 230 & 210 & 190 & 170 \\
\hline percentage food (vs. feed) & 65 & 75 & 85 & 95 \\
\hline area non-cereals & 70 & 60 & 50 & 40 \\
\hline irrigated area & 150000 & 125000 & 100000 & 85000 \\
\hline self-sufficiency ratio ${ }^{3}$ & 110 & 100 & 90 & 80 \\
\hline forest plantations sc. $A^{2}$ & 62.9 & $2.5 \mathrm{E}-3$ & 0.06 & 25160 \\
\hline forest plantations sc. $B^{2}$ & 9.53 & $1.9 \mathrm{E}-4$ & 0.08 & 50200 \\
\hline forest plantations sc. $C^{2}$ & 1.65 & $2.2 \mathrm{E}-5$ & 0.10 & 75000 \\
\hline forest plantations sc. $D^{2}$ & 0.29 & $2.9 \mathrm{E}-6$ & 0.12 & 100000 \\
\hline cattle number scen. $A^{2}$ & 150000 & 0.040 & $8.6 \mathrm{E}-3$ & 3750000 \\
\hline cattle number scen. $B^{2}$ & 148360 & 0.099 & 0.011 & 1500000 \\
\hline cattle number scen. $C^{2}$ & 109970 & 0.220 & 0.023 & 500000 \\
\hline cattle number scen. $D^{2}$ & 4462 & 0,013 & 0.075 & 350000 \\
\hline cattle productivity & 0.30 & 0.25 & 0.15 & 0.10 \\
\hline comm. wood prod. index ${ }^{2,5} \mathrm{~A}$ & 0.1846 & 0.1055 & 0.0317 & 1.75 \\
\hline comm. wood prod. index ${ }^{2,5} \mathrm{~B}$ & 0.1150 & 0.0767 & 0.0408 & 1.50 \\
\hline comm. wood prod. index ${ }^{2,5} \mathrm{C}$ & 0.0390 & 0.0300 & 0.0589 & 1.30 \\
\hline comm. wood prod. index ${ }^{2,5} \mathrm{D}$ & $1.0 \mathrm{E}-4$ & $1.0 \mathrm{E}-4$ & 0.1495 & 1.00 \\
\hline wood prod. int. index & 1.0 & 1.3 & 1.6 & 2.0 \\
\hline affected by fuelwood & \multicolumn{4}{|c|}{ ural population growth } \\
\hline
\end{tabular}

For notes see page 80 


\section{Notes concerning Africa:}

1 $A, B, C$ in formula pop $=A /\{B+\exp (-C t)\}, D$ : saturation level; base year 1900 2 selfsufficiency ratio $=$ consumption/production (when $<100$ : import/food aid) 3 agricultural expansion into non-forest areas

4 wood production index is 1 in 1985

FAO: in 1983 forest +woodlands $719.6 \mathrm{mln}$. ha., pasture $778.2 \mathrm{mln}$. ha., agricultura $183.1 \mathrm{mln}$. ha. and other lands $1277.1 \mathrm{mln}$. ha.

\section{Notes concerning Latin America:}

I $A, B, C$ in formula pop $=A /\{B+\exp (-C t)\}, D$; saturation level; base year 1900 2 self-sufficiency ratio = consumption/production (when $<100$ : import/food aid) a agricultural expansion into non-forest areas 4 wood production index is 1 in 1985

FAO: in 1983 forest twoodlands $932.7 \mathrm{mln}$. ha, agric. land $175.5 \mathrm{mln}$. ha, pasture $550.4 \mathrm{mln}$ ha and other lands $291.6 \mathrm{mln}$. ha

\section{Notes concerning Tropical Asia:}

1 Indonesia, Papua New Guinea, Burma, Malaysia, Philippines, Thailand, Vietnam, Kampuchea, Laos, Bhutan, Nepal, India, Bangladesh 2 A,B,C in formula pop $=A /\{B+\exp (-C * t)\}, \mathrm{D}$ : saturation level; base year 1900 a self-sufficiency ratio $=$ consumption $/$ production $($ when $<100: \mathrm{import} /$ food aid) - agricultural expansion into mon-forest areas * wood production index is 1 in 1985

FAO: in 1980 forest+woodlands $336.5 \mathrm{mln}$. ha., pasture $30.2 \mathrm{mln}$. ha., agricultural land $257.2 \mathrm{mln}$. ha. and other lands $185.0 \mathrm{mln}$. ha 


\section{Chapter 4}

\section{The Methane Module}

\subsection{Introduction}

Methane $\left(\mathrm{CH}_{4}\right)$, the most abundant hydrocarbon in the atmosphere, is considered as an important greenhouse gas, second only to carbon dioxide (Ramanathan et al., 1985, Wang and Molnar, 1985). Analysis of air contained in ice cores indicates that the methane concentration has been ca. $0.7 \mathrm{ppm}$ for maybe thousands of years (Khalil and Rasmussen, 1982, and 1987). Around 1700 A.D. the concentration seems to have started increasing slowly to ca. $0.9 \mathrm{ppm}$ around 1900 A.D. Only then did a rapid increase start, probably caused by changes in the sources as well as in the sinks of methane resulting in a present concentration of about $1.7 \mathrm{ppm}$ (Khalil and Rasmussen, 1987). The anthropogenic sources of methane, such as cattle breeding, rice cultivation and the exploitation of fossil fuels have grown over the last centuries, whereas the natural emissions are assumed to have remained unchanged (Khalil and Rasmussen, 1982, and 1985).

The main sink of methane is oxidation by hydroxyl $(\mathrm{OH})$ radicals. Besides this sink methane is removed from the troposphere by soils and transportation to the stratosphere. Due to the increased levels of methane and carbon monoxide (CO), the dominant consumers of hydroxyl, the hydroxyl concentration has decreased. Thus the removal rate of methane has decreased (the atmospheric lifetime of methane has increased). This combination of growing emissions and declining removal rate has caused the increase in the concentration of methane (Sze, 1977, Bolle et al., 1986, Crutzen, 1985, Khalil and Rasmussen, 1985, Isaksen and $\left.H \phi v_{y}, 1987\right)$.

This study describes the global $\mathrm{CH}_{4}-\mathrm{CO}-\mathrm{OH}$ cycle by both quantifying future emissions and simulating the main atmospheric chemical processes 
that influence the global concentrations of these trace gases. Moreover, the resulting temperature increase is calculated. This has resulted in the implementation of an independent, separate methane module within IMAGE (Rotmans et al., 1990b).

The purpose of the present study is to gain more insight into the driving forces of the $\mathrm{CH}_{4}-\mathrm{CO}-\mathrm{OH}$ cycle as well as to present estimates of possible future changes in chemical composition and temperatures of the atmosphere. As opposed to previous studies (Brühl and Crutzen, 1988, Thompson and Cicerone, 1986, Isaksen and $H \emptyset \mathrm{v}, 1987$ ), this study includes an extensive investigation of the sources of methane and carbon monoxide, leading to integrated future emission scenarios based on social and economic trends.

\subsection{Model Description}

\subsubsection{Structure}

The developed simulation model, an upgraded version of the methane module in Rotmans (1986), is time-dependent with a simulation time of 200 years, from 1900 to 2100 . In view of the time scale of our simulation model, the system has a global character, entailing absence of spatial dimensions. The structure of the methane module is depicted in Figure 4.1, which figure shows the cyclic character of the system.

\subsubsection{Calculation Procedure}

At an arbitrary point of time $T=t$ during the simulation, emissions and concentrations are supposed to be known, either by initialization or by calculation in a previous time step. Methane is removed from the troposphere by three processes, the most important of which is considered first: oxidation by $\mathrm{OH}$ radicals. The production of $\mathrm{OH}$ radicals is calculated from global trends in tropospheric ozone $\left(\mathrm{O}_{3}\right)$ and $\mathrm{NO}_{x}$. In our model the concentration of $\mathrm{OH}$ radicals is determined by the production of $\mathrm{OH}$ on the one hand and the loss rate due to reaction with $\mathrm{CH}_{4}$ and $\mathrm{CO}$ on the other hand.

The concentrations of $\mathrm{CH}_{*}$ and $\mathrm{OH}$ determine the rate of removal of $\mathrm{CH}_{4}$. The two other sinks of $\mathrm{CH}_{4}$ considered are uptake by soils and transport to the stratosphere, both considered as fixed fractions of the methane concentration at time $T=t$. 


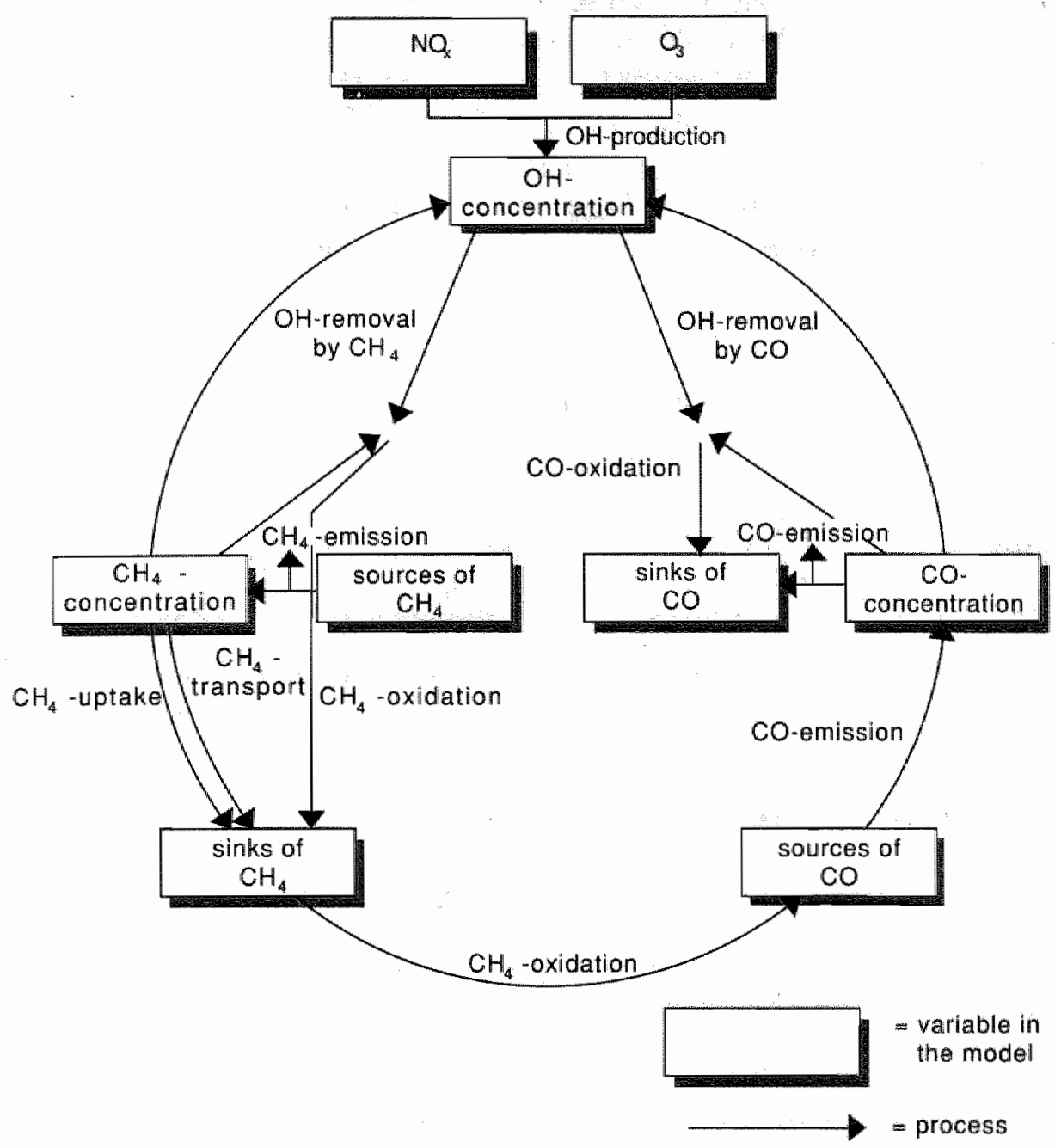

Figure 4.1: Schematic representation of IMAGE $\mathrm{CH}_{4}-\mathrm{CO}-\mathrm{OH}$ module.

At time $T=t+\Delta t$ the $\mathrm{CH}_{4}$ concentration is simulated by adding to the $\mathrm{CH}_{4}$ concentration at time $T=t$ the $\mathrm{CH}_{4}$ emissions during the interval $\Delta t$ and subtracting the removal from the troposphere by the three processes mentioned.

The main removal processes of $\mathrm{CO}$ are the oxidation by $\mathrm{OH}$ as well as the uptake by soils. Both are modelled identically to $\mathrm{CH}_{4}$ : the oxidation 
by calculation from the concentrations of $\mathrm{CO}$ and $\mathrm{OH}$, and the uptake as a fixed fraction of the $\mathrm{CO}$ concentration.

At time $T=t+\Delta t$ the $\mathrm{CO}$ concentration is calculated by adding the $\mathrm{CO}$ emissions during the interval $\Delta t$ and subtracting the removal of $C O$ during $\Delta t$.

Obviously the above mentioned processes are highly interdependent and therefore the $\mathrm{CH}_{4}-\mathrm{CO} \mathrm{OH}$ system can be considered as a cycle. In the following sections this system is described in more detail.

\subsubsection{Notation}

Henceforth the following conventions for notation hold:

$p X(t)=$ the tropospheric concentration of a trace gas at time $t$ (in ppm)

$p X(0)=$ the initial tropospheric concentration of a trace gas at time $t=0$; here, as $t=0,1900$ is selected

$e m X(t)=$ the global emission of a trace gas at time $t$ (in $T g / y$ )

$k_{1}=$ the reaction rate constant for the reaction of $\mathrm{CH}_{4}$ and $\mathrm{OH}$

$k_{2} \quad=$ the reaction rate constant for the reaction of $\mathrm{CO}$ and $\mathrm{OH}$

\subsection{Emissions}

\section{Scenarios}

For the period 1985 to 2100 four social tendencies are regarded, leading to four sets of emission scenarios. An emission scenario is defined as an integrated perception of a possible development of future emissions, without pretending to be a prediction. Furthermore, we define a set of scenarios as a similar, consistent development for all trace gases. The underlying scenario assumptions are based on trends in energy supply, agriculture, industry, world population growth, etc., as illustrated in Rotmans et al. (1990a). The four sets of scenarios are characterized as follows:

- scenario A: continued trends assumes a continuation of economic growth not limited by environmental constraints

- scenario B: reduced trends are based on the presently considered environmental measures

- scenario C: changing trends assumes implementation of international movement towards stricter policies 
- scenario D: forced changes assesses the possibilities of maximum efforts towards global sustainable development.

\section{Methane}

The sources of methane all emit directly into the atmosphere; no methane is formed in the atmosphere itself. The sources are divided into anthropogenic and natural sources. Anthropogenic sources are all controlled or influenced by man, such as rice paddies, cattle, biomass burning, fossil fuel usage and leakage of natural gas. The major natural sources are termites, swamps, fresh- and salt water and tundras (Seiler, 1984, Bartlett et al., 1985, Ehhalt, 1985, Crutzen et al., 1986a, Bingemer and Crutzen, 1987, Van Ham, 1987). In general, methane emissions inventories agree upon the nature of the sources, but the lower and the upper bound for the total emission differ by a factor of 6 (Van Ham, 1987, Bingemer and Crutzen, 1987). The possibility that the fossil carbon sources of methane could be more important than is commonly believed (Lowe et al., 1988) has not yet been taken into account. Table 4.1. gives a summary of the various sources and the corresponding methane emissions.

\begin{tabular}{|l|c|c|}
\hline sources & $\begin{array}{c}\text { emissions } \\
\text { (in } T G y^{-1} \text { ) }\end{array}$ & $\begin{array}{c}\text { range in } \\
\text { (in } T G y^{-1} \text { ) }\end{array}$ \\
\hline total & 490 & $213-1397$ \\
\hline anthropogenic & 325 & $190-720$ \\
\hline rice paddies & $70(\mathrm{~b})$ & $30-200$ \\
ruminants & 75 & $60-200$ \\
biomass burning & $60(\mathrm{c})$ & $20-110$ \\
natural gas leakage & $30(\mathrm{c})$ & $20-40$ \\
coal mining & $30(\mathrm{c})$ & $30-100$ \\
waste disposals (a) & 60 & $30-70$ \\
\hline natural & 165 & $23-677$ \\
\hline termites & 165 & $6-300$ \\
swamps/wetlands & $100(\mathrm{c})$ & $25-300$ \\
fresh and salt water & 5 & $0-12$ \\
\hline
\end{tabular}

From: Van Ham 1987

except (a) : from Bingemer and Crutzen 1987

(b) : also from Holzapfel-Pschorn and Seiler 1986

(c) : also from Crutzen 1985

Table 4.1: Estimated emissions of methane sources in 1985. 
Historical emissions of methane for the years 1900 to 1985 have been estimated in Bolle et al. (1986) and Khalil and Rasmussen (1985) and follow an exponential growth function.

Four scenarios have been developed for presumed future emissions for the period 1985 to 2500 . These scenarios are derived from the four sets of scenarios, which are, together with the underlying assumptions for the $\mathrm{CH}_{4}$, the emission scenarios described in Rotmans et al. (1990a). In Figure 4.2 an estimate of the build-up of the methane emissions in 2050 is given, disregarding the temperature feedback mechanisms on the methane emissions. Methane is a useful gas and therefore at some sources it is attractive to recover it, not only out of environmental concern, but also for economic reasons. This is particularly true for emissions during the exploitation of fossill fuels and from wastes. From scenario A to D decreasing estimates for the source strengths are used, as well as an increasing recovery rate for the rellevant sources.

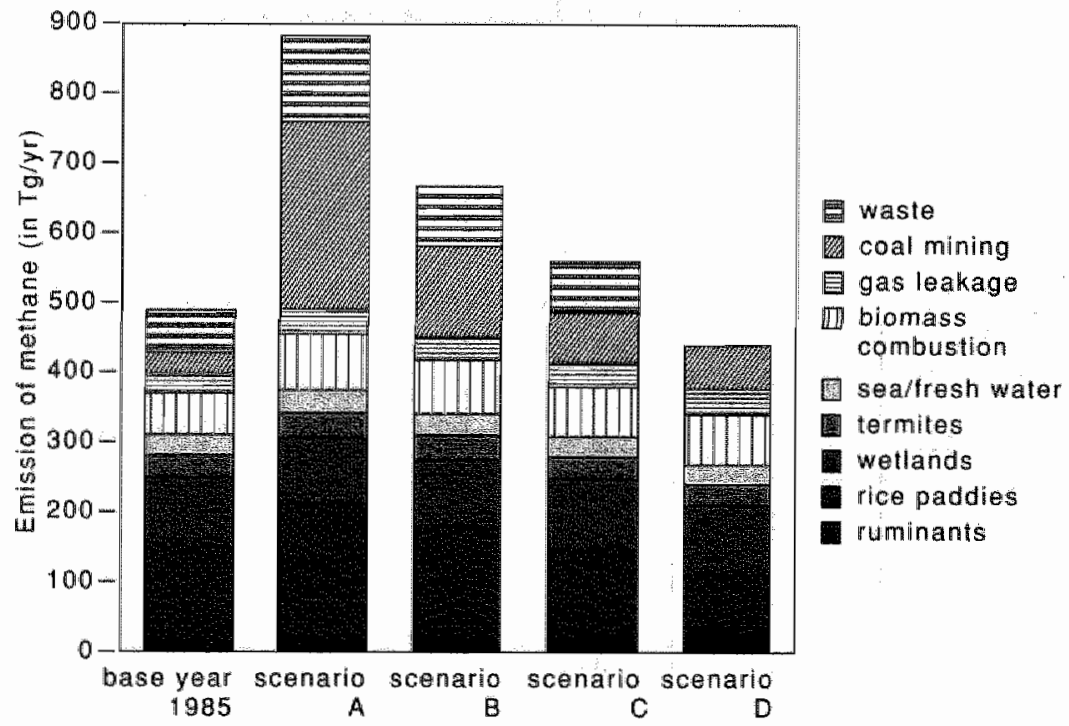

Figure 4.2: Build-up of the methane emissions in 2050 (from R.J. Swart, 1988). 


\section{Carbon monoxide}

Carbon monoxide is both emitted directly as well as produced in the atmosphere by oxidation of hydrocarbons, of both natural and anthropogenic origin. The direct sources are mainly the burning of biomass and fossil fuel, plants and oceans.

We distinguish three kinds of carbon monoxide emissions (in fact what we call emission is in-situ production):

- from the oxidation of $\mathrm{CH}_{4}$;

- from the oxidation of hydrocarbons other than $\mathrm{CH}_{4} ;$

- from the direct sources.

In the model these specifications are expressed in the following way:

$$
E m C O(t)=E m C O_{C H_{4}}(t)+E m C O_{N M H C}(t)+E m C O_{\text {direct }}(t)
$$

with:

$\operatorname{EmCO}(t) \quad=$ the total $\mathrm{CO}$ emissions at time $t$ (in $\mathrm{Tgy}^{-1}$ )

$E_{m C O} O_{C_{4}}(t)=$ the $\mathrm{CO}$ emissions at time $t$ due to $\mathrm{CH}_{4}$ oxidation (in $\operatorname{Tgy}^{-1}$ )

$\operatorname{EmCO}_{N M H C}(t)=$ the CO emissions at time $t$ due to the oxidation of nonmethane hydrocarbons (NMHC) (in $T_{g y}{ }^{-1}$ )

$E m C O_{\text {direct }}(t)=$ the $\mathrm{CO}$ emissions at time $t$ form the direct sources (in $T g y^{-1}$ )

The $\mathrm{CO}$ emission due to $\mathrm{CH}_{4}$ oxidation is modelled by the net $\mathrm{CO}$ yield from the methane oxidation by hydroxyl, which is approximately $80 \%$ according to Logan et al. (1981). This gives a source strength of $80 \%$ of the product of the $\mathrm{CH}_{4}$ concentration and the oxidation velocity; see Rotmans and Eggink (1988).

In order to quantify the direct emissions of $\mathrm{CO}$ and the oxidation by NMHC the relevant sources of these gases are divided into three categories: natural, fossil fuel related and other anthropogenic emissions. While for natural emissions of $\mathrm{CO}$ and $\mathrm{NMHC}$ constant figures were taken from Logan et al. (1981), for anthropogenic but non-fossil fuel related emissions growth has been assumed proportional to population. Sources treated this way are carbon monoxide and hydrocarbon emissions from deforestation, agricultural practices like savanna burning, solvent use, as well as residential combustion of fossil fuel. Thompson and Cicerone (1986) assumed all fossil fuel related $\mathrm{CO}$ emissions and the oxidation of $\mathrm{CO}$ by anthropogenic hydrocarbons to be proportional to fossil fuel consumption. 
However, the emissions of these trace gases are the result of incomplete combustion of fossil fuels (especially in traffic, residential heating) or losses during storage, transportation or use of non-energy fuel products (NMHC by evaporation). In future energy scenarios centralized fossil fuel combustion in the industrial and the electricity generating sector, where carbon monoxide and hydrocarbon emissions are low, plays a dominant role. Therefore this assumption appears incorrect. In this study alternative scenarios are adopted (Swart, 1988). Since ca. $80 \%$ of the global fossil fuel related $\mathrm{CO}$ emissions and ca. $50 \%$ of the NMHC emissions are presently caused by vehicular traffic, scenarios for this sector have been created, based on car densities.

Following an OECD methodology (OECD, 1983), saturation values of cars have been used for seven different regions consisting of countries with assumed similar characteristics as to car ownership. Extrapolating historical figures (Automobile International, 1929-1987) and using four sets of saturation values, the numbers of cars, trucks and buses have been calculated, using the mean UN-population scenario (UN, 1986) and logistical curves for both population and car ownership. The results are shown in Figure 4.3. With presently available technology, like catalysts and other engine types, emissions of $\mathrm{CO}$ and $\mathrm{NMHC}$ can be greatily reduced (up to 90\%) and fuel efficiency increased (factor 3, Cheng et al., 1986, Goldenberg et al., 1987a,b).

In the $\mathrm{CO}$ scenarios it is assumed that, from $\mathrm{A}$ to $\mathrm{D}$, the emission reduction percentages and fuel efficiency are increasing and have been introduced earlier. In developing countries the reduction percentages are assumed to be lower for reasons of worse maintenance and inapplicability of technologically sophisticated features and also introduced later, allowing for a time lag in law making and enforcement. The base year estimate for $\mathrm{CO}$ emissions from traffic is taken from Kavanaugh (1987), whose $152 \mathrm{Tg} / \mathrm{yr}$ appears to be more realistic than Logan's (1981) $233 \mathrm{Tg} / \mathrm{yr}$, according to Swart (1988). Another major CO source is the primary metal industry. Not only can the emissions be reduced by process changes or improvements, remaining $\mathrm{CO}$ can also be flared or reused. While iron and steel production per capita is already decreasing and aluminium production approaching saturation value, in the scenarios the unabated global production levels are assumed to be proportional to population growth, like other anthropogenic emissions of $\mathrm{CO}$ and $\mathrm{NMHC}$, apart from traffic. Even if high car ownership levels are combined with minimal emission reduction, the resulting emission levels are still much lower than would be the case with proportionality to fossil fuel consumption. 


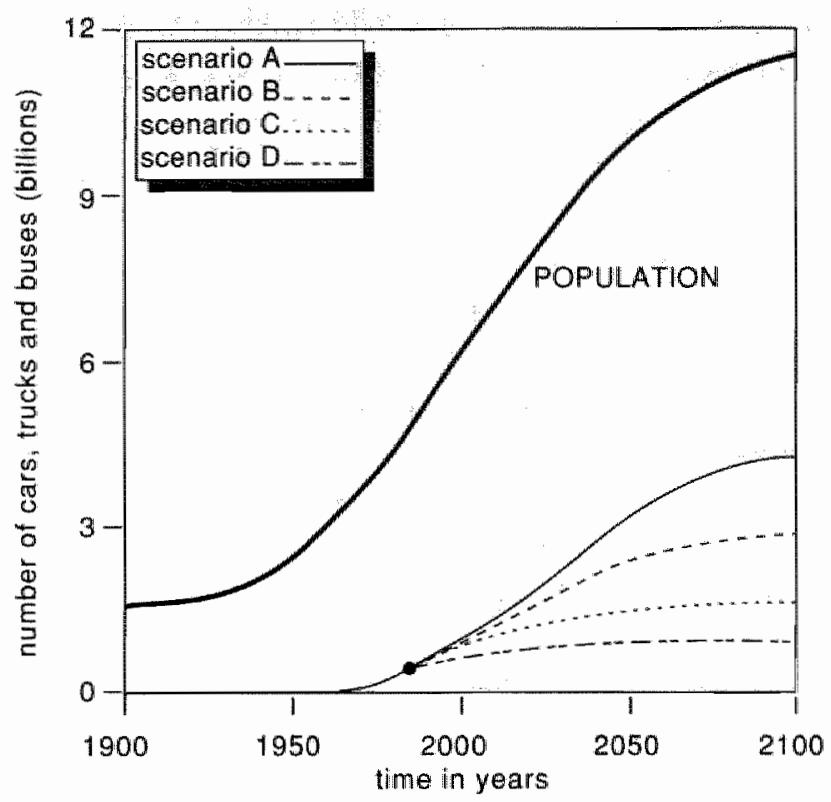

Figure 4.3: Number of cars, trucks and buses (from R.J. Swart, 1988).

\section{Hydroxyl}

The main source of hydroxyl radicals is the reaction of exited oxygen $\left(O\left({ }^{1} D\right)\right)$, produced by the photolysis of ozone $\left(\mathrm{O}_{3}\right)$, and water $\left(\mathrm{H}_{2} \mathrm{O}\right)$ (Hewitt and Harrison, 1985, Logan et al., 1981). Other (minor) sources are the recycling reactions of odd hydrogen $\left(\mathrm{OH}_{3} \mathrm{H}, \mathrm{HO}_{2}, \mathrm{H}_{2} \mathrm{O}_{2}\right)$ (Logan et al., 1981, Sze, 1977).

The limiting condition at the production of $\mathrm{OH}$ radicals is the magnitude of the $\mathrm{NO}_{x}$ concentration. Hameed et al. (1979) show the dependence of the $\mathrm{CH}_{4}$ - $\mathrm{CO}-\mathrm{OH}$ cycle on the $\mathrm{NO}_{x}$ background concentration.

Here a low ambient $\mathrm{NO}_{x}$ concentration is assumed which involves a decreasing $\mathrm{OH}$ concentration in case of increasing $\mathrm{CO}$ and $\mathrm{CH}_{4}$ concentration. The $\mathrm{OH}$ production is presumed to be commensurate with the concentrations of $\mathrm{NO}_{x}$ and $\mathrm{O}_{3}$ (Logan et al., 1981). A study of the literature shows general agreement on the fact that there has been an increase in tropospheric ozone and $\mathrm{NO}_{x}$ in the last century (Ramanathan et al., 1985, Crutzen, 1985, Thompson and Cicerone, 1986, Brasseur and de Rudder, 1987). Therefore, a rising historical $\mathrm{OH}$ production is implemented, under the assumption of 
a steady-state $\mathrm{OH}$ concentration and calibrated on the $\mathrm{OH}$ concentration; this yields an increase from ca. $0.3 \mathrm{ppm} \mathrm{y}^{-1}$ in 1900 to $0.6 \mathrm{ppm} \mathrm{y}^{-1}$ in 1985 . For the years 1986 to 2100 four $\mathrm{OH}$ production scenarios have been chosen, based on presumed future developments in tropospheric $\mathrm{O}_{3}$ and $\mathrm{NO}_{x}$ concentrations, according to Stewart et al. (1977), Brühl and Crutzen, (1985), Crutzen and Graedel, (1986b) and Isaksen and Høv, (1987).

Annual increases of both $\mathrm{NO}_{x}$ and $\mathrm{O}_{3}$ concentrations are varied from $+0.40 \%$ (scenario $A$ ), via $+0.20 \%$ (scenario $B$ ) and $+0.10 \%$ (scenario $C$ ) to $+0.05 \%$ (scenario D). Increases of abatement measures to combat acid rain have not been explicitly taken into account.

The production of $\mathrm{OH}$ is roughly determined by the sum of the trends in $\mathrm{NO}_{x}$ and $\mathrm{O}_{3}$, neglecting the other minor sources of hydroxyl radicals (Logan et al., 1981). The applied scenarios do not yet take account of the actual sources for lack of more detailed information.

\subsection{Concentrations}

\section{Methane}

The tropospheric concentration of methane is determined by the initial concentration, the emissions of methane and its removal. Three removal processes are considered: the uptake of methane by soils, the transportation of methane to the stratosphere and the oxidation of methane. The rates of the three processes considered here determine the atmospheric lifetime. We assume the uptake velocity by soils and the transportation velocity to the stratosphere to be time-independent and the oxidation velocity to be timedependent. This leads to the following expression for the $\mathrm{CH}_{4}$ concentration:

$$
\begin{aligned}
p C H_{4}(t)=p C H_{4}(t-1)+\int_{t-1}^{t} & \text { (conversion factor } C H_{4} * E m C H_{4}(\tau) \\
& - \text { uptake velocity } C H_{4} * p C H_{4}(\tau) \\
& - \text { transport velocity } C H_{4} * p C H_{4}(\tau) \\
& \left.- \text { oxidation velocity } C H_{4} * p C H_{4}(\tau)\right) d \tau
\end{aligned}
$$

with:

$p \mathrm{CH}_{4}(0) \quad=$ the initial $\mathrm{CH}_{4}$ concentration, at time $t=0$ (in 1900); is $0.9 \mathrm{ppm}$, varying between $0.85 \mathrm{ppm}$ (Khalil and Rasmussen, 1985, 1987) and $1.1 \mathrm{ppm}$ 
(Kerr, 1984)

conversion factor $\mathrm{CH}_{4}=$ factor that converts emissions of $\mathrm{CH}_{4}$ into global tropospheric concentrations of $\mathrm{CH}_{4} ;$ is $3.76 * 10^{-4}$ (in ppm $\mathrm{Tg}^{-1}$ ) (Khalil and Rasmussen, 1982)

uptake velocity $\mathrm{CH}_{4}=$ the rate with which $\mathrm{CH}_{4}$ is taken up by soils (in $y^{-1}$ ). $0.005 y^{-1}$, based on Van Ham (1987) and Keller et al. (1986)

transp. velocity $\mathrm{CH}_{4}=$ the rate with which $\mathrm{CH}_{4}$ is transported to the stratosphere (in $y^{-1}$ ). $0.015 y^{-1}$, according to Van Ham (1987)

oxidat. velocity $\mathrm{CH}_{4}=$ the rate with which methane is oxidized by $\mathrm{OH}$ at time $t$ (in $y^{-1}$ ). Following Volz et al. (1981), Logan et al. (1981) and Khalil and Rasmussen (1985) the product of the reaction constant $k$ and the $\mathrm{OH}$ concentration

A derived concept is the atmospheric life time of methane, defined as:

$$
\begin{aligned}
\text { lifetime } \mathrm{CH}_{4}(t)= & 1 /(\text { uptake velocity }+ \text { transp. velocity } \\
& + \text { ox. velocity }) \\
= & 1 /\left(0.005+0.015+k_{1} * p O H(t)\right)
\end{aligned}
$$

\section{Carbon monoxide}

Similar to methane, the $\mathrm{CO}$ concentration is determined by the initial concentration, the emissions and the removal from the troposphere. The major removal mechanism for $\mathrm{CO}$ is the oxidation by $\mathrm{OH}$ radicals, which accounts for ca. $80 \%$ of the $\mathrm{CO}$ sink. A second important sink is the uptake by soils (Logan et al., 1981, Volz et al., 1981, Khalil and Rasmussen, 1984, and 1985, Thompson and Cicerone, 1986). Although there may be some CO transport to the stratosphere or CO uptake by plants (Khalil and Rasmussen, 1984), these contributions are neglected in the model. The $\mathrm{CO}$ concentration is expressed as:

$$
\begin{aligned}
p C O(t)=p C O(t-1)+\int_{t-1}^{t} \quad & \text { (conversion factor } C O * \operatorname{Em} C O(\tau) \\
& - \text { uptake velocity } C O * p C O(\tau) \\
& - \text { oxidation velocity } C O * p C O(\tau)) d \tau
\end{aligned}
$$


with:

$p C O(0)$

$=0.048$, varying between $0.045 \mathrm{ppm}$ and $0.085 \mathrm{ppm}$ for 1860 (Thompson and Cicerone, 1986). We obtained the value of $0.048 \mathrm{ppm}$ from a concentration of $0.1 \mathrm{ppm}$ for 1977 and an increase of $30 \%$ since 1950 (Sze, 1977), assuming an exponentially growing concentration conversion factor $C O=$ factor that converts emissions of $C O$ into global tropospheric concentrations of $\mathrm{CO}$; is $2.0186 * 10 \mathrm{ppm}^{\mathrm{Tg}} \mathrm{g}^{-1}$ (Rotmans, and Eggink, 1988)

uptake velocity $\mathrm{CO}=$ the rate with which $\mathrm{CO}$ is taken up by soils (in $y^{-1}$ ). The uptake of $\mathrm{CO}$ by soils is ca. $320 \mathrm{Tg}^{-1}$ for around 1985 and depends linearly on the $\mathrm{CO}$ concentration, argued by Volz et al. (1981), resulting in a time-independent uptake velocity for $\mathrm{CO}$ of $0.64595 y^{-1}$

oxidation velocity $\mathrm{CO}=$ the rate with which $\mathrm{CO}$ is oxidized by $\mathrm{OH}$ at time $t$ (in $y^{-1}$ ). Following the interpretation of Logan et al. (1981) and Volz et al. (1981), this is the product of a reaction rate constant and the $\mathrm{OH}$ concentration

\section{Hydroxyl radicals}

The change in hydroxyl concentration is determined by the production (already discussed in the section emissions) and the loss of hydroxyl radicals. It is generally accepted that hydroxyl is the dominant consumer of methane and carbon monoxide, and conversely, methane and carbon monoxide are the major sinks of hydroxyl (Hewitt and Harrison, 1985, Logan et al., 1981). Therefore the reaction rates for the reactions of $\mathrm{CH}_{4}$ and $\mathrm{CO}$ with $\mathrm{OH}$ determine the loss rate of $\mathrm{OH}$, which, together with the hydroxyl concentration, determines the loss of $\mathrm{OH}$ :

$$
\text { loss rate } O H(t)=k_{1} * p C H_{4}(t)+k_{2} * p C O(t)
$$

with:

loss rate $O H(t)=$ the removal rate of $O H$ from the troposphere at time $t$ by the reactions with $\mathrm{CH}_{4}$ and $\mathrm{CO}$.

$k_{1} \quad=1.584 * 10 \mathrm{ppm}^{-1} \mathrm{y}^{-1}$, see Rotmans and Eggink, (1988) 
$k_{2}$

$$
\begin{aligned}
= & 8.91 * 10 \mathrm{ppm}^{-1} \mathrm{y}^{-1}, \text { from } 1.35 * 10(1+p / 1000) \mathrm{cm} \\
& \text { molec } \mathrm{s}^{-1} \text { with } p=\text { atmospheric } \\
& \text { pressure in mbar, see Rotmans and Eggink, (1988) }
\end{aligned}
$$

The foregoing results in a loss rate of ca. $10^{-7} y^{-1}$, which means a tropospheric lifetime of hydroxyl of ca. 3 seconds. This implies that the loss of $\mathrm{OH}$ approximately equals the production of $\mathrm{OH}$, justifying the supposition of a steady-state concentration of hydroxyl, or a negligible annual change in $\mathrm{OH}$ concentration, so:

$$
p O H(t)=\text { production } O H(t) /\left(k_{1} * p C H_{4}(t)+k_{2} * p C O(t)\right)
$$

based on Logan et al. (1981) and Levine et al. (1985).

\subsection{Results}

The emissions of $\mathrm{CO}_{2}$ (from fossil fuels), $\mathrm{CH}_{4}$ and $\mathrm{CO}$ are depicted in figures 4.4-4.6. These figures show a sharp rise of the emissions in scenario $A$ (continued trends). Scenarios B and C (reduced and changing trends) lead to logistical emission curves (showing a deflection owing to environmental measures); scenario $\mathrm{D}$ (forced changes) results in a substantial decrease of the $\mathrm{CO}_{2}$ emission, a slight fall of the $\mathrm{CH}_{4}$ emission and a slightly increasing $\mathrm{CO}$ emission.

Figures 4.4 and 4.6 clearly show the absence of a correlation (as supposed in literature) between the fossil fuel $\mathrm{CO}_{2}$ emission and the $\mathrm{CO}$ emission.

Figure 4.7 shows the $\mathrm{OH}$ production, ranging between a large increase of the production of hydroxyl radicals until 2100 for scenario $A$ and a slightly increasing production until 2100 for other scenarios.

The calculated global tropospheric concentrations of $\mathrm{CH}_{4}, \mathrm{CO}$ and $\mathrm{OH}$ are represented in Figures 4.8-4.10. Figure 4.8 shows an upward trend for scenarios $\mathrm{A}$ and $\mathrm{B}$ with a deflecting curve after 2050, a relatively constant $\mathrm{CH}_{4}$ concentration for scenario $\mathrm{C}$; only scenario D leads to a slightly decreasing $\mathrm{CH}_{4}$ concentration. 


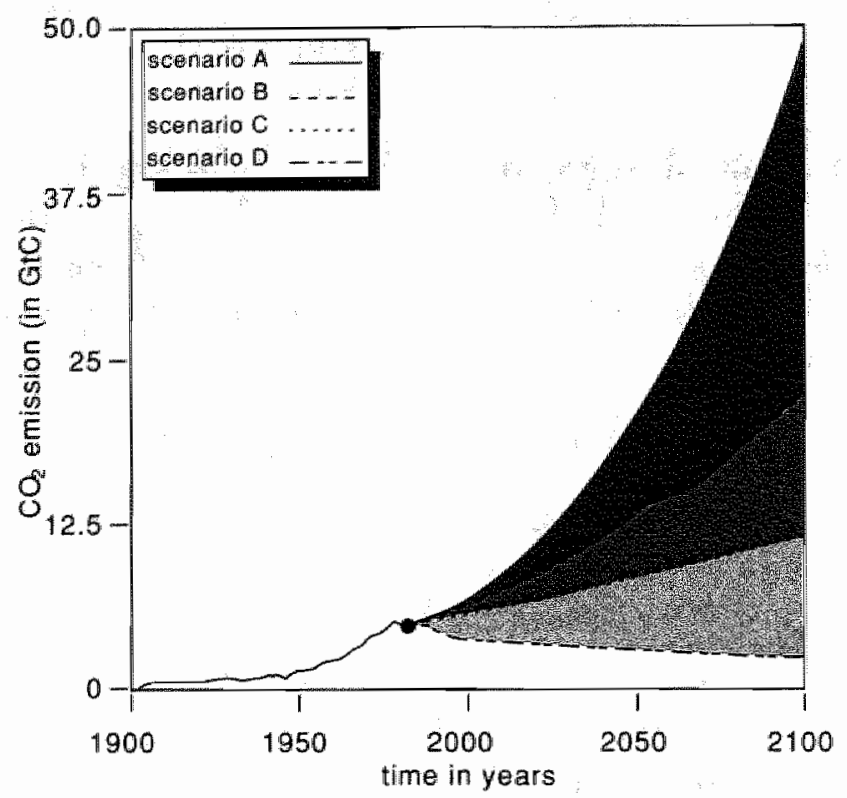

Figure 4.4: Emissions of $\mathrm{CO}_{2}$.

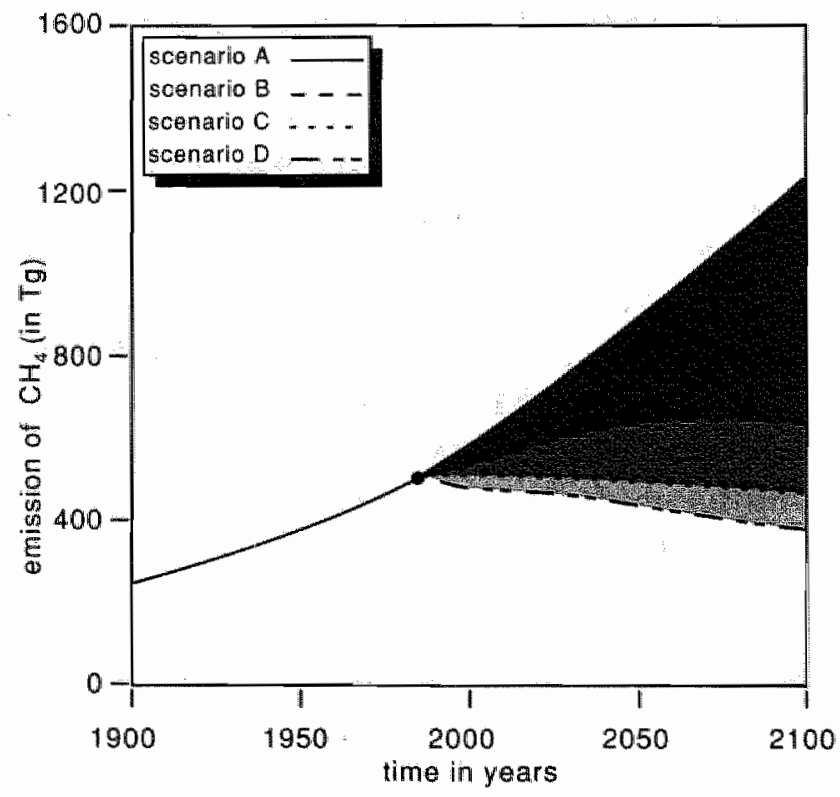

Figure 4.5: Emissions of $\mathrm{CH}_{4}$. 


\subsection{RESULTS}

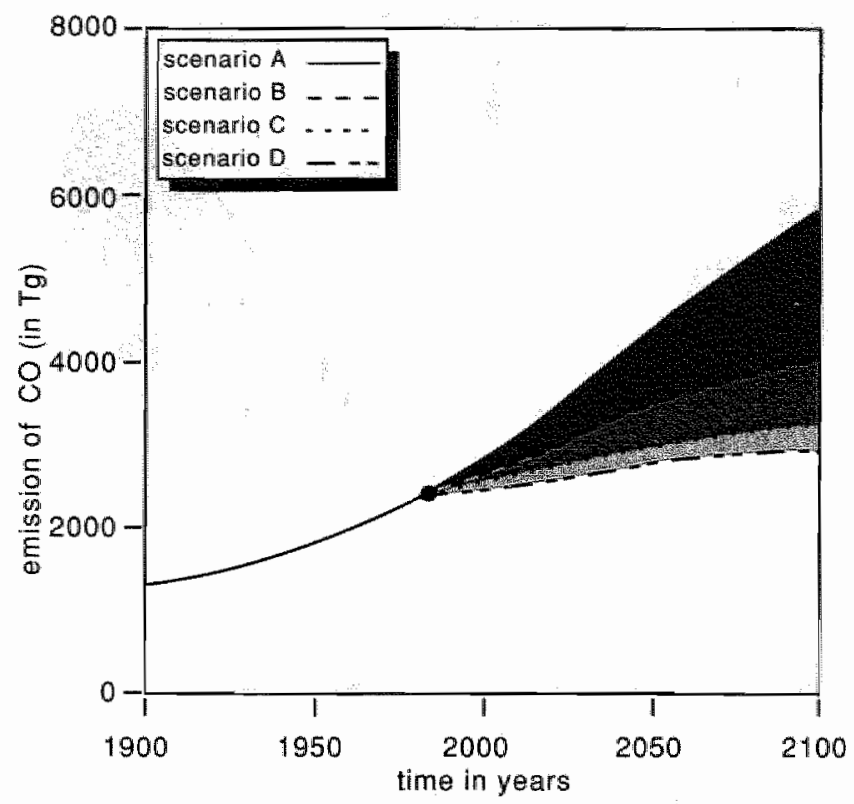

Figure 4.6: Emissions of $\mathrm{CO}$.

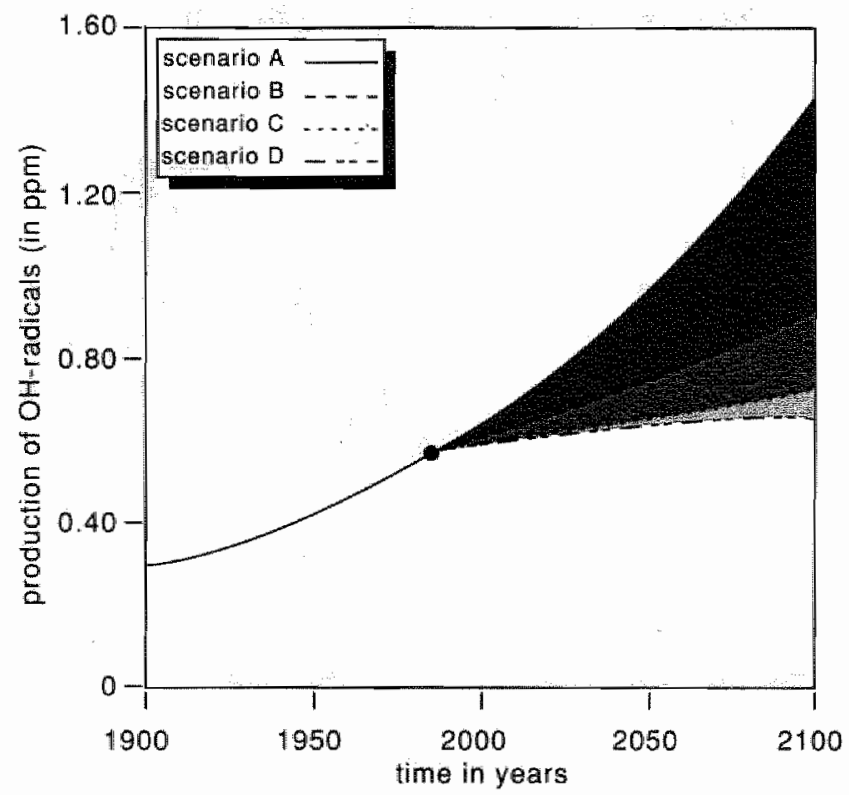

Figure 4.7: Production of $\mathrm{OH}$ radicals. 


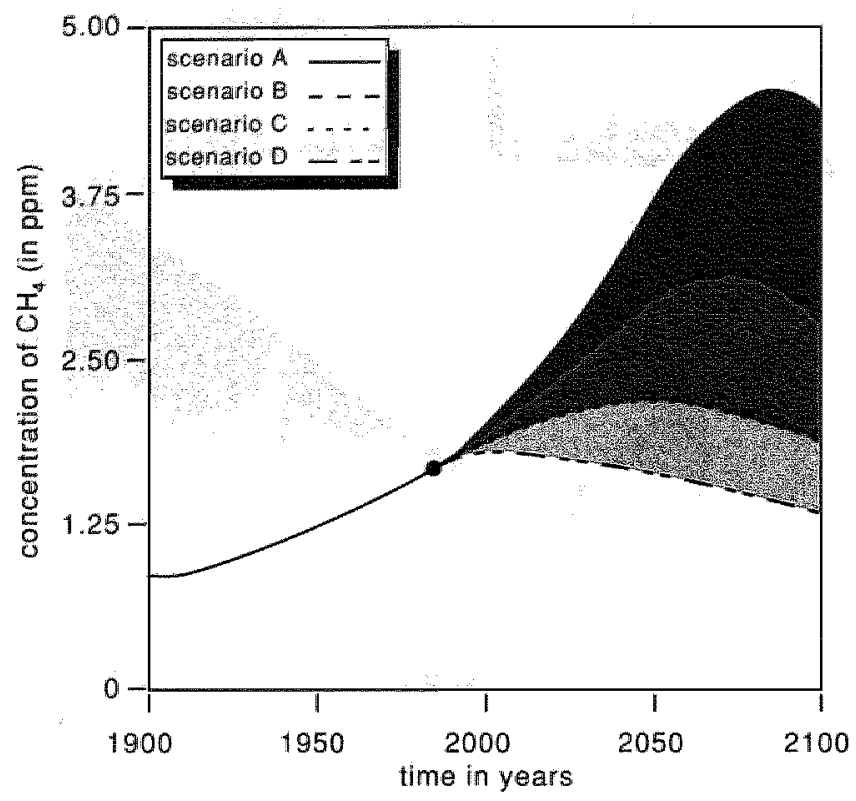

Figure 4.8: Concentration of $\mathrm{CH}_{4}$ (global tropospheric average).

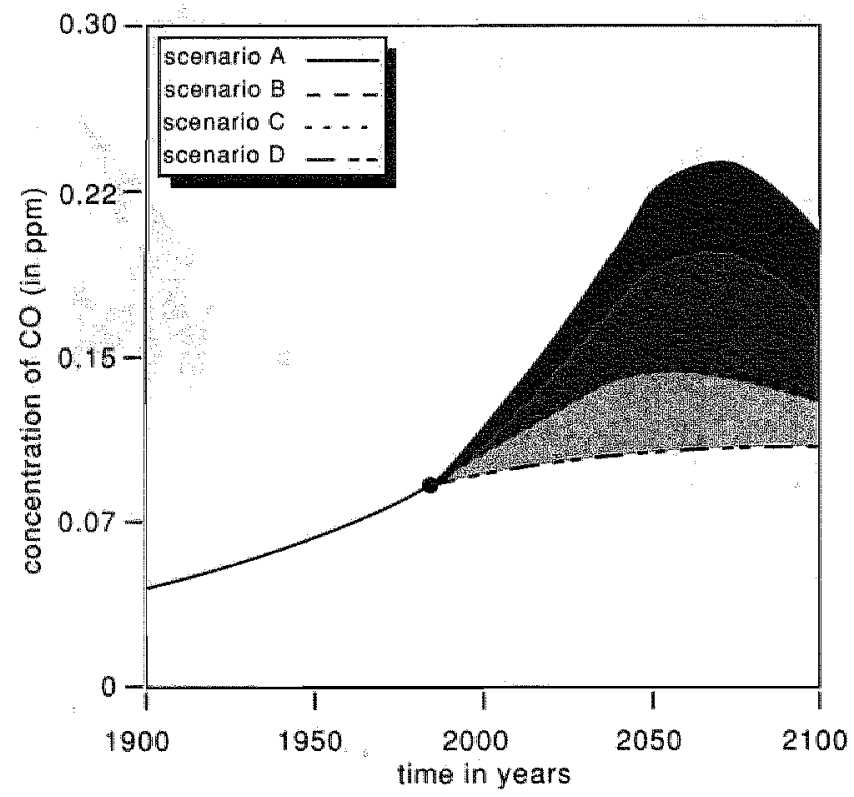

Figure 4.9: Concentration of $\mathrm{CO}$. 
Figure 4.9 shows a growth of the carbon monoxide concentration in case of scenarios A, B and C, stagnating after 2075; and even scenario D induces a minimal growth of the $\mathrm{CO}$ concentration. Both the $\mathrm{CH}_{4}$ concentrations and the $\mathrm{CO}$ concentrations show logistical behaviour. Primarily this is caused by the deflecting emissions, with a turning point about 2050; the system's cyclic character strengthens also this effect: decreasing $\mathrm{CO}$ concentrations have a restraining influence on the $\mathrm{CH}_{4}$ concentrations.

A remarkable result is that in our model even major environmental measures and maximum efforts towards global sustainable development cannot effectuate a robust falling-off of the concentrations. This is due to remaining methane emissions and those emissions of carbon monoxide, which are taken as being proportional to population growth.

In Figure 4.10 the calculated $O H$ concentration is depicted, showing for scenario $\mathrm{A}, \mathrm{B}$ and $\mathrm{C}$ a decreasing trend until 2050 , followed by an upward trend. As mentioned before this is connected with abating $\mathrm{CO}$ concentrations after 2050. The strong growth of the $\mathrm{OH}$ concentration in scenario $\mathrm{A}$ is due to both decreasing $\mathrm{CO}$ and $\mathrm{CH}_{4}$ and the relatively high $\mathrm{OH}$ production. Only scenario D yields a steady growth of the concentration.

The simulated atmospheric lifetime of $\mathrm{CH}_{4}$ is given in Figure 4.11. In 1900 the residence time of methane in the atmosphere is ca. 9 years. The lifetime path of methane is inversely proportional to the $\mathrm{OH}$ concentration (equation 4.3). Scenario D yields a slightly decreasing lifetime of $\mathrm{CH}_{4}$.

\section{Feedbacks}

Two major feedbacks which potentially may increase methane concentrations as a result from global warming have been identified. Methane hydrates have a large potential for being released at increasing rates when global temperatures increase. Lashof (1989) argues that this is the largest biogeochemical feedback in the climate system. According to Kvenvolden (1989) however, this increase is not yet expected to materialize in the coming decades. Another important potential feedback is formed by the increased decomposition of organic materials in anaerobic sediments in northern wetlands (Juashof, 1989). This additional release is modelled in a very provisional way by Burke et al. (1990) by assuming a simple relationship between methanogenesis and temperature. Next to these positive feedbacks there are also negative feedbacks with respect to methane. For instance the decrease in the concentration of methane by increased $\mathrm{OH}$ concentration, caused by increase in absolute humidity accompanying global temperature increase. 
Current scientific opinion is that the positive feedbacks largely dominate the negative feedbacks.

We have considered the relation between methanogenesis and temperature increase, supposing a 10 degree centigrade temperature increase would cause a fivefold increase of methane production, based on Burke et al. (1990).

This is modelled in a simple way by assuming a linear relationship between methanogenesis and temperature, following Burke et al. (1990):

$$
E m w t f b(t)=E m w t(t) *[1+0.4 * T t o t(t)]
$$

with:

Emwt $f b(t)=$ Emission of wetlands with temperature feedback at time $t$ $\operatorname{Emwt}(t)=$ Emissions of wetlands without feedback at time $t$ $\operatorname{Ttot}(t)=$ total equilibrium temperature increase

According to this relation a 10 degree celsius temperature increase would cause a fivefold increase of methane production. When this relationship is built into IMAGE, assumptions must be made for the developments of the other trace gases. Simulation runs were performed for the unrestricted trends scenario (A). Figure 4.12 shows the effect of the temperature feedback on wetland emissions, whereas Figure 4.13 gives the different $\mathrm{CH}_{4}$ concentrations with and without feedback.

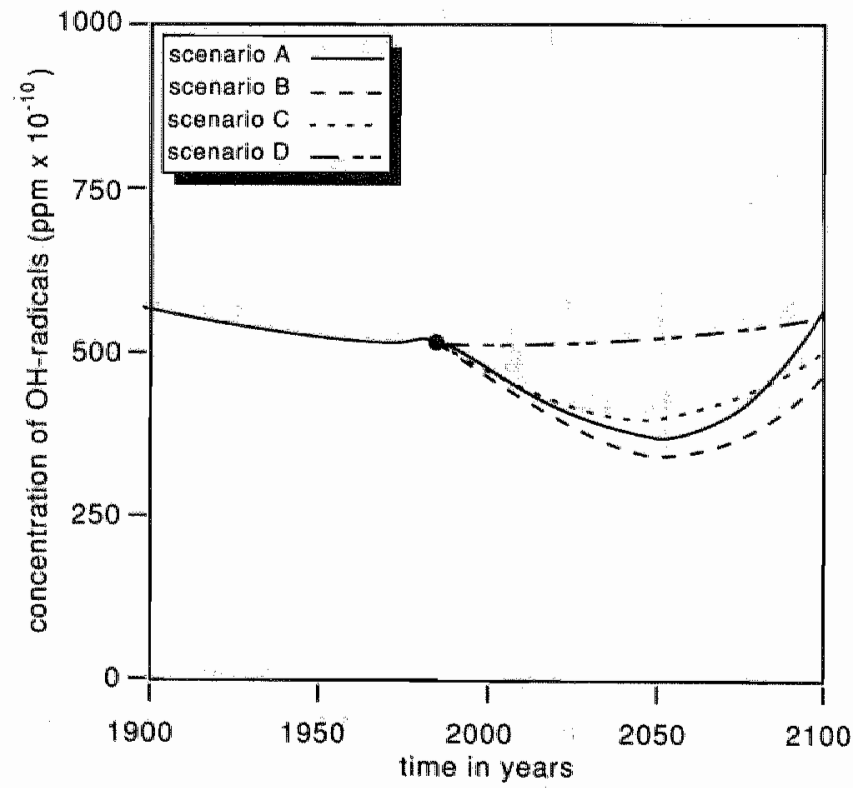

Figure 4.10: Concentration of $\mathrm{OH}$ radicals. 


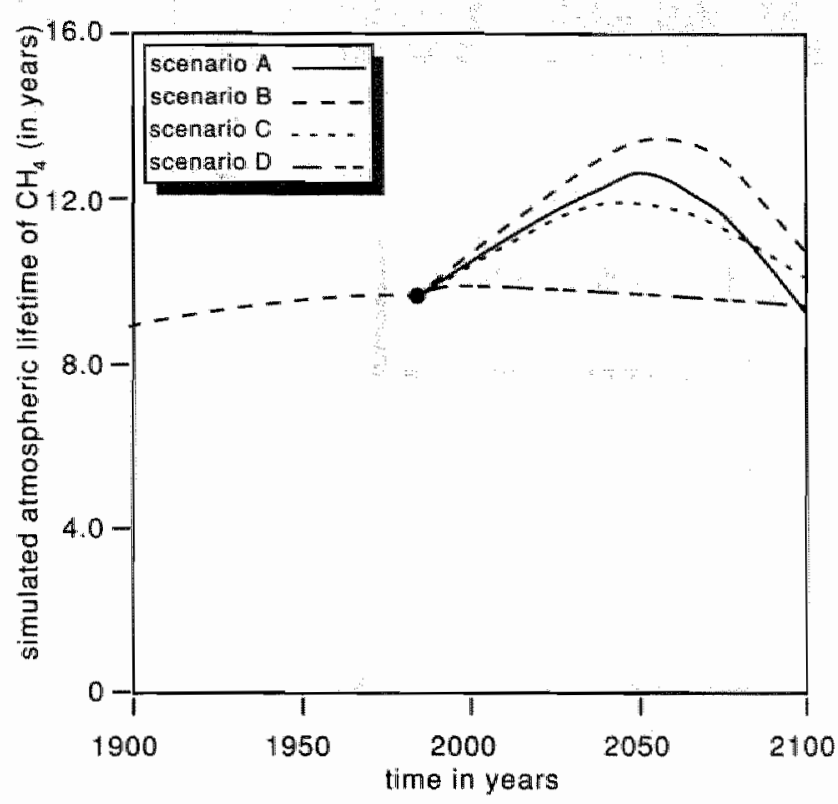

Figure 4.11: Simulated atmospheric lifetime of $\mathrm{CH}_{4}$.

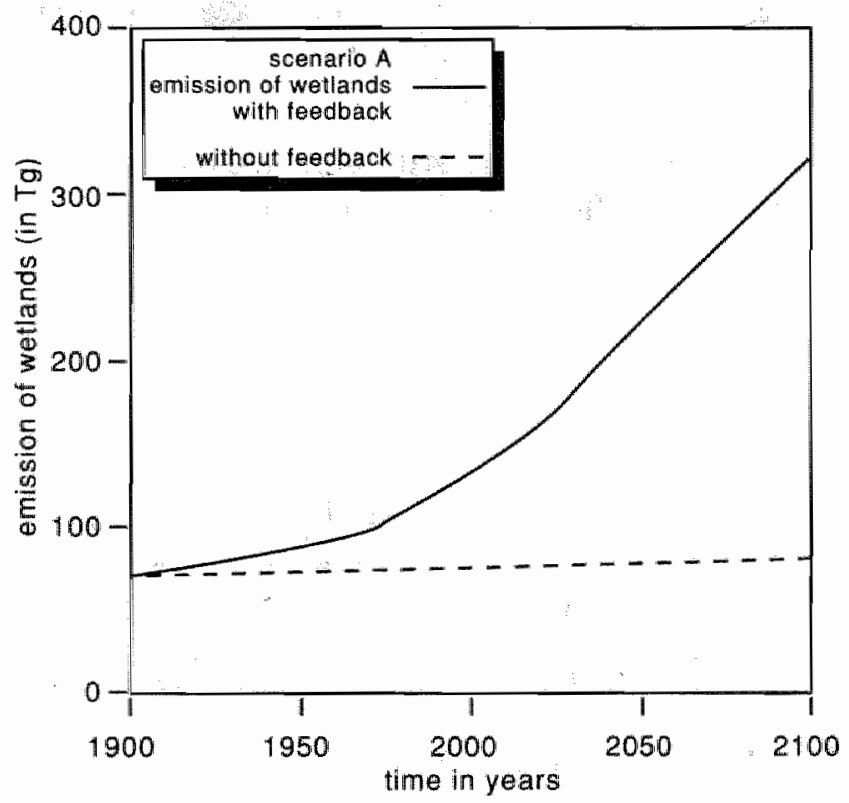

Figure 4.12: $\mathrm{CH}_{4}$ emission from wetlands with and without climate feedback. 
Figure 4.13 shows that methane concentrations might result to be about $50 \%$ higher by 2100 if this feedback would materialize.

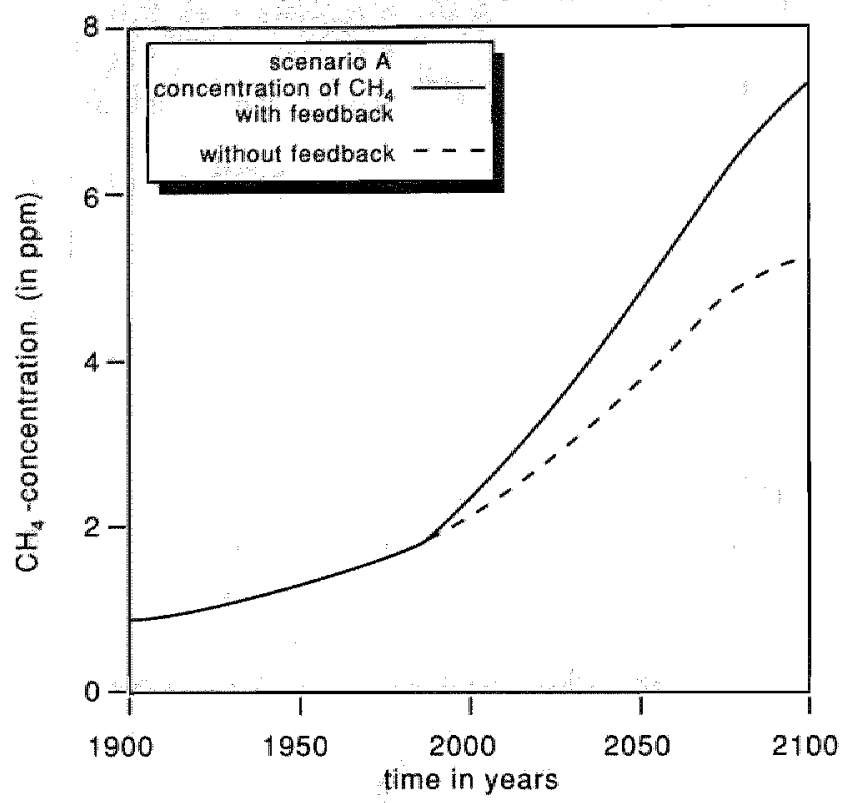

Figure 4.13 $\mathrm{CH}_{4}$ concentration for the unrestricted trends scenario (A) with and without climate feedback.

\subsection{Conclusions}

\section{Methane}

A considerable part of the sources of methane is anthropogenic in nature. At the moment the anthropogenic contribution amounts to approximately $66 \%$ and in the continuing and reduced trends ( $\mathrm{A}$ and $\mathrm{B}$ ) it is growing in the coming decades, ranging from $81 \%$ to $74 \%$ in 2050 , mainly due to the increase in coal mining, ruminants, waste disposals and biomass combustion. Only in the changing trends and forced changes (C and D) does the anthropogenic share gradually decrease to $65 \%$ and $63 \%$ in 2050 , respectively.

Unlike in the case of $\mathrm{CO}_{2}$ it may be advantageous to limit some anthropogenic methane emissions, methane being a useful gas. Examples are 
reduction of losses during fossil fuel exploitation, waste disposal and animal husbandry. This is particularly interesting, since the contribution of methane to the greenhouse effect per molecule is greater than that of $\mathrm{CO}_{2}$ and measures will quickly have an effect.

Even far-reaching environmental measures cannot prevent methane concentrations from rising during the coming century; a doubling of the methane concentration in comparison with the value in 1985 (1.7 ppm) can take place as early as the year 2040. It needs no emphasis that only forced changes can bring about a real decrease of the methane concentration.

\section{Carbon monoxide, hydrocarbons and nitrogen oxides}

Next to methane emissions, emissions of carbon monoxide and non-methane hydrocarbons strongly influence the methane concentration in the atmosphere. In the international literature the emissions of these gases have been taken to be proportional to global fossil fuel consumption or economic growth. In contrast to $\mathrm{CO}_{2}, \mathrm{CO}$ and $\mathrm{NMHC}$ are the result of incomplete combustion of fuels or inefficient use of non-energy fuel products. Preliminary scenarios have therefore been developed for this study, which take the sources into account. While $\mathrm{CO}$ and $\mathrm{NMHC}$ are useful products, it is quite possible, that emissions are reduced by increasing combustion efficiencies, reuse of emitted gas and, for $\mathrm{NMHC}$ only, reduction of evaporation losses not only for environmental, but also for economic reasons.

Emissions of carbon monoxide and NMHC from fuelwood combustion, deforestation practices and savanna burning, especially in the third world, are harder to control than fossil fuel related emissions and deserve special attention. Deforestation may not only contribute to the greenhouse effecti by direct $\mathrm{CO}_{2}$ emissions, but also indirectly, via the influence on the $\mathrm{CH}_{4}$ $\mathrm{OH}-\mathrm{CO}$ cycle.

Like methane, for carbon monoxide, hydrocarbons and nitrogen oxides, fossil fuel related emissions can be limited by other means than shifts towards non fossil fuels and fuel efficiency increases. Measures presently being introduced or developed to combat acid rain (catalysts, lean burn engines) also contribute indirectly to the prevention or delay of the greenhouse effect.

In the model increasing $\mathrm{NO}_{x}$ emissions have a decreasing influence on $\mathrm{CH}_{4}$ concentrations via $\mathrm{OH}$. The contribution of $\mathrm{NO}_{x}$ to the greenhouse effect as a precursor of the greenhouse gas ozone is not considered in this study. 


\section{General}

With the help of the developed simulation model global trends of emissions and concentrations of $\mathrm{CH}_{4}, \mathrm{CO}, \mathrm{OH}$ as well as the temperature effect of methane can be calculated. The model shows that there is no sense in a forced reduction of only the methane emissions. Even if the emissions were to be stabilized the methane concentrations would still rise, due to the interrelated influence of other trace gases like carbon monoxide and hydroxyl (by $\mathrm{NO}_{x}$ and $\mathrm{O}_{3}$ ). The sources of $\mathrm{NO}_{x}$ and $\mathrm{CO}$ are especially important.

In the model, in the second half of the 21st century the growth of the concentrations and consequently the temperature effect of $\mathrm{CH}_{4}$ reverses due to an increase in $\mathrm{OH}$ concentration. This increase is caused by a combination of stabilizing $\mathrm{CO}$ emissions and continuing $\mathrm{OH}$ production. Simulations with the $\mathrm{CH}_{4}-\mathrm{CO}-\mathrm{OH}$ cycle model, considered in this study, underline the importance of methane as a greenhouse gas.

Finally it is worth mentioning that the $\mathrm{CH}_{4}-\mathrm{CO}-\mathrm{OH}$ cycle, functioning as an internal feedback system, is a system which is critically sensitive to external perturbations. Further investigation of this system is necessary. 


\section{Chapter 5}

\section{The $\mathrm{N}_{2} \mathrm{O}$ Module}

\subsection{Introduction}

Nitrous oxide or laughing gas $\left(\mathrm{N}_{2} \mathrm{O}\right)$ is produced both naturally and artificially. This greenhouse gas is produced and consumed by biological processes in soil and water and is removed from the atmosphere much more slowly than methane. The yearly growth in the $\mathrm{N}_{2} \mathrm{O}$ emission trend varied from $0.1 \%$ at the beginning of this century to $1.3 \%$ in the last 10 years. The current average concentration of $\mathrm{N}_{2} \mathrm{O}$ is about $0.308 \mathrm{ppm}$ and is increasing at about 0.2 to 0.3 percent a year $(0.18--0.26 \%$ according to Lyon et al., 1989). For $\mathrm{N}_{2} \mathrm{O}$ a simple one-box emissions and concentration module has been implemented.

\section{2 $\quad \mathrm{N}_{2} \mathrm{O}$ Emissions Module}

We are not yet able to quantify $\mathrm{N}_{2} \mathrm{O}$ emissions. Both the anthropogenic and natural sources are subject to large uncertainty. Anthropogenic sources of $\mathrm{N}_{2} \mathrm{O}$ are strongly related to energy use (combustion of fossil fuels and biomass burning) and agriculture (nitrogen fertilizers). Although biomass burning and use of nitrogen fertilizers are the dominant sources of the anthropogenic emission of $\mathrm{N}_{2} \mathrm{O}$, other human activities also contribute to the atmospheric $\mathrm{N}_{2} \mathrm{O}$ concentration, such as acid rain and forest clearing (Marland and Rotty, 1985, Robertson and Tiedje, 1988). In the ernission module three major anthropogenic sources are taken into account: combustion of fossil fuels, biomass burning and fertilization, represented in Equation (5.1) (Marland and Rotty, 1985, van Ham, 1987, Conrad et al, 1980 and 1983, 
Crutzen, 1983, Hao et al., 1987, Kavanaugh, 1987, and Lyon et al., 1989).

$$
\mathrm{N}_{2} \mathrm{OHUM}(t)=\mathrm{N}_{2} \mathrm{OFSE}(t)+\mathrm{N}_{2} \mathrm{OBIO}(t)+\mathrm{N}_{2} O M A N(t)
$$

with:

$\mathrm{N}_{2} \mathrm{OFSE}(t)=$ Emissions of $\mathrm{N}_{2} \mathrm{O}$ by fossil fuel combustion at time $t$

$\mathrm{N}_{2} \mathrm{OBIO}(t)=$ Emissions of $\mathrm{N}_{2} \mathrm{O}$ by biomass burning at time $t$

$N_{2} O M A N(t)=$ Emissions of $\mathrm{N}_{2} \mathrm{O}$ by manure soils at time $t$

The natural emissions of $\mathrm{N}_{2} \mathrm{O}$ are primarily caused by the nutrient cycling in soils and aqueous systems. Three major natural sources are distinguished in the emission module: forest soils, other soils and oceans (Banin, 1986, Marland and Rotty, 1985, Elshout, 1989, Chamberlain et al., 1982, Keller et al., 1986, Anderson and Levine, 1987), which are given in Equation (5.2):

$$
N_{2} O N A T(t)=N_{2} O F O R(t)+N_{2} O S O I(t)+N_{2} O O C E(t)
$$

with:

$\mathrm{N}_{2} O F O R(t)=$ Emissions of $\mathrm{N}_{2} \mathrm{O}$ by forests soils at time $t$

$\mathrm{N}_{2} \mathrm{OSOI}(t)=$ Emissions of $\mathrm{N}_{2} \mathrm{O}$ by other soils at time $t$

$\mathrm{N}_{2} \mathrm{OOCE}(t)=$ Emissions of $\mathrm{N}_{2} \mathrm{O}$ by oceans at time $t$

There is little consensus as to the quantification of both the natural and anthropogenic sources of $\mathrm{N}_{2} \mathrm{O}$. Recent estimations of $\mathrm{N}_{2} \mathrm{O}$ emissions (van Ham, 1987, Lyon et al., 1989, EPA, 1989, Elshout, 1989) are much lower than earlier estimations (Chamberlain et al., 1982, Hahn, 1974, Hahn and Junge, 1977), particularly with respect to the contribution of the oceans and the combustion of fossil fuels. Lyon et al. (1989), and EPA (1989) suggest that, although nothing has been proved beyond the shadow of a doubt, combustion of fossil fuels is not a significant source of $\mathrm{N}_{2} \mathrm{O}$. Additionally the emissions by lightning can be neglected according to Hill et al. (1984), and Levine and Shaw (1983). Table 5.1 surveys the diversity of estimations of $\mathrm{N}_{2} \mathrm{O}$ emissions. 


\begin{tabular}{|c|c|c|c|c|c|c|}
\hline Bources & $\begin{array}{l}\text { Hahn } \\
\text { and } \\
\text { Junge } \\
1977\end{array}$ & $\begin{array}{c}\text { Khalil } \\
\text { and } \\
\text { Rasmussen } \\
1983\end{array}$ & $\begin{array}{c}\text { Crutzen } \\
1983\end{array}$ & $\begin{array}{l}\text { Bolle } \\
1986\end{array}$ & ${ }_{1987}^{\text {Kavanaugh }}$ & $\begin{array}{l}\text { Yan } \\
\text { Ham } \\
1987\end{array}$ \\
\hline oceans & $16-185$ & 9.0 & $1-2$ & 2 & 2 & $1-10$ \\
\hline natural soils & $6-65$ & 13.4 & - & 6 & 7.7 & $3-9$ \\
\hline $\begin{array}{l}\text { cultivated } \\
\text { solls }\end{array}$ & - & 6.6 & $1-3$ & $0.2-0.6$ & $=$ & $1-3$ \\
\hline manure soils & $6-20$ & - & $<3$ & $0.6-2.3$ & 0.8 & $0-8$ \\
\hline $\begin{array}{l}\text { biomass } \\
\text { burning }\end{array}$ & - & - & 1.2 & $1-2$ & 0.7 & $1-2$ \\
\hline $\begin{array}{l}\text { fossil fuel } \\
\text { burning }\end{array}$ & $1-4$ & - & 1.8 & 2 & 4.0 & $1-3$ \\
\hline lïghtning & $10-55$ & - & - & $<0.1$ & - & - \\
\hline Total & $39-329$ & 29.0 & $8-11$ & $12-15$ & 15.2 & $7-35$ \\
\hline
\end{tabular}

Table 5.1: Survey of global emissions in $\mathrm{TgN} / \mathrm{yr}$ of $\mathrm{N}_{2} \mathrm{O}$ from literature.

For the base year 1985 the following estimates of the anthropogenic and natural sources of $\mathrm{N}_{2} \mathrm{O}$ are incorporated into IMAGE:

1985

forest soils

manure soils

other soils

oceans

burning of biomass

burning of fossil fuels
$5.0 \mathrm{TgN} / \mathrm{yr}$

$1.5 \mathrm{TgN} / \mathrm{yr}$

$0.6 \mathrm{TgN} / \mathrm{yr}$

$2.0 \mathrm{TgN} / \mathrm{yr}$

$1.5 \mathrm{TgN} / \mathrm{yr}$

$0.5 \mathrm{TgN} / \mathrm{yr}+$

Total emissions

11.1 $\mathrm{TgN} / \mathrm{yr}$

Anthropogenic part

$3.5 \mathrm{TgN} / \mathrm{yr}$

Natural part

$7.6 \mathrm{Tg} N / \mathrm{yr}$

about $32 \%$ of total emission

about $68 \%$ of total emission

For $\mathrm{N}_{2} \mathrm{O}$ four emissions scenarios have been developed, of which the underlying assumptions are described in detail in Rotmans et al. (1990a). The highest scenario, A, unrestricted trends, assumes a large increase in $\mathrm{N}_{2} \mathrm{O}$ emission from coal use, no emission control measures, a rapid increase in fertilizer use in the third world up to European levels, an average estimate of 
anthropogenic sources and a continuing deforestation (emission from burning and a major influence of soil emissions). Scenario $B$, reduced trends, assumes, besides an increase in $\mathrm{N}_{2} \mathrm{O}$ emissions from coal consumption, a gradual increase in fertilizer use in the third world and a gradual reduction in deforestation is assumed. Scenario $\mathrm{C}$, changed trends, still assumes an increase in $\mathrm{N}_{2} \mathrm{O}$ emissions from coal consumption, a slight reduction in emission rates from fossil fuel combustion, a slow increase in fertilizer use in the third world and a major global effort towards halting deforestation. Finally, scenario $\mathrm{D}$, forced trends, is characterized by decreasing $\mathrm{N}_{2} \mathrm{O}$ emissions due to a shift towards non-fossil energy sources and implementation of $\mathrm{N}_{2} \mathrm{O}$ emission control technologies; a global program to introduce proper forest management, stop deforestation and start large scale reforestation and lastly a limited growth in fertilizer use.

\section{3 $\quad \mathrm{N}_{2} \mathrm{O}$ Concentration Module}

Although the ambient concentration of $\mathrm{N}_{2} \mathrm{O}$ is only one-thousandth that of $\mathrm{CO}_{2}, \mathrm{~N}_{2} \mathrm{O}$ is a relatively strong infrared absorber. $\mathrm{N}_{2} \mathrm{O}$ is stable in the troposphere and is destroyed in the stratosphere by photodissociation and by reaction with singlet oxygen. The sink of $\mathrm{N}_{2} \mathrm{O}$ is the most important source of $\mathrm{NO}$, which plays a major role in regulating the stratospheric ozone concentration. So an increasing $\mathrm{N}_{2} \mathrm{O}$ concentration indirectly threatens stratospheric ozone (Bolle et al., 1986, Jackman and Guthrie, 1985). $\mathrm{N}_{2} \mathrm{O}$ is removed from the atmosphere slowly, and has an average residence time of about 150 years. Estimations for the lifetime of $\mathrm{N}_{2} \mathrm{O}$ vary from $100-170$ years, most estimations agreeing upon 150-170 years. Owing to this stability and long residence time $\mathrm{N}_{2} \mathrm{O}$ is spread homogeneously all over the troposphere. In 1985 the average tropospheric $\mathrm{N}_{2} \mathrm{O}$ mixing ratio was 307.4 ppb (van Ham, 1987).

The atmospheric removal process in IMAGE is simulated by an exponentially delayed emission mechanism, described in Goodman (1974), and Rotmans (1986). The functional form of this exponentially delayed mechanism is given in Equation (5.3). Simulations with IMAGE show that the exponentially delayed emission corresponds with the removal process that is "used for CFCs; the latter process is inversely proportional to the atmospheric lifetime of $\mathrm{N}_{2} \mathrm{O}$ and is reflected by the negative exponential function $e^{-t / N L F}$, where NLF is the atmospheric lifetime of $\mathrm{N}_{2} \mathrm{O}$, determined in the $\mathrm{N}_{2} \mathrm{O}$ concentration model as 170 years. Both interpretations of the $\mathrm{N}_{2} \mathrm{O}$ 
removal process produce comparable results.

$$
\begin{aligned}
E M N D L(t)= & E M N D L(t-1)+\int_{t-1}^{t}\left[( 1 / L F T N _ { 2 } O ) * \left(E M N_{2} O(\tau)\right.\right. \\
& \left.\left.-E M N D L(\tau) / L F T N_{2} O\right)\right] d \tau
\end{aligned}
$$

with:

$E M N D L(t)=$ delayed emission of $\mathrm{N}_{2} \mathrm{O}$ at time $t$ (in $\mathrm{Tg}$ )

$L F T N_{2} \mathrm{O}=$ atmospheric lifetime of $\mathrm{N}_{2} \mathrm{O}$ (is 170 year; estimates of atmospheric lifetime of $\mathrm{N}_{2} \mathrm{O}$ vary from 120-170 year (Rotmans, 1986))

The atmospheric concentration of nitrous oxide is determined by the initial concentration, the sources and the sinks of nitrous oxide. The sources are enumerated in the emissions model description; whereas the main sink of nitrous oxide is caused predominantly by stratospheric losses, reflected by the exponentially delayed emissions mechanism, described above. This leads to the following expression for the $\mathrm{N}_{2} \mathrm{O}$ concentration.

$$
\begin{aligned}
P N_{2} O(t)= & P N_{2} O(t-1)+\int_{t-1}^{t} \llbracket C V F N_{2} O *\left(E M N_{2} O(r)\right. \\
& -E M N D L(\tau))] d r
\end{aligned}
$$

with:

$\mathrm{PN}_{2} \mathrm{O}(t)=$ concentration (mixing ratio) of $\mathrm{N}_{2} \mathrm{O}$ at time $t$ (in $p p b$ )

$\mathrm{PN}_{2} \mathrm{O}(\mathrm{O})=$ initial concentration of $\mathrm{N}_{2} \mathrm{O}, 285 p p b$ (estimates vary from 280 to $290 p p b$ (Weiss, 1981 and

Ramanathan et al., 1985)

$C V \mathrm{FN}_{2} \mathrm{O}=$ conversion factor of $\mathrm{N}_{2} \mathrm{O}$, is $0.2 \mathrm{ppb} / \mathrm{TgN}$ according to Bolle et al. (1986);

$E M N_{2} O(t)=$ emission of $\mathrm{N}_{2} \mathrm{O}$ at time $t$ (in $\mathrm{TgN} / \mathrm{yr}$ )

$E M N D L(t)=$ delayed emissions of $\mathrm{N}_{2} \mathrm{O}$ at time $t$ (in $\left.T g N / y r\right)$

\subsection{Results}

In Figure 5.1 a breakdown of the emissions of $\mathrm{N}_{2} \mathrm{O}$ for a particular year is given for the different scenarios. Figure 5.2 gives the total emissions of $\mathrm{N}_{2} \mathrm{O}$ for the different scenarios. These $\mathrm{N}_{2} \mathrm{O}$ emissions scenarios are considerably lower than those described in Rotmans et al., (1990a), due to more recent moderate estimates of fossil fuels combustion and soils emissions. 
The global $\mathrm{N}_{2} \mathrm{O}$ concentration, resulting from the emissions scenarios of Figure 5.2, is given in Figure 5.3. Due to the long atmospheric lifetime of this gas all emission scenarios lead to an increase of the concentrations. Because of this aspect nitrous oxide appears to become increasingly important.

\subsection{Conclusions}

Simulation experiments with IMAGE show that in the long run $\mathrm{N}_{2} \mathrm{O}$ will becorne a greenhouse gas of great importance. Even the most optimistic $\mathrm{N}_{2} \mathrm{O}$ emissions scenario, with nearly stabilizing emissions till 2100 , leads to an increasing $\mathrm{N}_{2} \mathrm{O}$ concentration, which in turn will bring about a rise in temperature. Clearly, policy measures can at least affect the pace with which atmospheric $\mathrm{N}_{2} \mathrm{O}$ will increase.

In any case, because of the uncertainty about the various sources, both natural and anthropogenic, additional research is needed to improve our knowledge of the sources and the validity of measurement techniques.

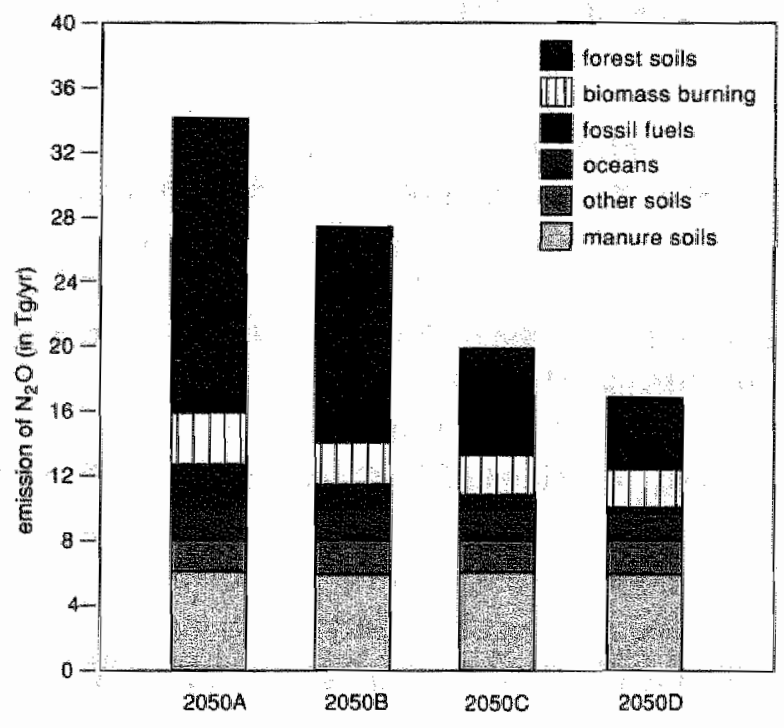

Figure 5.1: Breakdown of the $\mathrm{N}_{2} \mathrm{O}$ emissions for the year 2050 . 


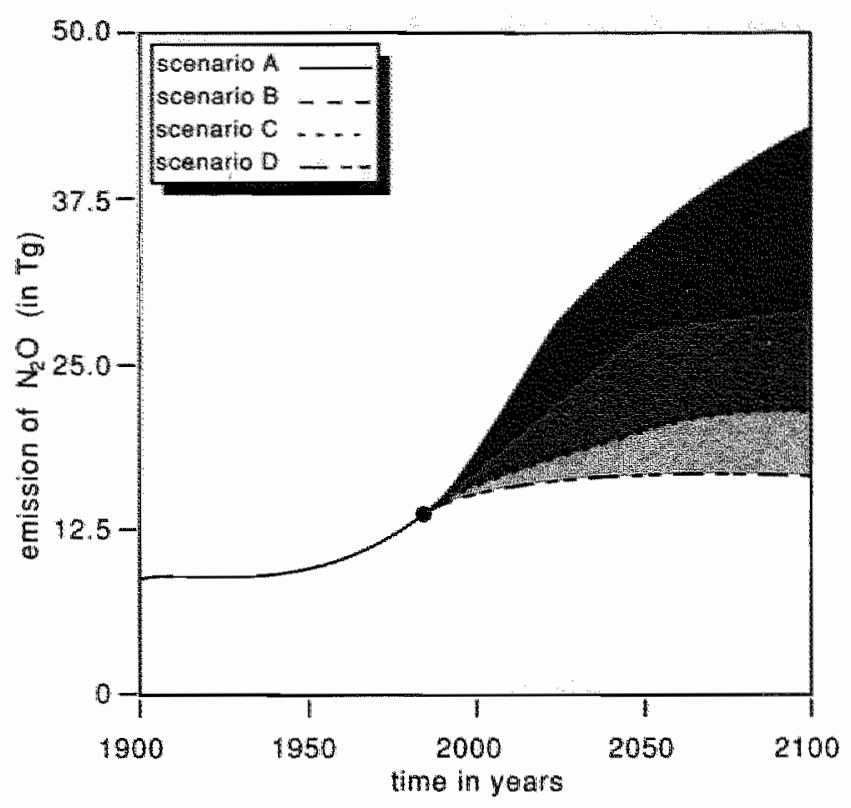

Figure 5.2: Emission of $\mathrm{N}_{2} \mathrm{O}$.

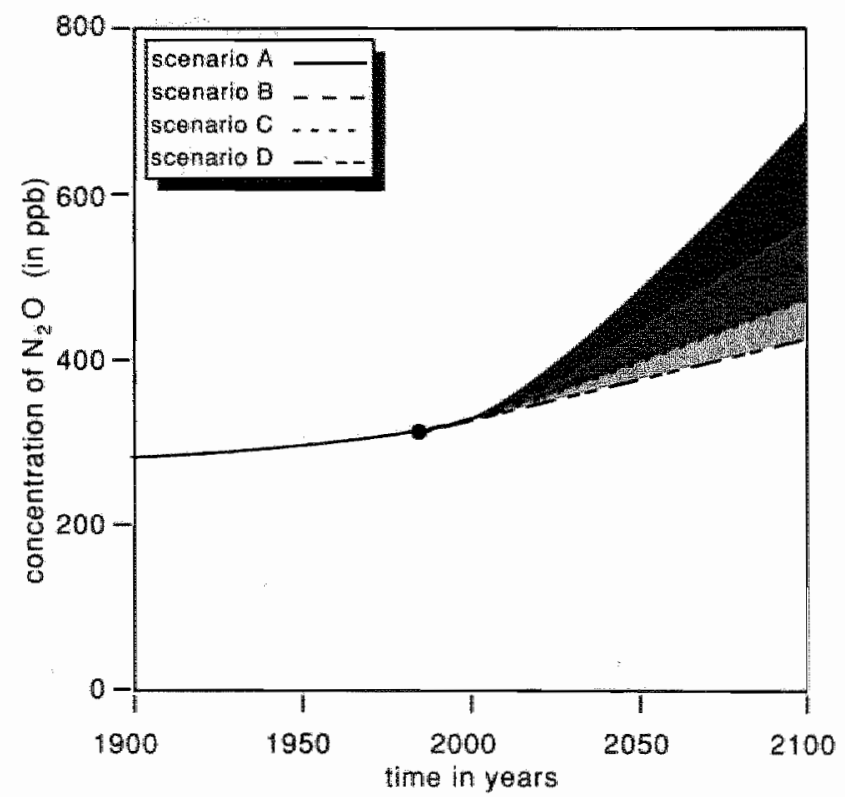

Figure 5.3: Concentration of $\mathrm{N}_{2} \mathrm{O}$. 


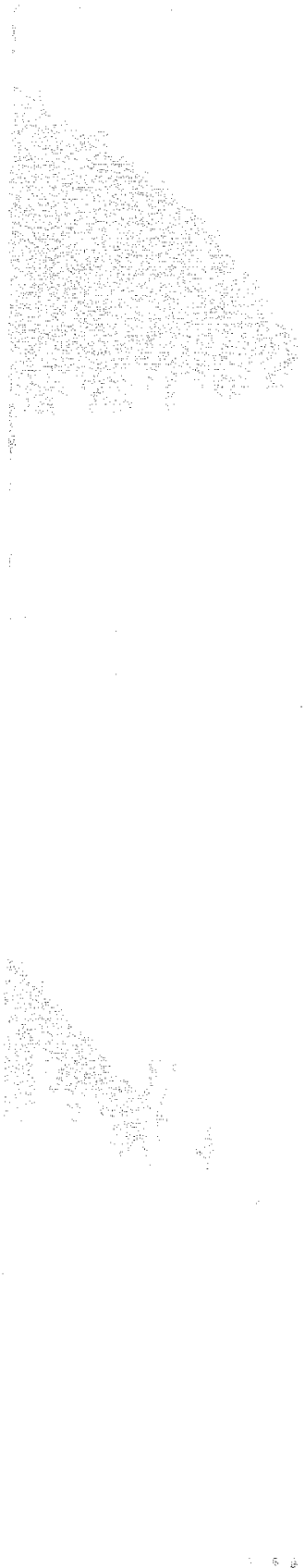




\section{Chapter 6}

\section{The CFCs Module}

\subsection{Introduction}

In the early seventies chlorofluorocarbons, or CFCs, were identified as substances with a strong potential for the depletion of the ozone layer. In the mid eighties the Antarctic ozone hole was discovered, and scientific evidence was found that CFCs, under specific meteorological circumstances, were responsible for this phenomenon. Therefore, in 1987, the Montreal Protocol came into force, implying the regulation of the main chlorofluorocarbons and halons. The regulating mechanism includes an ultimate freeze of $50 \%$ in 2000 , whereas developing countries are allowed to increase their production, and not all ozone depleting substances are regulated.

The CFCs emissions module of IMAGE provides estimates of emissions of the most important chlorofluorocarbons, CFC-11 and CFC-12. Although dozens of chlorofluorocarbons are currently being produced and emitted to the atmosphere, $\mathrm{CFC}-11$ and $\mathrm{CFC}-12$ are the dominant species.

Recently the module has been extended with other CFCs (especially CFC-113, CFC-114 and CFC-115), halons, methylchloroform and carbontetrachloride (Den Elzen et al., 1990b and c). Future production of CFCs is triggered by policy assumptions rather than economic developments and demographic trends. The CFC concentrations module is a two box model based on Wigley. (1988).

With this simple CFC two box model the effect of the Montreal Ozone Protocol on future concentrations of CFCs are calculated and evaluated. 


\subsection{CFCs Emissions Module}

Historical production figures of CFC-11 and CFC-12 are gathered by the Chemical Manufacturers Association (CMA, 1987). In Figures 6.1 and 6.2 historical production numbers of CFC-11 (from 1931) and $\mathrm{CFC}-12$ (from 1939) are given. These numbers contain many imponderables (Rotmans, 1986). The model disaggregates production of CFCs into four major categories of end use, partly based on Gamlen et al.(1986): aerosols and open cell foams, closed cell foams, hermetically and non-hermetically sealed refrigerators. For these four categories manufacturing losses, direct emissions and delayed emissions are calculated.

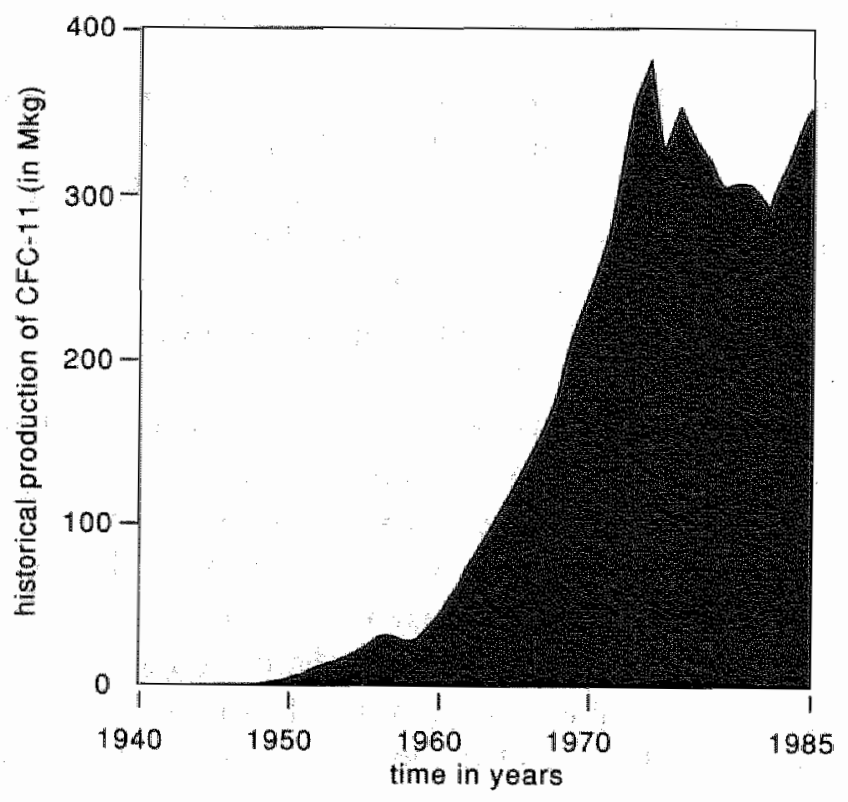

Figure 6.1: Historical production of CFC-11. 


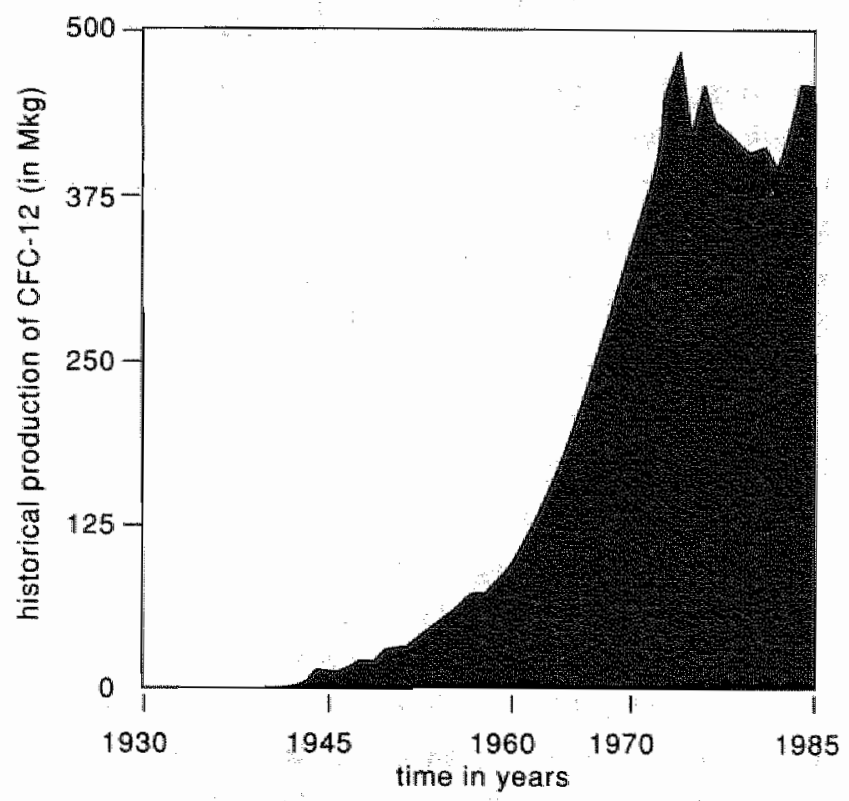

Figure 6.2: Historical production of CFC-12.

The subdivision of chlorofluorocarbons into end use categories is described by the following equation:

$$
P R D(t)=S_{\text {aroc }}(t)+S_{c c}(t)+S_{h s r f r}(t)+S_{n h s r f r}(t)
$$

with:

$P R D(t)=$ production of CFC at time $t$ (in $M \mathrm{kgCFC}$ )

$S_{\text {aroc }}(t)=$ sales of aerosols and open cell foams at time $t$ (in $M \mathrm{kgCFC}$ )

$S_{c e}(t)=$ sales of closed cell foams at time $t$ (in $M k g C F C$ )

$S_{h \text { frr }_{r}}(t)=$ sales of hermetically sealed refrigerators at time $t$ (in $M k g$ CFC)

$S_{n h a r f r}(t)=$ sales of non-hermetically sealed refrigerators at time $t$ (in $M k g C F C$ )

Equation (6.1) only holds for countries which report to the CMA. The uncertainties in the production data from the CMA reporting companies are 
probably not more than $\pm 0.5 \%$ (Gamlen et al., 1986). For other countries (non CMA-participating countries which produce CFCs, like the USSR, China, India and Argentina) the estimated range of uncertainties is much larger. This causes an uncertainty in cumulative release figures for all CFC producing countries of about $4 \%$ for CFC-11 and about $2.8 \%$ for CFC-12 according to Gamlen et al. (1986). For the non-reporting countries only a distinction is made between aerosols and non-aerosols. The historical production of the non-reporting countries is known for the period 1965-1975, while for the period 1975-1986 an annual growth of $8 \%$ is supposed. Future production for the period $1986-2100$ is presumed to follow the scenarios for the CMA reporting countries, which are described below.

Four CFC use scenarios have been distinguished, see Rotmans et al. (1990a). In the unrestricted trends (A) scenario it is assumed that the Montreal protocol (United Nations Environment Program, 1987) is not fully implemented: production and use will be increasing, albeit at a moderate rate, and will stabilize in the first half of the 21 st century.

In the reduced trends (B) scenario the Montreal protocol is supposed to be implemented by linearly decreasing the production towards the limits set for $1993(80 \%)$ and $1998(50 \%)$, followed by stabilization after 1999 . The allowed growth of planned production is not taken into account because of a lack of data. The objectives are reached by turning to substitutes, limiting losses and gradually increasing recycling.

In the changed trends (C) scenario the basic protocol is upgraded to a limit of $15 \%$ of the 1986 production and consumption figures for 1998, after which annual production and consumption are assumed to stabilize. No additional production capacity is built, since this seems to be useless under these circumstances. The efforts towards the development of 'safe" substances, recycling and loss reduction are increased.

In the forced trends (D) scenario a total phase-out is assumed in 2050 in addition to the $85 \%$ reduction in the changed trends scenario (C). A possibly remaining use for purposes considered to be essential is neglected. The CFC emissions are split up into prompt emissions and delayed emissions. The prompt CFC emission is composed of fugitive emission, aerosol and open cell foam emission, closed cell foam emission, refrigerator emission and nonCMA reported emissions. Each end use category has a different lifetime, represented in the model by specific fractions. These constants are empirically based on the lifetime of the different products, which is less than 1 year for aerosols and open cell foams, about 4 years for closed cell foams, about 4 years for non-hermetically sealed refrigerators and about 12 years 
for hermetically sealed refrigerators (Gamlen et al., 1986).

Not all the CFC-11 and CFC-12 manufactured is sold. Some is lost immediately during the production process, with no delay between production and release. These fugitive emissions are estimated to be $2 \%$ of CFC-11 production and $3.3 \%$ of CFC-12 production (CMA, 1983). The following equation is used to estimate the prompt emissions of CFCs:

$$
\begin{aligned}
E M C F C(t)= & E M_{f u g}(t)+P R D_{\text {aroc }}(t) \\
& +A L F C C F * P R D_{\text {ccf }}(t) \\
& +A L F R F N * P R D_{\text {nhsr } f r}(t)+A L F R F H * P R D_{h s r f r}(t) \\
& +P R D_{\text {aronc }}(t)+A L F O C * P R D_{\text {naronc }}(t)
\end{aligned}
$$

with:

$E M C F C(t)=$ emission of CFCs at time $t$ (in $M k g$ )

$E M_{f u g}(t)=$ fugitive emission of CFCs

$P R D_{\text {aroc }}(t)=$ production of CFCs by aerosols and open cell foams at time $t$

$A L F C C F=$ fraction of closed cell foams production released to the atmosphere (equivalent to the inverse average life time of closed cell foams, $1 / 4$ )

$P R D_{c c f}(t)=$ production of CFCs by closed cell foams at time $t$

$A L F R F N=$ fraction of non-hermetically sealed refrigerators released to the atmosphere (inverse average lifetime of nonhermetically sealed refrigerators, is $1 / 4$ )

$P R D_{n h a r f r}(t)=$ production of CFCs by non-hermetically sealed refrigerators time $t$

$A L F R F=$ fraction of hermetically sealed refrigerators released to the atmosphere (only for CFC-12, is $1 / 12$ )

$P R D_{h s r f r}(t)=$ production of CFCs by hermetically sealed refrigerators at time $t$

$P R D_{\text {aronc }}(t)=$ not CMA reported production of CFCs by aerosols at time $t$

$A L F O C=$ average fraction of not CMA reported production of $\mathrm{CFCs}$ by non-aerosol applications released to the atmosphere (is $1 / 4$ )

$P R D_{\text {naronc }}(t)=$ not CMA reported production of CFCs by non-aerosol applications at time $t$ 
Besides prompt emissions of CFCs the model also contains delayed emissions, accounting for the fraction of production of CFCs that does not immediately escape into the atmosphere. These delayed emissions are modelled by a delayed-release box according to Wigley (1988):

$$
\begin{aligned}
D L E M C F(t)= & D L E M C F(t-1)+\int_{t-1}^{t}[1-A L F R F N) * P R D_{n h s f r}(\tau) \\
& +(1-A L F R F H) * P R D_{h a r f r}(\tau) \\
& +(1-A L F C C F) * P R D_{c c f}(\tau) \\
& +(1-A L F O C) * P R D_{\text {naronc }}(\tau) \\
& -C F C B E T * D L E M C F(\tau)] d(\tau)
\end{aligned}
$$

with:

$D L E M C F(t)=$ delayed emission of CFCs (in $M k g$ )

$D L E M C F(0)=$ delayed emission at time $t=0$, in 1931, and is 0

$C F C B E T=$ annual fraction that leaks from the delayed release box into the atmosphere box; calibrated on historical data, is 0.08 for CFC-11 and 0.15 for $\mathrm{CFC}-12$ )

\subsection{CFCs Concentrations Module}

The concentration model used is a simple representation of the complicated atmospheric chemistry and comprises a second box which is directly linked to the delayed emissions box. The removal process of CFCs is assumed to be inversely proportional to the atmospheric lifetime of CFCs, the latter being constant. Estimates for lifetimes of CFCs are given in Bolle et al. (1986), Cunnold et al. (1983a and 1983b), Ramanathan et al. (1985) and Wigley (1988): they are 75 years for CFC-11 with a range of uncertainty 50-107 years, and 125 years for CFC-12 with a range of uncertainty $65-400$ years. The tropospheric concentration of CFCs is determined by the initial concentration of CFCs, their emissions and their removal. CFCs are assumed to be removed from the atmosphere due to stratospheric loss only and in proportion to their concentration. Then the fraction of CFCs remaining at time $t$ is reflected by the negative exponential function $e^{-t / L F T C F C}$, where LFTCFC is the atmospheric lifetime of CFCs.

The global tropospheric concentration is then calculated as follows: 


$$
\begin{aligned}
P C F C(t)= & P C F C(t-1)+\int_{t-1}^{t}[(C V F C F C * E M C F C(\tau) \\
& -P C F C(\tau) / L F T C F C \\
& +C V F C F C * C F C B E T * D L E M C F(\tau)] d(\tau)
\end{aligned}
$$

with:

$P C F C(t)=$ tropospheric concentration of CFCs at time $t$ (in ppt)

$P C F C(0)=$ initial tropospheric concentration of $\mathrm{CFCs}_{\text {, is }} 0$

$C V F C F C=$ conversion factor of CFCs (in ppt/Mkg) is $0.047 \mathrm{ppt} /$ $M k g \mathrm{CFC}-11$ and is $0.050 \mathrm{ppt} / \mathrm{Mkg} \mathrm{CFC}-12$, according to Chamberlain et al. (1982)

$\operatorname{EMCFC}(t)=$ emission of CFCs at time $t$ (in $M \mathrm{~kg} / \mathrm{yr}$ )

$L F T C F C=$ atmospheric lifetime of CFCs (75 year for CFC-11 and 125 year for CFC-12, assumed to be constant

$D L E M C F(t)=$ delayed emission of CFCs (in $M k g / y r$ )

$C F C B E T=$ annual fraction that leaks from the delayed release box into the atmosphere box; calibrated on historical data, is 0.08 for CFC-11 and 0.15 for CFC-12)

\subsection{Results}

Figures 6.3 and 6.4 shows these production scenarios for $\mathrm{CFC}-11$ and $\mathrm{CFC}$ 12, respectively. These production scenarios are somewhat higher than those given in Rotmans et al. (1990a). Additionally, production scenarios for another controlled CFC is represented, CFC-113. CFC-113 is widely used as a solvent in the electronics industry.

Historical production numbers of CFC-113 are derived from GEMS (1989), and for the period 1986-1990 a growth factor of 7.6 percent annually is used (Hammitt et al., 1986). Figure 6.5 represents the CFC-113 production scenarios. 


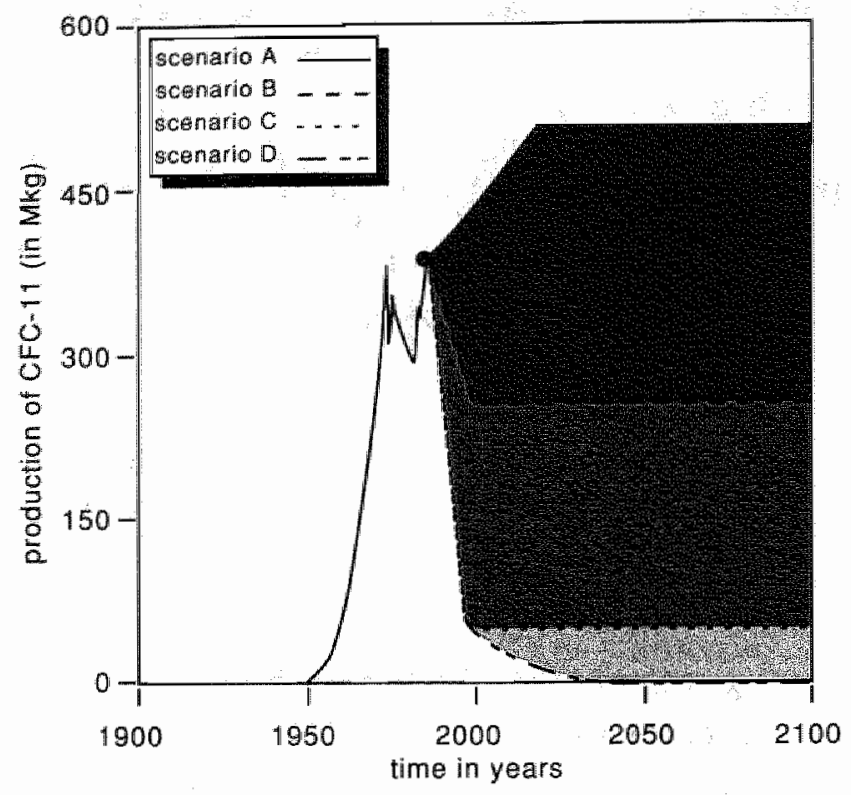

Figure 6.3: Production of CFC-11.

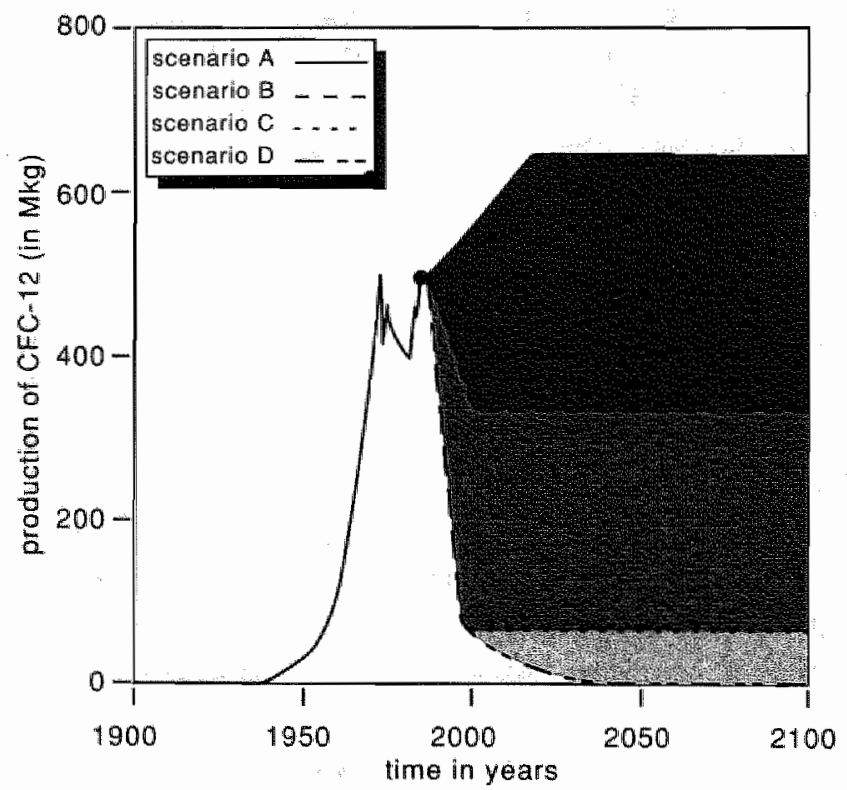

Figure 6.4: Production of CFC-12. 


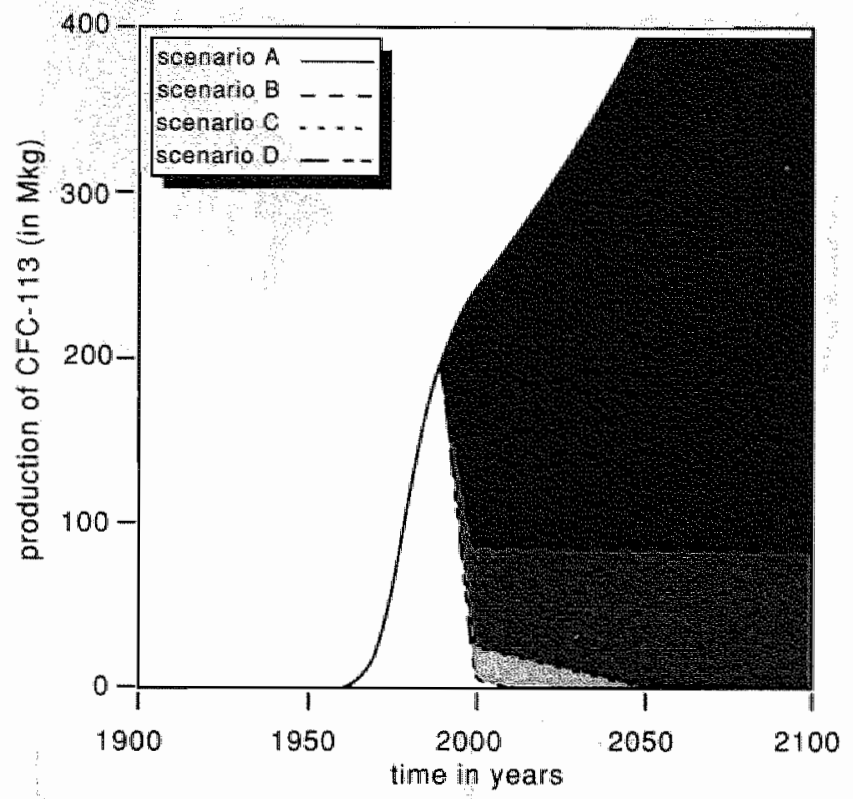

Figure 6.5: Production of CFC-113.

Figures 6.6 and 6.7 give the concentrations for $\mathrm{CFC}-11$ and $\mathrm{CFC}-12$, respectively. Although the influence is undeniable, the UNEP Ozone Protocol cannot prevent CFC-11 and CFC-12 concentrations from increasing over the next decades.

Only by upgrading the Montreal Protocol (scenario $\mathrm{C}$, the changed trends) the concentrations of CFC-11 and CFC-12 can be maintained at the present level. Figure 6.8 gives the concentration of $\mathrm{CFC}-113$. In spite of control by the Montreal Protocol scenario A yields a concentration value in 2100 of more than 20 times the 1985 concentration value. Only scenarios $C$ and D lead to concentrations in 2100 that are comparable with that of 1985 .

These results may therefore even be considered to be optimistic. Due to the long atmospheric lifetime of $\mathrm{CFCs}$ still further reduction of emissions (scenario D, the forced trends) is needed to lower CFC concentrations in the second half of the next century. 


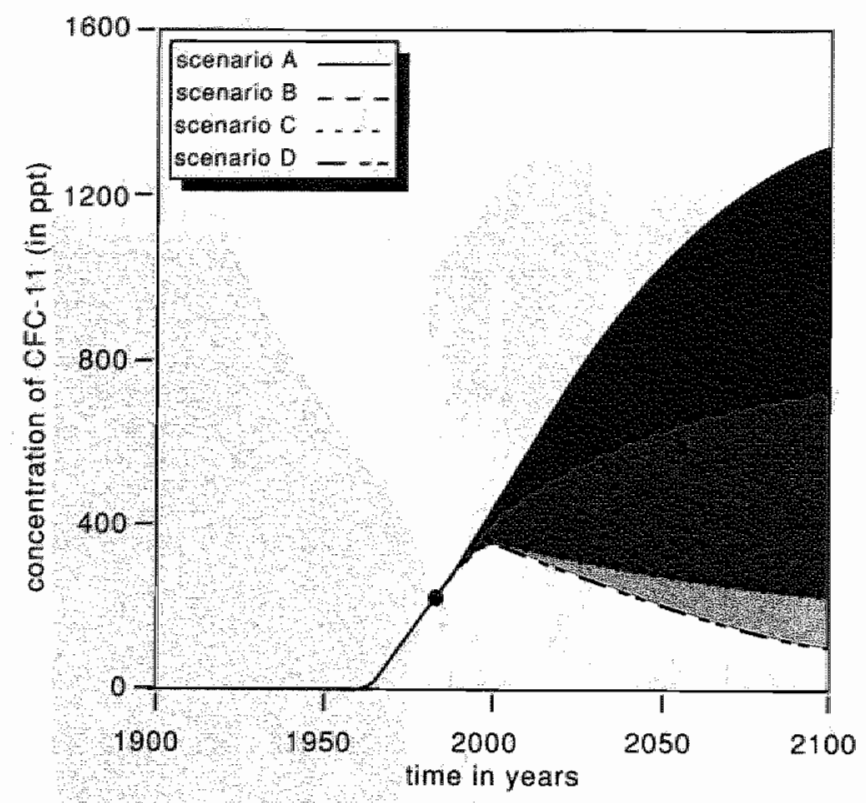

Figure 6.6: Concentration of CFC-11.

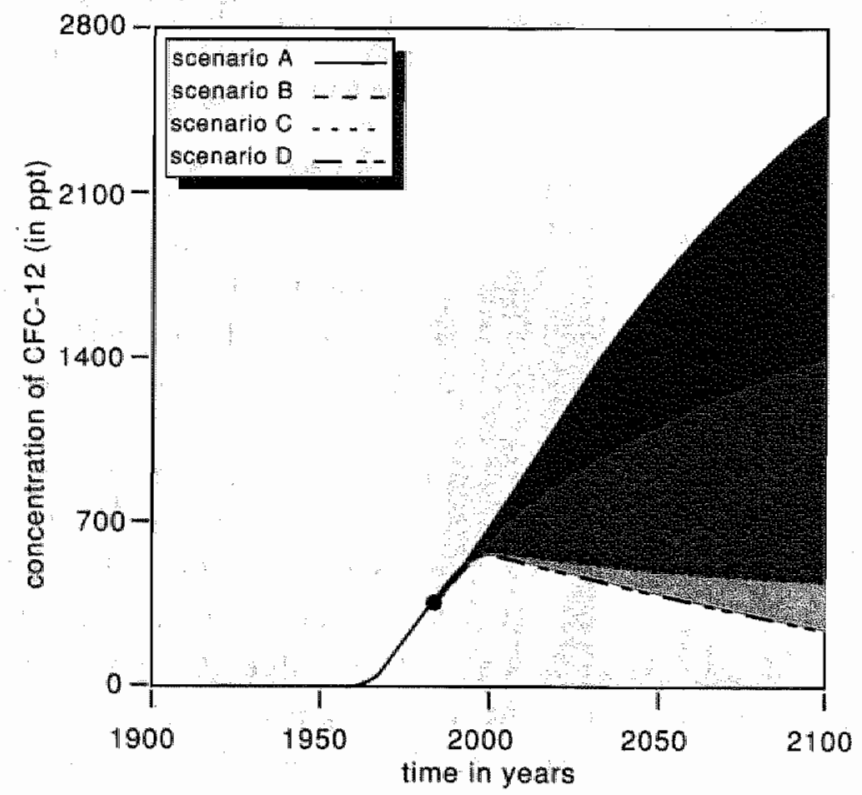

Figure 6.7: Concentration of CFC-12. 


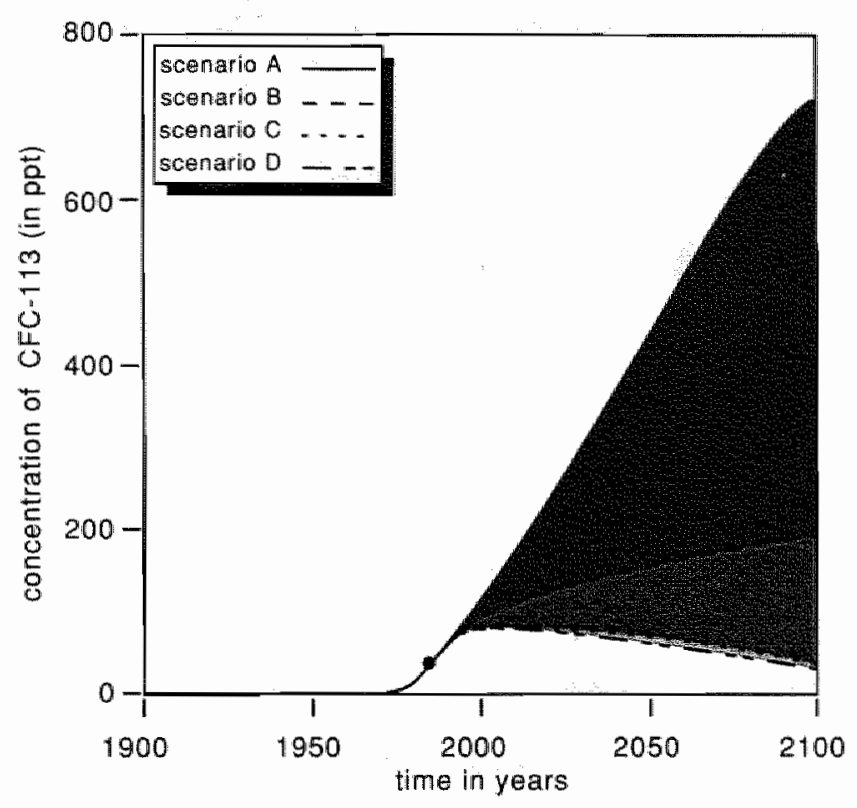

Figure 6.8: Concentration of CFC-113.

\subsection{Conclusions}

In light of simulation results with IMAGE it can be concluded that the effect of the implementation of the Montreal Ozone Protocol is important to stabilize the relative role of $\mathrm{CFCs}$ in the greenhouse effect and is a significant step forward. However under the present Protocol conditions CFC concentrations can still increase considerably. To eliminate the role of CFCs in the greenhouse effect it is necessary to strongly upgrade the ozone agreement of Montreal. 


\section{Chapter 7}

\section{The Climate Module}

\subsection{Introduction}

The very complex climate system involves transfers of energy between the atmosphere and land surface, oceans, biomass and cryosphere. Our present understanding of this climate system is still not satisfactory. Climate models try to consider the primary processes, radiation, dynamics and surface processes, and their interactions within the climate system (Shine and Henderson-Sellers, 1983, Dickinson, 1986). Climate modelling has developed rapidly in recent decades. A broad range of such climate models have been developed, varying from simple zero-dimensional to elaborate three dimensional models (Hasselman, 1988, and Washington and Parkinson, 1986). Generally four climate model types may be are distinguished:

1. Energy Balance Models (EBM): EBMs predict the change in temperature at the earth's surface resulting from a change in heating based on the requirement that the net flux of energy does not change. The largest limitation of EBMs is that they do not have a physically based model of the atmosphere (Schlesinger, 1985);

2. Radiative Convective Models (RCM): RCMs compute the vertical (usually globally averaged) temperature structure of the atmosphere from the balance between radiative heating or cooling and the vertical heat flux; Because RCMs are only "average" models of the global climate system, the quantitative model results of RCMs strongly depend upon the assumptions (cloud feedback, surface albedo) and therefore are not very reliable (Shine and Henderson-Sellers, 1983, Schlesinger, 1986); 
3. Two-dimensional statistical dynamical (SD) models mostly combines the latitudinal dimension of the energy balance models with the vertical dimension of the radiative-convective models. A set of statistics is used to represent the wind speeds and directions. Although they provide insight into the complex climate system, their use in climate prediction is rather limited because of the lack of zonal resolution (HendersonSellers and Verstraete, 1987);

4. General Circulation Models (GCM): GCMs calculate the changes in atmospheric dynamics, without the restriction of explicit spatial averaging. Because the full three-dimensional nature of the atmosphere is resolved, trying to represent all important physical processes, GCMs are the most sophisticated models currently available. These models have a horizontal resolution of several hundred kilometers. The two major problems of GCMs are the limits upon computer time and adequate data sets (Schlesinger, 1985, Shine and Henderson-Sellers, 1983). A further distinction is often drawn between oceanic general circulation models (OGCMs) and atmospheric general circulation models (AGCMs). Coupled atmosphere-ocean general circulation models (A/O GCMs) have a coarse resolution and are very costly to run. In addition only a very small number of simulations have been performed with these models (Harvey, 1989a).

In Figure 7.1 these different types of climate models are represented by the climate modelling pyramid. The higher its position up the pyramid the more complex a climate model is and the greater are the interactions between the primary processes radiation, dynamics and surface processes.

In spite of their deficiencies simple climate models are very useful. On the one hand they enhance insight in the intricate climate processes and are a tool for interpreting more detailed models, while on the other their flexibility compared to more elaborate models, allows wide variation in parameter values (Dickinson, 1986). IMAGE uses a one-dimensional energy balance model, based on Wigley and Schlesinger (1985), which will be discussed in this chapter. 

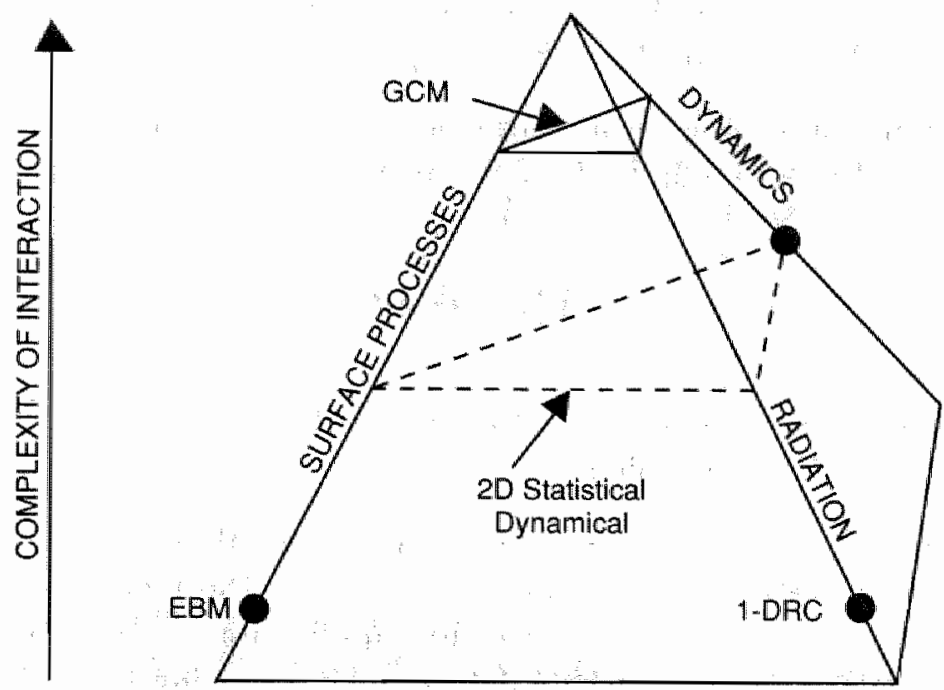

Figure 7.1: The climate modelling pyramid (from Shine and Henderson-Sellers, 1983).

\subsection{Model Description}

\subsubsection{Equilibrium Response}

The simplest useful climate model which can be written is (Dickinson, 1986):

$$
C_{m} * \frac{d \Delta T}{d t}=\Delta Q-\lambda * \Delta T
$$

with:

$C_{m}=$ effective heat capacity of the earth (in $W \cdot y / m^{2} \cdot{ }^{\circ} \mathrm{C}$ )

$\Delta T^{\top}=$ change in global surface temperature from some climatological value (in ${ }^{\circ} \mathrm{C}$ )

$\Delta Q=$ perturbation in the energy flux to the surface (in $W / m^{2}$ ) 
$\lambda=$ climate sensitivity parameter $\mathrm{LAMBDA} ; \lambda=\frac{\Delta F}{\Delta T}-\frac{\Delta S}{\Delta T}$, where $F$ and $S$ respectively denote the global mean emitted infrared and net downward solar fluxes at the top of the atmosphere. Thus $\lambda$ represents a change in climate due to a given radiative forcing $\Delta Q . \lambda$ itself depends on the integrated effect of a number of feedback processes involving clouds, surface albedo, and the atmospheric vertical temperature and humidity structure (in $W / m^{2}{ }^{\circ} \mathrm{C}$ ).

In equilibrium, supposing an instantaneous response of global temperature to external radiative forcing, the first term is zero, yielding the following equation, which is modelled in IMAGE:

$$
\Delta T_{e}=\Delta Q / l
$$

with:

$\Delta T_{e}=$ the change of the global mean surface temperature (in ${ }^{\circ} \mathrm{C}$ ) in the equilibrium phase

This equilibrium temperature is induced by the radiative perturbation (forcing) of the surface-troposphere system, caused by the increase in trace gas concentrations. In order to calculate this equilibrium temperature increase the total radiative forcing must be determined. Knowing the different trace gas concentrations for $\mathrm{CO}_{2}, \mathrm{CH}_{4}, \mathrm{~N}_{2} \mathrm{O}, \mathrm{CFC}-11$ and CFC-12, the radiative forcing can be calculated. To estimate the total change in radiative forcing at the tropopause $(\Delta Q)$ induced by the trace gases, the total forcing is modelled as follows (Wigley, 1985, 1987):

$$
\Delta Q=\Delta Q_{C O_{2}}+\Delta Q_{C H_{4}}+\Delta Q_{N_{2} O}+\Delta Q_{C F C-11}+\Delta Q_{C F C-12}
$$

with:

$\Delta Q$ $\Delta Q_{\mathrm{CO}_{2}}, \Delta Q_{C \mathrm{H}_{4}}, \Delta Q_{\mathrm{N}_{2} \mathrm{O}}$ $\triangle Q_{C F C-11}, \triangle Q_{C F C-12}=$ change in radiative forcing by $\mathrm{CO}_{2}, \mathrm{CH}_{4}$, $\mathrm{N}_{2} \mathrm{O}, \mathrm{CFC}-11$ and $\mathrm{CFC}-12$ (in $\mathrm{W} / \mathrm{m}^{2}$ )

Following Wigley (1987) the relationship between change in radiative forcing and change in concentration is assumed to be linear at low concentrations, square root at intermediate values and logarithmic at high concentrations. Approximately this yields a logarithmic relation for $\mathrm{CO}_{2}$, a square root relation for $\mathrm{CH}_{4}$ and $\mathrm{N}_{2} \mathrm{O}$, and a linear relation for the CFCs. According to Ramanathan et al. (1979) the following approximate relation holds for $\mathrm{CO}_{2}$ : 


$$
\Delta Q_{C O_{2}}=\left(\Delta Q_{2 x C O_{2}} / \operatorname{Ln}(2)\right) * \operatorname{Ln}\left(p C O_{2} / p C O_{2} i n\right)
$$

with:

$\Delta Q_{2 x \mathrm{CO}_{2}}=$ radiative forcing for a doubled $\mathrm{CO}_{2}$ concentration; is $4.3 \mathrm{~W} / \mathrm{m}^{2}$ according to Ramanathan et al., 1985, and Hansen et al., 1988

$\mathrm{pCO}_{2}=$ atmospheric $\mathrm{CO}_{2}$ concentration (in ppm) $\mathrm{pCO}_{2}$ in $=$ pre-industrial atmospheric $\mathrm{CO}_{2}$ concentration, in 1900 (in ppm)

Augustsson and Ramanathan (1977) state that this relation is valid only for $\mathrm{CO}_{2}$ concentrations within the interval between the present and four times the present $\mathrm{CO}_{2}$ concentration. For $\mathrm{CH}_{4}$, the change in radiative forcing is estimated to be proportional to the square root of the concentrations of $\mathrm{CH}_{4}$ and $\mathrm{N}_{2} \mathrm{O}$, whereas the proportionality constant 0.0398 (in $W /\left(m^{2} \cdot p p b\right)$ ) is based on model results of Kiehl and Dickinson (1987):

$$
\Delta Q_{C H_{4}}=0.0398 *\left(\sqrt{p C H_{4}}-\sqrt{p C H_{4}} i n\right)
$$

with:

$p \mathrm{CH}_{4}=$ atmospheric $\mathrm{CH}_{4}$ concentration (in $p p b$ )

$p C H_{4} i n=$ pre-industrial atmospheric $\mathrm{CH}_{4}$ concentration, in 1900 (in $\left.p p b\right)$

This relation is fitted with the Kiehl-Dickinson model over the range 700 $p p b$ to $3100 p p b$. In IMAGE this relation is also used for $\mathrm{CH}_{4}$ concentrations falling outside this range. However, this seems to be permitted in light of the fact that the radiative forcing functions are probably accurate to about $10 \%$ (Wigley, 1987). For $\mathrm{N}_{2} \mathrm{O}$ a square root relationship is supposed as well, following Ramanathan et al. (1985):

$$
\Delta Q_{N_{2} O}=0.105 *\left(\sqrt{p N_{2} O}-\sqrt{p N_{2} O i n}\right)
$$

with:

$p \mathrm{~N}_{2} \mathrm{O}=$ atmospheric $\mathrm{N}_{2} \mathrm{O}$ concentration (in $p p r n$ )

$p \mathrm{~N}_{2} \mathrm{O}$ in $=$ pre-industrial atmospheric $\mathrm{N}_{2} \mathrm{O}$ concentration, in 1900 (in ppm)

For $\mathrm{CFC}-11$ and $\mathrm{CFC}-12$ a linear relation is used, with linear proportionality constants of Ramanathan et al. (1985): 


$$
\Delta Q_{C F C-11}=0.27 * p C F C-11
$$

with:

$p C F C-11=$ atmospheric $\mathrm{CFC}-11$ concentration (in $p p m$ )

$$
\triangle Q_{C F C-12}=0.31 * p C F C-12
$$

with:

$p C F C-12=$ atmospheric CFC-12 concentration (in ppm)

Following Wigley (1985) and Tricot and Berger (1987) an equivalent $\mathrm{CO}_{2}$ concentration can be defined, including the combined radiative forcing of all these trace gases $\left(\mathrm{CO}_{2}, \mathrm{CH}_{4}, \mathrm{~N}_{2} \mathrm{O}, \mathrm{CFC}-11\right.$ and $\mathrm{CFC}-12$ ). This $\mathrm{CO}_{2}$ equivalent concentration expresses the total effect of all trace gases compared to the effect of $\mathrm{CO}_{2}$ alone. Using Equation (7.4) the equivalent $\mathrm{CO}_{2}$ concentration can be defined as:

$$
\Delta Q=\left(\Delta Q_{2 x \mathrm{CO}_{2}} / \operatorname{Ln}(2)\right) * \operatorname{Ln}\left(p \mathrm{CO}_{2} e q / p C \mathrm{O}_{2}\right)
$$

with:

$p \mathrm{CO}_{2} e q=\mathrm{CO}_{2}$ equivalent concentration (in ppm)

Substituting Equation (7.3) in this relation yields the following expression: $p C O_{2} e q=p C O_{2} * e^{\left[\ln (2) / \Delta Q_{2 x} C O_{2} *\left(\Delta Q_{C H_{4}}+\Delta Q_{N_{2} O}+\Delta Q_{C F O-11} \Delta Q_{O F O-12}\right)\right]}$

with:

$\mathrm{pCO}_{2} e q$

$\mathrm{pCO}_{2}$

$\triangle Q_{2 x C O_{2}}$

$\Delta Q_{C H_{4}}+\Delta Q_{N_{2} O}+$

$\Delta Q_{C F C-11}+\triangle Q_{C F C-12}=$ radiative forcing, resulting from changes in $\mathrm{CH}_{4}, \mathrm{~N}_{2} \mathrm{O}, \mathrm{CFC}-11$, and CFC-12 concentration (in $W / m^{2}$ )

Equation (7.10) can be expressed in another way:

$=\mathrm{CO}_{2}$ equivalent concentration (in $p p m$ )

$=$ atmospheric $\mathrm{CO}_{2}$ concentration (in $p p m$ )

$=$ radiative forcing for a doubled $\mathrm{CO}_{2}$ concentration (in $W / m^{2}$ ) 


$$
p \mathrm{CO}_{2} e q=p C \mathrm{O}_{2} \text { in } * e^{\left[\left(\operatorname{Ln}(2) / \Delta Q_{23} \mathrm{CO}_{2} * \Delta Q\right)\right.}
$$

with:

$\mathrm{pCO}_{2}$ in $=$ pre-industrial $\mathrm{CO}_{2}$ concentration (in ppm)

$\Delta Q=$ total radiative forcing, caused by changes in concentrations of all trace gases, as defined in Equation (7.3) (in $\mathrm{W} / \mathrm{m}^{2}$ )

The $\mathrm{CO}_{2}$ equivalent concentration, as expressed in (7.10) and (7.11), defines a $\mathrm{CO}_{2}$ concentration of which the radiative forcing is as large as the combined effect of the trace gases $\mathrm{CO}_{2}, \mathrm{CH}_{4}, \mathrm{~N}_{2} \mathrm{O}, \mathrm{CFC}-11$ and $\mathrm{CFC}-12$. In the framework of the Intergovernmental Panel on Climate Change (IPCC) the $\mathrm{CO}_{2}$ equivalent concentration functions as a target indicator, as shown in Chapter 9.

\subsubsection{Transient Response}

The reconstructed global mean temperature increase from 1900 to 1985 indicates a warming effect of $0.5--0.7^{\circ} \mathrm{C}$ (Schlesinger, 1986, Wigley, 1987, and Hansen et al., 1988). However, climate model calculations show a global mean equilibrium temperature increase which is about twice as much. A main contributor to this difference is supposed to be the phenomenon that the actual transient (delayed) response of the climate systems lags the equilibrium response because of the thermal inertia of the ocean (Schneider and Thompson, 1981). Also other factors might offset the greenhouse effect on global mean temperature, such as the internal climate variability, variations of solar radiation, aerosols and albedo changes (IPCC, 1990). The transient temperature effect can be calculated with an energy balance box-diffusion model, based on Wigley and Schlesinger (1985). This climate rnodel includes a land box, an ocean box and atmosphere boxes over land and ocean. The basic equation of the energy balance model is the following:

$$
C_{m} * \frac{d \Delta T}{d t}=\Delta Q-\lambda * \Delta T-\Delta F
$$

with:

$C_{m}=$ bulk heat capacity of the ocean mixed layer (in $W \cdot y / m^{2} \cdot{ }^{o} \mathrm{C}$ )

$\Delta T=$ change in temperature of the ocean mixed layer (in ${ }^{\circ} \mathrm{C}$ )

$\Delta Q=$ perturbation in the energy flux to the surface (in $W / m^{2}$ )

$\lambda=$ climate sensitivity parameter, see Equation (7.1)

$\Delta F=$ change in heat flux at the bottom of the mixed layer (in $W / m^{2}$ ) 
The $\Delta F$ can be calculated by the following equation:

$$
\Delta F^{\prime \prime}=-C_{m} * D I F F / D *\left[\frac{\delta \Delta T_{0}}{\delta z}\right]_{z=0}
$$

with:

$\Delta F=$ change in heat flux at the bottom of the mixed layer (in $\mathrm{W} / \mathrm{m}^{2}$ )

$C_{m}=$ effective heat capacity of the mixed ocean layer; (in $W \cdot y / m^{2} \cdot{ }^{\circ} \mathrm{C}$ ) is estimated as (7.4) W.y/ $\mathrm{m}^{2}{ }^{\circ}{ }^{\circ} \mathrm{C}$, based on Wigley and Schlesinger (1985)

$D I F F=$ diffusion coefficient; is $4000 \mathrm{~m}^{2} / \mathrm{yr}$, based on Goudriaan and Ketner (1984); varies in the literature from about 3700 or 6000 $\mathrm{m}^{2} / y r$, according to Hoffman (1984), see Chapter 2 (in $\mathrm{m}^{2} / y r$ )

$D \quad=$ depth of the mixed layer of the ocean (in $\mathrm{m}$ )

$\Delta T_{o}=$ change in temperature of the deep ocean (in ${ }^{\circ} \mathrm{C}$ )

$z \quad=$ depth below the bottom of the mixed layer (deep ocean) (in $m$ )

The $\Delta T_{0}$ is determined by the following diffusion equation:

$$
\frac{\delta \Delta T_{0}}{\delta t}=D I F F * \frac{\delta^{2} \Delta T_{0}}{\delta z^{2}}
$$

with the boundary conditions $\Delta T_{0}=\Delta T$ when $z=0$, and $\Delta T_{0}=0$ when $z$ goes to infinity. While Wigley and Schlesinger (1985) give an approximate analytical solution $\Delta T_{0}$, in the climate model of IMAGE the delayed temperature effect is calculated in two ways. The first solution is the numerical approach, where the partial differential equation is solved by writing it in a discrete way. The second solution involves an analytical approach, following Wigley and Schlesinger (1985). Only the numerical approach will be discussed here. Equation (7.13) is therefore written as:

$$
\Delta F=-C_{m} * D I F F / D *\left(\frac{\Delta T_{0}(1)-\Delta T^{2}}{\Delta z}\right)
$$

with:

$\Delta F=$ change in heat flux at the bottom of the mixed layer (in $W / \mathrm{m}^{2}$ )

$\Delta T_{0}(1)=$ change in temperature of first deep ocean layer $\left({ }^{\circ} \mathrm{C}\right)$

$\Delta T=$ change in temperature of the ocean mixed layer (in ${ }^{\circ} \mathrm{C}$ )

$\Delta z=$ thickness of a certain deep ocean layer (in $m$ )

while Equation (7.14) is written as:

$$
\begin{gathered}
\frac{d \Delta T_{0}(i)}{d t}=D I F F *\left(\frac{\Delta T_{0}(i-1)-2 * \Delta T_{0}(i)+\Delta T_{0}(i+1)}{\Delta z^{2}}\right) \\
i=1, \ldots, n-1
\end{gathered}
$$


with:

$\Delta T_{0}(i)=$ change in temperature in deep ocean layer $i, i=1, \ldots, n-1$ with $\Delta T_{0}(n)=0$

In matrix-notation:

$\left[\begin{array}{c}\Delta T_{0}(1) \\ \vdots \\ \vdots \\ \vdots \\ \vdots \\ \vdots \\ \vdots \\ \Delta T_{0}(n)\end{array}\right]=D I F F / \Delta z^{2} *\left[\begin{array}{ccccccc}1 & -2 & 1 & 0 & \ldots & 0 & \Delta T_{0}(0) \\ 0 & 1 & -2 & \mathbb{1} & \ldots & 0 & \Delta T_{0}(\mathbb{1}) \\ 0 & \ldots & \ldots & \ldots & \ldots & \ldots & \Delta T_{0}(2) \\ \ldots & \ldots & \ldots & \ldots & \ldots & \ldots & \cdots \\ \ldots & \ldots & \ldots & \ldots & \ldots & \ldots & \ldots \\ \ldots & \ldots & \ldots & \ldots & \ldots & \ldots & \ldots \\ \ldots & \ldots & \ldots & 1 & -2 & 1 & \Delta T_{0}(n-1) \\ 0 & 0 & \ldots & \ldots & \ldots & 0 & 0\end{array}\right]$

Then the temperature change of the atmosphere over land can be calculated. Assuming that the temperature change of the atmosphere over the ocean equals the temperature change in the mixed ocean layer, the surface-air temperature change can be expressed as (Wigley and Schlesinger, 1985)

$$
\Delta T_{s a}=\frac{\mathrm{f} \lambda \Delta T_{e q}+k \Delta T}{\mathrm{f} \lambda+k}
$$

with:

$\Delta T_{s a}=$ change in surface-air temperature $\left({ }^{\circ} C\right)$, which in the following is called transient air temperature

$\Delta T_{e q}=$ change in equilibrium temperature $\left({ }^{\circ} \mathrm{C}\right)$

$\Delta T=$ change in temperature of the ocean mixed layer $\left({ }^{\circ} \mathrm{C}\right)$

f $\quad=$ fraction of the global covered by land

$\lambda=$ climate sensitivity parameter, see Equation (7.1) $\left(W / m^{2}{ }^{\circ} \mathrm{C}\right)$

$k=$ coefficient that represents the heat transfer between land and ocean.

This model fully parameterizes the exchange of heat between the different boxes.

Concerning the ocean box, a more elaborate version with diffusion and upwelling, has been implemented, based on Michael et al. (1981). Simulation results with this model cannot yet be presented. 
In order to obtain a stable solution, the following stability requirement must hold:

$$
(D I F F * \Delta t) / \Delta z^{2} \leq 0.5
$$

with:

$D I F F=$ diffusion coefficient; is $4000 \mathrm{~m}^{2} / \mathrm{yr}$, as stated above (in $\mathrm{m}^{2} / \mathrm{yr}$ ).

$\Delta t=$ simulation time step (in $y r$ )

$\Delta z=$ thickness of a deep ocean layer (in $m$ )

Taking a $\Delta z$ value of 100 meter, and DIFF $=4000$, then $\Delta t$ must be less tham 1.25 year. This is in line with the general simulation time step of 0.5 year for the whole simulation program (see Chapter 2). Presuming a simulation time step of 0.5 year, the minimum thickness value appears to be about 63 meter. Otherwise a $\Delta z$ value of about 15 meter, as taken by Hoffman et al. (1983), requires a maximum simulation time step of about 0.03 year (or 10 days).

A number of simulation experiments have been made with $\Delta z$ varying from 15 to 200 meters. It appeared that, by choosing a $\Delta z$ value of 25 meters, the numerical solution approximates the analytical solution. The simulation time step must then at any rate be less then 0.078 year, but simulation experiments showed a time step of $1 / 20$ year to be necessary and sufficient to get a stable solution, and to approximate the analytical solution.

The disadvantage of such a small time step is the huge amount of computer time it requires. Following Spelman and Manabe (1984), who suggest that, on a time scale of several decades, only the deep layer down to 1000 meters will be warmed up, resulting in a mixed ocean layer of 75 meters and a deep layer of 925 meters, the deep ocean layer is divided into 37 layers of 25 meters each.

The thermal diffusivity is assumed to be constant (although it is dependent on depth and temperature), and is used as a substitute for complex circulation processes that transport heat. This may lead to an overestimation of downward heat transport (Hoffman et al., 1983). To investigate the role of the diffusion coefficient a sensitivity analysis has been performed with a range of diffusion coefficients used, 3700 to $6000 \mathrm{~m}^{2} / \mathrm{yr}$. Additionally extreme values, falling outside this used range, are even possible, due to the temperature dependence of the thermal diffusivity coefficient. In this way a temperature increase may induce extreme values of the thermal diffusion coefficient. Various simulation experiments have been performed with different values of the thermal diffusivity, which are presented in the results section. 
The ratio $\Delta T / \Delta T_{e q}$ (with $T$ the delayed or transient temperature effect, and $T_{e q}$ the equilibrium temperature effect) is a measure of the degree of equilibrium. In equilibrium phase $\Delta T / \Delta T_{e q}$ is 1 , while deviation from 1 indicates a disequilibrium phase (in the results section the ratio $\Delta T / \Delta T_{e q}$ is plotted for different scenarios). The ocean surface response time (time to reach $1-e^{-1}$ of equilibrium response) is strongly dependent on the climate feedback factor $\lambda$ (Hansen et al., 1985).

\subsubsection{Climate Feedbacks}

One of the largest gaps in our knowledge of the greenhouse problem concerns the climate feedback mechanism, often specified by the climate feedback factor or, equivalently, by the equilibrium $\mathrm{CO}_{2}$ doubling temperature change. A doubling of the $\mathrm{CO}_{2}$ concentration, taking no account of feedbacks, would cause a global mean surface temperature increase of about $1.2^{\circ} \mathrm{C}$, according to various model calculations (Schlesinger, 1986, Schuurmans et al., 1982). However, taking feedback mechanisms into account, a doubling $\mathrm{CO}_{2}$ temperature increase lies in the range $1.5--4.5^{\circ} \mathrm{C}$. This wide range is caused by the many uncertainties about feedback mechanisms in the climate system, often pointed to as the climate sensitivity. Kellog (1983) distinguishes five climate feedback loops, of which three are considered as positive and two as negative.

Following Lashof (1989), feedbacks can be subdivided into geophysical and biogeochemical feedbacks. The most important geophysical feedbacks are the water vapor feedback factor, the cloud feedback, and the ice and snow feedback. In contrast to these feedbacks, which are involved in current climate models, the biogeochemical feedbacks have not yet been taken up in these models.

Major biogeochemical feedbacks are the release of methane hydrates, changes in ocean chemistry, and changes in the vegetation albedo. Lashof (1989) tries to quantify the gain from the biogeochemical feedbacks, which is about $0.05-0.29$, compared with $0.17-0.77$ for the geophysical feedbacks. Table 7.1 gives an overview of the various feedbacks:

One has to be very careful with adding all these contributions in Table 7.1, because of the different time scales of the separate feedbacks. Apart from this, the given total gain is only indicative, because the sum of the separate feedback gains does not equal to the total gain. Clearly, more research is urgently needed to reduce the wide range of climate sensitivities. 
GEOPHYSICAL FEEDBACK

GAIN

\begin{tabular}{lcr}
\hline Water Vapor & 0.39 & $(0.28-0.52)$ \\
Ice and Snow & 0.12 & $(0.03-0.21)$ \\
Clouds & 0.09 & $(-0.12-0.29)$ \\
Sub-Total & 0.64 & $(0.17-0.77)$
\end{tabular}

BIOGEOCHEMICAL FEEDBACK

\begin{tabular}{lcr}
\hline Methane Hydrates & 0.10 & $(0.01-0.20)$ \\
Tropospheric Chemistry & -0.04 & $-(0.01-0.06)$ \\
Ocean Chemistry & 0.008 & \\
Ocean Eddy-Diffusion & 0.02 & \\
Ocean Biology \& Circulation & 0.06 & $(0.00-0.10)$ \\
Vegetation Albedo & 0.05 & $(0.00-0.09)$ \\
Vegetation Respiration & 0.01 & $(0.00-0.03)$ \\
$\mathrm{CO}_{2}$ Fertilization & -0.02 & $-(0.01-0.04)$ \\
Methane from Wetlands & 0.01 & $(0.003-0.015)$ \\
Methane from Rice & 0.006 & $(0.00-0.01)$ \\
Electricity Demand & 0.001 & $(0.00-0.004)$ \\
Sub-Total & 0.16 & $(0.05-0.29)$ \\
Total & 0.80 & $(0.32-0.98)$
\end{tabular}

Table 7.1: Estimated gain from geophysical and biogeochemical feedbacks, from Lashof (1989).

\subsection{Results}

As mentioned before the feedback parameter remains a crucial source of uncertainty, resulting in a wide range of $1.5--4.5^{\circ} \mathrm{C}$ for the global $\mathrm{CO}_{2}$ doubling equilibrium temperature rise $\left(\Delta T_{2 x \mathrm{CO}_{2}}\right)$. Therefore simulation results will be presented for different values of $\Delta T_{2 x \mathrm{CO}_{2}}$, viz. $\Delta T_{2 x \mathrm{CO}_{2}}=2.0,3.0$ and $4.0^{\circ} \mathrm{C}$.

The results of combined calculations, as shown in Figure 7.2, are quite surprising. Choosing a value of $3.0^{\circ} \mathrm{C}$ for $\Delta T_{2 x \mathrm{CO}_{2}}$, even with the most restrictive emissions scenarios a $2.0{ }^{\circ} \mathrm{C}$ increase of the equilibrium temperature will occur before 2020. Actually for 1985 a global equilibrium temperature increase of $1.4{ }^{\circ} \mathrm{C}$ has been simulated, which is in line with other models (Dickinson, 1986, Wigley, 1987). Double the amount of $\mathrm{CO}_{2}$ in scenario $\mathrm{A}$ results in an increase of $3.0^{\circ} \mathrm{C}$ in about 2050 , while the total effect then of all trace gases is a $5.0^{\circ} \mathrm{C}$ increase. 


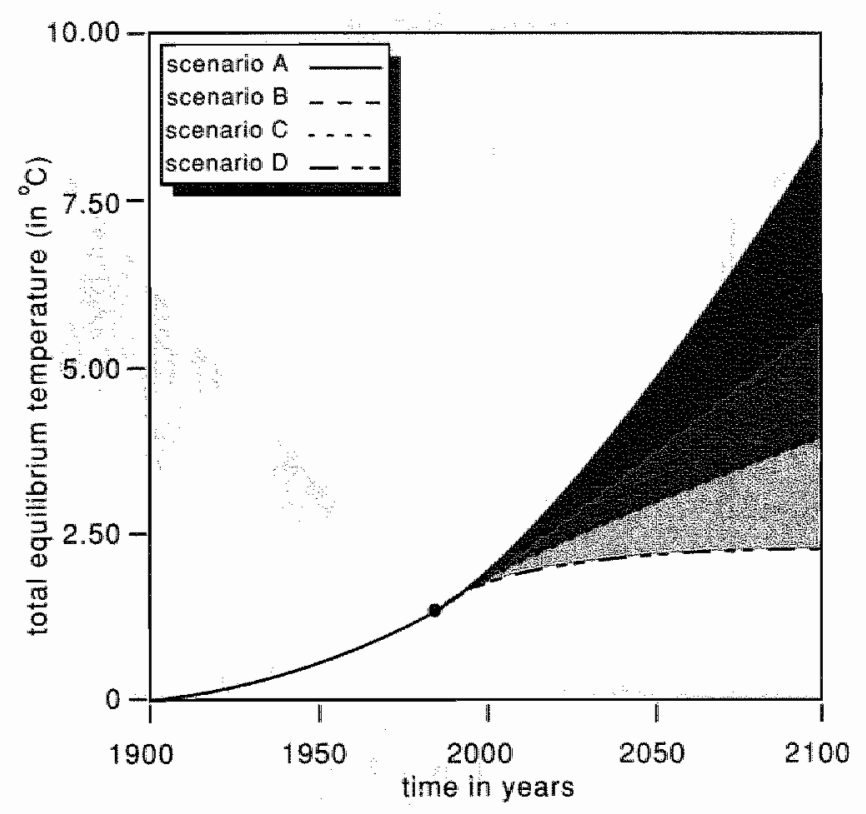

Figure 7.2: Global mean equilibrium temperature increase for different scenarios, with $\Delta T_{2 x \mathrm{CO}_{2}}=3.0^{\circ} \mathrm{C}$.

Figure 7.3 shows the resulting combined equilibrium temperature response, but then with $\Delta T_{2 x C O_{2}}=2.25^{\circ} \mathrm{C}$. This figure yields a global equilibrium temperature increase of $4.0^{\circ} \mathrm{C}$ in case of doubling the $\mathrm{CO}_{2}$ concentration. 


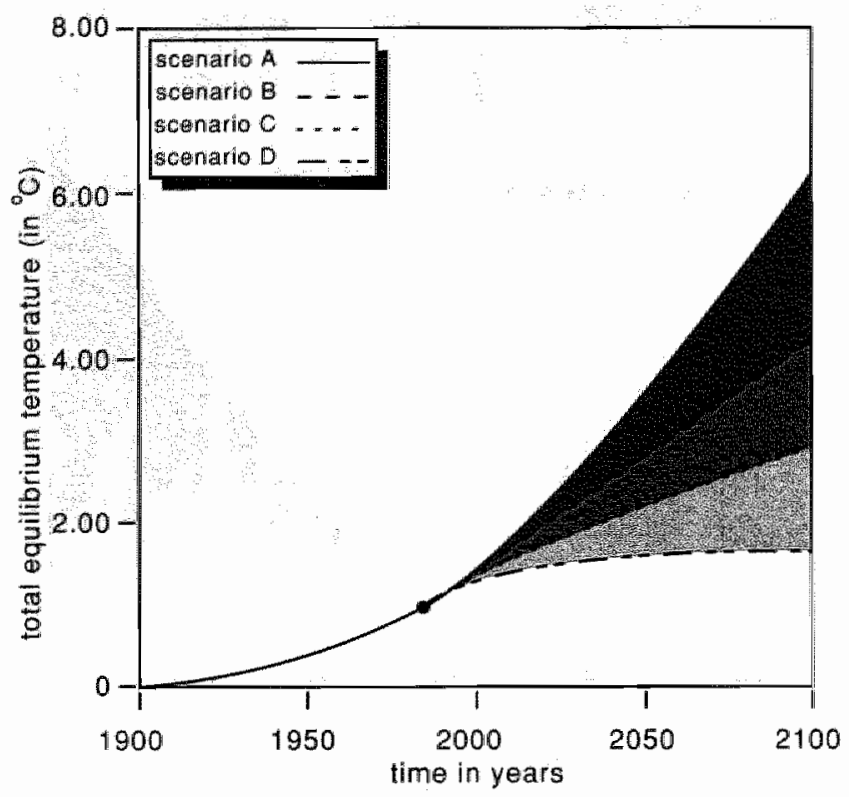

Figure 7.3: Global mean equilibrium temperature increase for different scenarios, with $\Delta T_{2 x \mathrm{CO}_{2}}=2.25^{\circ} \mathrm{C}$.

Figure 7.4 shows the global equilibrium temperature increase for the unrestricted trends scenario, for $\Delta T_{2 x \mathrm{CO}_{2}}$ values of $2.0,3.0$ and $4.0^{\circ} \mathrm{C}$ respectively. Choosing a climate sensitivity $\left(\Delta T_{2 x \mathrm{CO}_{2}}\right)$ of 2.0 or $4.0^{\circ} \mathrm{C}$ gives a difference in total equilibrium temperature rise of more than $4.0^{\circ} \mathrm{C}$ in the year 2100 , again stressing the importance of the varied climate sensitivity. 


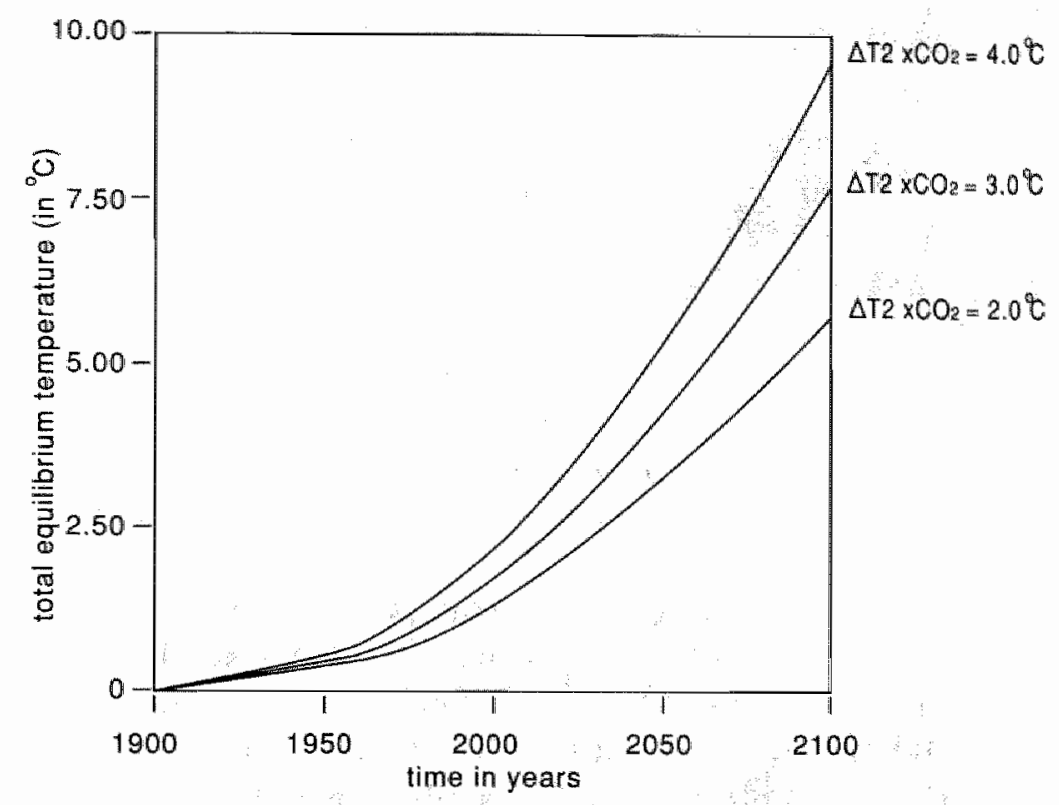

Figure 7.4: Global mean equilibrium temperature increase for the unrestricted trends scenario, for $\mathrm{CO}_{2}$ doubling temperature increase values of $2.0,3.0$ and $4.0^{\circ} \mathrm{C}$, respectively.

The global transient temperature response is represented in Figure 7.5. For 1985 a transient response is simulated of $0.6^{\circ} \mathrm{C}$, which corresponds with measured global mean temperature rises, varying from 0.5 to $0.7^{\circ} \mathrm{C}$ (Schlesinger, 1986, Wigley, 1987, and Hansen et al. 1988). For 2100 the transient temperature response varies from about $5{ }^{\circ} \mathrm{C}$ for the unrestricted trends scenario (A) to about $1.5^{\circ} \mathrm{C}$ for the forced trends scenario (D).

In Figure 7,6 the equilibrium and transient air temperature response over the period 1900-1985 are both depicted. The total equilibrium response in 1985 is about $1.4^{\circ} \mathrm{C}$, while the transient response in 1985 is about $0.6{ }^{\circ} \mathrm{C}$. From this figure it follows that more than half of the expected global warming effect has not yet been realized, given a sensitivity (or $\Delta T_{2 x \mathrm{CO}_{2}}$ ) of $3.0^{\circ} \mathrm{C}$. 
In Figure 7.7 both the equilibrium and transient response are depicted, for a moderate scenario, a changed trends scenario, leading to an equilibrium temperature difference of about $1.3^{\circ} \mathrm{C}$.

Figure 7.8 gives both the surface air transient and ocean mixed layer temperature response. In particular, until 2050 they hardly differ from each other, and only thereafter does the difference become significant; this is caused by the parametrization chosen. Other realistic parameterizations will lead to various differences between the surface air and ocean response, although these differences will not alter dramatically.

Figure 7.9 gives the relative contribution of the individual trace gases to equilibrium temperature rise, which varies over the scenario sets and is time dependent. The contribution is simulated for two scenario sets. A and D, while three years are chosen, 1985, 2050 and 2100. The results presented are not cumulative, but are calculations for one year. This implies that the contribution of a certain trace gas in an arbitrary year indicates the difference in temperature increase between the previous year and the chosen arbitirary year.

In both scenarios $\mathrm{CO}_{2}$ is the dominant greenhouse gas. The present contribution of $\mathrm{CO}_{2}$ is found to be about $60 \%$. The contributions of both $\mathrm{CO}_{2}$ and the other gases for 1985 are in line with the figure presented by Hansen et al. (1988). The contribution of the CFCs to the total temperature effect is remarkable. A present $22 \%$ contribution is found to decrease to about $11 \%$ in 2050 to $8 \%$ in 2100 for scenario $A$ to $0 \%$ in scenario D. This means that the role of $\mathrm{CFCs}$, in spite of the Montreal Protocol, is not played out yet.

Table 7.10 gives the $\mathrm{CO}_{2}$ equivalent concentration, as defined in (7.10) and (7.11), for the different scenarios. The $\mathrm{CO}_{2}$ equivalent doubling value, which is $570 \mathrm{ppm}$ in IMAGE (starting from a value of $285 \mathrm{ppm}$ ), is reached in 2030 for scenario $A$, the unrestricted trends, in 2040 for scenario B, in 2070 for scenario $C$ and will not be reached for scenario $D$. 


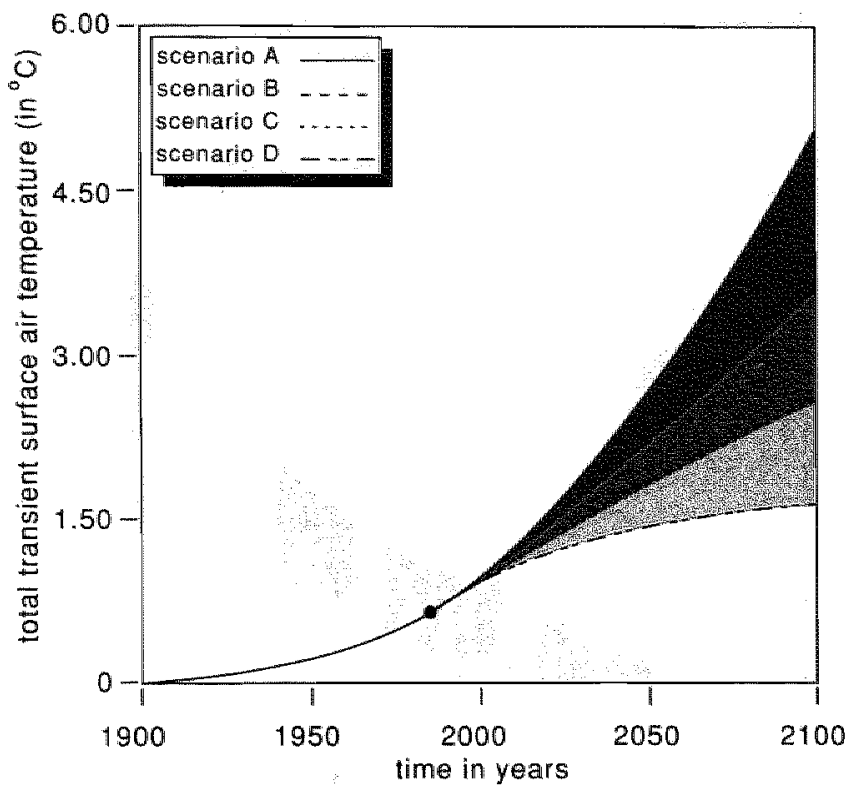

Figure 7.5: Global transient surface air temperature increase for the different scenarios, for $\Delta T_{2 x C O_{2}}=3^{\circ} C$.

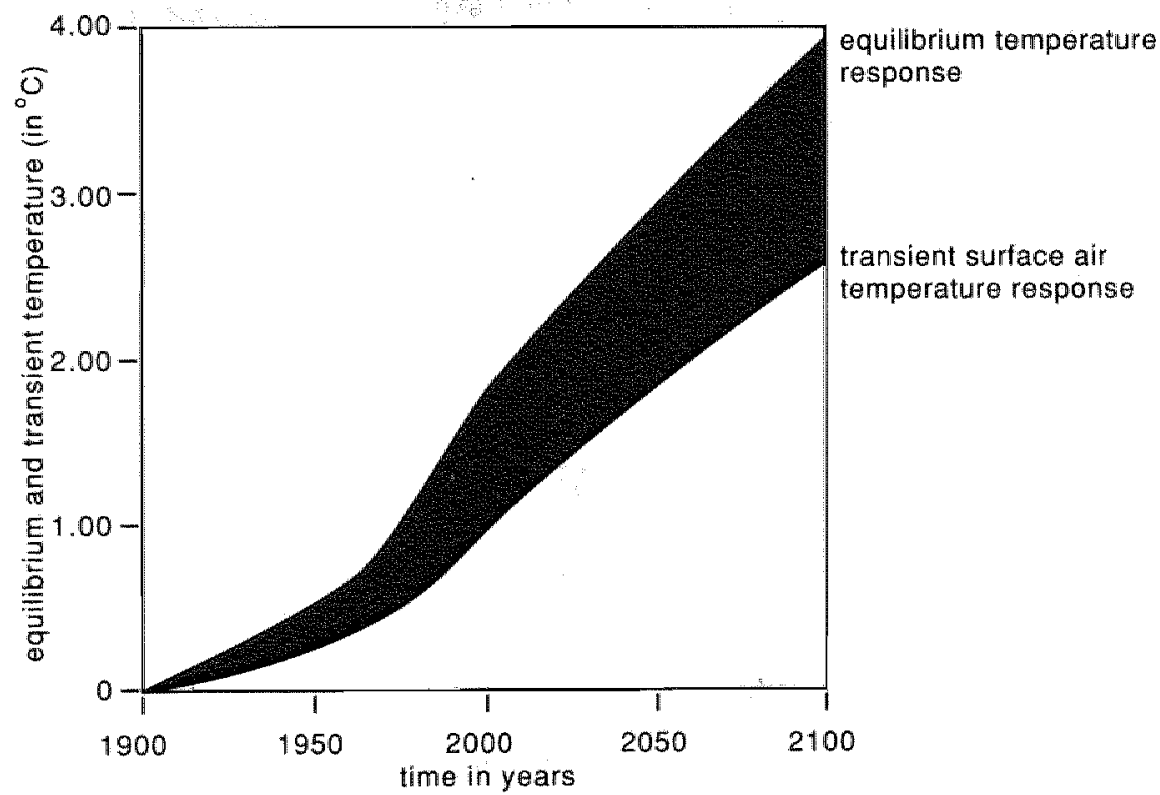

Figure 7.6: Equilibrium and transient surface air temperature response over the period $1900-1985$, for $\Delta T_{2 x C O_{2}}=3^{\circ} C$. 


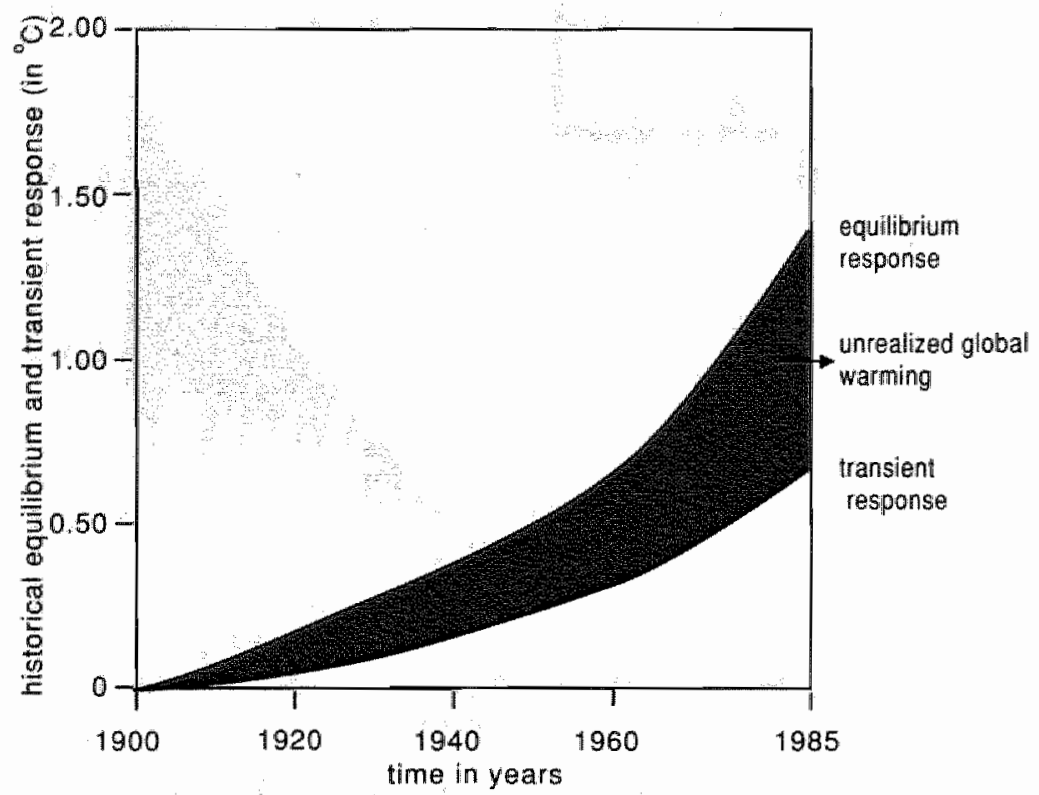

Figure 7.7: Equilibrium and transient surface air temperature response for a changed trends scenario, for $\Delta T_{2 x \mathrm{CO}_{2}}=3^{\circ} \mathrm{C}$.

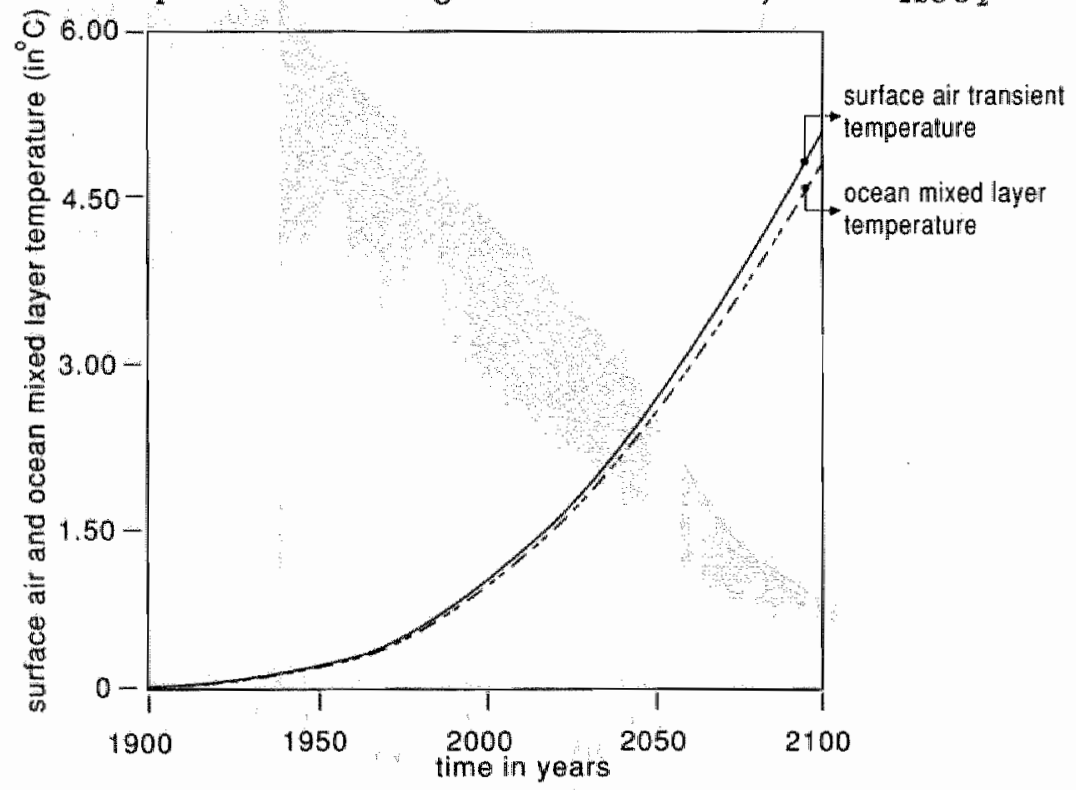

Figure 7.8: Surface air transient and ocean mixed layer transient temperature response. 

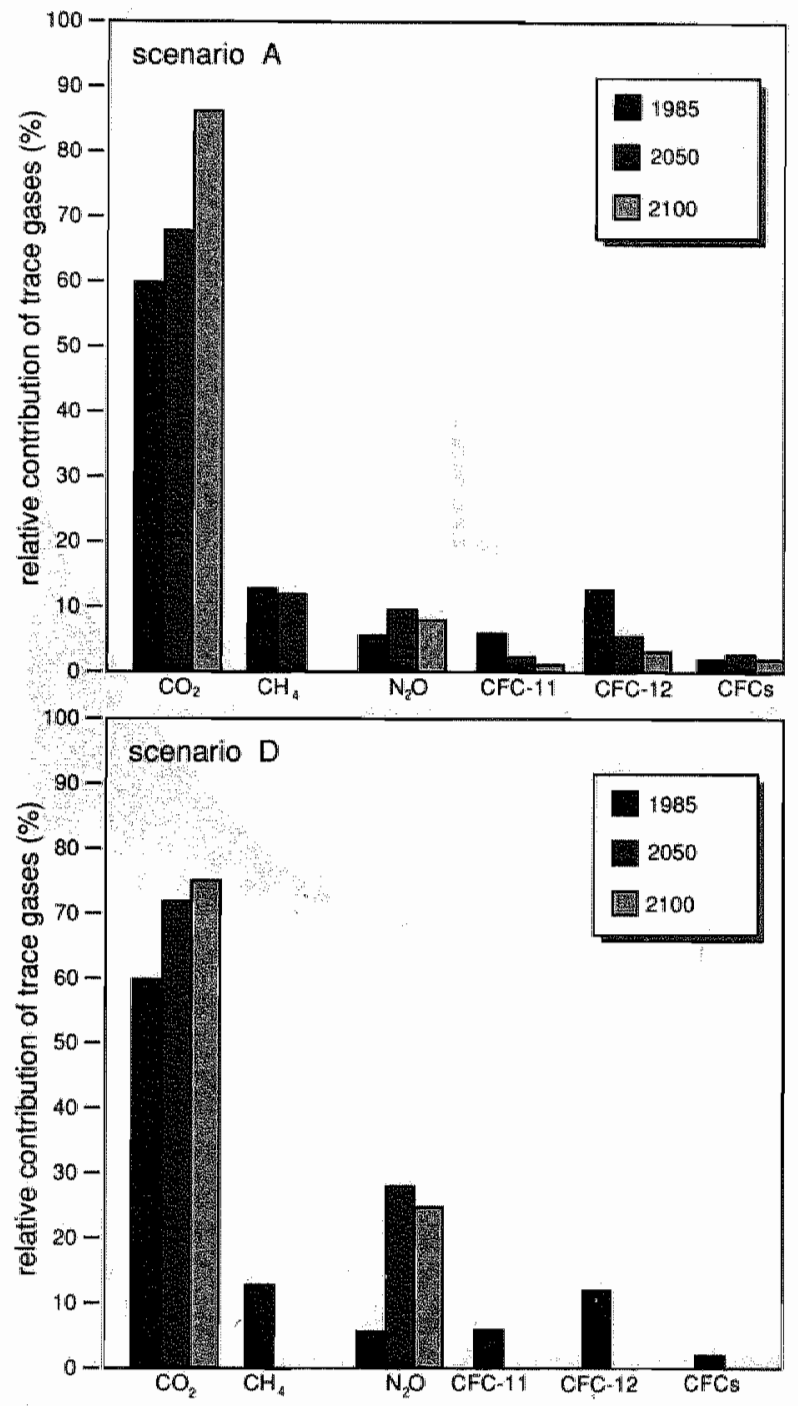

Figure 7.9: Relative contribution of trace gases to the greenhouse effect for scenario A and D. 


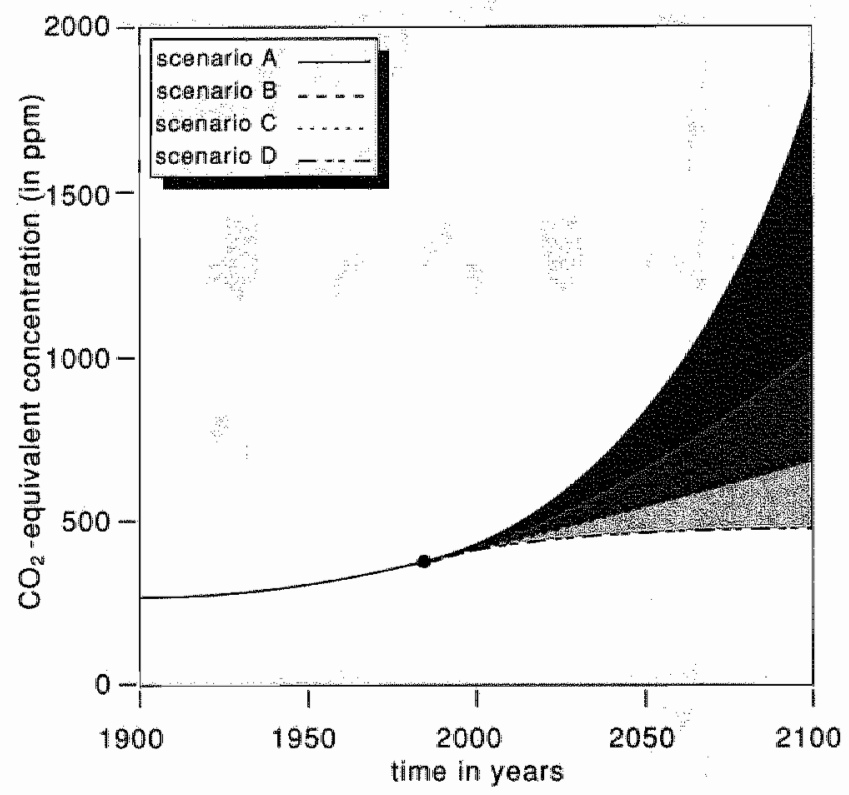

Figure 7.10: $\mathrm{CO}_{2}$ equivalent concentration.

Finally a kind of sensitivity analysis has been performed. Firstly the diffusion coefficient is varied from 1000 to $8000 \mathrm{~m}^{2} / \mathrm{yr}$, with an average value of $4000 \mathrm{~m}^{2} / \mathrm{yr}$. The results are presented in Figure 7.11 , giving the change in the surface air transient temperature response for the various values of the thermal diffusion coefficient. Figure 7.11 illustrates the importance of the diffusivity factor, and the sensitivity of the transient response to alterations in this factor. 


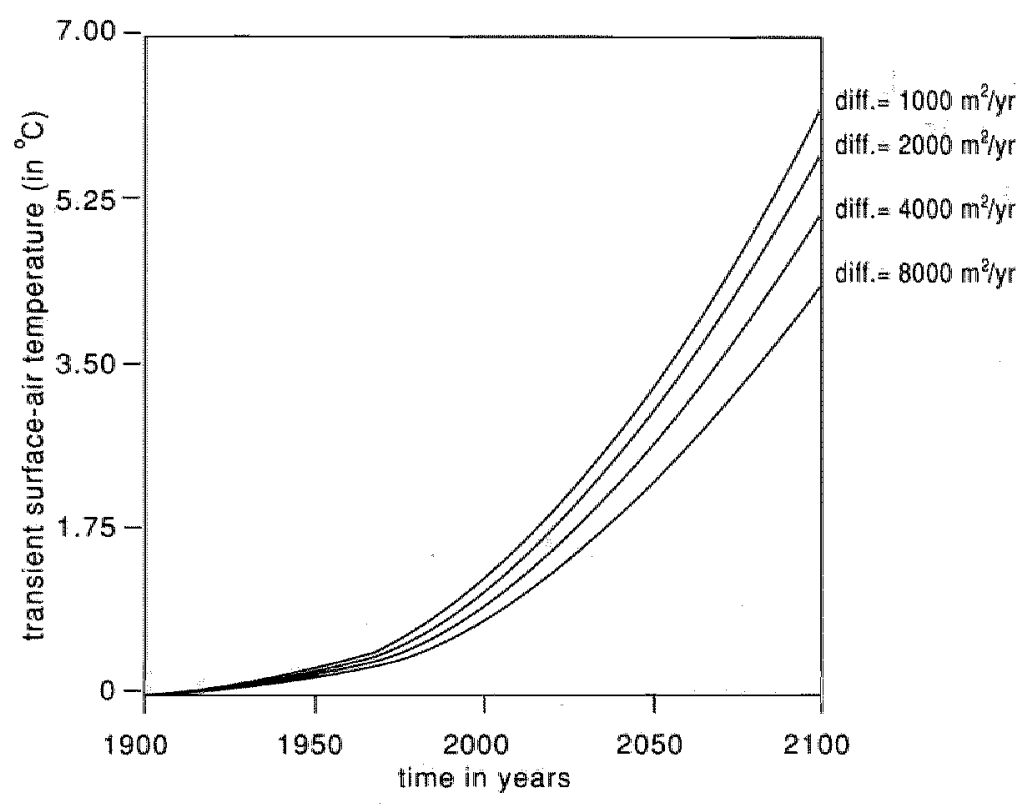

Figure 7.11: Transient surface air temperature response for different values of the diffusivity, $1000,2000,4000$, and $8000 \mathrm{~m}^{2} / \mathrm{yr}$.

Secondly the thickness of the mixed ocean layer $(\Delta z)$ is varied, from 25 meters to 150 meters. The results are depicted in Figure 7.12. The transient temperature response appears to be more sensitive to alternations of the depth mixed layer than for alternations of the diffusivity factor. However the uncertainty range for the diffusivity is larger than for the depth mixed ocean layer. 


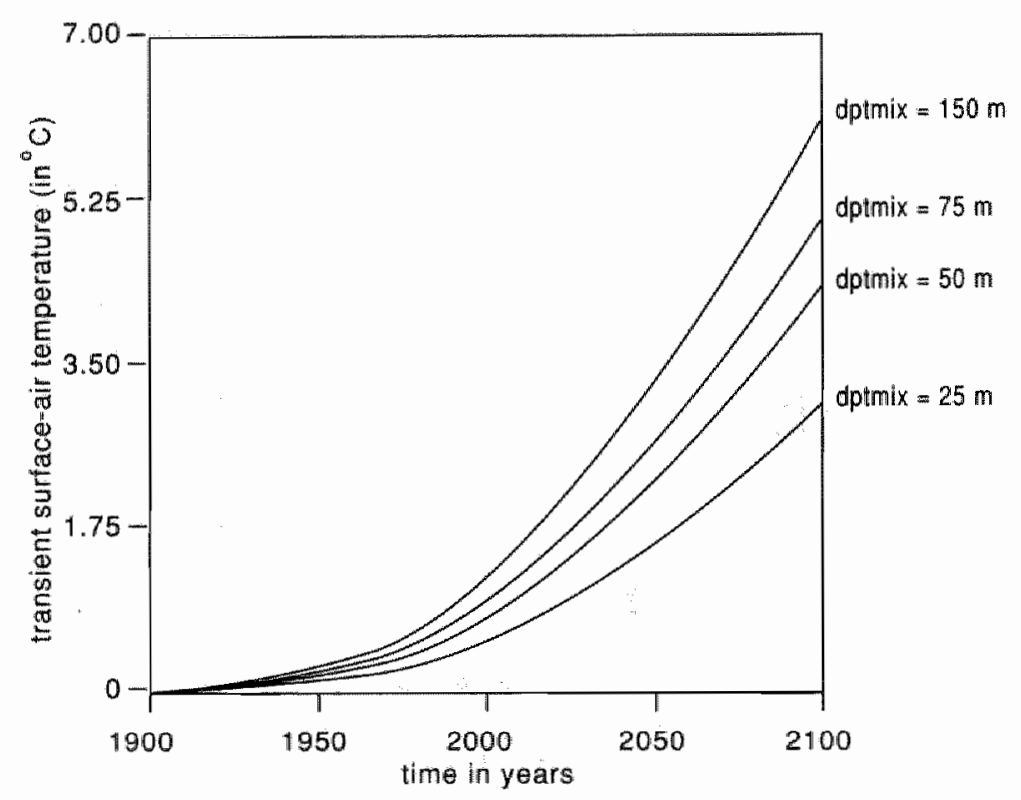

Figure 7.12: Transient surface air ocean temperature response for different values of the mixed ocean layer, $25,50,75$, and $150 \mathrm{~m}$.

Figure 7.13 gives the ocean response time or, equivalently, E-folding time (Schneider and Thompson, 1981). This E-folding time indicates the time to reach $1-e^{-1}$ (or about 0.63 ) of the equilibrium temperature response for different values of the diffusivity coefficient. Assuming the standard value of the diffusivity, $4000 \mathrm{~m}^{2} / \mathrm{yr}$, yields an E-folding time about 50 years. Varying the diffusivity factor from 500 to $6000 \mathrm{~m}^{2} / \mathrm{yr}$ yields a range in the E-folding time from 10 years to about 100 years. 


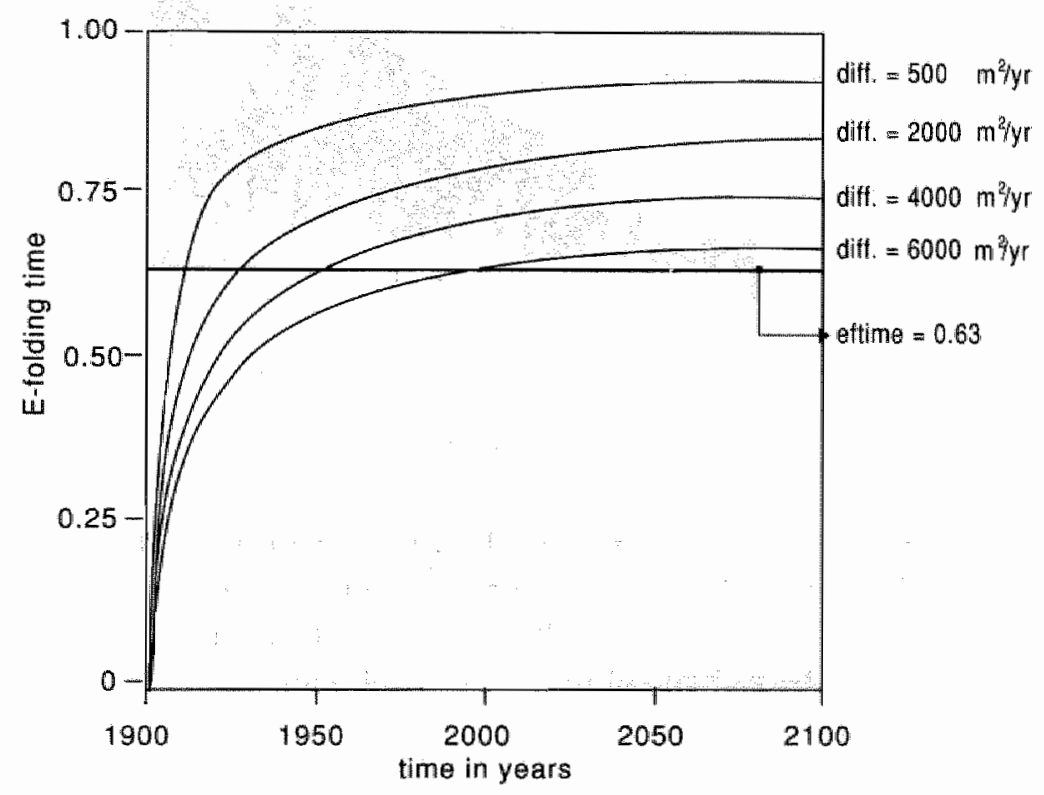

Figure 7.13: E-folding time at an instant $\mathrm{CO}_{2}$ doubling, from $280 \mathrm{ppm}$ to $560 \mathrm{ppm}$, for different values of the diffusivity: $500,2000,4000$, and $6000 \mathrm{~m}^{2} / \mathrm{yr}$.

In Figure 7.14 the influence of the climate feedback factor, or, equivalently, the climate sensitivity to a doubling of the $\mathrm{CO}_{2}$ concentration, is expressed. This figure shows that the unrealized warming depends strongly upon the climate feedback factor, or $\triangle T_{2 x C O_{2}}$. Assuming a value for $\Delta T_{2 x C O_{2}}$ of $3.0^{\circ} \mathrm{C}$ or more, it can be concluded that only a decreasing fraction of the global warming has yet been realized. 


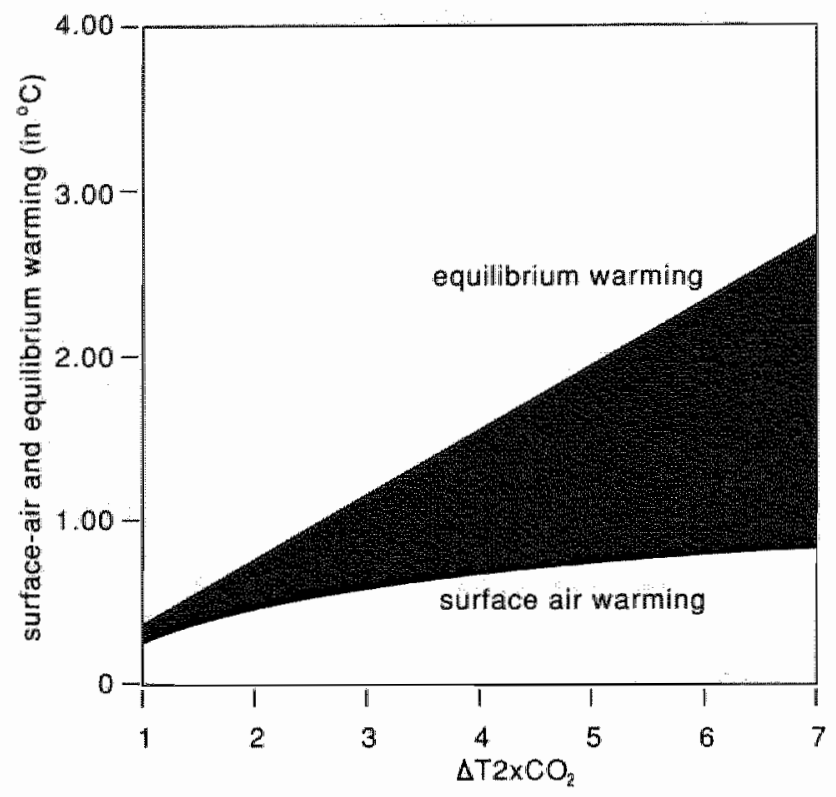

Figure 7.14: Surface air warming and the equilibrium warming for the period $1900-1985$ as a function of climate sensitivity to a doubling of the $\mathrm{CO}_{2}$ concentration, or, equivalently, the climate feedback factor.

\subsection{Conclusions}

The simple one-dimensional climate module within IMAGE cannot treat possibly important processes in any detail, including those that are determined by local or regional circumstances. Usually the different model parameters are turned within ranges found in the literature so as to mimic historical trends as far as these are known. Important aspects which are not or only very poorly incorporated in such a model are the treatment of clouds, ocean heat transport and circulation, and ocean-atmosphere feedbacks.

In spite of these shortcomings, these simple climate models are very useful. They can perform calculations over a long simulation period not 
being feasible yet with three dimensional models. For policy evaluations, sensitivity analysis, and educational tools there is basically no alternative.

Calculations with IMAGE show that continuation of the recent trend of emissions of the relevant greenhouse gases leads to a rapid increase in the global mean temperature. Even the most restrictive forced trend scenario (D) leads to a $1.5^{\circ} \mathrm{C}$ temperature increase. The simple climate module within IMAGE indicates that more than half of the expected global warming effect has not yet been realized.

The $\mathrm{CO}_{2}$ equivalent concentration, defined to combine the radiative perturbation of all greenhouse gases, doubles within 40 year for scenario $A$, whereas a doubling will not be reached for scenario $\mathbb{D}$. Sensitivity analyses with the climate module show the sensitivity of the transient response to alternations of the climate feedback factor, the thickness of the mixed ocean layer and, to a lesser extent, to the diffusivity factor. Additional research is urgently needed to improve the knowledge which underlies the parameterizations in these simple climate models. 



\section{Chapter 8}

\section{The Sea Level Rise Module}

Undoubtedly sea level rise is potentially one of the most threatening consequences of the greenhouse phenomenon. Nearly one-third of the world's population, including many of the world's largest cities, lives within $60 \mathrm{~km}$ of a coastline. Even a sea level rise of 1 meter would have a tremendous influence on habitation patterns, causing large-scale migrations of millions of people. Nevertheless the relation between a global temperature change and global sea level rise is not yet clear, and our knowledge of processes causing sea level rise is still deficient. Although on a large time scale geological processes are of crucial importance, on a relatively small time scale of centuries, three dominating causes of sea level rise are distinguished in the sea level rise module: thermal expansion of ocean water, melting of mountain glaciers, and the reaction of land ice. These causes associated with the greenhouse issue explain only a part of the basic sea level trend. Next to these anthropogenic causes, there are other factors which should be taken into account when studying the sea level rise. First, the internal variability of the climate system, regarded as all climatic fluctuations which are not related to anthropogenic activities or to changes in isolation of the earth (Oerlemans, 1982). Second, the systematic changes on long time scales. In this study only the latter are assumed to form the unexplained part of the basic trend, although it could be possible that climate variability is also related to the unexplained part of the basic trend. 


\subsection{Basic Trend}

Sea level changes at any time and at any location is determined by both geological and climatic factors. Geological causes may have been responsible for a drop in sea level of about three hundred metres over the last eighty million years (Barth and Titus, 1984). But these geological events affecting sea leve] are generally slow and unlikely to accelerate. Generally the same holds for the climatic influence on sea level in the past. For the last two million years sea level rise and climate have changed together, in cyclic periods of about 100,000 years. During the last glacial era, sea level was approximately one hundred meters lower than today, while during the warm interglacial periods temperature and sea level have risen to approximately present levels (Barth and Titus, 1984).

In the last century sea level has risen by about 10-15 cm (Barnett, 1983 and 1985, Gornitz et al., 1982). The variations in these estimations arise from local effects. For the Netherlands and Belgium the sea level rise in the last century has been higher, about $20 \mathrm{~cm}$. The global trend of $10-$ $15 \mathrm{~cm}$ cannot yet be fully explained. Therefore in this study the basic or natural trend is assumed to be the unexplained part of the observed trend. Considering a trend of $20 \mathrm{~cm}$ per century for the Netherlands, the trend for the period 1900-1985 is about $17 \mathrm{~cm}$. The model simulates for this period an anthropogenic sea level rise of $8.0 \mathrm{~cm}$, consequently inducing a natural sea level trend of $9.0 \mathrm{~cm}$. This induces a simulated natural trend of about $10.6 \mathrm{~cm}$ per century.

\subsection{Thermal Expansion}

Thermal expansion of the ocean is thought to be a major contributor to sea level rise. To calculate the thermal expansion effect, a simple box diffusion model is used, as described in Chapter 7. This approach, also used by Hoffman et al. (1983) and Oerlemans (1989), ignores the upwelling effect. Wigley and Raper (1987) use an upwelling diffusion model to calculate the thermal expansion effect. Here one single ocean column is used because, according to Oerlemans (1987), it follows, when splitting up the ocean into a. warm and a cold column, the thermal expansion effects in both columns are similar. As described in Chapter 7 , the diffusion equation is discretized, and numerically solved for a mixed ocean layer of 75 meters, and in 37 deep ocean layers of 25 meters. The diffusivity coefficients is kept constant, viz. $4000 \mathrm{~m}^{2} / \mathrm{yr}$. Using the negative exponential temperature profile as given by 
Oerlemans (1989), each of the 38 ocean layers has its own thermal expansion coefficient and consequently its own contribution to thermal expansion. For each layer the sea level change due to thermal expansion can be described as:

$$
S L R_{t h}(i)=\int_{0}^{T(i)}[\Delta V(i) / V(i)] d z
$$

and

$$
\Delta V(i)=T d(i) * V(i) * e c(i)
$$

with:

$S L R_{t h}(i)=$ sea level rise by thermal expansion of layer $i$ (in $m$ )

$V(i) \quad=$ volume of ocean layer $i$ (in $\mathrm{m}^{3}$ )

$T(i) \quad=$ thickness of ocean layer $i$ (in $m$ )

$T d(i)=$ transient temperature response in ocean layer $i$ (in ${ }^{\circ} \mathrm{C}$

$e c(i)=$ thermal expansion coefficient in layer $i\left(\right.$ in $\left.{ }^{\circ} C^{-1}\right)$

At a certain time the total contribution of all layers is then:

$$
S L R_{t h}=\sum_{i=1}^{38} S L R_{t h}(i)
$$

Integrating these contributions for the whole simulation period yields the total sea level rise by thermal expansion.

\subsection{Glaciers and Small Ice Caps}

Although the ice mass of glaciers and small ice caps seems to be negligible in comparison with the immense ice masses of Antarctica and Greenland, their contribution to sea level rise may be substantial. Robin (1986) estimates the total area of mountain glaciers, all ice except for Greenland and Antarctica, as $0.54 * 10^{6} \mathrm{~km}^{2}$ and $0.12 * 10^{6} \mathrm{~km}^{3}$ water equivalent; this represents about $0.4 \%$ of total land ice, and corresponds to a potential sea level rise of about $33 \mathrm{~cm}$. Oerlemans (1986b) estimates the total land ice mass at $0.6 * 10^{6} \mathrm{~km}^{2}$ and $0.18 * 10^{6} \mathrm{~km}^{3}$ water equivalent, corresponding to about $50 \mathrm{~cm}$ sea level equivalent.

Over the last hundred years there has been a world-wide retreat of the glaciers. The most comprehensive study in this field has been done by Meier (1984), who examined the mass balance of $\mathbb{1 3}$ glaciers. Meier (1984) estimates the contribution of glacier melting to sea level rise in the last hundred 
years to be 1 to $5 \mathrm{~cm}$. Oerlemans (1988) argues that the greenhouse warming is responsible for about $50 \%$ of the glacier retreat over the last hundred years. Low volcanic activity is accountable for the remaining $50 \%$ of the glacier retreat.

Because local circumstances determine the specific character of each type of glacier, a global approach to the estimation of the entire melting of glaciers and small ice caps is rather precarious. So far, however, attempts to simulate the historic glacier retreat during the last hundred years, by using local data, have failed. Thus, for want of a more sophisticated approach, a simple global approach is chosen, according to Oerlemans (1989). Under the assumptions of a constant characteristic response time of glaciers, proportionality of melting rates to both temperature increase and remaining glacier volume, and an exponential decrease of glacier volume with surface temperature, the volume of glaciers and small ice caps can be described as follows:

$$
\begin{aligned}
V \operatorname{glac}(t)= & V \operatorname{glac}(t-1)(t-1) \\
& +\int_{t-1}^{t}\left[\alpha * T s *\left(\operatorname{Vglin} * e^{-T s / \beta}-\operatorname{Vglac}(t)\right)\right]
\end{aligned}
$$

with:

$V$ glac $=$ ice volume of glaciers at time $t$ (in $m$ sea level equivalent)

$V$ glin $=$ initial ice volume of glaciers; the starting simulation time is 1900 , and the chosen initial glacier volume is 0.45 meter sea level equivalent

$\alpha=$ constant, which involves a characteristic response time of glaciers; is $0.05(y r K)^{-1}$

$T_{s}=$ global transient surface temperature response $\left(\right.$ in ${ }^{\circ} \mathrm{C}$ )

$\beta \quad$ constant that determines the global temperature increase for which the ice volume becomes $e^{-1}$ of the initial value; is $4.5^{\circ} \mathrm{C}$

The constants are taken from Oerlemans (1989), while the global transient surface temperature increase is calculated with the climate module of IMAGE, described in Chapter 7.

\subsection{Greenland Ice Cap}

The Greenland ice cap covers an area of $1.8 * 10^{6} \mathrm{~km}^{2}$, and a volume of $3 * 10^{6} \mathrm{~km}^{3}$, corresponding with a sea level equivalent of about 7.5 meter (Oerlemans, 1989). Because of a lack of data it is not clear whether or not 
the Greenland ice cap is in its equilibrium state. In any case it is generally assumed that the Greenland ice cap is not far from its equilibrium state. In Rotmans (1986) three possibilities are distinguished, based on USDOE (1985c): firstly, according to the budget method (estimation of the total of accumulation, melting and calving), Greenland should be in equilibrium.

\begin{tabular}{lll} 
Accumulation & $:$ & $+500 \pm 100 \mathrm{~km}^{3} /$ year \\
Melting & $:$ & $-295 \pm 100 \mathrm{~km}^{3} /$ year \\
Calving & $:$ & $-205 \pm 100 \mathrm{~km}^{3} /$ year + \\
\hline
\end{tabular}

Net balance

Secondly, recent research indicates that the Greenland ice cap is in a disequilibrium state, varying from an increase of $+0.3 \mathrm{~mm} / \mathrm{yr}$ to a decrease of $-0.7 \mathrm{~mm} / \mathrm{yr}$.

Finally, extrapolating recent observations results in an ablation of 0.2 to $0.3 \mathrm{~mm} / \mathrm{yr}$ and an accumulation of $-0.1 \mathrm{~mm} / \mathrm{yr}$. The net effect, then, would be a thinning of $-0.1 \mathrm{~mm} / \mathrm{yr}$.

In the model it will be assumed that in the initial phase, in 1900, the Greenland ice cap is in equilibrium (net balance is 0 ).

A very simple budget estimating method will be used to obtain a simple relationship between a global temperature increase and the change in mass balance of the Greenland ice cap. Assuming a global average temperature increase of $3.5^{\circ} \mathrm{C}$, this will elevate the height of the equilibrium line, by which the ablation surface area increases by about $25 \%$ and the melting rate increases by about 50\% (Robin, 1986). Together these two factors would cause an increase in melting of about $-184 \mathrm{~km}^{3}$. The accumulation area would decrease with about $5 \%$; accumulation rate stays constant or increases by $10 \%$ (USDOE, $1985 \mathrm{c}$ ), yielding an extra accumulation of 0 or $47 \mathrm{~km}^{3}$. The decrease in accumulation area and increase in accumulation rate would lead to an accumulation range of $-24 \mathrm{~km}^{3}$ to $+23 \mathrm{~km}^{3}$. Ultimately, for a $3.5^{\circ} \mathrm{C}$ temperature increase the net budget decrease would vary from -208 $\mathrm{km}^{3}$ to $-161 \mathrm{~km}^{3}$. Supposing a linear relationship, the net effect per degree Celsius will vary from $-46 \mathrm{~km}^{3}$ to $-59 \mathrm{~km}^{3}$, corresponding with a sea level rise of $0.128 \mathrm{~mm} / \mathrm{yr}^{\circ} \mathrm{C}$ to $0.166 \mathrm{~mm} / \mathrm{yr}^{\circ} \mathrm{C}$, with an average value of about $0.147 \mathrm{~mm} / \mathrm{yr}^{\circ} \mathrm{C}$.

The contribution to sea level rise is modelled by multiplying this average melting rate of $0.147 \mathrm{~mm} / \mathrm{yr}^{\circ} \mathrm{C}$ to the simulated transient surface-air temperature increase. 
In Rotmans (1986) the global temperature response is differentiated into several zones and into a summer and winter value, roughly based on GCM data. Because the melting process will occur only in the summer period, the average summer temperature increase is used, which, however, is chosen equal to the global average temperature increase.

Oerlemans (1989) summarizes several estimates which have been made for the change in mass balance of the Greenland ice cap per degree Celsius. He states that the contribution of the Greenland ice cap to sea level change can be estimated as $0.5 \mathrm{~mm} / \mathrm{yr}$ per degree Celsius, with an uncertainty range of about $50 \%$. This is rather high compared to the value found here of $0.147 \mathrm{~mm} / \mathrm{yr}$ per degree Celsius. This is mainly caused by the accumulation rate, which is a maximum of $10 \%$ in this analysis, and which is being kept constant in the analysis, leading to $0.5 \mathrm{~mm} / \mathrm{yr}$ per degree Celsius.

\subsection{Antarctic Ice Cap}

The Antarctic ice sheet contains $11.97 * 10^{6} \mathrm{~km}^{2}$, a volume of $29.33 * 10^{6} \mathrm{~km}^{3}$, which is more than $90 \%$ of the total amount of land ice, and corresponds to about a 65 meter sea level equivalent. As for the Greenland ice sheet, it is generally supposed that the Antarctic ice sheet is not far from its equilibrium state. There is still an uncertainty range of about $20 \%$. According to a simple budget method, the Antarctic ice sheet should be slightly increasing:

Accumulation $:+2000 \mathrm{~km}^{3} /$ year
Ice flow

On the Antarctic ice cap the ice flow is primarily caused by calving, while the melting is negligible, because of the extremely cold climate. In case of a temperature increase the accumulation is expected to increase, causing a drop in sea level. To calculate coarsely the effect of a temperature rise on the Antarctic mass balance, again a simple budget estimation is used (Rotmans, 1986).

Assuming once more a global average temperature increase of $3.5^{\circ} \mathrm{C}$, this may lead to an increase in accumulation by about 10 to $25 \%$, corresponding to about +200 to $+500 \mathrm{~km}^{3} /$ year. On the other hand, the ablation rate will double over twice the ablation area, implying a quadrupling of the ablation. To determine the net balance effect in consequence of such a global temperature rise, several options can be chosen (Rotmans, 1986). One with. 
an initial net balance of zero, or one with a net balance of $+20 \%$, or a $10 \%$ or $25 \%$ accumulation rate increase, etc. Taking account of these various options, the range, expressed in $\mathrm{mm} / \mathrm{yr}$ per degree Celsius, varies from -0.1088 $\mathrm{mm} / \mathrm{yr}$ per degree Celsius to $-0.3648 \mathrm{~mm} / \mathrm{yr}$ per degree Celsius. Selecting an average net budget increasing value of $-0.237 \mathrm{~mm} / \mathrm{yr}$ per degree Celsius, this is multiplied by the simulated transient surface-air temperature increase in summer, which value is parameterized as 1.5 times the global transient surface-air response. The resulting net budget increasing value is then -0.36 $\mathrm{mm} /$ year per degree Celsius.

Oerlemans (1989) estimates the contribution to sea level change in two different ways. On the one hand, by using a model for the Antarctic ice sheet (Oerlemans, 1982), resulting in an estimation of $-0.5 \mathrm{~mm} / \mathrm{yr}$ per degree Celsius, and on the other by directly considering the mass balance effect, leading to a $-0.43 \mathrm{~mm} /$ year per degree Celsius estimate. This does not deviate too far from the value used in this study of $0.36 \mathrm{~mm} / \mathrm{yr}{ }^{\circ} \mathrm{C}$. The possible disintegration of the West Antarctic Ice Sheet (WAIS) is not taken into account in this analysis, because it seems unlikely that this disintegration will already occur in the next century. Even if this happens the effects in the coming hundred years will be small (National Health Council, 1986). Although there is ample qualitative knowledge about the ice sheet system, it is hard to make quantitative projections. Various attempts have been made to model the West Antarctic ice sheet system (Thomas and Bentley, 1978, Van der Veen, 1986). Oerlemans (1982, and 1989) argues that the earlier modelling estimates were too high, and estimates the contribution of the West Antarctic Ice Sheet at about $0.1 \mathrm{~mm} / \mathrm{yr}$ for the next century. However this quantification is surrounded by large uncertainties, and is consequently ignored in this study.

\subsection{Uncertainties}

The uncertainties with respect to future sea level rise projections are very large. The uncertainties in the various separate contributions to future sea level rise are about $50 \%$ for the changes on the Greenland and Antarctic ice cap, about $50 \%$ for the glacier melting, and approximately $30 \%$ for the thermal expansion effect. The uncertainties of the individual contributions are assumed to be independent of each other. Concerning the total or accumulated uncertainty, Oerlemans (1989) argues that $40 \%$ of this is caused by uncertainty in climate modelling, and the remaining $60 \%$ is due to lack 
of data and inadequacy of the models that explain sea level rise.

\subsection{Sea Level Rise Potential}

Effective targets are needed in order to develop environmental long-term goals with respect to the effects of climate change. Next to global temperature increase, sea level rise might be used as a long-term target for climate change, from which concerted emission control policies can be derived. Sea level rise should be taken into consideration, since many valuable ecological and economic areas are in coastal regions, and even a moderate sea level rise could have a potentially disastrous effect.

When considering sea level rise as a long-term target of climate change, a tolerable sea level rate should be defined. According to Gornitz et al. (1982) the sea level trend over the past 6000 years is $2 \mathrm{~cm}$ per century, which is very small as compared to long-term trends of 1 meter per century at times of continental ice sheet growth or decay. As mentioned above, however, the global trend over the last hundred years is about $10-15 \mathrm{~cm}$. This interval of 10 to $15 \mathrm{~cm}$ per century could be taken as a reference target value for sea level rise for the coming century. Another possibility is to relate the sea level rate to global temperature increase recommendations, as was done at the Villach/Bellagio workshop (Bolin et al., 1986, Jäger 1988). There a reference value of $0.1{ }^{\circ} \mathrm{C}$ per decade was suggested, a rate of change at which ecosystems might be able to adapt effectively to climate change. Using this global temperature increase scenario of $0.1^{\circ} \mathrm{C}$ per decade as input scenario for IMAGE, a global sea level rise of about $20 \mathrm{~cm}$ per century is calculated, whereas for the Netherlands a sea level rise of $25 \mathrm{~cm}$ would be expected. Thus, a global temperature increase target of $0.1^{\circ} \mathrm{C}$ per decade would keep pace with a global sea level rise target of $20 \mathrm{~cm}$ per century (25 for the Netherlands).

If the control of sea level change is to be used as a long term goal, it should be possible to derive emission pathways from this goal. Therefore an index to compare the sea level rise effect of greenhouse gas emissions is needed. By analogy with the Temperature Increasing Potential (TIP), which is in turn a greenhouse counterpart to the Ozone Depleting Potential (ODP), here the concept of a Sea Level Rise Potential (SRP) is introduced. IMAGE is used to obtain a relationship between an emission and its associated effect on sea level. The complexity of the processes involved seems to make an analytical approach, as used for determining the TIP concept, difficult. 
In view of the strong resemblance between the TIP and the SRP, calculation of both potentials will be based on the same methodology. This modelling approach is described extensively in Chapter 11, and in Rotmans and Den Elzen (1990). The modelling method will be explained briefly below.

Again, the SRP is defined as the sea level rise effect of 1 or $10^{-3}$ Gt emission of a particular trace gas relative to $\mathrm{CO}_{2}$. For that, stabilizing scenarios have been developed for each trace gas, resulting in steady-state concentrations in the second half of the next century. Starting these scenarios in 1985, in 1986 for each trace gas a one year emission impulse of 11 or $10^{-3} \mathrm{Gt}$ is generated, and added to such a stabilization scenario. Then in each case two stabilization scenarios are compared in pairs, one with and one without an emission impulse. In this way, for each greenhouse gas, two sea level rise responses are simulated, again with and without an emission impulse. By subtracting these two responses, the influence of the scenario choice is reduced, yielding the net sea level rise effect. These net contributions are integrated over the whole simulation period. Dividing this sea level rise integration of $\mathrm{CH}_{4}, \mathrm{~N}_{2} \mathrm{O}, \mathrm{CFC}-11$, and $\mathrm{CFC}-12$ by that of $\mathrm{CO}_{2}$ gives the SRP. Again, because $\mathrm{CO}_{2}$ has no specific atmospheric residence time, for $\mathrm{CO}_{2}$ two time horizons have been taken into account, 100 and 500 years, respectively. Also, the same parametrizations have been used as in the TIP modelling approach (Rotmans and Den Elzen, 1990).

As opposed to the equilibrium states as used in the TIP concept, the complex nature of the forcing processes in simulating the SRP compels the use of transient responses.

\subsection{Results}

The total sea level rise is calculated for the four scenarios. The resulting sea level rises are presented in Figure 8.1. The sea level rise range varies from about 0.95 meter for the unrestricted scenario (A) to about 0.45 meter for the forced trends scenario (D). Considering the large uncertainties mentioned above, it appears that for the changed trend scenario (C) the outcomes of the unrestricted trend and the forced trend scenarios are approximately the upper and lower bounds, respectively, of such a simple uncertainty analysis. 


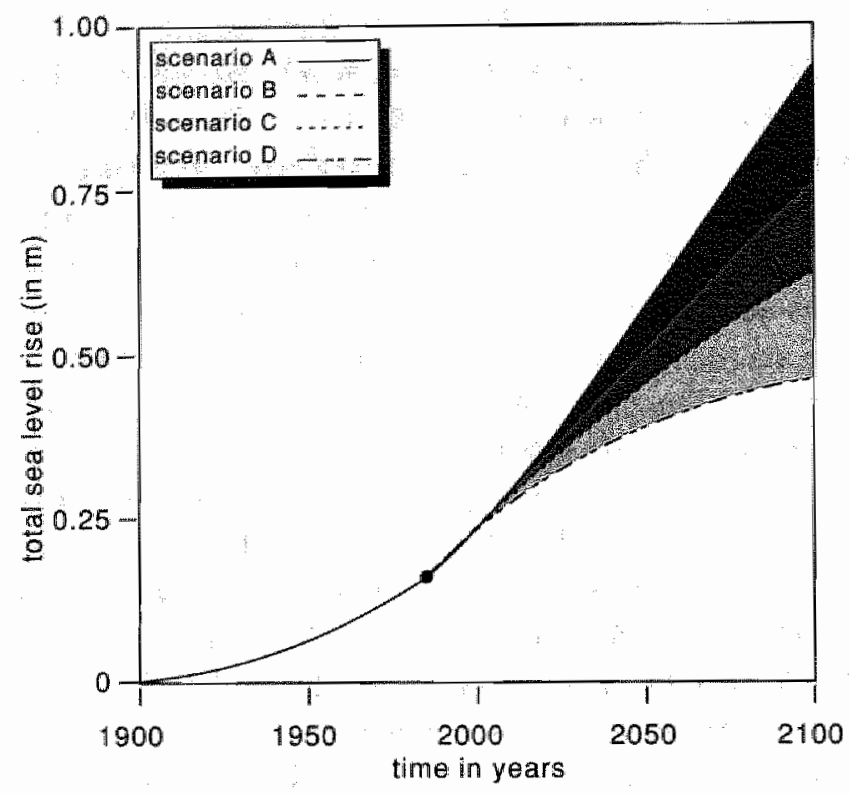

Figure 8.1: Total sea level rise for the different scenarios.

Figure 8.2 gives the different components of the sea level rise for the unrestricted trends scenario of about 0.95 meter. Clearly, the thermal expansion contribution dominates. Next to thermal expansion, melting of glaciers and small ice caps play an important role. The melting of the Greenland ice cap and the accumulation of Antarctica are of minor importance in this simulation. 


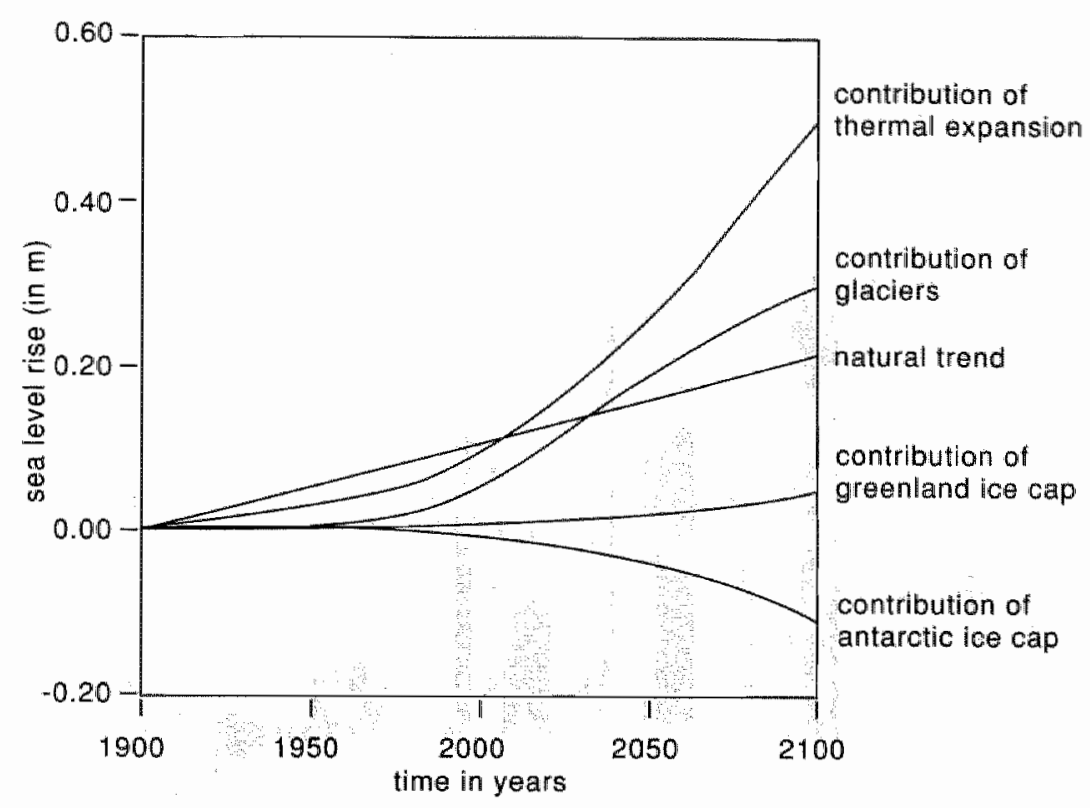

Figure 8.2: Different components of the total sea level rise for the unrestricted trends scenario (A).

Figure 8.3 contains the relative contributions of the different components to sea level rise. These simulation results show primarily an increasing share of thermal expansion and glacier melting, and a decreasing natural sea level rise component. For 1985 the total simulated sea level rise is $17 \mathrm{~cm}$, of which $8 \mathrm{~cm}$ has an anthropogenic nature and the remaining $9 \mathrm{~cm}$ forms the basic trend. This is in line with the 'explained' sea level rise of about $9.5 \mathrm{~cm}$ over the last 150 years found by Oerlemans (1989). The major contributor is the thermal expansion of about $6 \mathrm{~cm}$, which is fairly high as compared to Oerlemans ${ }^{2}$ estimate of $5 \mathrm{~cm}$, and the estimated range of $2-5 \mathrm{~cm}$ found by Wigley and Raper (1987) for the thermal expansion effect over the last hundred years. The reason is probably the use of a constant diffusion coefficient and larger expansion coefficients.

Another important contributor are the glaciers and small ice caps, with $2.3 \mathrm{~cm}$. Oerlemans gives about $3.5 \mathrm{~cm}$, while Meier (1984) gives a range of 
1 to $5 \mathrm{~cm}$ over the past hundred years.

Generally, the simulated sea level rise for 1985 , as well as the separate contributions of different components, are reasonably in line with results given in the literature.

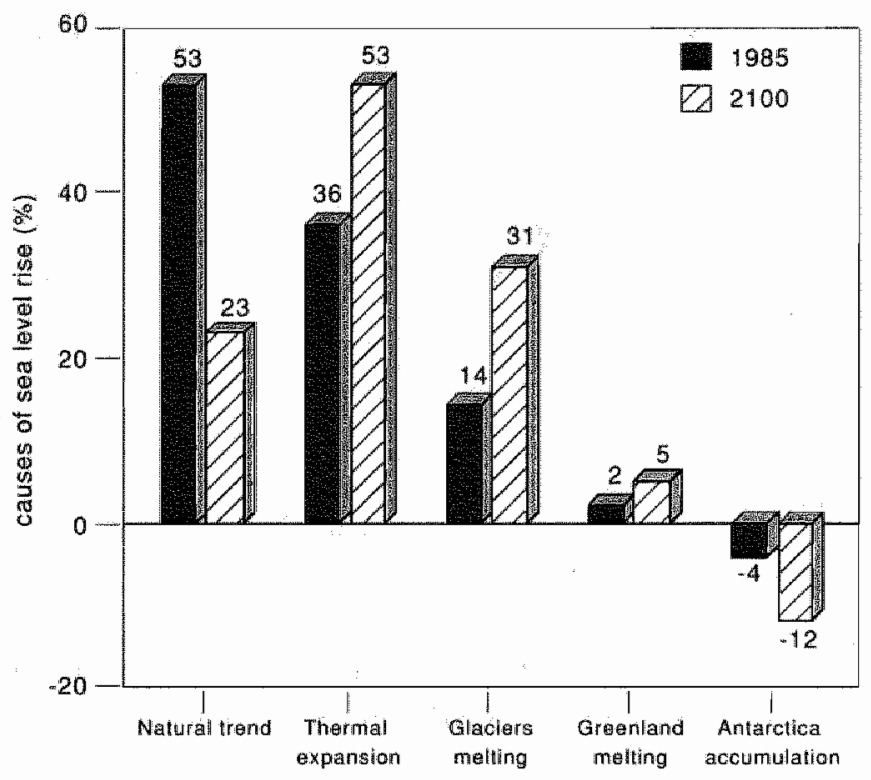

Figure 8.3: Relative contribution of the different components to sea level rise for the years 1985 and 2100 ; the latter for the unrestricted trends scenario (A). 
The sea Level Rise Potentials (SRPs) of the different greenhouse gases are represented in Table 8.1.

\begin{tabular}{|l|c|c|}
\hline SRP value & $\begin{array}{c}\mathrm{CO}_{2} \text { time horizon } \\
\text { is } 100 \text { years }\end{array}$ & $\begin{array}{c}\mathrm{CO}_{2} \text { time horizon } \\
\text { is 500 years }\end{array}$ \\
\hline $\mathrm{CO}_{2}$ & 1 & 1 \\
$\mathrm{CH}_{4}$ & 15 & 6 \\
$\mathrm{~N}_{2} \mathrm{O}$ & 275 & 330 \\
$\mathrm{CFC}-11$ & 3780 & 2560 \\
$\mathrm{CFC}-12$ & 8250 & 5000 \\
\hline
\end{tabular}

Table 8.1 SRP calculated with IMAGE for different time horizons.

Comparing these SRP values with the TIP values presented in Chapter 11, and in Rotmans and Den Elzen (1990), shows that for a $\mathrm{CO}_{2}$ time horizon of 100 years the SRP values are slightly lower than the TIP values. For a $\mathrm{CO}_{2}$ time horizon of 500 years, however, the SRP values are considerably higher. This can be explained by the fact that the SRP is based on transient states, whereas the TIP indicates an equilibrium phase. The transient response induces a delay effect which causes a shift towards the time horizon of 500 years. For instance the SRP for $\mathrm{N}_{2} \mathrm{O}$ is higher for the 500 years time horizon than for the 100 years horizon.

\subsection{Conclusion}

Simulation experiments with IMAGE show a sea level rise range of about 0.45 to 0.95 meter for the next century. The simulated increase for the next hundred years falls within the interval of 0.28 to 0.78 meter, which means an increrase of about 2 to 5 times that of the past centuries. The dominant causes of this sea level rise will be the thermal expansion of the ocean, and the melting of glaciers and small ice caps. For the next hundred years changes in the mass of polar ice sheets may have a significant effect on sea level, but will be minor components compared to expansion and glaciers.

Notwithstanding the large uncertainties with which the processes that determine a sea level rise are surrounded, it seems worth the effort to develop sea level rise targets. The IMAGE model has been used to develop Sea Level Rise Potentials (SRPs) for the greenhouse gases, analogous to the 
Temperature Increasing Potentials (TIPs) described in Chapter 11. SRPs can serve as a useful tool for setting long term goals in environmental policy. SRPs could be used to estimate greenhouse gas emissions associated with a specific sea level rise target. The results presented here show that it is possible to derive SRPs for the various greenhouse gases.

The SRPs are not identical to the TIPs because the SRPs are based on transient responses, whereas TIPs are calculated for the equilibrium response. As a result, the SRP estimates are relatively more uncertain than the TIP estimates. 


\section{Chapter 9}

\section{Socio-Economic Impact}

\subsection{Introduction}

IMAGE contains a separate module for roughly estimating the socio-economic impact of global temperature and sea level rise on Dutch society. The module is based on a tentative socio-economic study, not pretending to give a comprehensive overview of the consequences for the Netherlands. Sea level rise is a major issue in the Netherlands, because of the country's vulnerability to rising sea level, which has resulted in the so-called Delta flood protection plan after the last tragic flood in 1953 (2000 people drowned). The socio-economic impact module includes most relevant aspects that can be quantified for the Netherlands. The most important impacts considered relate to the protection of coastal area (by dikes and dunes) and the adaptations required for the water management. Four consistent sets of scenarios have been worked out, based on differences in economic growth, energy use, international environmental measures etc, which are described in Chapter 2. Given these scenarios estimates are made of the costs of coastal defence and water management in the Netherlands as a result of adaptation to impacts of regional climate change and sea level rise. For other social sectors, such as agriculture and energy use, only tentative conclusions are drawn.

Ecological effects have not been considered yet but, on a European scale, some will be added to the existing model in the near future. In view of the many uncertainties, the results from this socio-economic simulation model give only indicative ranges of costs for the different sectors. 


\subsection{General Model Description}

As mentioned before the modelling framework used is the IMAGE model, which has been described extensively in previous chapters. In this study all socio-economic consequences are based upon the four different scenarios, of which an elaborate description is given in Chapter 2 and in Rotmans et al. (1990a). The highest scenario, A: unrestricted trends, assumes a continuation of economic growth, not limited by environmental constraints. Scenario B: reduced trends, supposes the implementation of environmental measures presently being considered to control other environmental problems like acidification. Scenario C: changed trends, assumes the enforcement of stricter environmental control. Finally, scenario D: forced trends, assesses the possibilities of maximum efforts efforts towards global sustainable development. World population growth, a factor that is assumed not to be influenced by greenhouse policies, reaches 10.8 billion in 2100 in all scenarios.

Based on these four scenarios IMAGE calculates global temperature increase and sea level rise (Figures 9.1 and 9.2), providing the input for the socio-economic impact model. One of the missing links of the model is the regional shift in the main hydrological pattern, direcly influencing the runoff of the great rivers Rhine and Meuse and thus the country's water balance.

The emissions of trace gases are input for the calculation of several global phenomena such as trace gas concentrations, temperature increase and sea level rise. The latter two are input for the socio-economic impacts modules, in which the costs and benefits of various socio-economic consequences for the Netherlands are calculated. The separate model on the socio-economic impacts of the greenhouse effect for the Netherlands again consists of independent, interlinked modules, and is based on both an extensive study of the literature and knowledge transfer resulting from a close cooperation with specialized Dutch experts of Rijkswaterstaat Netherlands, Delft Hydraulics, Dutch Organization for Applied Scientific Research (TNO) etc. Figure 9.3 gives the modular build-up of the socio-economic impact model.

Simple dynamic modules have been developed, which will be described in the next section, reflecting the complicated mechanisms in the fields of coastal defence and water management, resulting in dynamic relationships between input (climate change, sea level rise) and output (damage or profit expressed in terms of money). 


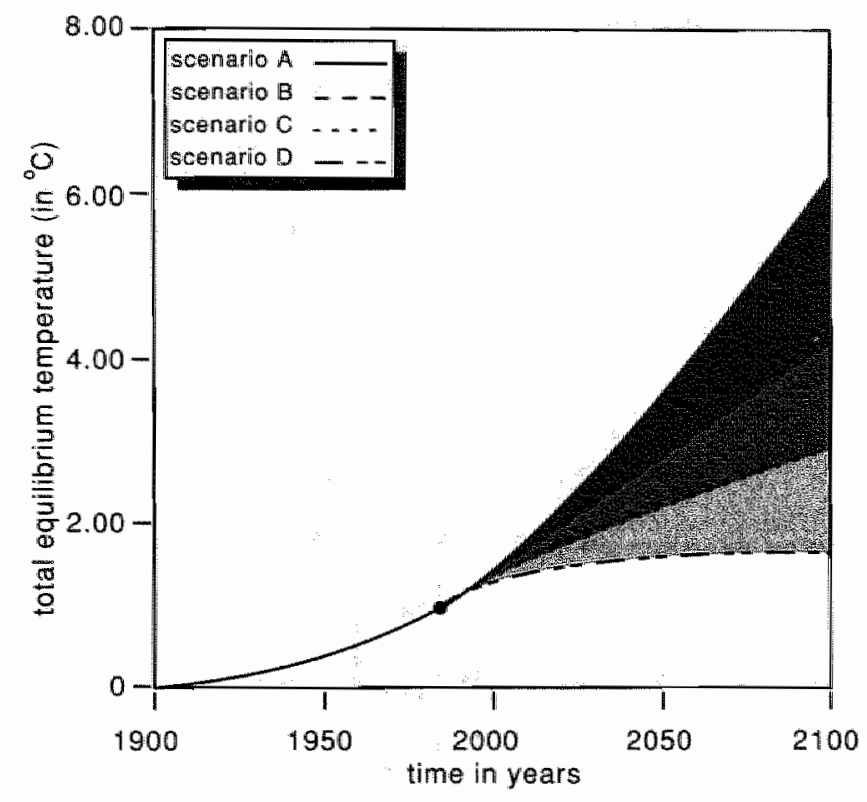

Figure 9.1: Global mean equilibrium temperature increase.

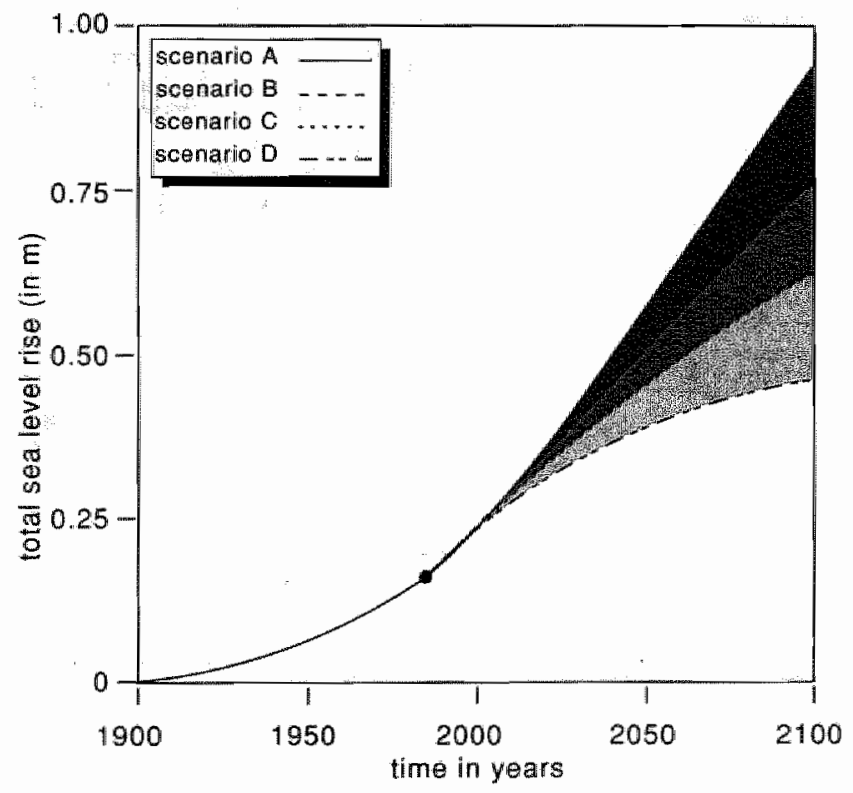

Figure 9.2: Global mean sea level rise. 


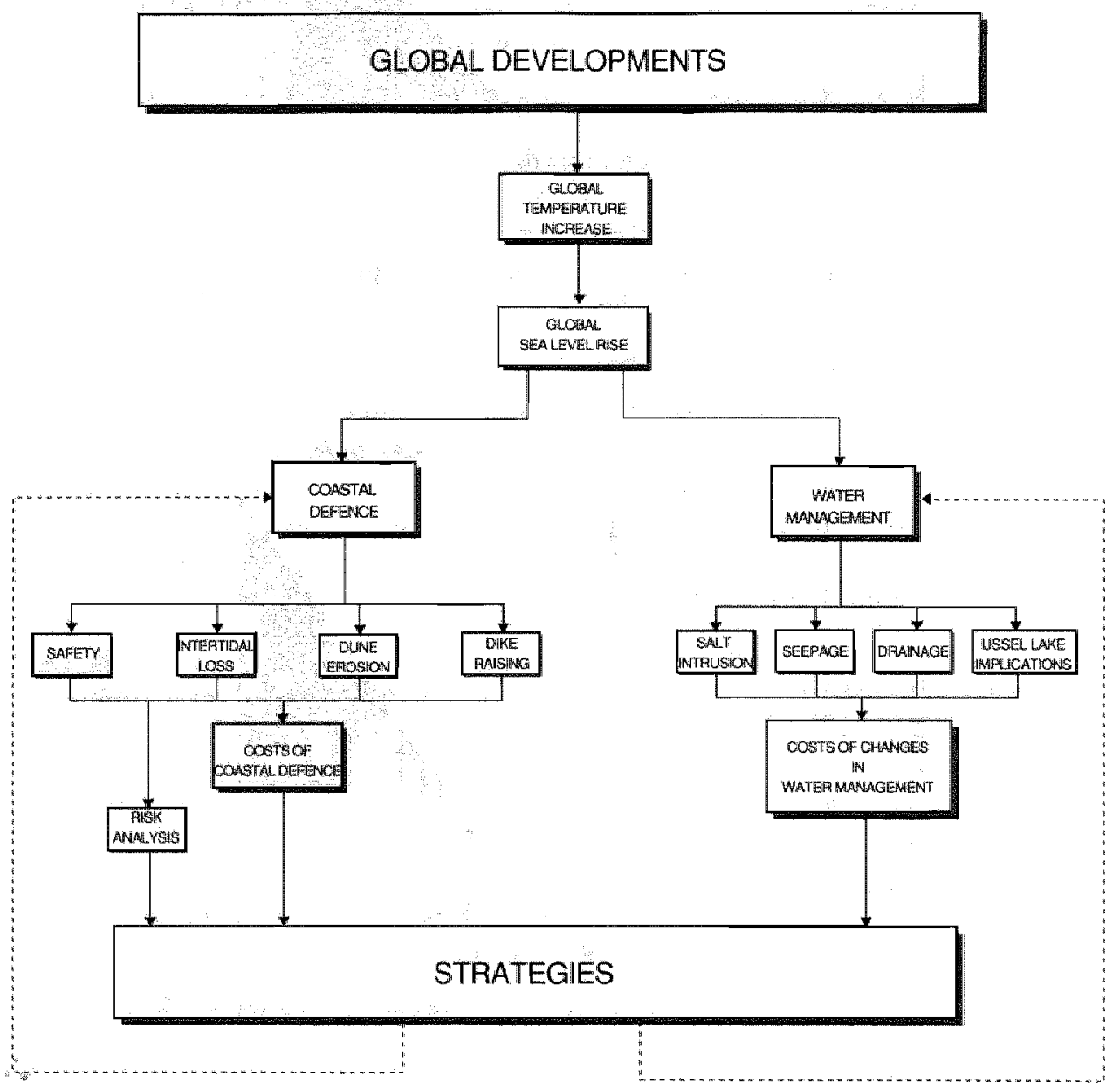

Figure 9.3: Socio-Economic Impact Model for the Netherlands. 
The impact modules have a simulation period of 110 years, from 1990 to 2100 , unlike the simulation period of 200 years for the global phenomena. For the agricultural and energy sector only tentative quantifications have been made, due to large uncertainties with respect to regional climate changes, in particular the changes in the hydrological cycle.

In Figures $9.4 \mathrm{a}, 4 \mathrm{~b}$ and $4 \mathrm{c}$ the spatial segmentation of the Netherlands is given for the coastal defence and water management (seepage and drainage). This picture shows three kinds of coastal defence systems, dikes, dunes and intertidal zones. The dikes are segmented into three parts, the Delta area, the Western and the Northern part. The dunes are mainly concentrated in the Western part and the Frisian Islands. The main intertidal areas for the Netherlands are the Wadden area and the Delta area. For the Dutch coastal zones the optimal economic dike height is calculated as well as the erosion of dune areas and losses of intertidal areas. However the latter is done in a very schematic way, considering the barely known changes in the morphology of the intertidal zones, which are mainly determined by the increase or decrease of the tidal volume in relation to the change of the cross profile of the tidal inlet (de Ronde, 1988). Another difficulty relates to the economic value of intertidal areas, so the socio-economic consequences for the intertidal zones are not taken into account.

With regard to the water management sector various areas have been differentiated, 22 seepage areas, 7 drainage areas, the New Waterway area for salt intrusion and the IJssel lake. Based on this zoning both the principal financial consequences and the various alternative countermeasures for the water management sector are set out. 


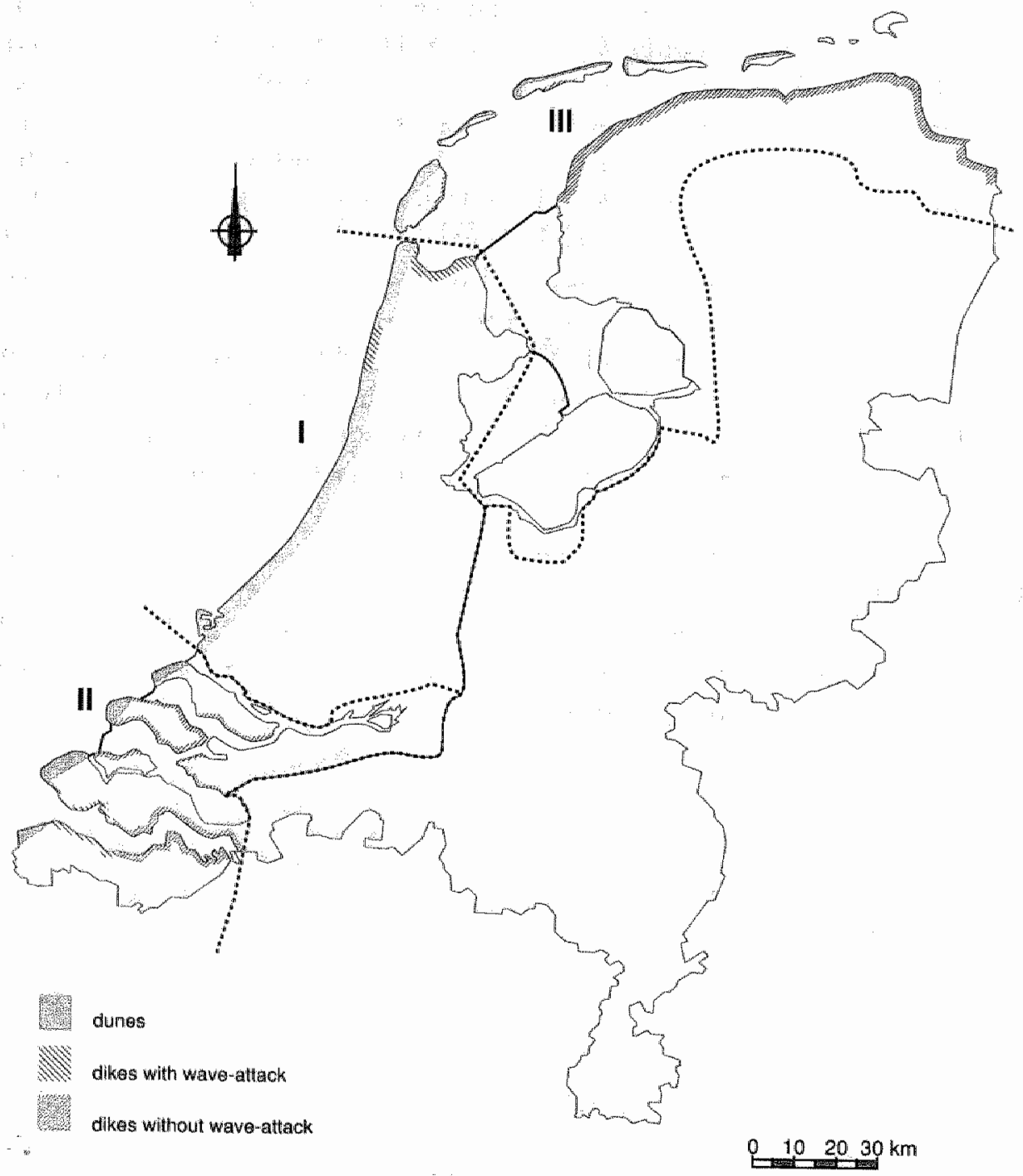

Figure 9.4a: Coastal Defence system of the Netherlands. 


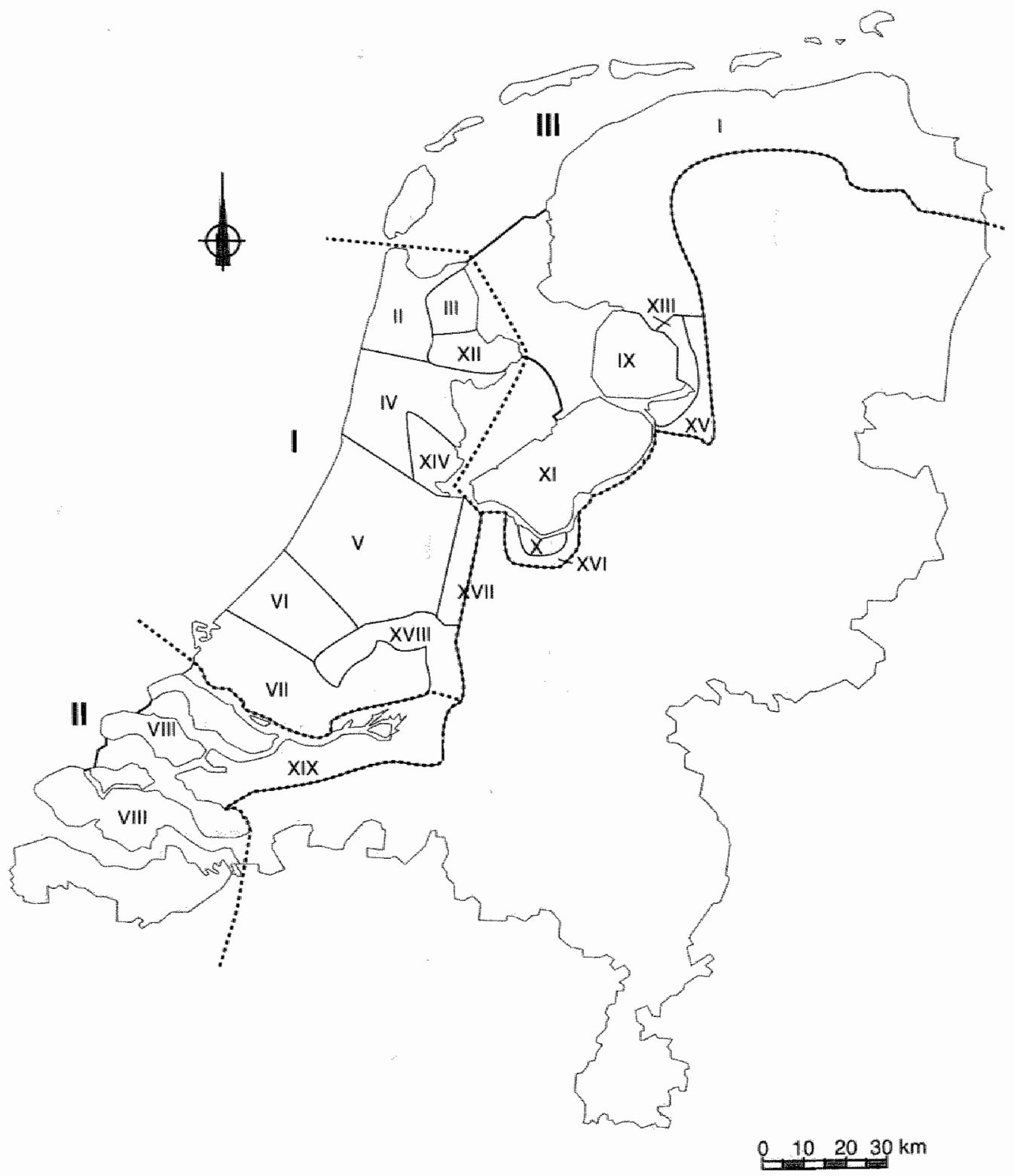

Figure 9.4b: Seepage regions for the Netherlands. 


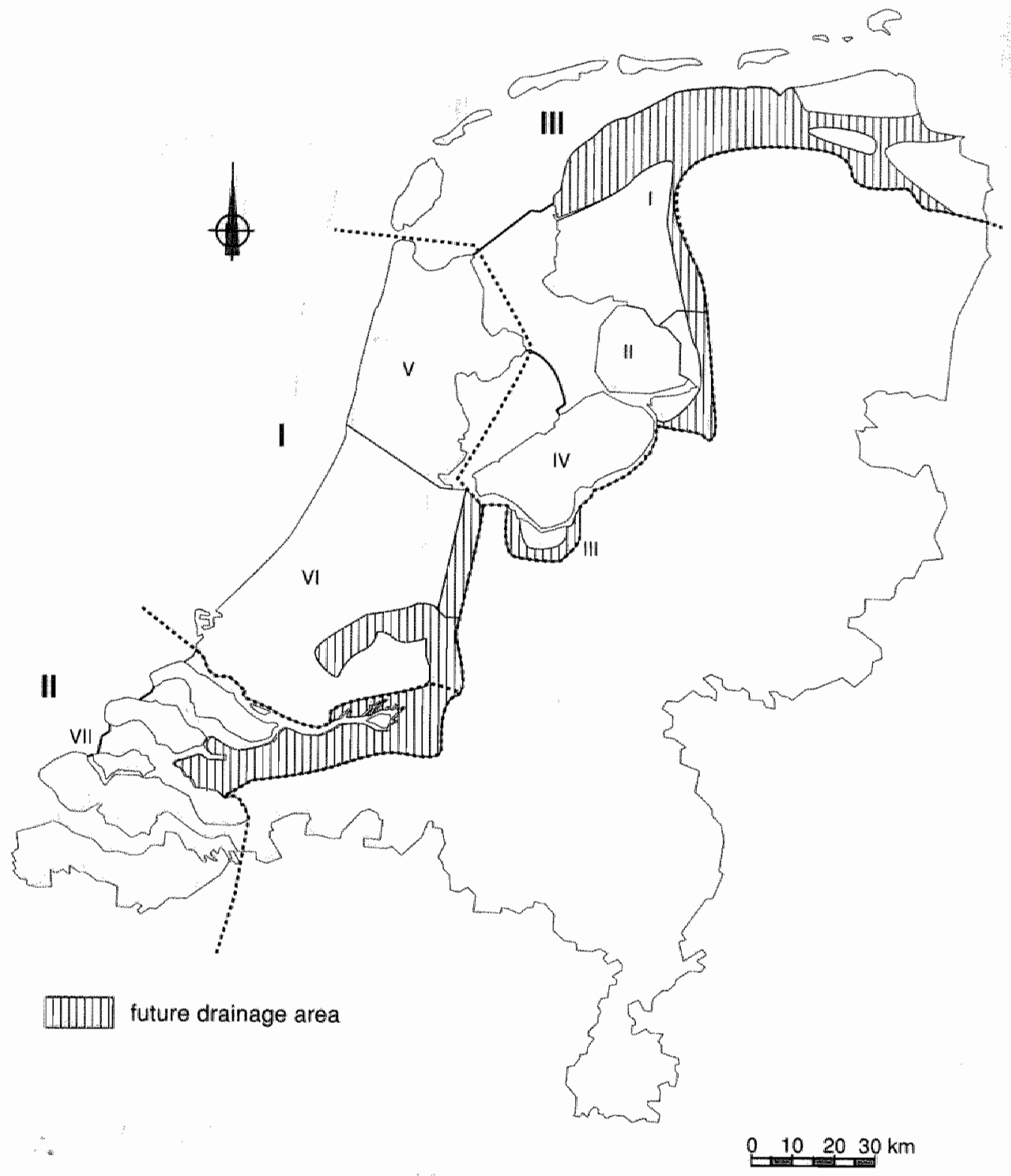

Figure 9.4c: Drainage regions for the Netherlands. 


\subsection{Quantification of Impacts for Various Sectors}

\subsubsection{Introduction}

The Netherlands have been struggling with the sea level for hundreds of years already, and this has resulted in a highly organized protective system of dikes and dunes. A sea level rise induced by climate change would affect the structures of this protective system. A sea level rise is therefore of crucial importance to the Netherlands. Because it is not yet possible to quantify ecological and geomorphological impacts, in this study only the economic and societal implications of sea level rise are modelled for the Netherlands. The economic impacts relate to the protection of coastal area by dike raising and dune strengthening, and adaptations required for water management. With respect to dike raising several mathematical models have been developed. One model considers dike raising as an economic decision problem, taking into account the safety levels, dike raising costs, and the expected damage costs in case of an inundation. Another model primarily focuses on stabilizing the present safety level. Concerning the sandy coast protection our model depends heavily upon more detailed models of Rijkswaterstaat.

Next to economic impacts of sea level rise in socio-economic terms are also treated, such as loss of intertidal areas, salt intrusion, seepage, drainage problems, etc. One of the missing links in our socio-economic modules is the regional shift in the main hydrological pattern, directly influencing the runoff of the great rivers Rhine and Meuse and so the country's water balance.

In the following sections the background and mathematical dynamics of the modules concerning coastal defence, both fixed coast and sandy coast, and water management are presented. It should be noted that all sums of money have been expressed in terms of Dutch guilders (Df: is approximately 0.5 US Dollar).

\subsubsection{Coastal Defence}

The Netherlands' coast is half protected by dunes and half by dikes (see Figure 9.4a). Concerning the dikes, two types of dikes are distinguished, dikes with wave attack and dikes without wave attack, which differ in average height. Dikes with wave attack have a height between 10 and 15 meters above N.A.L. (Normal Amsterdam Level), whereas dikes without wave attack are lower, from 5 to 7 meters above N.A.L. This difference has to do with the situation of the dikes. Dikes with wave attack are situated along the Dutch 
coast in direct contact with the open North Sea, and must be able to resist a storm surge of +5 meter N.A.L. and its attendant heavy wave attacks. These heavy wave attacks necessitate an extra dike height of 5 till 10 meter, on top of the already required +5 meter N.A.L. for the storm surges, resulting in a total dike height of 10 to 15 meters N.A.L. By contrast, the dikes without wave attack are situated in Zeeland and along the Northern coast, having no direct contact with the North Sea, see Figure 9.4a. Therefore for these dikes a dike height of 5 to 7 meters will suffice. As for the dunes no distinction has been made with respect to dune height, but a segmentation into 13 dune segments has been used, based mainly on morphological properties (Den Elzen and Rotmans, 1988).

Assuming that the Dutch coastal defence system will only be extended and reinforced, but not fundamentally altered, for these two kinds of coastal defence systems an attempt has been made to model the consequences of an accelerated sea level rise. When raising the dikes, two additional features should be taken into account. First the additional sea level rise of 5 centimeters due to the high tide level. Consequently, maintaining the present safety level implies an additional dike raising of 0.05 meter (Eversdijk, 1989). Second, the extra strength of the higher waves requires an extra raising of the dikes with wave attack, represented by a correction factor.

Next the following aspects are discussed: safety, dike raising, and dune strengthening.

\section{Safety}

Safety is defined here as the protection against flooding, which can be expressed in terms of the frequency of overtopping the flood protection system. After the disastrous flood in February 1953 in Zeeland, by which most of the Delta area in the Netherlands was flooded, almost all dikes along the Dutch coast were raised, now enabling them to resist a storm surge of +5 meter N.A.L. The present theoretical chance of inundation, the so-called "Delta norm" is 0.0001 for Central Holland, being a risk of inundation once every 10,000 years, and 0.00025 for the other threatened areas in the Netherlands, Zeeland and the Northern part. The last big storm of 1953 reached +3.80 meter N.A.L. and had a statistical chance of inundation of 0.0045 (Delta Commission, 1960),

The relationship between frequency of overtopping and sea level rise is assumed to be exponential, based on historical sea level data (Van Dantzig, 1956, De Jong, 1985, Rijkswaterstaat, 1989, De Ronde, 1988, Delta Com- 
mission, 1960 and Vrijling, 1985):

$$
P(h \geq H)_{t}(i)=P(h \geq H)_{0}(i) * e^{\ln (10) *\left(\alpha * \Delta H_{i}(i)\right.}
$$

with:

$P(h \geq H)_{t}(i)=$ probability of exceeding of dike height $H$ at time $t$ in area $i, i=1,2,3$

$\mathrm{H}=$ dike height above mean sea level $(0 \mathrm{~m} . \mathrm{A} . L).(m)$

$\alpha \quad=$ gradient of flooding frequencies of storm surges (=1.5, Wind, 1987)

$P(h \geq H)_{0}(i)=$ the present safety norm (equals to 0.0001 for area 1 and to 0.00025 for area 2 and 3 )

$\triangle H_{t}(i) \quad=S L R_{t}+\psi+C R F C-D R_{t}(i)$

$S L R_{t} \quad=$ sea level rise at time $t(m)$

$\psi$

$C R F C \quad=$ correction factor for dike raising, caused by extra wave height in case of dikes with wave attacks $(m)$

$=\beta * S L R_{2100}$

$\beta \quad=0.6$, for dikes with wave attack (De Ronde and De Vogel, 1989)

$=0.0$, for dikes without wave attack

$D R_{t}(i) \quad=$ total dike rise at time $t$ for area $i(m)$

Practically, this means that reducing the present safety norm, or equivalently, Delta norm, of 0.0001 to a tenth, involves a necessary dike raising of about 0.70 meter.

\section{Dike Raising}

An accelerating sea level rise will cause a decrease in safety, according to Equation (9.1), meaning numbers of people and goods at risk. Countering this threat requires a raising of the dikes. Because it seems impossible to predict both sea level rise and the pace of it, we assume dike raising will be carried out stepwise. Construction in one step would mean an unnecessarily high financial and material risk. Based on this assumption, the total dike raising for the whole period of 1990 till 2100 is calculated. Subsequently an algorithm is applied which generates the time pathway of a stepwise dike raising for the whole period till 2100, using the already calculated total dike raising. This algorithm is described in detail in Den Elzen and Rotmans (1988). 
As mentioned before, the construction of a total dike raising operation depends upon the type of dike considered. Next to adaptation to sea level rise itself, additional standard raisings are necessary due to both high tide level and higher waves, the latter only for dikes with wave attack, in order to maintain the present Delta norm.

The problem of dike raising is here considered as an economic decision problem, where the criterion for dike raising is related to the value of the people and materials at risk. This implies that the present safety norm will be no longer given in advance as 0.0001 , but should be calculated based on this economic analysis. The economic decision problem is the calculation of an optimal dike raising at minimal costs for the period 1990-2100. This results in the following total dike raising equation:

$$
D R(i)_{2100}=O P D R(i)+\psi+C R F C
$$

with:

$D R(i)_{2100}=$ total dike raising in the year 2100 in area $i=1,2,3(\mathrm{~m})$

$O P D R(i)=$ optimal dike raising in area $i(m)$

$\psi \quad=0.05$

$C R F C=\beta * \operatorname{SLR}_{2100}(m)$

$S L R_{2100}=$ sea level rise at the end of the simulation period, in $2100(\mathrm{~m})$

$\beta \quad=0.6$, for dikes with wave attack (De Ronde and De Vogel, 1989)

$=0.0$, for dikes without wave attack

The goal function to be minimized in this analysis, the total costs over the period 1990 to 2100 , consists of the sum of the costs of dike raising, and the capitalized damage expectation of the material and human losses when dike breach occurs. This goal function is expressed in Equation (9.3) (Den Elzen and Rotmans, 1988 and Den Elzen et al., 1990). The costs of dike raising are assumed to be linear with dike raising; this means that if dike raising equals $x$ meter, the costs of dike raising will be proportional to the product of the marginal costs of dike raising per meter raising per kilometer dike, and the factor $x$. To carry out this economic analysis in a sound way all economic monetary units (in Df) in the goal function (9.3) have to be discounted to the year 1990.

$$
\begin{aligned}
l(i) * & {\left[I_{0}(i)+k(i) * O P D R(i)\right] } \\
+ & \sum_{t=1990}^{2100}(1-\delta / 100)^{t-1990} * W_{0}(i) * P(h \geq H)_{0}(i) *
\end{aligned}
$$




$$
e^{\alpha * \ln (10) *\left(S L R_{t}-O P D R(i)\right)}
$$

with:

$O P D R(i) \quad=$ optimal raising of the design level in area $i(\mathrm{~m})$

$I_{0}(i)=$ initial costs of dike raising for one kilometer dike (Dft $/ \mathrm{km}$ )

$l(i)=$ length of dikes in area $i(\mathrm{~km})$

$k(i)=$ marginal costs of dike raising in area $i$ per meter raising per kilometer dike (Dfl $/ \mathrm{m} . \mathrm{km}$ )

$\delta \quad=$ reduced rate of interest (real interest minus inflation) (in $\%)$

$p(h \geq H)_{0}(i)=0.0001$, for area 1

$=0.00025$, for area 2 and 3

$W_{0}(i)=$ economic value of area $i$ at risk in $1990(\mathrm{Dfl})$

$=p_{d} * N(i) * V_{0}(i)+M_{0}(i)$

$M_{0}(i)=$ capitalized value of the protected goods, including firms, cattle, etc. for area $i(\mathrm{DF})$

$p_{d} \quad=$ the probability of dying given an inundation (see Table 9.1, Vrijling, 1985)

$N(i) \quad=$ number of protected people in area $i$

$V_{0}(i) \quad=$ capitalized value of one human being in 1990 (see Table 9.1) (Dfl)

$\alpha \quad=$ gradient of flooding frequencies (see Equation (9.1))

$S L R_{i} \quad=$ sea level rise at time $t(m)$

This reaches a minimum for the optimal dike raising:

$$
\begin{aligned}
O P D R(i)= & \ln \left(\left(\ln (10) * \alpha * W_{0}(i) * P(h \geq H)_{0}(i) *\right.\right. \\
& \left.\left.\sum_{t=1990}^{2100}(1-\delta / 100)^{t-1990} * e^{\ln (10) * \alpha * S L R_{t}}\right) / k(i) * l(i)\right) / \alpha
\end{aligned}
$$

The values of all parameters used are listed in Table 9.1.

For calculating the total costs for dike raising, the inner dikes in Zeeland are also taken into account. The raising of the design level for those dikes is supposed to be equal to the raising of the design level throughout Zeeland. The algorithm generating the stepwise execution of dike raising is described in detail in Den Elzen and Rotmans (1988).

In Den Elzen and Rotmans (1990) a second strategy, based on maintaining the present safety norm is discussed. The resulting dike raisings for both 
methods are presented and compared with each other.

\section{Dune Strengthening}

An accelerated sea level rise will increase present erosion, which is about 6.5 million $m^{3}$ yearly (Rijkswaterstaat, 1989, Stive, 1989, Beafort et al., 1989), and will cause a retreat of the whole coastline. This would jeopardize the safety of many people and material goods in the areas lying behind the dunes. Therefore the dunes will have to be strengthened. With the help of computer simulation models developed by Rijkswaterstaat, (Dillingh et al., 1984), the dune erosion can be simulated. In Knoester et al. (1989) assessments have been made for the coastal retreat for a sea level rise in 2090 of 0.2 meter, and 0.6 meter, respectively. In view of all uncertainties concerning coastal morphological processes, a linear relationship between the coastal retreat and the rate of the sea level rise is supposed. Thirteen dune areas are distinguished, and for each area the coastal retreat is calculated at any time, interpolating with linear regression the already known reference points at a sea level rise of 0.2 and 0.6 meter:

$$
C R_{t}(i)=a(i) * R S L R_{t}+b(i)
$$

with:

$C R_{t}(i)=$ coastal retreat at time $t$ for area $i, i=1,2, \ldots, 130$ $a(i), b(i)=$ coefficients for area $i$

$R S L R_{t}=$ rate of sea level rise at time $t(m)$

The present policy on dune erosion implies concentration on taking measures only in case of threats to safety, nature, water supply or recreation. A further retreat of the dunes and the coastline is socially unacceptable and moreover too expensive in the long run. So, for large parts of the Dutch coast, full compensation of erosion such as sand depletion is necessary. The costs of a policy to arrest dune erosion are simulated on the basis of the calculated dune erosion. These costs are composed of the present costs (about 30 million Dfl yearly) and the costs caused by extra dune erosion (about 5 Df per $m^{3}$ erosion (Vrijling, 1985)).

In Knoester et al. (1989) the relation between coastal retreat and yearly dune maintenance costs, as well as the relation between coastal retreat and côsts for dune erosion is given. The total costs for the dunes can then be expressed by:

$$
D C_{t}=\sum_{i=1}^{13} m * C R_{t}(i)+e * C R_{t}(i)
$$


with:

$D C_{t}=$ total costs for dunes at time $t$ (Df)

$m=$ coefficient caused by dune maintenance costs $(\mathrm{DH} / \mathrm{m})$

$e \quad=$ coefficient caused by dune erosion costs $(\mathrm{Df} / \mathrm{m})$

\begin{tabular}{|c|c|c|c|}
\hline & area 1 & area 2 & area 3 \\
\hline & Central Holland & $\begin{array}{c}\text { Zeeland } \\
(+ \text { inner Zeeland })\end{array}$ & $\begin{array}{l}\text { Friesland and } \\
\text { Gromingen }\end{array}$ \\
\hline $\begin{array}{l}\text { gradient of } \\
\text { frequencies }(\alpha)\end{array}$ & 1.5 & 1.5 & 15 \\
\hline $\begin{array}{l}\text { present safety norm } \\
p(h \geq H)_{0}\end{array}$ & 0.0001 & 0.00025 & 0.00025 \\
\hline $\begin{array}{l}\text { Initial costs of dike } \\
\text { raising }\left(I_{0}\right)(\mathrm{Dft} / \mathrm{m})\end{array}$ & $310^{6}$ & $310^{6}$ & $310^{6}$ \\
\hline $\begin{array}{l}\text { marginal costs of } \\
\text { dike raising }(k) \\
(\mathrm{DH} / \mathrm{m} . \mathrm{km})\end{array}$ & $410^{6}$ & $4.10^{6}$ & $410^{6}$ \\
\hline $\begin{array}{l}\text { reduced rate } \\
\text { of interest }\end{array}$ & 2 & 2 & 2 \\
\hline $\begin{array}{l}\text { economic value of } \\
\text { materials at risk (Df) }\end{array}$ & $1.41810^{12}$ & $2.6710^{11}$ & $2.8510^{11}$ \\
\hline $\begin{array}{l}\text { chance of dying at } \\
\text { inundation }\end{array}$ & 0.01 & 0.01 & 0.01 \\
\hline $\begin{array}{l}\text { capitalized value of a } \\
\text { human being (DAl) }\end{array}$ & $510^{6}$ & $510^{6}$ & $510^{6}$ \\
\hline $\begin{array}{l}\text { number of people } \\
\text { (in 1985) }\end{array}$ & $6.0510^{6}$ & $0.8510^{6}$ & $1.310^{6}$ \\
\hline $\begin{array}{l}\text { length of dikes }(\mathrm{km}) \\
\text { with wave attack } \\
\text { without wave attack }\end{array}$ & 45 & $\begin{array}{c}90 \\
(370)\end{array}$ & $\begin{array}{l}15 \\
150\end{array}$ \\
\hline
\end{tabular}

Table 9.1: The values of the parameters used in the socio-economic model. The economic values are based on projections of the Central Planning Bureau (1984). 


\subsubsection{Water Management and Water Supply}

For the water management and water supply sectors the consequences of an accelerated sea level rise and an intensification of the hydrological cycle have been examined and modelled. Four different conceivable problems are involved: salt intrusion, seepage, drainage, and the mainten ance of the IJssel lake.

\section{Salt Intrusion}

In the Netherlands salt intrusion mainly occurs in two branchings of the New Waterway: Old Meuse and New Meuse - Dutch IJssel (see Figure 9.4). The inland salt load due to salt intrusion depends, according to a method developed by Bruggeman (1988a), on the slope and water depth of the New Waterway and discharge of the Rhine and Meuse. In this method the sedimentation pattern of the New Waterway is assumed to remain unchanged. Another influential factor in the calculations is the discharge of the New Waterway. In light of the uncertainties about the regional pattern of an impending climate change it is not yet possible to estimate this future discharge. Therefore it is assumed to be constant in time. In case of a sea level rise the salt tongue intrudes further inland, and it passes a fixed point in the Old Meuse or in the Dutch IJssel more frequently. This results in an increasing salinity in the Westland (an area near Rotterdam), and causes great agricultural damage.

Moreover, the increasing salt intrusion threatens several water-collection areas. The total costs incurred because of salt intrusion are much higher than costs of intrusion-preventing actions (Pulles, 1985).

\section{Seepage}

Seepage is the constant underground current of salt water in the direction of low-lying areas as a consequence of the head difference between sea level rise and large areas situated below sea level behind the dunes (see Figure 9.4). The inland salt load caused by seepage depends on the resistance of the geological beds in the dunes, the difference between sea levell and polder level and precipitation (Bruggeman, 1988b). Sea level rise occasions not only an increase in the difference between sea level and polder level, but also an enlargement of regions below sea level, together leading to an increasing seepage in the regions behind the dunes. This yields the following expression 
for the total salt load due to seepage in the 22 specific seepage regions:

$$
Q_{t}(i)=L *\left(G_{1}(i) *\left(H(i)+S L R_{t}\right)+\alpha * G_{2}(i) * N\right)
$$

with:

$Q_{t}(i)=$ salt load flux in area $i$ at time $t$ (in $\mathrm{m}^{3} /$ day) $i=1, \ldots, 22$ (22 seepage regions)

$\mathrm{L}=$ length of the coast line (in $m$ )

$G_{1}, G_{2}(i)=$ geological constants of the dunes in area $i$ (in $m /$ day)

$H(i)=$ difference between the sea and polder level in area $i$ (in $m$ )

$S L R_{t}=$ global sea level rise at time $t$ (in $m$ )

$\mathrm{N} \quad=$ yearly mean precipitation (in $m$ )

$\alpha \quad=$ geohydrological correction factor

The primary effect of seepage is great agricultural damage in those low-lying areas (Figures $9.4 a$ and $b$ ).

\section{Drainage}

In winter the remainder of precipitation (precipitation minus evaporation) and the total salt load owing to seepage and salt intrusion must be drained out of the inland waters. An increasing sea level rise will induce an increasing total discharge owing to both an increase in salt load and an enlargement of the drained area, as well as a growing difference between sea and polder level. This will entail extra costs upon drainage, depending on the increase in total discharge and the sea level rise. The relation between these two is supposed to be linear according to Abrahamse et al. $(1982 \mathrm{a}, \mathrm{b}, \mathrm{c})$, and de Jong (1986).

$$
D_{t}(i)=\left(C_{1} * \Delta U_{t}(i)+C_{2} * Q\right) *\left(S L R_{t}+H\right)
$$

with:

$D_{t}(i)=$ extra drainage costs for area $i$ at time $t$ (in Dflyr) $i=1, \ldots 7$ (seven drainage segments)

$C_{1}=$ constant of area $i$ (in Dfl $/ m^{3} \cdot m \cdot y r$ )

$C_{2}=$ constant of area $i$ (in Dfl $/ m^{3} \cdot m \cdot d a y$ )

$\Delta U_{t}(i)=$ increase in discharge in area $i$ (in $\left.\mathrm{m}^{3}\right)$

$\mathrm{Q}=$ daily water amount in area $i$ (in $\mathrm{m}^{3}$ )

$S L R_{t}=$ sea level rise $(m)$

$H \quad=$ raising height in view of resistance (in $m$ ) 


\section{IJssel Lake}

Presently, there is a natural water discharge from the IJssel lake to the Wadden Sea, caused by the head difference between the sea level of the IJssel lake and the Wadden Sea at low tide $(-0.9 \mathrm{~m}$ N.A.L. $)$. An accelerated sea level rise, exceeding 0.4 meter, will drastically disturb this natural discharge. Measures have to be taken in order to restore the water balance, of which three different options are proposed in den Elzen and Rotmans (1988), namely:

- drainage of the IJssel lake, with high drainage costs;

- raising of the level of the lake, requiring an equivalent corresponding raising of the dikes around the lake;

- digging a canal through the lake, necessitating a dike construction through the lake.

De Ronde and De Vrees (1990) argue that the drainage of the IJssel lake would be the best solution, because of the flexibility and the possibility of spreading the costs for changing the infrastructure. Within 30 years the situation of the IJssel lake might come to a head, and then a choice from the possible options must be made.

\subsubsection{Agriculture}

Temperature is one of the major growth factors in agriculture. Crops differ in their heat and water requirements. For some crops, like seed plants, a surplus of degree days caused by a temperature increase will decrease the yield, as a consequence of a shortened growth season, while for others the growing season will be extended. Nowadays in the Netherlands there is a precipitation shortage during summer, which will only become worse in the expected new hydrological conditions (Den Elzen and Rotmans, 1988).

The preliminary research of Goudriaan (1988) into the consequences of the greenhouse effect on agriculture for the Netherlands shows that there may be a complex shift in agricultural species; with predominantly positive effects. The greatest disadvantages arise from a possible prolonged dryness in summer. Positive aspects come from the stimulating effect of the increased carbon dioxide concentration on the photosynthesis of most crops. The production growth (cropped portion) of most $C 3$ plants by increased $\mathrm{CO}_{2}$ will amount to 0.17 percent per year per $p p m \mathrm{CO}_{2}$ (Health Council of the Netherlands, 1986). However climate changes as well as other air pollutants 
might undo this positive effect. Unambiguous climate/crop models have not yet been developed. In spite of this it can be tentatively concluded that the Dutch agricultural sector will not suffer greatly under the direct harmful consequences of climate changes. It will be rather influenced by new technological developments, and environmental measures adopted by the European Community.

\subsubsection{Energy Use}

Climate and energy are linked. On the one hand, climate changes influence energy use (heating, cooling and drainage); and on the other hand, climate is influenced by energy use (greenhouse effect). In Den Elzen and Rotmans (1988) the consequences of a temperature increase have been examined for the cooling and space heating sectors, the lattier being broken down into heating for households and offices.

The energy saving for households by increased temperature is calculated with a simulation model developed by the Dutch Organization for Applied Scientific Research, TNO (Dubbeld, 1985), resulting in the following expression:

$$
\Delta E(t)=\Delta T_{e q}(t) *(0.126 * E N S P+31.73)
$$

with:

$\Delta E(t)=$ energy saving of a mean household in the Netherlands at time $t$ (in $\mathrm{m}^{3} / y r$ )

$\Delta T_{e q}(t)=$ global mean equilibrium temperature increase at time $t$ (in ${ }^{\circ} \mathrm{C}$ ) $E N S P=$ energy use for space heating for a mean household (about 1900 gas $\mathrm{m}^{3} /$ year in the Netherlands according to Huizinga, 1988) (in $\mathrm{m}^{3} / \mathrm{yr}$ )

This linear relationship does not hold beyond a temperature increase of $5^{\circ} \mathrm{C}$. In the heating sector the temperature increase may lead to high profits in energy saving. Quantifying these profits is difficult, because the future fuel and gas prices are unknowns. Calculations presented here assume no change in energy use and insulation of houses. Besides, apart from a temperature increase, remaining future climate conditions are supposed to be unaltered. Future fuel and gas prices are based on a moderate (middle) scenario of the Dutch Central Planning Bureau (Huizinga, 1988). On the other hand the reduced demand for heating would create a loss for the Dutch economy. Therefore it is still unclear how this decrease in heating demand will affect the Dutch economy. 
In the cooling sector we use a subdivision into cooling of food (refrigerators, freezers and cold stores) and space cooling (air conditioning) (Den Elzen and Rotmans, 1988). A temperature increase would mean additional costs for cooling and investment costs for air conditioning in public and private buildings (Gibbs et al, 1987). It is not yet possible to give reliable cost estimates for the cooling sector. In conclusion, weighing the costs and benefits for the energy use sector, the costs do not seem to outweigh the profits.

\subsection{Results}

As mentioned before the results are based on the four scenarios described in section 2.3. In the pictures only the range built up from the scenarios $A$ and $D$ is represented. Some results are shown by means of a map of the Netherlands, analogous to those given in the Figures $9.4 \mathrm{a}, 4 \mathrm{~b}$ and $4 \mathrm{c}$.

\section{Coastal Defence}

The frequency of overtopping the flood protection for the threatened area in the present situation as well as in a situation with a sea level rise of 0.5 meter, or 1.0 meter, respectively, is given in Figure 9.5. The frequency of overtopping in 2100 will increase from 0.0016 for scenario $D$ (forced trend) to more than 0.021 for scenario A (unrestricted trend) for Central Holland; the latter value goes far beyond the statistical chance of inundation of the disastrous big storm surge in 1953 . Figure 9.6 shows how the safety of the Western coastal zone (Central Holland) will change by application of the strategy of optimal dike raising for the scenarios $A$ and $D$. The path of frequency is sawtoothed, because of the sudden drop after each dike raising. After this the frequency will slowly increase, under the influence of a continuing sea level rise. The frequency at the end of the simulation ranges from 0.0000127 (scenario D) to 0.000044 (scenario $A$ ), being averaged only a quarter of the present Delta norm of 0.0001. Because this 'average" frequency of about 0.000028 forms the result of an econornic analysis, which takes into account the future worth of material goods and people at risk, this value can be considered as a new safety level. However, this value is much lower than the Delta norm. This means that, at the end of the next century, after having simulated several dike raising steps, the increased economic worth of the threatened area, necessitates a stricter safety norm. Based on the foregoing it can be concluded that the Delta norm should be tightened up. 
Figure 9.7 shows the calculated step-wise dike raising over the period 1990 to 2100 for the Western zone (Central Holland) for scenarios A and D. The number of steps and the raising per step depends on the total optimal dike raising and the minimum adaptation of a dike, which has been chosen as 30 centimeters. The total dike raising for the period 1990 to 2100 for scenario $A$ is about 2.40 meters (Central Holland), 2.30 meters (Zeeland), and 2.10 meters (Friesland and Groningen). For scenario $D$ the dike raising in 2100 is about 1.80 meters (Central Holland), 1.70 meters (Zeeland), and 1.55 meters (Friesland and Groningen). The total costs involved amounts up to about 20 billion guilders.

In both cases this optimal dike raising is added with extra adaptations due to high tide level and higher waves, of about $55 \mathrm{~cm}$. The relatively minor difference between the total dike raising in scenario $A$ and $D$ is caused by considering the dike raising issue as an economic decision problem.

Another strategy which could have been used is that of maintaining the safety level at the present "Delta norm" level (Den Elzen and Rotmans, 1988, and Den Elzen and Rotmans, 1990). Using this strategy gives a dike raising in the year 2100 of $1.55 \mathrm{~m}$ for scenario $\mathrm{A}$, and $0.80 \mathrm{~m}$ for scenario D. Now the maximum difference between the total dike raising for the two different strategies is about $1.60 \mathrm{~m}$. For this strategy the total costs vary from about 15 to 18 billion guilders.

\section{Dune Strengthening}

Figure 9.8 gives the costs of dune erosion for the period 1990 to 2100 for both scenarios. The total cost of dune strengthening will increase up to 5 billion guilders for scenario $\mathrm{D}$ to nearly 6.5 billion guilders for scenario $\mathrm{A}$ at the end of the simulation period (2100). 

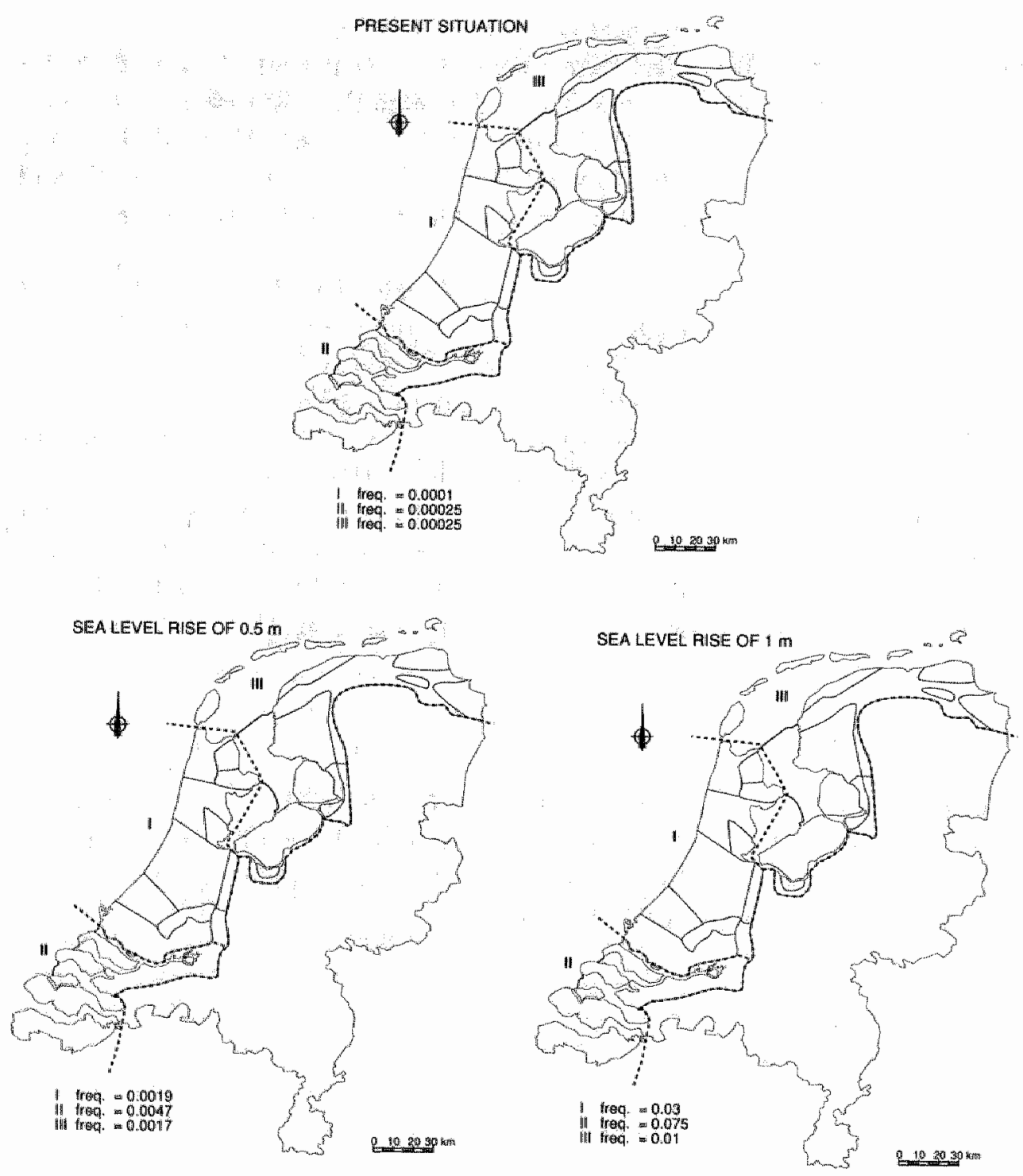

Figure 9.5: Flooding frequency (safety) of the threatened area in the present situation and in case of a sea level rise of 0.5 and $1.0 \mathrm{~m}$. 


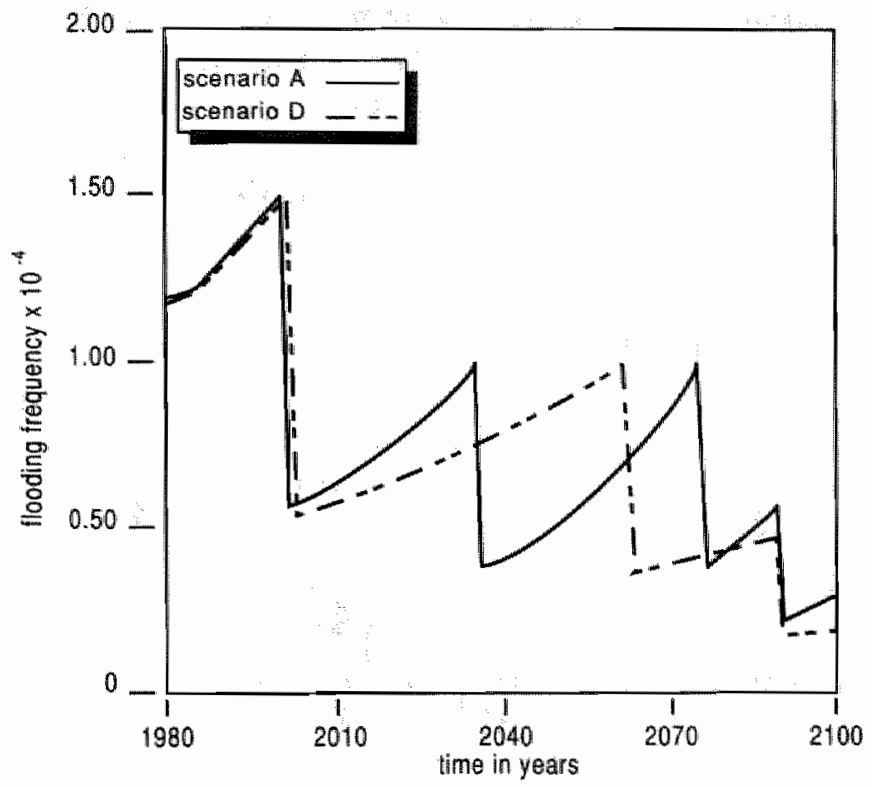

Figure 9.6: Flooding frequency for scenarios A and D for the Western coastal zone (Central Holland).

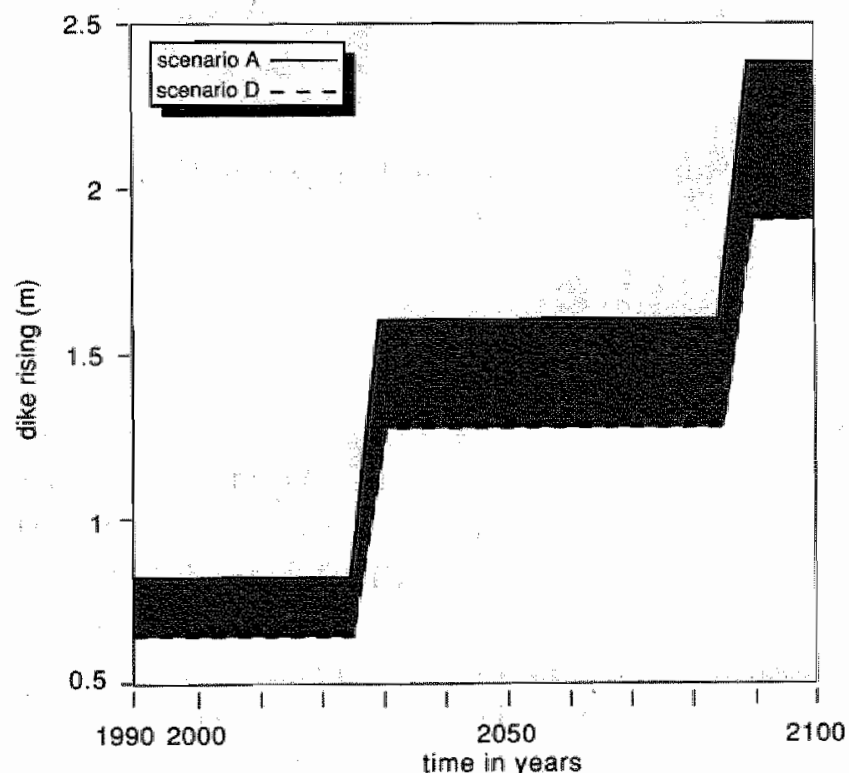

Figure 9.7: Simulated step-wise dike raising for scenarios A and D for the Western coastal zone (Central Holland). 


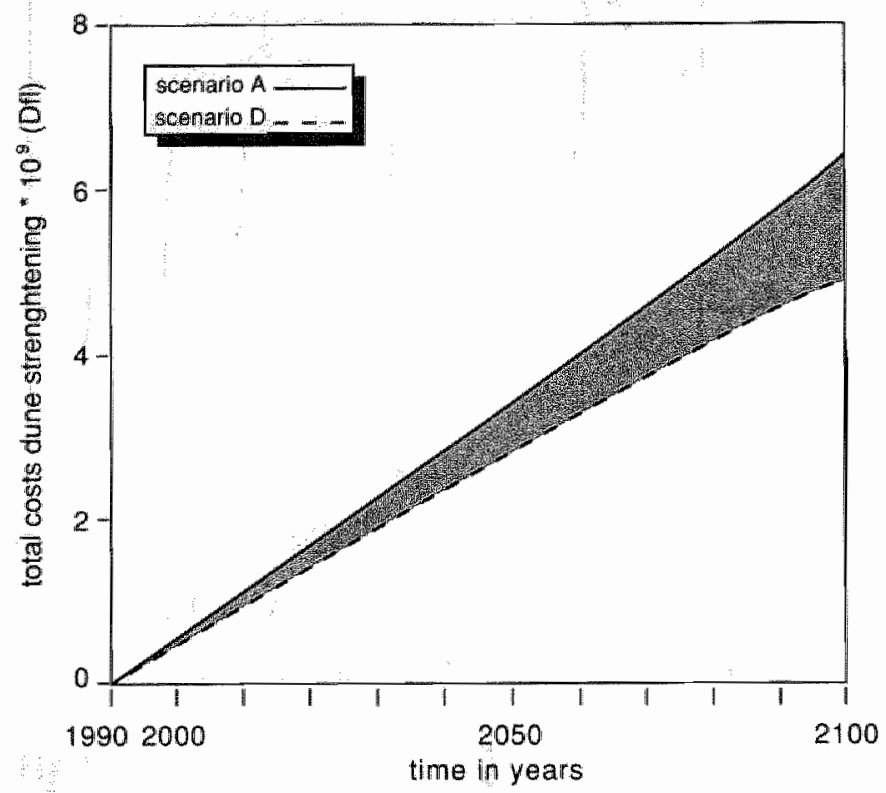

Figure 9.8: Simulated total costs of dune strengthening for scenario $A$ and $D$.

\section{Water Management}

Figure 9.9 gives the change in length of the salt tongue, measured from the Hook of Holland for a low Rhine discharge $\left(1000 \mathrm{~m}^{3} / \mathrm{s}\right)$ for scenarios A and D. The Dutch IJssel is situated at 30 kilometers from the Hook of Holland and with the situation as it stands the Dutch IJssel is not being penetrated by salt water. If sea level rise were to continue, the Dutch IJssel would become brackish for both scenarios, as Figure 9.9 shows. At another low discharge rate $\left(>1000 \mathrm{~m}^{3} / \mathrm{s}\right)$ the Dutch $1 J_{s s e l}$ will be intruded only for scenario A. Generally, in case of a continuing sea level rise, the Dutch IJssel will be intruded more frequently, which would cause high agricultural damage.

Figure 9.10 illustrates both the present and the future seepage situation for the Netherlands at a sea level rise of 0.5 and 1.0 meter, respectively. 
The total amount of seepage increases by $40 \%$ for scenario $D$ and by $80 \%$ for scenario A. The total present salt damage caused by seepage and salt intrusion, about 533 million guilders, will be nearly doubled, as the sea level rise amounts to 1 meter.

In Figure 9.11 the calculated drainage costs are depicted. In case of a 1 meter sea level rise the present costs, 12 million guilders, will increase to about 55 million guilders.

In Table 9.2 the pros (profits) and cons (costs) of the different options for the IJssel lake are represented by means of a multi-criteria analysis. Based on such an analysis, the digging of a canal through the lake, turns out to be the best solution. However, such a construction would bring about a dramatic change in the lake's infrastructure. Therefore priority should be given to the second solution.

Table 9.3 summarizes indications for the total costs for different scenarios (A and D). Actually the costs may be higher, because the influence on the fishing, shipping, industry, health and recreation sectors has not been taken into account.

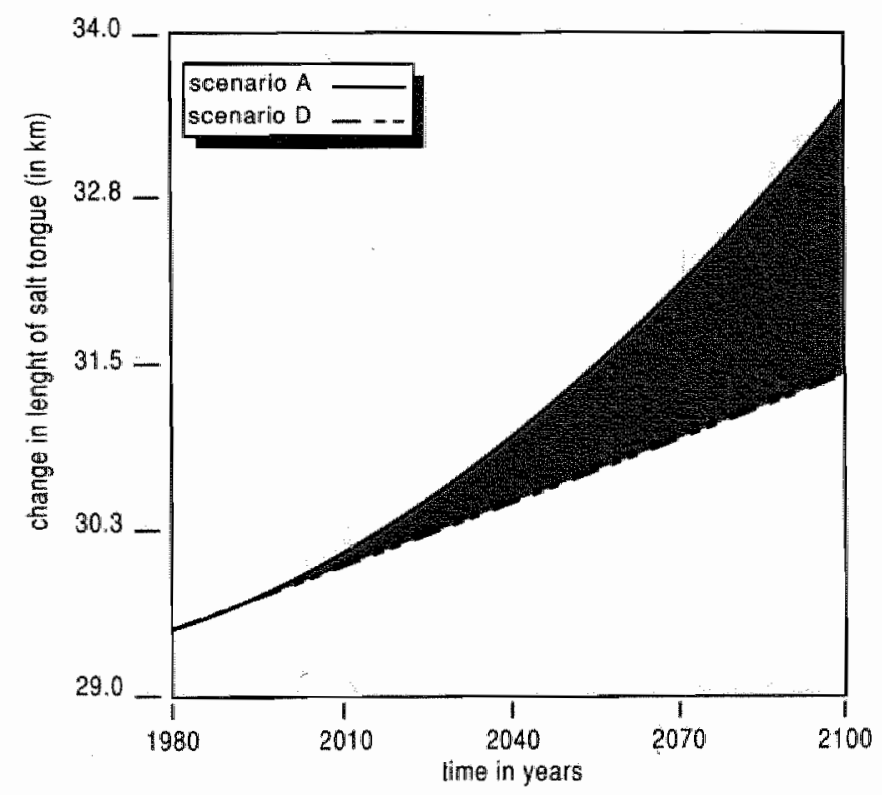

Figure 9.9: Simulated change in length of the salt tongue. 

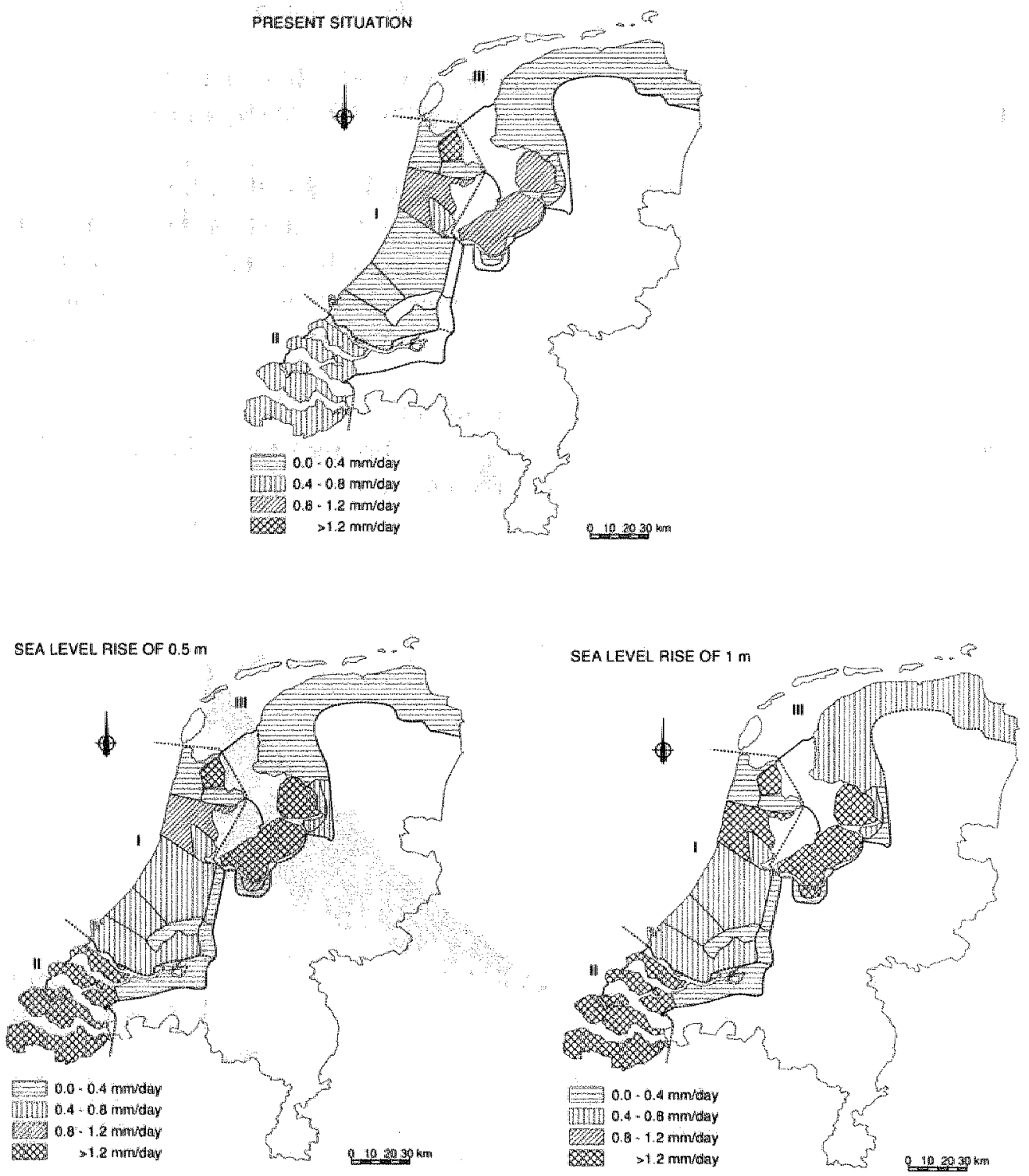

Figure 9.10: Present and future seepage situation in the Netherlands in case of a sea level rise of $0.5 \mathrm{~m}$ and $1.0 \mathrm{~m}$. 


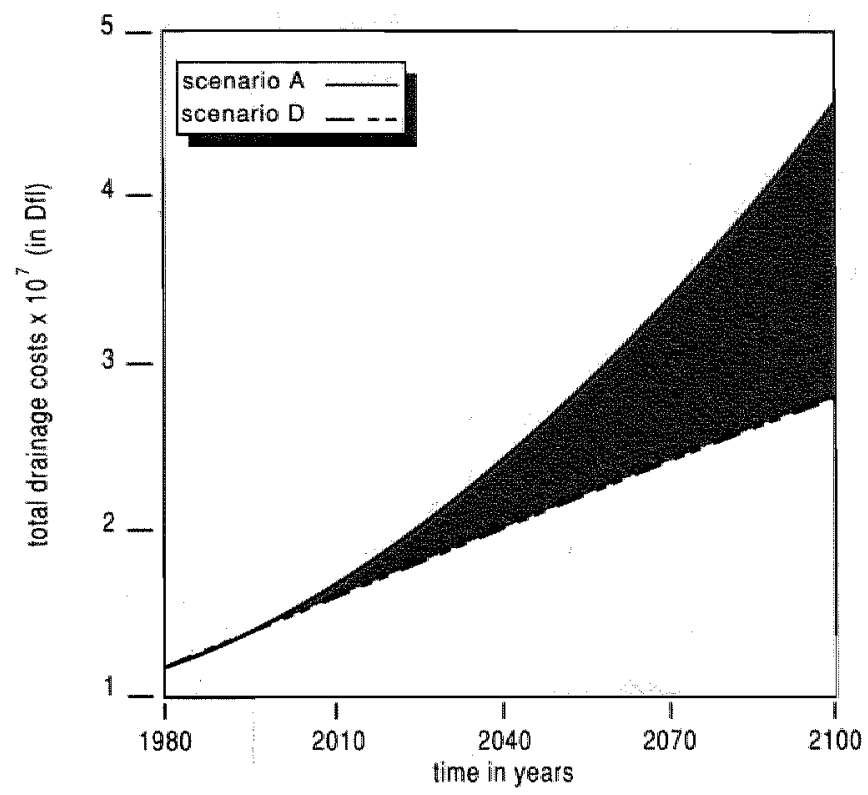

Figure 9.11: Simulated total drainage costs. 


\begin{tabular}{|c|c|c|c|c|c|}
\hline golut & a affety & $\begin{array}{l}\text { wer ex } \\
\text { etrpply }\end{array}$ & sallt logad & setgage & $\begin{array}{l}\text { total } \\
\text { costa }\end{array}$ \\
\hline 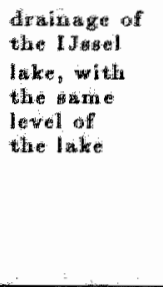 & 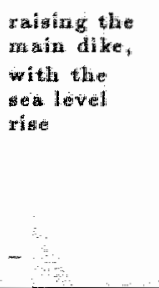 & wrillaxped & 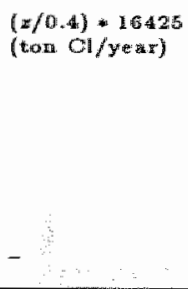 & 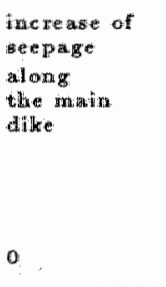 & 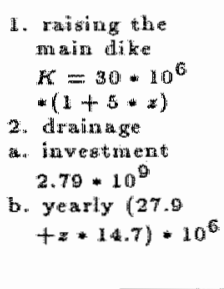 \\
\hline 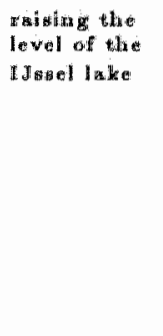 & 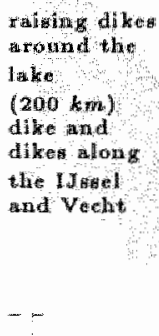 & 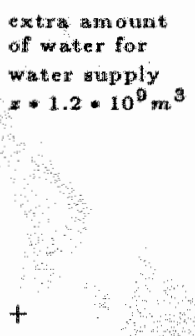 & unctam $m \in d$ & 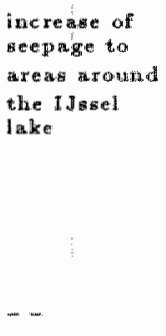 & 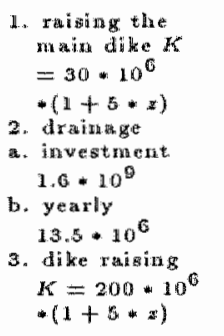 \\
\hline 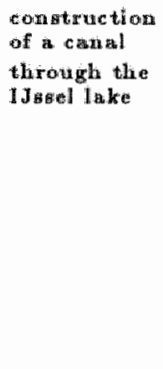 & 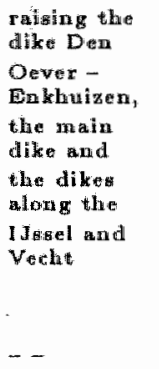 & $\begin{array}{l}\text { extra anount } \\
\text { of water } \\
\text { for water } \\
\text { oupply } 20.5 \\
+10^{9} \mathrm{~m}^{3}\end{array}$ & unchanged & $\begin{array}{l}\text { increatse of } \\
\text { aecpage to } \\
\text { Mediendolit } \\
\text { Flavolandi } \\
\text { aud } \\
\text { Wheringer } \\
\text { Lake }\end{array}$ & 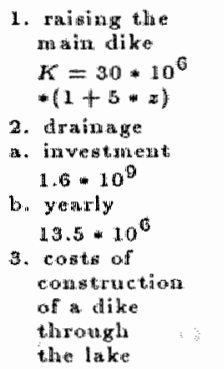 \\
\hline
\end{tabular}

Table 9.2: Countermeasures for the IJssel lake with a sea level rise (of $z$ meter)

$$
\begin{aligned}
& --=\text { strong negative effect } \\
& -=\text { negative effect } \\
& 0=\text { no effect } \\
& +=\text { positive effect } \\
& ++=\text { strong positive effect }
\end{aligned}
$$




\begin{tabular}{|l|l|l|}
\hline & \multicolumn{2}{|c|}{ tor period from 1990 till 2100} \\
\hline & scenario A & scenario D \\
\hline dikes & $20 \mathrm{Dfl}$. & 15 Dfl. \\
\hline dunes & $6.5 \mathrm{Dfl}$. & 5 Dfl. \\
\hline intertidal area & ++ & + \\
\hline salt intrusion & ++ & + \\
\hline seepage & $+80 \%$ & $+40 \%$ \\
\hline increase in 2100 & increase in 2100 \\
\hline drainage & 3 Dfl. & 2.5 Dfl. \\
\hline agriculture & $+/-$ & $+/-$ \\
\hline energy & - & - \\
\hline IJssel lake & 4.5 Dfl. + & 4 Df. + \\
\hline & extra costs $(++)$ & extra costs $(+)$ \\
\hline shipping & ++ & + \\
\hline
\end{tabular}

Table 9.3: Indicative costs for different scenarios (A and D) for several sectors of Dutch society

$+\quad=$ increase in costs

$++=$ strong increase in costs

- $\quad=$ decrease in costs

\subsection{Conclusions}

Simulations with IMAGE suggest that the socio-economic consequences of the greenhouse effect for the Netherlands are large, involving considerable 
cumulative costs for the next century. However, the yearly costs will be less than a half percent of the gross national product. This is in line with a recent study by Delft Hydraulics (1990).

Our calculations show that for all scenarios the dikes will have to be raised before 2000, otherwise the safety will decrease far below the Delta norm (the present safety level). Applying the strategy of optimal dike raising, which is preferable from an economic point of view, it follows that the minimum extra dike raising for the next century is 2 meters. This would imply high costs, which amount to about 20 billion guilders. A major inference is that the Delta norm is too low and should be tightened up to 0.000025 , a quarter of the present value, entailing a better protection of human lives and material goods. This results in an extra dike raising of about 0.55 meter.

In order to avoid a further, socially unacceptable retreat of the Dutch coastline, a policy review to a policy that arrests dune erosion is recommended. In that case the present yearly costs of dune erosion, about 30 million Dutch guilders, will in the future increase to at least 350 million guilders and at most 600 million guilders. The total cost of coastal defence range, depending on which scenario and which strategy will be chosen, from a few billion up to 30 billion guilders for the period from 1990 to 2100 .

For the water management sector the intrusion of salt water as well as the increasing seepage will become major future problems, especially for the agricultural sector. Additionally the yearly drainage costs will increase considerably and the situation for the IJssel lake is getting worse. Having regard to the costs and the infrastructure of the lake the best solution is to raise the level of the IJssel lake. According to model calculations with IMAGE the total extra costs that have to be spent on the water management due to a sea level rise are expected to be more than ten billion guilders.

Although not pretending to give a comprehensive overview of the consequences of the greenhouse phenomenon for the Netherlands, this study gives indicative figures concerning the socio-economic consequences. In general, for the Netherlands the socio-economic costs induced by the greenhouse effect will be considerable, but can be kept under control if Dutch policy makers will anticipate in time. 


\section{Chapter 10}

\section{Policy Analysis}

\subsection{Introduction}

Even faster than the depletion of the ozone layer the anticipated climate change has come to play a role in high level policy debates. Since the problem is very complex by nature a need has arisen among policy makers to have at their disposal a tool that gives a clear and concise overview of the workings of the greenhouse effect and the relevance of potential policy options. The Integrated Model to Assess the Greenhouse Effect (IMAGE) was developed at the National Institute for Public Health and Environmental Protection (RIVM in Dutch) from 1986, at a stage when the recognition of climate change was intended to be its primary role (Rotmans, 1989). Since the enhanced greenhouse effect is created by a multitude of effects; the model tries to capture these causes and effects in an integrated fashion. The main difficulty thwarting policy response to the greenhouse effect is that the causes are not only many; they also form the fundamental basis of our society: the present practices with respect to energy production and consumption, agriculture and industry. Dependent on the assumptions and definitions it can be generally said that the agricultural sector, including deforestation, causes $25 \%$ of the problem, while $75 \%$ is caused by the energy and industry sectors. Within the energy sector transportation, power generation and other combustion processes play about an equal role (see Figure 10.1).

In the last few years IMAGE has been used to evaluate long-term climate strategies. In this chapter some calculation examples, made for the Intergovernmental Panel on Climate Change (IPCC), are presented. 


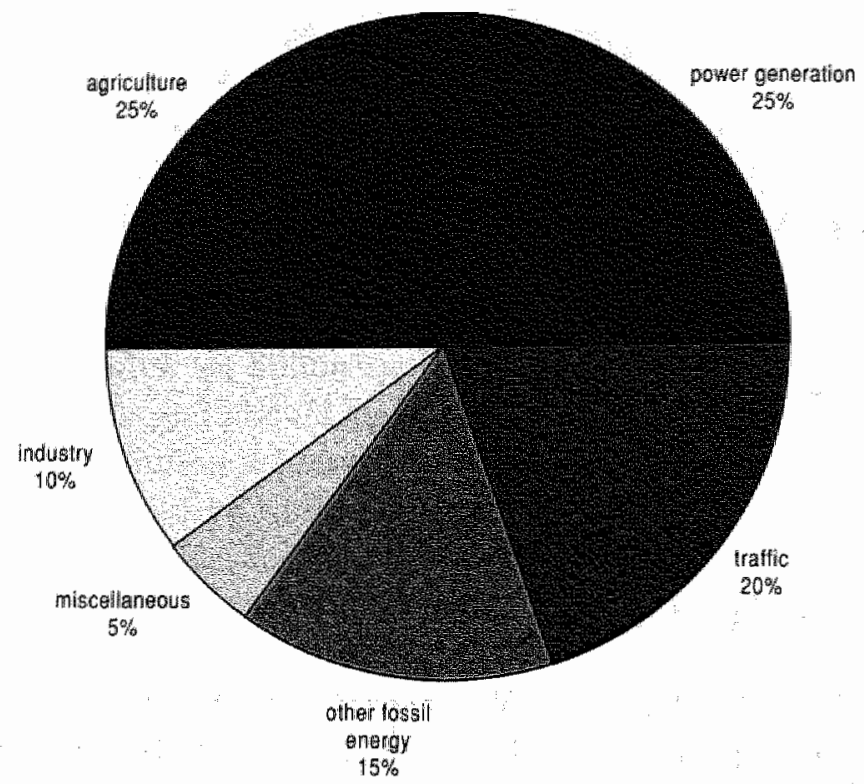

Figure 10.1: Relative contribution to climate change.

\subsection{Scenario Calculations}

The main application of IMAGE is the development and evaluation of longterm scenarios, up to 2100 . It has been used extensively in the Netherlands over the last few years to evaluate different future world options with respect to climate change. Besides demonstration sessions for different groups the model was used for different Dutch environmental studies, such as the preparatory document for the National Environmental Plan (Langeweg, 1989).

Recently, IMAGE entered the international arena. Some scenario results from calculations made within the framework of the Intergovernmental Panel on Climate Change (IPCC) will be briefly discussed here. In early 1989 the Steering Committee of the Response Strategies Working Group of IPCC requested the USA and the Netherlands to prepare a document on three emissions scenarios for use in different IPCC working groups. Initially these scenarios had to be designed in such a way that they would lead to a doubling of $\mathrm{CO}_{2}$ equivalent concentrations in the years 2030,2060, and subsequently in 2090 . In the last scenario the concentration would stabilize 
afterwards. The Dutch contribution to the draft report (IPCC, 1989), which was prepared jointly with EPA, consisted, besides the determination of the conceptual approach, of the performance of a number of IMAGE calculations. Preliminary scenarios made with EPAs Atmospheric Stabilization Framework (EPA, 1989) were evaluated and, secondly, a number of additional analyses were made. Since the consequences of policies in the decades to come are of crucial importance for the purpose of IPCC, some runs were performed simulating delayed response actions.

\subsection{Low Climate Risk Scenario}

The Netherlands and some other countries were not satisfied with the range of scenarios selected, primarily since even the lowest scenario would lead to temperature increases that are unprecedented in the last 100,000 years and more. Not considering the feasibility of pursuing such a scenario (which is low) some calculations were made to access tolerable emissions which would limit climate change risks sufficiently. Such a low scenario is important for the assessment of the reaction of the climate system by scientists and is the first step towards painting a picture of a sustainable world. It is not yet included in the draft report referred to above.

At a workshop in Bellagio (Jäger, 1988) it was suggested to take a global rate of temperature of $0.1^{\circ} \mathrm{C}$ per decade as an initial target value, which would allow for adaptation of ecosystems. The German Physical and Meterological Societies recommended an abolute temperature change of 1 to 2 degree celsius temperature rise from pre-industrial levels (German Enquete Commission, 1988). These values are consistent with estimates of maximum natural climate variations in the past according to Sassin et al. (1988), who evaluated past rates of temperatures and abolute changes from ice core temperature records. Since no past evidence appears to be available for faster temperature changes than approximately $0.1^{\circ} \mathrm{C}$ per decade, we used this as a reference value for a policy of risk minimization. The resulting "low climate risk' scenario can be considered as a first approximation of a longterm environmental goal enabling a sustainable development of the world economy.

The global low climate risk scenario induces a gradual decrease of global $\mathrm{CO}_{2}$ emissions, which is more or less consistent with the Toronto recommendations (Environment Canada, 1988), if applied worldwide: a 20\% reduction in 2005 and a $50 \%$ reduction by half way through the next century. Kram 
and Okken (1989) calculated that such reductions are possible in the Netherlands after 2020 .

\subsection{Results}

In order to determine a $\mathrm{CO}_{2}$ emission pathway complying with the abovementioned rate of temperature change we assumed maximum control for the emissions of the other trace gases (Table 10.1), as estimated in the IPCC scenario leading to stabilization at double pre-industrial $\mathrm{CO}_{2}$ equivalent concentration after $2090(570 \mathrm{ppm})$.

\begin{tabular}{|c|c|c|c|c|c|c|}
\hline & $\begin{array}{c}\mathrm{CO}_{2} \\
(G t)\end{array}$ & $\begin{array}{c}\mathrm{CH}_{4} \\
(T g)\end{array}$ & $\begin{array}{c}\mathrm{N}_{2} \mathrm{O} \\
(\mathrm{Tg})\end{array}$ & $\begin{array}{c}\mathrm{CFC}-11 \\
(\mathrm{Mkg})\end{array}$ & $\begin{array}{c}\mathrm{CFC}-12 \\
(\mathrm{Mkg})\end{array}$ & $\begin{array}{c}\mathrm{CO} \\
(\mathrm{Tg})\end{array}$ \\
\hline 1985 & 5.40 & 510 & 11.3 & 296 & 433 & 2429 \\
2000 & 4.32 & 538 & 11.8 & 217 & 280 & 2479 \\
2025 & 2.70 & 579 & 12.0 & 32 & 22 & 2724 \\
2050 & 2.70 & 584 & 12.0 & 21 & 21 & 2909 \\
2075 & 2.70 & 540 & 11.7 & 22 & 23 & 3030 \\
2100 & 2.70 & 471 & 10.2 & 24 & 26 & 3098 \\
\hline
\end{tabular}

Table 10.1: Emissions of trace gases for the Low Climate Risk Scenario.

In Figure 10.2 the resulting low climate risk scenario is shown, together with the IPCC scenarios. It appears that the highest IPCC scenario would allow an increase of $\mathrm{CO}_{2}$ emissions by a factor of 4 in 2100 , while, in order to follow the lowest pathway, these emissions can only grow by about $40 \%$ towards the mid-21st century as compared to 1985 . For comparison we drafted the expected carbon dioxide emissions associated with the most recent IEA World Energy Outlook (IEA, 1989). If world energy use and fuel mix were to follow this projected path, the emissions of $\mathrm{CO}_{2}$ and other trace gases would exceed even the highest scenario as taken into account by the IPCC. To put the scenarios into an even more pessimistic perspective: in the lower scenarios it has been assumed that the emissions of the other trace gases can be limited within the same time schedule as $\mathrm{CO}_{2}$, albeit at different levels. For regulated CFCs this might not cause problems, but for gases with as yet not fully quantified sources, like methane, nitrous oxide and carbon monoxide, this tends to be an optimistic assumption. If these limitations could not 
be achieved, the necessary control of carbon dioxide should even be stricter than envisaged in the present IPCC scenarios in order to reach the same goals. In terms of geographical distribution the lowest scenario allows for increasing emissions in the developing countries and more or less stabilizing emissions in the industrialized countries. In the Netherlands National Environment Plan this stabilization (to be achieved in 2000 at 1989 levels) has been included as a provisional goal for the emissions of carbon dioxide.

The global low risk scenario could only be achieved by a massive and rapid change of the world energy system towards maximum energy efficiency and the application of $\mathrm{CO}_{2}$ free technology. Although such a change might lead to continuing or even accelerated economic growth for some groups in some countries, there is a risk in major parts of the world that these emission reductions might only be achieved by limitations to quantitative economic growth which are unacceptable from the viewpoint of the present day national ambitions.

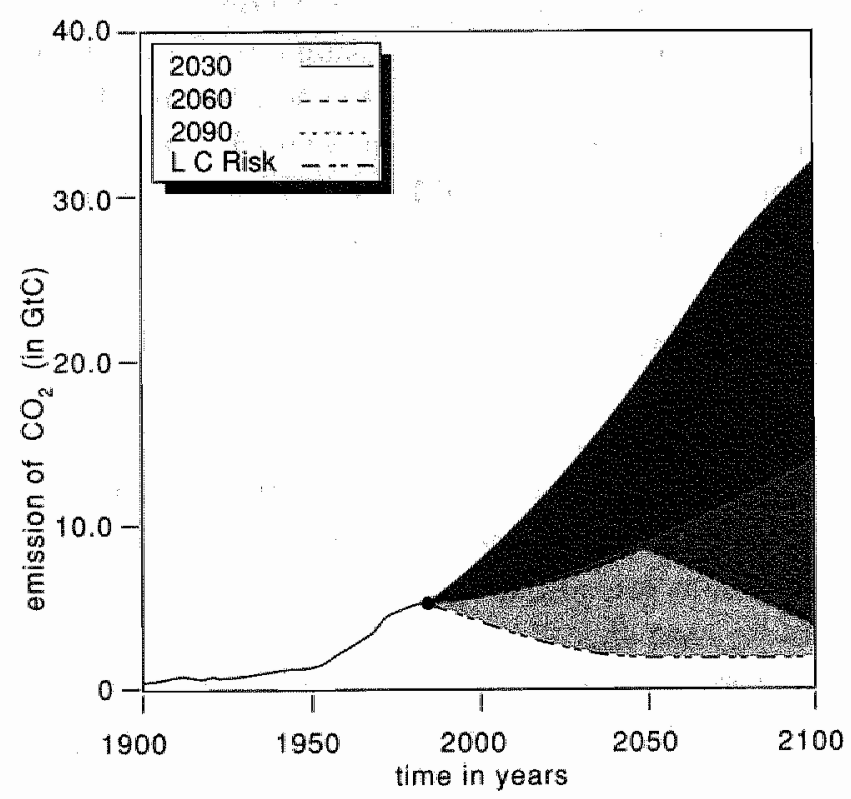

Figure 10.2: IPCC and Low Climate Risk Scenario. 
A $20 \% \mathrm{CO}_{2}$ reduction in 2000 and a further reduction to $50 \%$ results in the concentrations for the different trace gases shown in Table 10.2.

\begin{tabular}{|c|c|c|c|c|c|c|}
\hline & $\begin{array}{c}\mathrm{CO}_{2}-e q \\
(p p m)\end{array}$ & $\begin{array}{c}\mathrm{CO}_{2} \\
(p p m)\end{array}$ & $\begin{array}{c}\mathrm{CH}_{4} \\
(p p m)\end{array}$ & $\begin{array}{c}\mathrm{N}_{2} \mathrm{O} \\
(p p b)\end{array}$ & $\begin{array}{c}\mathrm{CFC}-11 \\
(p p b)\end{array}$ & $\begin{array}{c}\mathrm{CFC}-12 \\
(p p b)\end{array}$ \\
\hline 1985 & 380 & 345 & 1.68 & 303 & 0.22 & 0.38 \\
2000 & 405 & 355 & 1.85 & 312 & 0.37 & 0.62 \\
2025 & 422 & 362 & 2.09 & 326 & 0.33 & 0.60 \\
2050 & 429 & 365 & 2.29 & 339 & 0.26 & 0.52 \\
2075 & 431 & 368 & 2.22 & 349 & 0.21 & 0.45 \\
2100 & 421 & 371 & 1.76 & 353 & 0.17 & 0.40 \\
\hline
\end{tabular}

Table 10.2: Concentrations of trace gases for the Low Climate Risk Scenario.

In Figure 10.3 the $\mathrm{CO}_{2}$ equivalent concentrations as agreed upon by the IPCC Working Group are shown.

Figure 10.4 shows the resulting temperature curves for climate sensitivities of 2 and $3^{\circ} \mathrm{C}$. These results are thus consistent with the Toronto recommendations provided that the reductions are implemented worldwide and also measures are taken to control the emissions of the other greenhouse gases. The IPCC 2090 stabilization scenario would allow for slightly increasing emissions of $\mathrm{CO}_{2}$, but would lead to temperature rises which are far above the suggested $0.1^{\circ} \mathrm{C}$ per decade.

\subsection{Delayed Response}

To underscore the importance of rapid decision making we performed a final analysis, in which we delayed the start of international response actions from the present to $2000,2010,2020$ and 2030, respectively. It has been (optimistically) assumed that greenhouse gas emissions would follow the emissions of the 2030 doubling case should no action be taken to limit greenhouse gas emissions. Furthermore it is assumed that if the international decision is taken and followed up to start controlling climate change, the policy target would be stabilization of concentrations in 2090 at double $\mathrm{CO}_{2}$ equivalent levels (the lowest IPCC scenario). 


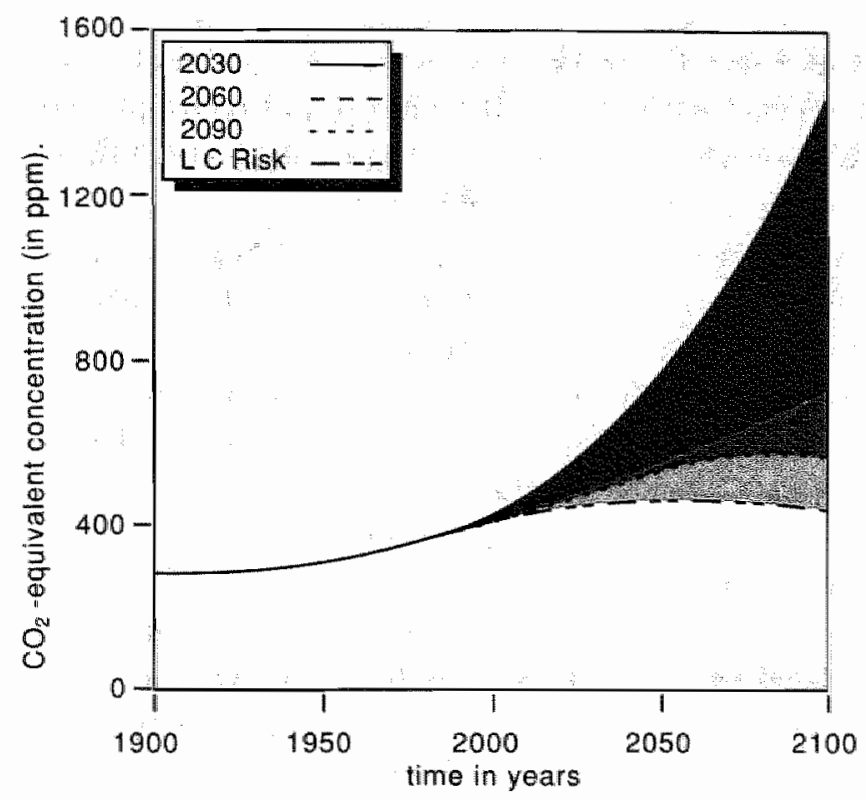

Figure 10.3: $\mathrm{CO}_{2}$ equivalent concentrations for the IPCC scenarios and the Low Climate Risk Scenario.

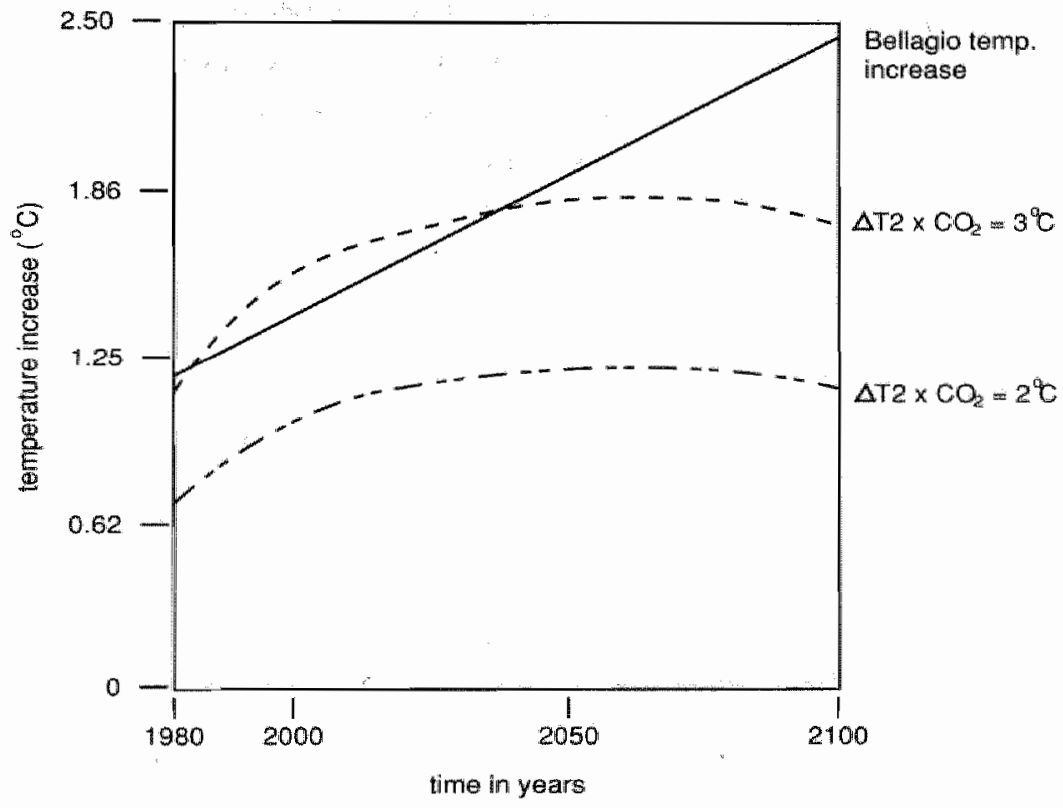

Figure 10.4: Equivalent temperature curves for the Low Climate Risk Scenario (for climate sensitivities of 2 and $3^{\circ} \mathrm{C}$ ) compared with the Bellagio temperature increase curve (i.e. $0.1^{\circ} \mathrm{C}$ per decade). 
Emissions of non- $\mathrm{CO}_{2}$ trace gases were assumed to be deflected towards the values associated with the 2090 scenario and consequently the allowable emissions of $\mathrm{CO}_{2}$ were determined. In Figure 10.5 the emissions of $\mathrm{CO}_{2}$ for different delayed response runs are depicted.

It appears that waiting until 2000 would imply only a slight necessary decrease of emissions. Even a slight increase of the emissions is permitted to reach stabilization, because a continuing decrease of the emissions should result in decreasing concentrations instead of stabilizing concentrations. In consequence of this 'stabilizing concentrations' target, the same temporary increase in emissions occur in the 2020 and 2030 responses. Waiting 10 years more would necessitate gradual emission reductions of about $40 \%$. Again, 10 years later, in 2020, almost $70 \%$ emission reduction would have to be achieved in less than 10 years in order to reach the target. As can be expected, because of the choice of baseline emissions (leading to 2030 doubling), delaying response until 2030 would render a complete and swift phase-out of $\mathrm{CO}_{2}$ emissions from fossil fuel combustion necessary. Should the $0.1^{\circ} \mathrm{C}$ per decade scenario be chosen as a target rate the emission reductions should even be more dramatic.

The resulting changes in atmospheric composition for the delayed response scenarios, as calculated by IMAGE, are represented in Figure 10.6. Only for the 2030 emission response scenario is it nearly impossible to stay under the target $\mathrm{CO}_{2}$ equivalent scenario of $570 \mathrm{ppm}$.

\subsection{Future Worlds}

What kind of world would meet the requirements of the "tolerable" scenario presented above? Although an infinite number of worlds with different combinations of energy systems and agricultural practices with associated emissions of greenhouse gases would meet the target, some brief indications will be given of how the emission scenarios that fulfilled the requirements can be arrived at. World population is assumed to approach 10.8 billion in 2100 . The Low Climate Risk Scenario can be simulated with the Edmonds and Reilly model in a number of ways. When assuming a per capita economic growth rate of $1.7 \%$ in the developed world and $2.9 \%$ in the developing countries the most important policies would include: an annual end use efficiency increase in the industrialized world of $1.5 \%$ and $1.8 \%$ in the third world, while at the same time stimulating sollar energy (reducing the costs within 40 years to US $\$ 10 .-/ G J)$, preventing production of synfuels by high 
non-energy costs and gradually introducing environmental taxes on end use proportional to the carbon content of the fuel type. Compared to the present situation, coal is fully phased out, oil supply is more or less stable, the use of natural gas increases, but the major part of the growth of the energy demand (moderated by large efficiency increases) is captured by renewables. To illustrate the dependence of these results of economic growth: when for instance Asian and Latin-American countries are assumed to achieve higher per capita economic growth (3.5\% annually), efficiency increases in those countries should be higher ( $2.2 \%$ per year) and renewables introduced faster (solar costs US\$ 8.-/GJ in 25 years) than in the previous analysis. The final implication of a $\mathrm{CO}_{2}$ emission reduction strategy would be a shift away from fossil fuels, implying that the available resources will not be fully used. It is a major question if the global energy system, which is now based for more than $80 \%$ on fossil fuel consumption will be able to cope with the social and economic effects of such a shift.

For CFCs we assumed an almost total phase-out with the exception of a number of developing countries not participating in the Montreal Protocol. To arrive at the assumed more than $95 \%$ production decreases the Protocol would have to be strengthened. Methane emissions are assumed to be stabilized by limiting the consumption of meat and dairy and gradually (applying logistic curves) increasing recovery of methane losses from coal mining and waste dumps to $50 \%$. Anthropogenic $\mathrm{CO}$ emissions are limited by technological measures for vehicle exhausts and in industry. Growth of anthropogenic $\mathrm{N}_{2} \mathrm{O}$ emissions from fertilizer application is controlled by balancing increases in fertilizer consumption in the developing world against decreases in the developed world enabled by modifications in agricultural practices. 


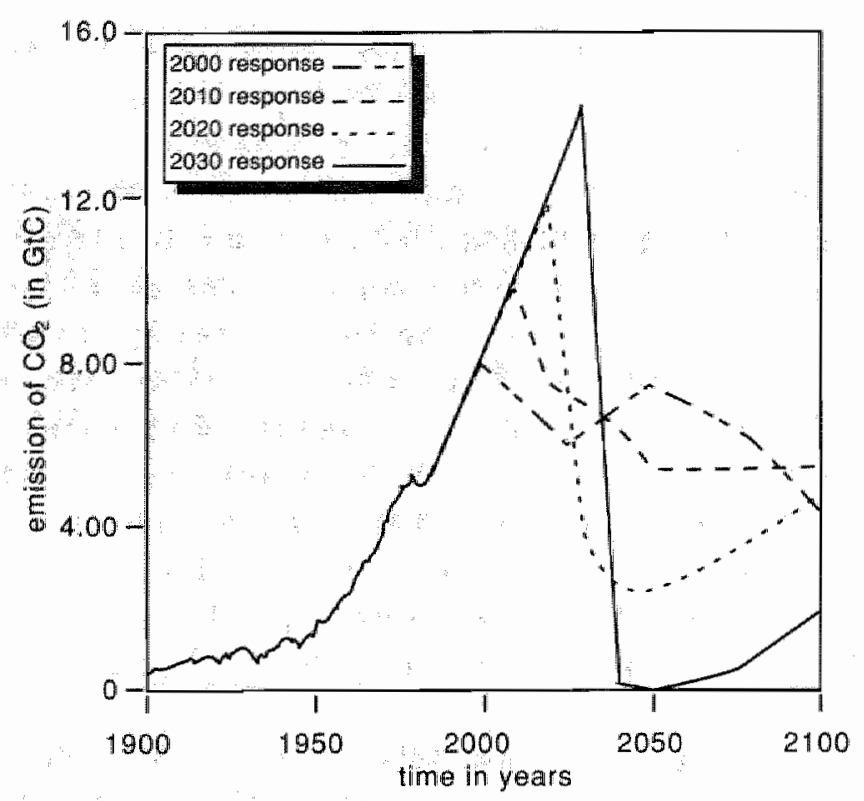

Figure 10.5: $\mathrm{CO}_{2}$ emissions for delayed response analysis.

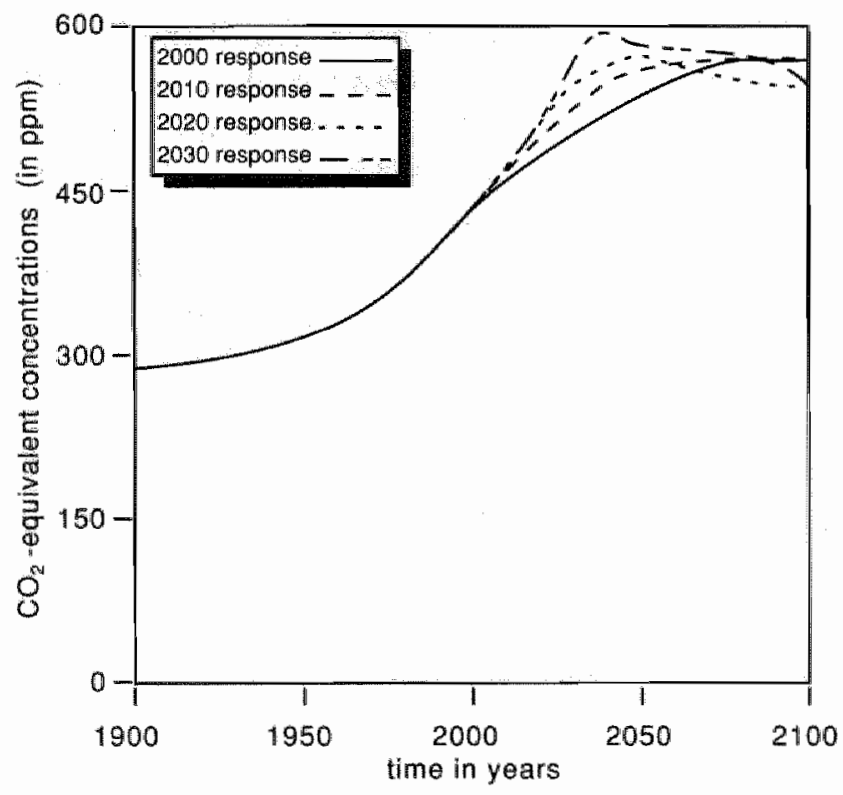

Figure 10.6: $\mathrm{CO}_{2}$ equivalent concentrations for delayed response analysis. 


\subsection{Conclusions}

Calculations with IMAGE suggest that the rate of global temperature change can be limited to values which do not go beyond past climate experience by the global implementation of $\mathrm{CO}_{2}$ emission reductions of $20 \%$ in 2000 and $50 \%$ in 2025 . These figures are consistent with the recommendations of the Toronto Conference on the Changing Atmosphere in 1988, provided these reductions are applied globally and a strong effort is undertaken to control the emissions of the other greenhouse gases, including a near phase-out of CFCs.

The projections of IEA (IEA, 1989) show that if the greenhouse effect is not taken into account in energy policy planning, emissions of greenhouse gases will show accelerated growth if the present world economic growth continues, based on the same energy system as before. Abundant reserves of cheap coal will be used unless technological and financial mechanisms are developed to push energy supply development in a more benevolent direction.

According to the IMAGE calculations the different lag effects in physical and socio-economic processes make a very rapid initiation of international policies necessary in order to limit major risks of climate change. Although the necessary changes appear to be technically feasible, major social and economic impediments will have to be removed to achieve the recommended reductions, but a complete phase-out of fossil fuels would not be necessary. IMAGE simulations show that the emissions in the industrialized countries should be decreased by at least $80 \%$ over the coming 50 years in order to prevent serious risks to the world community. Delays in policy formulation will be followed by long lead times for introduction of measures, increasing the amount of climate change 'in the bank' because of the slow response of the physical climate system. Therefore rapid response action is warranted.

In order to evaluate recent and future proposals for control of greenhouse gas emissions it is recommended to determine a long-term environmental or climate goal that would allow for a sustainable development of the world economy. 


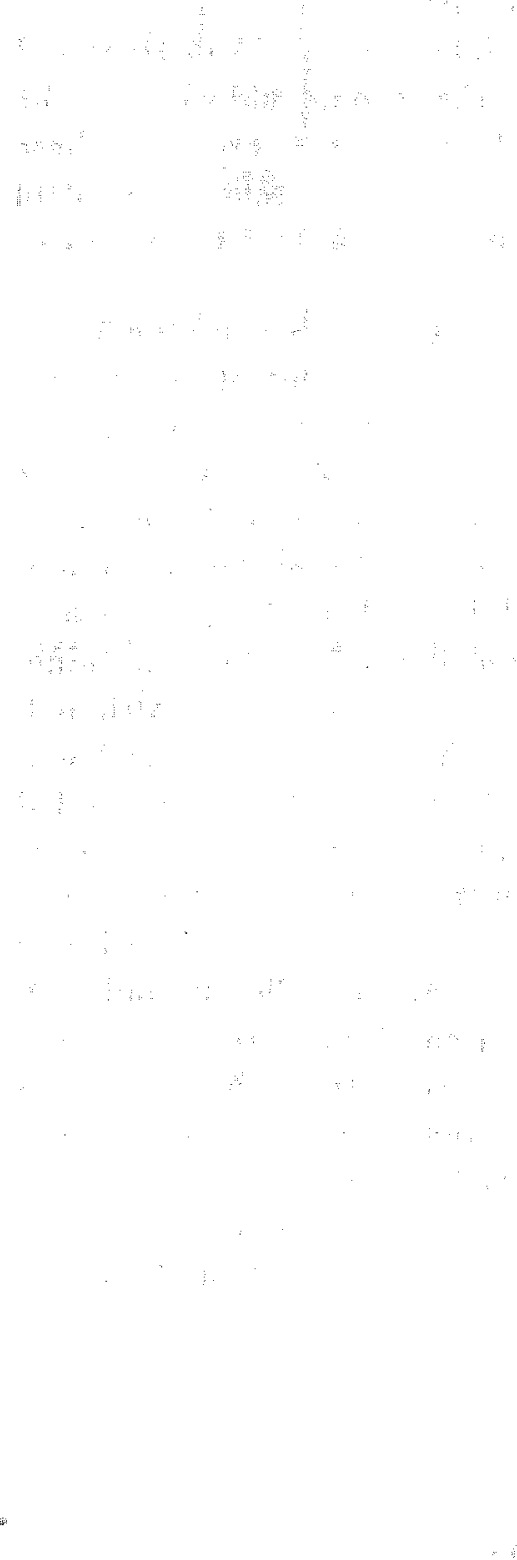




\section{Chapter 11}

\section{Temperature Increasing Potential}

\subsection{Introduction}

In order to develop environmental long-term goals with respect to climate change an index is needed to compare the temperature increasing effect of greenhouse gas emissions. Here the concept of Temperature Increasing Potential (TIP) is introduced as a greenhouse counterpart to the ozone depleting potential (ODP). To obtain the relationship between an emission and its associated effect on temperature both the model approach (IMAGE) and the analytical approach is used. Furthermore, both approaches are compared to previous efforts to determine relative greenhouse gas potentials.

\subsection{Relation between Temperature and Emis- sions}

In deriving emission targets from a set goal for global mean temperature increase, many nonlinear relationships within the atmosphere have to be considered. The emission of greenhouse gases initially leads to increased atmospheric concentrations. These gases are remoyed by a diversity of processes, varying with each gas and its atmospheric concentration: uptake by oceans, deposition, photochemical reactions, uptake by biota and soils. These removal processes determine the atmospheric lifetime of the gases. Furthermore, many other factors related to the greenhouse problem interact with the removal processes; for example, the concentration of other energy- 
related gases like carbon monoxide (CO) and non-methane hydrocarbons and the influence of climate change on the carbon cycle and on methane $\left(\mathrm{CH}_{4}\right)$ release from natural reservoirs. Additionally the radiative absorption rate is neither constant nor proportional to their respective concentrations. Finally these processes and their underlying assumptions are scenario dependent. Generally, in order to compare the result with previous efforts (e.g. Lashof and Ahuja, 1990, Derwent, R.G., 1990, Fisher et al., 1990) equilibrium temperature effect will be used instead of transient responses.

The relation between an emission and its associated effect on temperature can be expressed in terms of Temperature Increasing Potential (TIP), or Global Warming Potential (GWP), as used in the literature. This is comparable to the ozone depletion potential (ODP) defined by Wuebbles (1981) which interrelates different ozone-depleting substances. However the actual TIP is time-dependent, and not a scalar constant with which one could multiply emissions like the ODPs. Nevertheless, for want of a better alternative, the relative radiative potential of the trace gases will be approximated by a scalar.

\subsection{Methodology}

\subsubsection{Definition}

To achieve a direct relationship between an emission of a greenhouse gas and its corresponding temperature response the following strategy will be used. For the greenhouse gases $\mathrm{CO}_{2}, \mathrm{CH}_{4}$, and $\mathrm{N}_{2} \mathrm{O}$, one emission impulse of $1 \mathrm{Gt}$ will be generated during one year, the year 1986. For CFCs emissions a pulse of $10^{-3} \mathrm{Gt}$ will be posited during one year, because the emissions of CFCs are of magnitude $10^{3}$ till $10^{4}$ lower than of the other gases, and a pulse of 1 $G t$ might lead to systems instabilities. Of course the corresponding pulse of $\mathrm{CO}_{2}$ will in case of CFCs also be equal to $10^{-3} \mathrm{Gt}$. To test the sensitivity of this modelling approach to variations in the emission pulses, simulation runs with variations in both magnitude and time-span have been carried out. It appeared that the method is fairly robust for variations in magnitude and time-span of emission pulses (Rotmans and Den Elzen, 1990). Grarns and not moles are used, because in the international literature emissions are mostly expressed in grams.

The Temperature Increasing Potential, or TIP, of a greenhouse gas is then defined as the integrated temperature effect (which consists of the integral of time-dependent temperature distributions from 0 to a time $t$ ) of $1 \mathrm{Gt}$ 
emission of that specific gas compared to that of $\mathrm{CO}_{2}$ :

$$
T I P_{i}(t)=\frac{\text { integr. temp. effect of } \left.1 \text { (or } 10^{-3}\right) G t \text { of trace gas } i \text { at time } t}{\text { integr. temp. effect of } 1 \text { (or } 10^{-3} \mathrm{Gt} \text { of carbon dioxide at time } t}
$$

with:

$T I P_{i}(t)=$ temperature increasing potential of trace gas $i$ at time $t$

Other possible definitions are given in Lashof and Rotmans (1990).

In determining the TIP, two quintessential matters must be considered. First the influence of the rather arbitrarily chosen time-span and height of the emission impulse. To measure the influence of various kinds of pulses a sensitivity analysis has been carried out with emission impulses of 0.25 , 0.50 , and $1.0 \mathrm{Gt}$ (and $0.2510^{-3}, 0.510^{-3}$, and $10^{-3}$ for CFCs), during 1 , 5 , and 10 years, respectively. The results of this analysis are presented in Rotmans and Den Elzen (1990). Secondly, the target point in time of the TIP, being a crucial aspect in the TIP analysis, has to be determined. The time dependency of the TIP is mainly due to the fact that $\mathrm{CO}_{2}$ does not have a specific atmospheric lifetime, but is exchanged between atmosphere, ocean, and terrestrial biosphere. To overcome this problem two case studies will be treated, one with a relatively short time horizon (instead of atmospheric residence time) with respect to $\mathrm{CO}_{2}$ of 100 years, and a second one with an extremely long time horizon of $\mathrm{CO}_{2}$ of 500 years. So only the limits of the integration are varied, not the internal dynamics of the $\mathrm{CO}_{2}$ model.

According to these assumptions and based on definition (11.1), the TTP can be calculated in two different ways. Earlier attempts were based on simple analytical approaches (Lashof and Ahuja, 1990), which directly calculated the temperature effect from the emissions. Here also an indirect analytical method is presented, calculating concentrations first and then global temperature effects.

An alternative way of solving the TIP problem, which has not been applied before, is using integrated greenhouse models, relating emissions to global temperature rise. Presently there are three such integrated greenhouse models: IMAGE (Integrated Model to Assess the Greenhouse Effect, Rotmans et al., 1990a), the Model of Warming Commitment of the World Resource Institute (Mintzer, 1987) and the Atmospheric Stabilization Framework of the U.S. Environmental Protection Agency (EPA, 1989), which have recently been compared (AGGG, 1990). The models produced very similar temperature results for the same emission inputs for different trace gases, 
although very different approaches have been chosen for the representation of the carbon cycle, atmospheric chemistry processes, and other model aspects (Response Strategies Working Group, 1989a and 1989b). Therefore, notwithstanding the fact that these models embrace many uncertainties, international consensus on assumptions and methodologies should be possible, based on the best arailable knowledge (Swart et al., 1989).

Here MAGE is used to calculate the TIP concept. Both the analytical and modelling approach will be compared and evaluated.

\subsubsection{Modelling Approach}

IMAGE is used in order to determine the relative radiative potential of the greenhouse gases $\mathrm{CO}_{2}, \mathrm{CH}_{4}, \mathrm{~N}_{2} \mathrm{O}, \mathrm{CFC}-11$ and $\mathrm{CFC}-12$. To reduce the influence of the type of scenario used, stabilization scenarios have been developed for all trace gases; these emission stabilization scenarios result in steady-state concentrations in the second half of the next century. In each case two stabilization scenarios are compared in pairs, one with an emission impulse of a certain trace gas, and one without such an emission impulse. An emission impulse induces an emission of 1 (or $10^{-3} \mathrm{Gt}$ during one year (1986), and is zero both after and before 1986. An example of such a pair of emission stabilization scenarios is given in Figure 11.1, where a $\mathrm{CO}_{2}$ emission scenario with and without impulse is depicted. Figure 11.2 gives the concentrations in pairs for $\mathrm{CH}_{4}$.

Then two equilibrium temperature responses are simulated, again with and without an emission impulse. By subtracting these two temperature responses, the influence of the scenario choice is reduced, yielding the net temperature effect. This net temperature effect is integrated from time 0 (in 1900) to the time horizon. Dividing the integrated net temperature effect of $\mathrm{CH}_{4}, \mathrm{~N}_{2} \mathrm{O}$ or $\mathrm{CFCs}$ by that of $\mathrm{CO}_{2}$, gives the TIP.

Specifically to simulate the TIP-concept, the usual simulation time-span, covering 200 years, from 1900 to 2100 , is extended to the year 2500 . The year 2500 relates to the chosen "endless" $\mathrm{CO}_{2}$ atmospheric residence time of 500 years. The various assumptions for the different trace gases are given in Table 11.1: 


\begin{tabular}{|c|c|c|c|c|}
\hline & $\begin{array}{c}\text { Concentration } \\
\text { in } 1985\end{array}$ & $\begin{array}{c}\text { Residence } \\
\text { Time }\end{array}$ & $\begin{array}{c}\text { Instantaneous } \\
\text { Forcing }\end{array}$ & $\begin{array}{c}\text { Conversion } \\
\text { Factor }\end{array}$ \\
\hline $\mathrm{CO}_{2}$ & $346(\mathrm{ppm})$ & - & $0.0107\left({ }^{\circ} \mathrm{C} / \mathrm{ppm}\right)$ & $0.471(\mathrm{ppm} \mathrm{G} t)$ \\
$\mathrm{CH}_{4}$ & $1.70(\mathrm{ppm})$ & time-dependent & $0.333\left({ }^{\circ} \mathrm{C} / \mathrm{ppm}\right)$ & $0.376(\mathrm{pmm} / \mathrm{G} t)$ \\
$\mathrm{N}_{3} \mathrm{O}$ & $307(\mathrm{ppb})$ & $170(\mathrm{yrs})$ & $1.83\left({ }^{\circ} \mathrm{C} / \mathrm{ppm}\right)$ & $0.200(\mathrm{ppm} / \mathrm{Gt})$ \\
$\mathrm{CFC}-11$ & $0.22(\mathrm{ppb})$ & $75(\mathrm{yrs})$ & $190\left({ }^{\circ} \mathrm{C} / \mathrm{ppm}\right)$ & $0.046\left(\mathrm{ppb} / \mathrm{T}^{\mathrm{g}} \mathrm{g}\right)$ \\
$\mathrm{CFC}-12$ & $0.38(\mathrm{ppb})$ & $125(\mathrm{yrs})$ & $220\left({ }^{\circ} \mathrm{C} / \mathrm{ppm}\right)$ & $0.048(\mathrm{ppb} / \mathrm{Tg})$ \\
\hline
\end{tabular}

Table 11.1: Survey of parameter values in IMAGE.

The radiative forcing factors are instantaneous radiative perturbations and are based on Ramanathan (1985) and Wigley (1987), and are slightly different from those given in Rotmans (1986). These values are valid for the ranges 280-390 ppm for $\mathrm{CO}_{2}, 0.90-1.70$ for $\mathrm{CH}_{4}, 285-500 \mathrm{ppb}$ for $\mathrm{N}_{2} \mathrm{O}, 0-30$ $p p b$ for $\mathrm{CFC}-11$, and $0-40 p p b$ for CFC-12. These radiative perturbations implicate a climate feedback sensitivity of $1.44 \mathrm{~W} / \mathrm{m}^{2}{ }^{\circ} \mathrm{C}$.

For $\mathrm{CO}_{2}$ the atmospheric stabilization scenario is fed into the integrated carbon cycle module of IMAGE, consisting of the coupled ocean, terrestrial biota, and deforestation module. The stabilization scenario includes a sharp decrease of fossil fuels as well as a moderate deforestation scenario.

In the $\mathrm{CH}_{4}-\mathrm{CO}-\mathrm{OH}$ cycle module of IMAGE the concentrations of $\mathrm{OH}$ radicals and $\mathrm{CO}$ are maintained at a constant 1985 level. A substantial fraction of the increase in the methane concentration in the atmosphere is most probably caused by $\mathrm{CO}$ competing for $\mathrm{OH}$ radicals (Rotmans and Eggink, 1988). To measure this influence of $\mathrm{CO}$ on $\mathrm{CH}_{4}$, an emission impulse of CO, $1 \mathrm{Gt}$ in 1986 only, is also generated. Because methane emissions have an increasing effect on tropospheric ozone and stratospheric water vapor concentrations, the temperature effect of $\mathrm{CH}_{4}$ is assumed to be enhanced by 70\% (Lashof and Ahuja, 1990), represented by a factor 1.7. The temperature effects of $\mathrm{CH}_{4}$ with and without a $\mathrm{CO}$ emission impulse are then compared to each other (Rotmans and Den Elzen, 1990).

The CFCs modules in IMAGE include a delay time between production and emission, which is assumed to be different for different applications. The extra impulse is added to the emission and not to the production, and so has no time delay.

Finally $\mathrm{N}_{2} \mathrm{O}$ concentrations are computed from the emissions by taking into account an exponentially delayed emission mechanism, and a constant atmospheric lifetime of $\mathbf{1 7 0}$ years. 


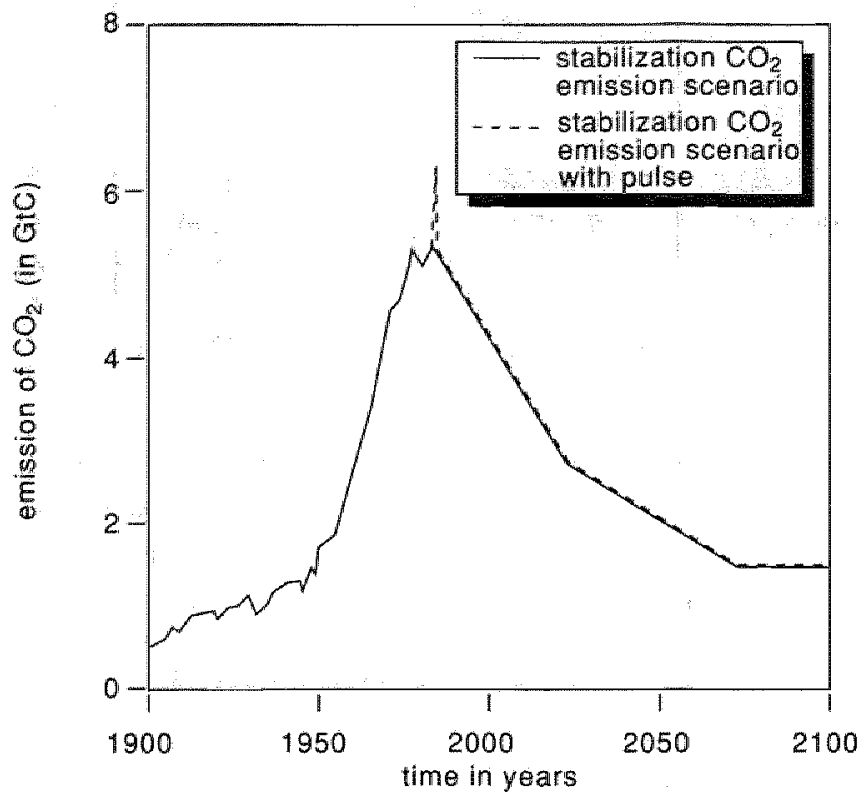

Figure 11.1: $\mathrm{CO}_{2}$ emissions scenario with and without impulse.

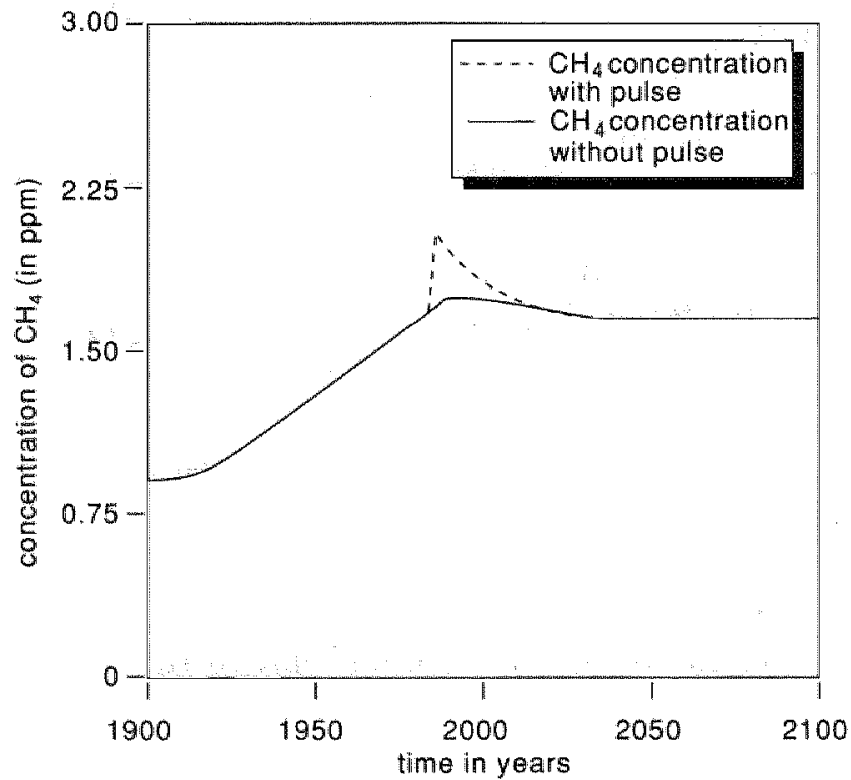

Figure 11.2: $\mathrm{CH}_{4}$ concentration with and without impulse. 


\subsubsection{Analytical Approach}

Next to the modelling approach two different analytical methods are introduced, mainly to verify the results computed with IMAGE. To determine straightforwardly the relationship between the emission and the temperature effect of a trace gas, definition (11.1) is transformed into an analytically useful form:

$$
T I P_{i}(t)=\frac{C V F_{i} * T M P_{i} * \int_{0}^{T}\left[E M_{i}(t)-R M V_{i}(t) d t\right]}{C V F_{c} * T M P_{c} * \int_{0}^{T}\left[E M_{c}(t)-R M V_{c}(t) d t\right]}
$$

with:

$T I P_{i}(t)=$ temperature increasing potential of trace gas $i$ at time $t$, whereas $t=0$ represents the year 1985

$C V F_{i}=$ conversion factor of trace gas $i$ (in $\left.p p m / G t\right)$

$T M P_{i}=$ radiative forcing factor of trace gas $i$ (in ${ }^{\circ} \mathrm{C} / \mathrm{ppm}$ )

$T \quad=$ time horizon (in years)

$E M_{i}(t)=$ global emission of trace gas $i$ at time $t$; is here an emission of 1 (or $10^{-3}$ ) $G t$ in 1986 and 0 elsewhere (in $G t / y r$ ) $R M V_{i}(t)=$ atmospheric removal of trace gas $i$ at time $t$ (in $G t / y r$ )

$\mathrm{CVF}_{\mathfrak{c}}, \mathrm{TMP}_{\mathfrak{c}}, \mathrm{L}(\mathrm{c}), \mathrm{EM}_{\mathfrak{c}}, \mathrm{RMV}_{c}$ are the corresponding values for $\mathrm{CO}_{2}$ in the denominator.

The parameter values of $\mathrm{CVF}_{i}, \mathrm{CVF}_{c}, \mathrm{TMP}_{i}$ and $\mathrm{TMP}_{c}$ are identical to those used in the modelling approach and which are represented in Table 11.1. The global emissions, denoted by $E M_{i}$ and $E M_{c}$ respectively, are emission pulses: 1 (or $10^{-3}$ ) Gt in 1986, and zero before and after this year.

The atmospheric removal process of $\mathrm{CO}_{2}$ is reflected by the airborne fraction, defined as the fraction of the $\mathrm{CO}_{2}$ emission that remains in the atmosphere, which is simply assumed to be a constant, $60 \%$. For $\mathrm{N}_{2} \mathrm{O}$ and CFCs the atmospheric retention can be described by a single atmospheric residence time. The atmospheric removal is supposed to be proportional to the concentration of these trace gases. This means that the fraction of a trace gas $i$ that remains in the atmosphere can be represented by $e^{-t / L(i)}$. For $\mathrm{CH}_{4}$, however, this is a far from realistic representation, in light of the complex atmospheric-chemical interactions with $\mathrm{CO}$ and $\mathrm{OH}$. Therefore, instead of an exponential mechanism, a delayed exponential relationship is introduced, represented by $e^{-(t-\delta) /(L(i)+n)}$, where $\delta$ represents the time delay (5 years), and $n$ represents the lengthening of the atmospheric residence time ( 1 year). These values of $\delta$ and $n$ are calibrated on simulations with the $\mathrm{CH}_{4}$ module 
of IMAGE. Lashof and Ahuja (1990) obviate this inadequacy by assuming that each mole of $\mathrm{CO}$ emitted increases the atmospheric $\mathrm{CH}_{4}$ concentration by 0.09 moles. Following Lashof and Rotmans (1990), the temperature effect of methane is enhanced by $70 \%$, due to the forming of tropospheric ozone and stratospheric water vapor.

The second way of analytically calculating the TIP includes, starting from emissions, a simplified calculation of the greenhouse gas concentrations and the resulting equilibrium temperature rises. This is similar to the modelling approach, and can be considered as an analytical approximation of the simulation method. This analytical approach has the advantage that the temperature effect, derived from emissions, is independent of any emission scenario. The total temperature effect over the atmospheric lifetime of each gas is calculated, both for an emission impulse and without an emission impulse. This emission impulse is 1 (or $10^{-3}$ ) $G t$ for each trace gas in the year 1985. It should be noticed that metamodelling (Rotmans and Vrieze, 1990) is an outstanding method for determining a relationship between a greenhouse gas emission and its induced temperature effect. It is intended to work out this concept in the near future.

This analytical method, being the analytical equivalent to the modelling approach, involves another analytical interpretation of the TIP definition in (11.1):

$$
T I P_{i}(t)=\frac{\int_{0}^{T}\left[\Delta T_{i}^{i m}(t)-\Delta T_{i}^{w i m}(t)\right] d t}{\int_{0}^{T} \Delta T_{C O_{2}}^{i m}(t)}
$$

with:

$T I P_{i}(t)=$ temperature increasing potential of trace gas $i$ at time $t$

$\Delta T_{i}^{i m}(t)=$ equilibrium temperature change with an emission impulse of 1 (or $10^{-3}$ ) $G t$ of trace gas $i$, at time $t\left({ }^{\circ} \mathrm{C}\right.$ )

$\Delta T_{i}^{w i m}(t)=$ equilibrium temperature change without an emission impulse, at time $t\left({ }^{\circ} \mathrm{C}\right)$

$\Delta T_{C O_{2}}^{i m}(t)=$ equilibrium temperature change with an emission impulse of 1 (or $10^{-3}$ ) Gt $\mathrm{CO}_{2}$, at time $t$. N.B.: the equilibrium temperature effect of $\mathrm{CO}_{2}$ without an emission impulse is zero, contrary to that of other gases, due to the logarithmical approximation of the radiative perturbations for $\mathrm{CO}_{2}$.

$T \quad=$ time horizon 
$\mathrm{CO}_{2}$

In a simplified manner the atmospheric concentration of $\mathrm{CO}_{2}$ can be approximated by the following equation, based on Equation (2.2):

$$
p \mathrm{CO}_{2}(t)=\mathrm{pCO}_{2}(t-1)+\int_{t-1}^{t}[A T M C F * A F * F S E M(t) d \tau]
$$

with:

$\mathrm{pCO}_{2}(t)=$ atmospheric $\mathrm{CO}_{2}$ concentration (in ppm)

$A T M C F=$ factor that converts emissions of $\mathrm{CO}_{2}$ into concentrations; is $0.471 \mathrm{ppm} / \mathrm{GtC}$ according to Brewer (1983) (in ppm/GtC)

$F \operatorname{SEM}(t)=$ fossil fuel combustion flux at time $t$ (in $G t C / y r)$

$A F \quad=$ airborne fraction, assumed to be constant, 0.60

Then the total equilibrium temperature effect integrated over the time horizon of $\mathrm{CO}_{2}$ can be expressed as (see Appendix):

$$
\begin{aligned}
T_{\mathrm{CO}_{2}}= & T_{2 x C \mathrm{O}_{2} / \operatorname{Ln}(2) * T * \operatorname{Ln}(1+} \\
& \left.(A T M C F * A F * F S E M) / p C \mathrm{O}_{2}(0)\right)
\end{aligned}
$$

with:

$\mathrm{T}_{\mathrm{CO}_{2}} \quad=$ equilibrium temperature increase integrated over the time horizon of $\mathrm{CO}_{2}$ (in ${ }^{\circ} \mathrm{C}$ )

$\mathrm{T}_{2 x \mathrm{CO}_{2}}=$ temperature increase for a doubled $\mathrm{CO}_{2}$ concentration (in ${ }^{\circ} \mathrm{C}$ )

$T \quad=$ time horizon (in years)

$F S E M=$ emission impulse of 1 (or $10^{-3}$ ) Gt $\mathrm{CO}_{2}$ (in Gt)

\section{$\mathrm{CFCs}$}

The atmospheric removal process of $\mathrm{CFCs}$ is calculated by a negative exponential function, with removal rate inversely proportional to the atmospheric lifetime of CFCs. Thus the atmospheric CFC concentration can be represented by the following expression:

$$
p C F C(t)=e^{-t / L F T C F C} *(p C F C(0)+C V C F C * E M C F C)
$$

with:

$p C F C(t)=$ atmospheric CFC concentration (in $p p b)$ 
$p C F C(0)=$ initial atmospheric CFC concentration, in 1985 (in $p p b$ )

$L F T C F C=$ atmospheric lifetime of CFC (in years)

$C V C F C=$ conversion factor of CFC (in $p p b / G t$ )

$E M C F C=$ emission impulse of $10^{-3} \mathrm{Gt}$ CFC (in $G t$ )

Then the total equilibrium temperature effect can be derived from the difference in concentrations with and without an emission impulse of $10^{-3} \mathrm{Gt}$ respectively (see the Appendix to this Chapter):

$$
T C F C=A C F C *\left[\left(1-e^{-T / L F T C F C}\right) * L F T C F C * C V C F C * E M C F C\right]
$$

with:

$T C F C=$ equilibrium temperature effect of CFC integrated over atmospheric lifetime of $\mathrm{CFC}$ (in ${ }^{\circ} \mathrm{C}$ )

$A C F C=$ CFC temperature coefficient, obtained from Ramanathan et al. (1985) (in ${ }^{\circ} C / p p b$ )

$T \quad=$ time horizon

\section{$\mathrm{N}_{2} \mathrm{O}$ and $\mathrm{CH}_{4}$}

In analogy to the atmospheric removal process of CFCs the removal of $\mathrm{N}_{2} \mathrm{O}$ and $\mathrm{CH}_{4}$ is described by a single residence time. For $\mathrm{N}_{2} \mathrm{O}$ and $\mathrm{CH}_{4}$ similar radiative perturbations are given by Wigley (1987), see the Appendix to this Chapter. This leads to the total equilibrium temperature effect:

$$
\begin{aligned}
T N_{2} O= & A N_{2} O *\left[2 * L F T N_{2} O *\left(1-e^{-T / 2 * L F T N_{2} O}\right) *\right. \\
& \left(\sqrt{\left(C V F N_{2} O\right.} * E M N_{2} O+P N_{2} O(0)\right) \\
& -\sqrt{\left(p N_{2} O(0)\right)}
\end{aligned}
$$

with:

$T \mathrm{~N}_{2} \mathrm{O}=$ equilibrium temperature effect of $\mathrm{N}_{2} \mathrm{O}$ integrated over atmospheric lifetime of $\mathrm{N}_{2} \mathrm{O}$ (in ${ }^{\circ} \mathrm{C}$ )

$A N_{2} \mathrm{O}=\mathrm{N}_{2} \mathrm{O}$ temperature coefficient, obtained from Ramanathan et al. (1985) (in ${ }^{\circ} \mathrm{C} / \mathrm{ppb}$ )

LFT $\mathrm{N}_{2} \mathrm{O}=$ atmospheric lifetime of $\mathrm{N}_{2} \mathrm{O}$ (in years)

$C V F N_{2} \mathrm{O}=$ conversion factor of $\mathrm{N}_{2} \mathrm{O}$ (in $p p b / G t$ )

$E M N_{2} O=$ emission impulse of $1 \mathrm{Gt} \mathrm{N}_{2} \mathrm{O}$ (in Gt)

$p N_{2} O(0)=$ initial atmospheric concentration of $\mathrm{N}_{2} \mathrm{O}$, in 1985 (in $p p b$ ) 
And for $\mathrm{CH}_{4}$ :

$$
\begin{aligned}
\operatorname{TCH}_{4}= & A C H_{4} * e^{\left(\delta /\left(L F T C H_{4}+n\right)\right)} *\left[2 *\left(L F T C H_{4}+n\right) *\right. \\
& \left(1-e^{-T / 2 *\left(L F T C H_{4}+n\right)}\right) * \\
& \left.\left(\sqrt{\left(C V F C H_{4}\right.} * E M C H_{4}+P C H_{4}(0)\right)-\sqrt{\left(p C H_{4}(0)\right.}\right)
\end{aligned}
$$

where $\mathrm{TCH}_{4}, \mathrm{ACH}_{4}, \mathrm{LFTCH}_{4}, \mathrm{CVFCH}_{4}, \mathrm{EMCH}_{4}, \mathrm{pCH} \mathrm{H}_{4}(0)$ correspond to the symbolic names of $\mathrm{N}_{2} \mathrm{O}$ in Equation (11.8).

\subsection{Results}

The temperature increasing potentials (TIPs) of the different trace gases are represented in Tables $11.2,11.3$ and 11.4 .

\begin{tabular}{|c|c|c|}
\hline $\begin{array}{c}\text { IMAGE APPROACH } \\
\text { TIP }\end{array}$ & $\begin{array}{c}\text { Time horizon } \\
\text { is 100 years }\end{array}$ & $\begin{array}{c}\text { Time horizon } \\
\text { is 500 years }\end{array}$ \\
\hline $\mathrm{CO}_{2}$ & 1 & 1 \\
$\mathrm{CH}_{4}$ & 22 & 8 \\
$\mathrm{~N}_{2} \mathrm{O}$ & 320 & 240 \\
CFC-11 & 4904 & 2099 \\
CFC-12 & 9295 & 5861 \\
\hline
\end{tabular}

Table 11.2: TIP for modelling approach with IMAGE.

\begin{tabular}{|c|c|c|}
\hline $\begin{array}{c}\text { ANALYTICAL } \\
\text { APPROACH }\end{array}$ & $\begin{array}{c}\text { Time horizon } \\
\text { TIP }\end{array}$ & $\begin{array}{c}\text { Time horizon } \\
\text { is 500 years }\end{array}$ \\
\hline $\mathrm{CO}_{2}$ & 1 & 1 \\
$\mathrm{CH}_{4}$ & 28 & 6 \\
$\mathrm{~N}_{2} \mathrm{O}$ & 264 & 159 \\
$\mathrm{CFC}-11$ & 5067 & 1374 \\
$\mathrm{CFC}-12$ & 7630 & 2720 \\
\hline
\end{tabular}

* indirect analytical approach (analytical equivalent to the modelling approach (from emissions to concentrations to temperature effect)

Table 11.3: TIP for indirect analytical approach. 


\begin{tabular}{|c|c|c|}
\hline $\begin{array}{c}\text { ANALYTICAL } \\
\text { APPROACH } \\
\text { TIP }\end{array}$ & $\begin{array}{c}\text { Time horizon } \\
\text { is } 100 \text { years }\end{array}$ & $\begin{array}{c}\text { Time horizon } \\
\text { is 500 years }\end{array}$ \\
\hline $\mathrm{CO}_{2}$ & 1 & 1 \\
$\mathrm{CH}_{4}$ & 19 & 4 \\
$\mathrm{~N}_{2} \mathrm{O}$ & 336 & 143 \\
$\mathrm{CFC}-11$ & 5853 & 1588 \\
$\mathrm{CFC}-12$ & 8814 & 3143 \\
\hline
\end{tabular}

** direct analytical approach (from emissions to temperature effect)

Table 11.4: TIP for analytical and modelling approaches.

From Tables 11.2, 11.3 and 11.4 it follows that, considering a $\mathrm{CO}_{2}$ time horizon of 100 years, the results of both analytical methods correspond reasonably with the IMAGE results;.

Comparing the analytical and modelling TIP values for a $\mathrm{CO}_{2}$ time horizon of 500 years reveals a structural difference between these two procedures. The modelling TIP values appear to be considerably higher than the analytical TIPs. This is due to the linear increase in $\mathrm{CO}_{2}$ contribution in the analytical method (illustrated in Tables 11.3 and 11.4), in contrast to the more realistic, nonlinear way $\mathrm{CO}_{2}$ is modelled in IMAGE, shown in Table 11.2 .

Consequently, the time horizon (in fact the chosen atmospheric lifetime of $\mathrm{CO}_{2}$ ) appears to be of crucial importance. However, $\mathrm{CO}_{2}$ does not have a specific atmospheric residence time. This dynamical feature of the TIP is clearly demonstrated in Figure 11.3, giving the TIP of $\mathrm{CH}_{4}$ as a function of the time horizon, which has been varied from 1 to 500 years. In particular, when varying the time horizon of $\mathrm{CO}_{2}$ from 1 to 100 years, the TIP value of $\mathrm{CH}_{4}$ sharply decreases. 


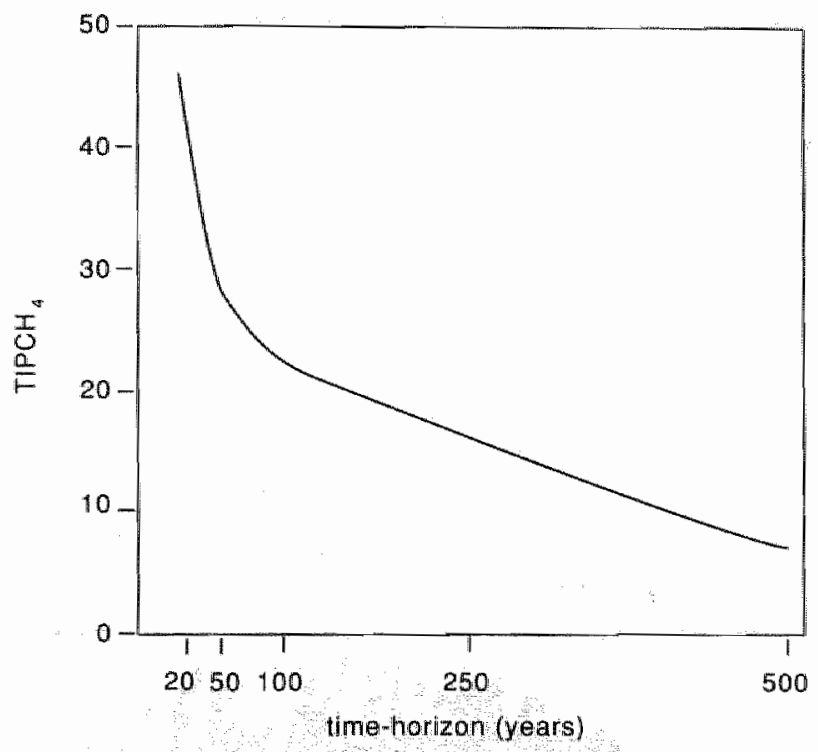

Figure 11.3: TIP of $\mathrm{CH}_{4}$ as a function of the chosen time horizon.

Another advantage of the modelling approach is the possibility of taking the $\mathrm{CH}_{4}$-CO-OH interactions into account. From series of experiments with $\mathrm{CO}$ emission impulses, it follows that a $\mathrm{CO}$ emission increase of $50 \%$ can increase the $\mathrm{CH}_{4}$ concentration by about $25 \%$.

Based on the foregoing results, an uncertainty range of TIPs for the most prominent greenhouse gases is presented in Table 11.5 for a time horizon of 100 years. This range is compared with the figures of IPCC (1990). 


\begin{tabular}{|c|c|c|}
\hline TIP & $\begin{array}{c}\text { TIP range based } \\
\text { on this study for } \\
\text { a time horizon of }\end{array}$ & $\begin{array}{c}\text { TIP values of } \\
\text { IPCC (1990) for } \\
\text { a time horizon } \\
\text { of } 100 \text { years }\end{array}$ \\
\hline $\mathrm{CO}_{2}$ & 100 years & 1 \\
$\mathrm{CH}_{4}$ & 1 & 21 \\
$\mathrm{~N}_{2} \mathrm{O}$ & $264-336$ & 290 \\
$\mathrm{CFC}-11$ & $4904-5853$ & 3500 \\
$\mathrm{CFC}-12$ & $7630-9295$ & 7300 \\
\hline
\end{tabular}

Table 11.5: TIP approach of IMAGE (with time horizon of 100 years) compared to the TIP approach followed by Lashof and Ahuja (1990)

Generally, the TIPs presented here, are somewhat higher than the (tentative) TIPs or GWPs of the IPCC, especially for the CFCs.

Using the Temperature Increasing Potentials calculated with IMAGE the relative contributions of the different greenhouse gases for the year 1985 can be calculated. In Figure 11.4 the original relative contributions are given, based on the simulated atmospheric concentrations of IMAGE.

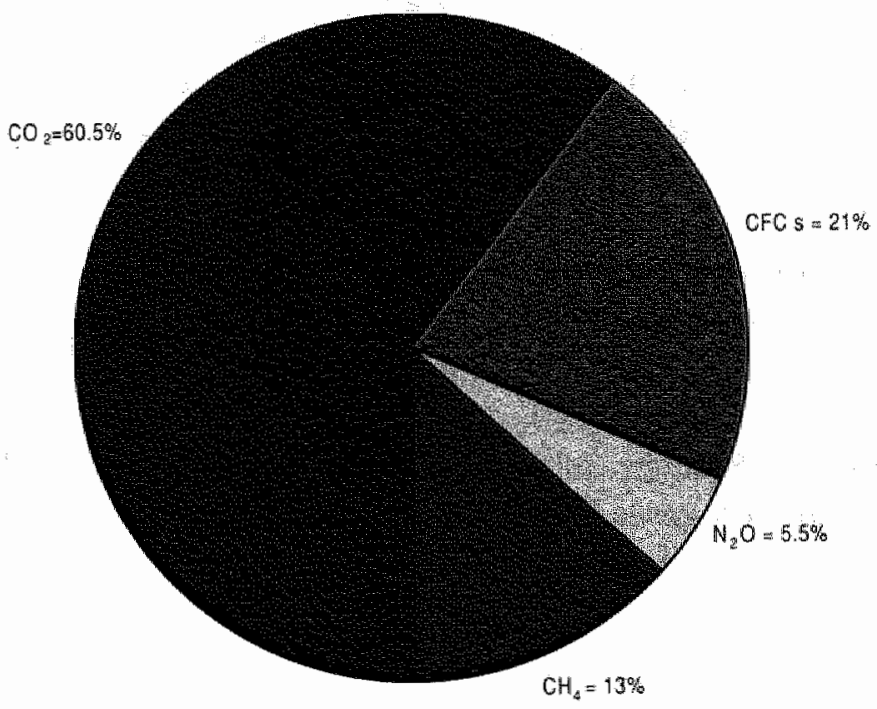

Figure 11.4: Relative contributions of trace gases to equilibrium temperature increase for the year 1985 , based on global atmospheric concentrations calculated with IMAGE. 
Figures 11.5 and 11.6 give relative curnulative contributions of the major greenhouse gases, which are based on emissions in 1985, combined with the TIP ratios calculated with IMAGE, assuming a time horizon of 100 years.

Figure 11.5 shows the contributions of the different greenhouse gas emissions of 1985 to the cumulative equilibrium temperature effect over the next 100 years. The resulting relative contributions of Figure 11.5 consist of the 1985 emissions multiplied by the TIP ratios of IMAGE. In Figure 11.6 the same procedure is followed, but only for the man-made (or anthropogenic) emissions. Comparing these figures, the TIP calculations of Figure 11.5 indicate an underestimation of $\mathrm{CH}_{4}$ and $\mathrm{N}_{2} \mathrm{O}$ as greenhouse potentials, and on the other hand an overestimation of CFC-11 and CFC-12. The minor role of CFCs according to the IMAGE TIP concept can be clarified by the realization of the Montreal Protocol, by which the emissions of these gases will be sharply reduced (United Nations Environment program, 1987). The higher contribution of Figure 11.4 is based on the current rapidly increasing concentrations of these CFCs. Recently other CFCs and also halons have been incorporated in IMAGE, allowing the TIPs of these greenhouse gases to be estimated with IMAGE, see Lashof and Rotmans (1990).

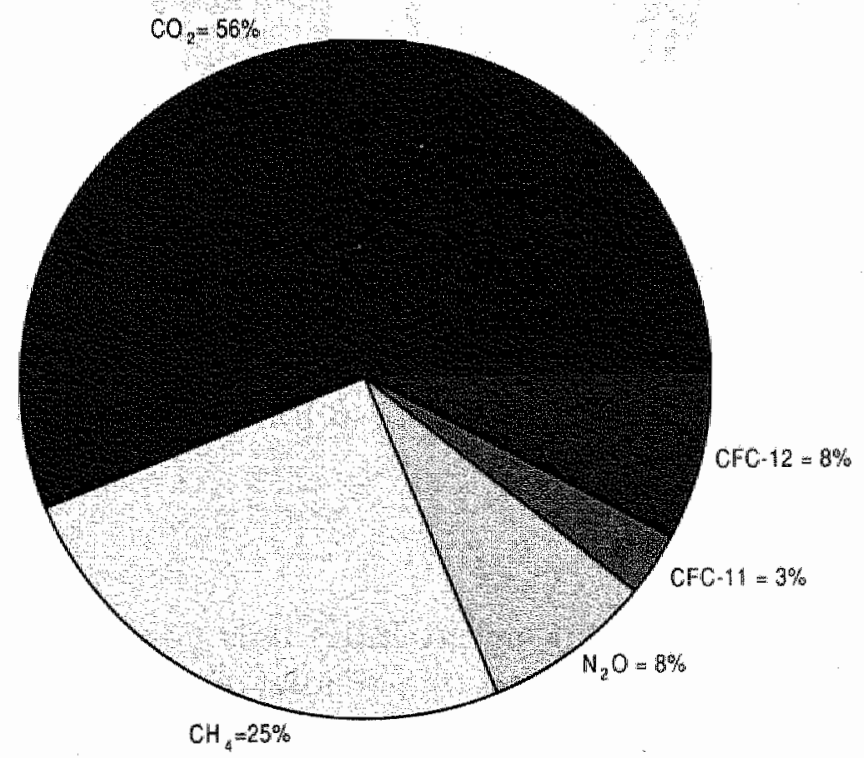

Figure 11.5: Relative contributions of greenhouse gas emissions of the year 1985 to cumulative equilibrium temperature increase for the next century, following the TIP concept according to IMAGE simulations. 
Taking into account only anthropogenic emissions, the contribution of $\mathrm{CO}_{2}$ becomes about $66 \%$, as is shown by Figure 11.6. It should be noted that the $\mathrm{CO}_{2}$ emission is composed of the fossil fuel component, about $5.4 \mathrm{GtC}$, and the deforestation component, about $1.5 \mathrm{GtC}$ according to Swart and Rotmans $(1989 \mathrm{a}, \mathrm{b})$.

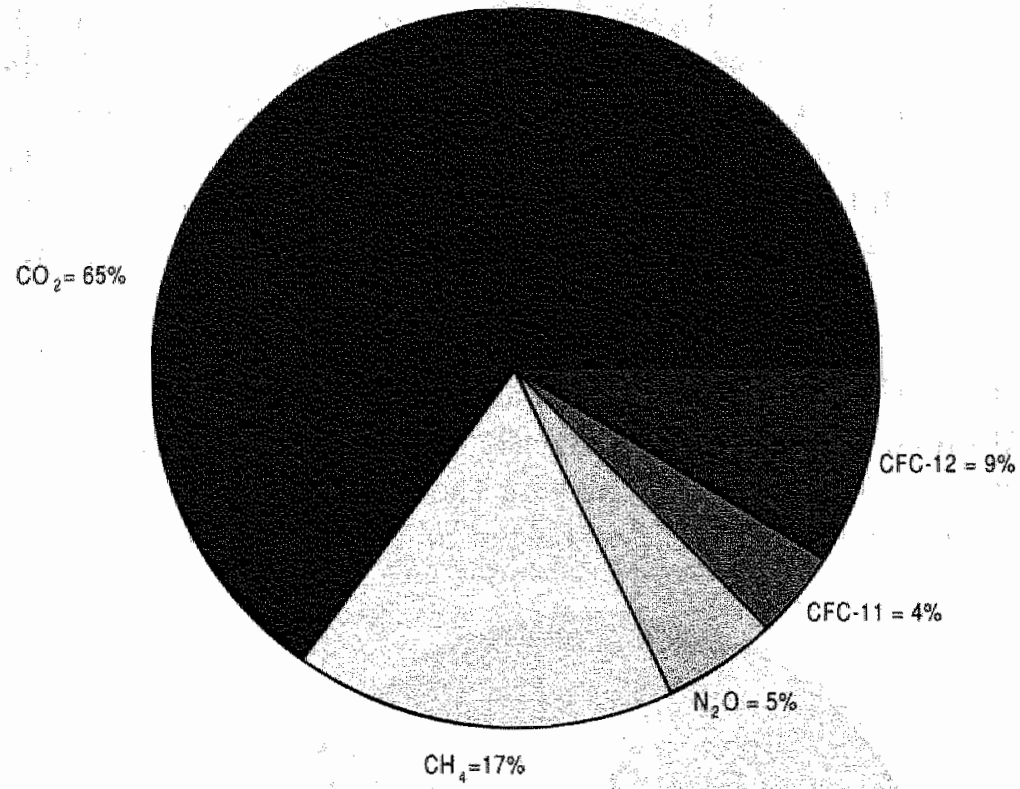

Figure 11.6: Relative contributions of man-made (or anthropogenic) greenhouse emissions of the year 1985 to cumulative equilibrium temperature increase for the next century, following the TIP concept according to IMAGE simulations.

\subsubsection{Conclusions}

Although surrounded by many uncertainties it is possible to estimate an index by which the global temperature potential of various greenhous gases can be compared. Such an index is the Temperature Increasing Potential, or TIP, which has been developed in different ways. In determining the TIP, both analytical and simulation methods can be applied, and although there appeared to be differences, both methods can be used in calculating TIP values.

Simulation experiments with IMAGE demonstrate the dynamical aspect 
of the TIP. Therefore the time-dependent TIP definition, presented here as calculating at any time the temperature effect of a 1 (or $10^{-3}$ ) $\mathrm{Gt}$ emission of a particular greenhouse gas compared to that of $\mathrm{CO}_{2}$, is to be preferred to the static TIP definitions given so far.

Results based on calculations with IMAGE showed that particularly $\mathrm{CH}_{4}$ and $\mathrm{N}_{2} \mathrm{O}$, being about 22 and 320 times as effective as $\mathrm{CO}_{2}$ respectively, might now be underestimated. This appeared from the relative contributions of greenhouse gases of 1985 to global warming over the next century, calculated with the TIP concept according to IMAGE, which showed a considerable share of $\mathrm{CH}_{4}$ and $\mathrm{N}_{2} \mathrm{O}$ especially. Based on the TIP estimates it can be concluded that, next to $\mathrm{CO}_{2}, \mathrm{CH}_{4}$ and $\mathrm{N}_{2} \mathrm{O}$ will be threatening greenhouse potentials for the future. To a lesser degree the same holds for CFC-11 and CFC-12, although the emissions of these both gases will be sharply reduced by the realization of the Montreal Protocol.

With these TIPs, for each trace gas future global temperature increases, based on emission potentials, can be estimated directly. In this way these TIPs can be used to define quantified environmental targets which can serve as reference values for the development of international response strategies. While using TIPs as a basis for comprehensive regulation of greenhouse gas emissions may not be workable in practice, TIPs can serve as an important instrument in relating emissions to environmental targets, at least on the conceptual level. 


\subsection{Appendix}

In the analytical approach for each trace gas two equilibrium temperature increase effects are callculated, both with and without an impulse of $1 \mathrm{Gt}$.

\section{$\mathrm{CO}_{2}$}

Following Wigley (1987) the equilibrium temperature effect due to $\mathrm{CO}_{2}$ can be defined as:

$$
T_{\mathrm{CO}_{2}}(t)=T_{2 x C O_{2}} / \operatorname{Ln}(2) * \operatorname{Ln}\left(p C O_{2}(t) / p C O_{2}(0)\right)
$$

with:

$T_{\mathrm{CO}_{2}}(t)=$ equilibrium temperature increase due to $\mathrm{CO}_{2}$ at time $t$ (in ${ }^{\circ} \mathrm{C}$ )

$\mathrm{T}_{2 \times \mathrm{CO}_{2}}=$ temperature increase for a doubled $\mathrm{CO}_{2}$ concentration (in ${ }^{\circ} \mathrm{C}$ )

$p \mathrm{CO}_{2}(0)=$ initial $\mathrm{CO}_{2}$ concentration, in the year 1985 (in $p p m$ )

To calculate the temperature effect over a longer period, Equation (11.10) has to be integrated:

$$
T_{C O_{2}}=\int_{0}^{T} T C O_{2}^{i}(\tau) d \tau-\int_{0}^{T} T C O_{2}^{w i}(\tau) d \tau
$$

where:

$\mathrm{TCO}_{2}^{i}$ and $\mathrm{TCO}_{2}^{w i}$ are the temperature effect of $\mathrm{CO}_{2}$ with and without impulse and $T$ is the time horizon.

However, assuming an immediate steady state concentration of $\mathrm{CO}_{2}$, the temperature effect of $\mathrm{CO}_{2}$ without impulse can be neglected. Thus, combining (11.4), (11.10) and (11.11) yields expression (11.5).

\section{$\mathrm{CFCs}$}

The CFC temperature effect is defined according to Ramanathan et al. (1985):

$$
T C F C(t)=A C F C *[p C F C(t)-p C F C(0)]
$$

with:

$T C F C(t)=$ equilibrium temperature increase due to $\mathrm{CFC}\left(\right.$ in ${ }^{\circ} \mathrm{C}$ ) $A C F C=C F C$ temperature coefficient, obtained from Ramanathan et al. (1985) (in ${ }^{\circ} \mathrm{C} / \mathrm{ppb}$ ) 
Then the total temperature effect, integrated over the time horizon $T$ is:

$$
T C F C=\int_{0}^{T} T C F C^{i}(t) d t-\int_{0}^{T} T C F C^{w i}(t) d t
$$

where $T C F C^{i}(t)$ and $T C F C^{w i}(t)$ are the temperature effect at time $t$ with and without an emission impulse.

Combining (11.6), (11.12) and (11.13) yields for the temperature effect with impulse:

$$
\begin{aligned}
T C F C^{i}= & A C F C *\left[\left(1-e^{-T / L F T C F C}\right) *\right. \\
& (p C F C(0)+C V C F C * E M C F C) \\
& * L F T C F C-L F T C F C * P C F C(0)
\end{aligned}
$$

and without emission impulse:

$$
\begin{aligned}
T C F C^{w i}= & A C F C *\left[\left(1-e^{-T / L F T C F C}\right) * p C F C(0) * L F T C F C\right. \\
& -L F T C F C * P C F C(0)]
\end{aligned}
$$

where $T C F C^{i}$ and $T C F C^{w i}$ are the total temperature rises with and without emission impulse respectively, and $T$ is the time horizon. Equations (11.14) and (11.15) produce the total temperature rise, given in (11.7).

\section{$\mathrm{CH}_{4}$ and $\mathrm{N}_{2} \mathrm{O}$}

The equilibrium temperature effect of $\mathrm{CH}_{4}$ is based on model results of Kiehl and Dickinson (1987):

$$
\mathrm{TCH}_{4}=A C H_{4} *\left(\sqrt{p C H_{4}(t)}-\sqrt{p C H_{4}(0)}\right)
$$

with:

$\mathrm{TCH}_{4}(t)=$ equilibrium temperature increase due to $\mathrm{CH}_{4}\left(\right.$ in $\left.{ }^{\circ} \mathrm{C}\right)$ $p \mathrm{CH}_{4}(t)=$ atmospheric $\mathrm{CH}_{4}$ concentration (in $p p m$ )

$p \mathrm{CH}_{4}(\mathrm{O})=$ initial atmospheric $\mathrm{CH}_{4}$ concentration, in 1985 (in ppm)

$\mathrm{ACH}_{4}=\mathrm{CH}_{4}$ temperature coefficient, obtained from Kiehl and Dickinson (1987)

Then the total temperature effect with an emission impulse can be described as: 


$$
\begin{aligned}
\operatorname{TCH}_{4}^{i}= & A C H_{4} * e^{\left(\delta / L F T C H_{4}+n\right)} *\left[\sqrt{\left(C V F C H_{4}\right.} * E M C H_{4}\right. \\
& \left.+P C H_{4}(0)\right) * 2 *\left(L F^{\prime} T C H_{4}+n\right) \\
& \left.\left(1-e^{-T / 2 *\left(L F T C H_{4}+n\right)}\right)-\sqrt{\left(p C H_{4}(0)\right.} *\left(L F T C H_{4}+n\right)\right]
\end{aligned}
$$

with:

$C V F C H_{4}=$ conversion factor of $\mathrm{CH}_{4}$ (in ppm/Gt)

$L F T C H_{4}=$ atmospheric lifetime of $\mathrm{CH}_{4}$ (in years)

$E M C H_{4}=$ emission impulse of $1 \mathrm{Gt} \mathrm{CH}_{4}$ (in $G t$ )

$T=$ time horizon

and without this emission impulse:

$$
\begin{aligned}
T C H_{4}^{w i}= & A C H_{4} * e^{\left(\delta / L F T C H_{4}+r\right)} *\left[\sqrt{P C H_{4}(0)} * 2\right. \\
& *\left(L F T C H_{4}+r\right) *\left(1-e^{-T / 2 *\left(L F T C H_{4}+n\right)}\right) \\
& \left.-\sqrt{P C H_{4}(0)} *\left(L F T C H_{4} * r\right)\right]
\end{aligned}
$$

Then the total temperature effect, integrated over the atmospheric lifetime of $\mathrm{CH}_{4}$ is obtained by subtracting the temperature effect without emission impulse from the temperature with emission impulse, yielding Equation (11.9).

The corresponding formula for $\mathrm{N}_{2} \mathrm{O}$, given in Equation (11.8), can be derived identically. 


\section{Chapter 12}

\section{Sensitivity Analysis}

\subsection{Introduction}

The technique of metamodelling and experimental design (Kleijnen, 1987), which has already been applied to IMAGE (Rotmans et al., 1988, Rotmans and Vrieze, 1990, Rotmans et al., 1990), is used to perform sensitivity experiments with IMAGE. In this chapter it is explained how the technique of metamodelling enables us to search for a relationship between input and output variables of IMAGE and how experimental designs can be used to carry out experiments on this model in an efficient and effective way. Various modules of IMAGE have been analysed in this way; the modules concerning the costs of dike raising and the carbon cycle module. First the modules concerning dike raising and the costs of dike raising have been analyzed, because these modules are expected to behave linearly. Afterwards the carbon cycle module was subject to sensitivity analysis, since this is a quintessential constituent of the model. The carbon cycle module is split up into an ocean module and a terrestrial biota module, as described in Chapter 3, and these modules are treated separately. The deforestation module, already integrated in the carbon cycle module now, has not yet been put to the sensitivity test. Moreover it is worth mentioning that an uncertainty analysis has been applied on the modules concerning dike raising and the ocean module of the carbon cycle, with help of the Latin Hypercube Sampling method (Lammerts, 1989). 


\subsection{Metamodelling}

Following Kleijnen (1987), a metamodel has to be interpreted as a regression model of the actual simulation model. Suppose the functional relationship between an independent variable, denoted by $Y$, and $k$ chosen factors $z$ of the simulation model is given by:

$$
Y=f_{1}\left(z_{1}, z_{2}, \ldots, z_{k}\right)
$$

where $z_{1}, \ldots, z_{k}$ correspond to the chosen factors of the simulation model. Using a Taylor expansion we can approximate (12,1) by

$$
\tilde{Y}=\sum_{j=0}^{n} a_{j} w_{j} \simeq Y
$$

where $n$ is some natural number, $a_{j}, j \in\{0, \ldots, n\}$ are constants and $w_{j}, j \in$ $\{0, \ldots, n\}$ are suitable chosen functions of $z_{1}, \ldots, z_{k}$ with $w_{0}=1$. For instance a first-order approximation would give $n=k$ and $w_{j}=z_{j}, j \in$ $\{0, \ldots, k\}$. Alternatively an approximation with interactions would give $n=k+(k *(k-1)) / 2$, where $w_{0}, \ldots, w_{k}$ are the same as in the first-order case and $w_{k+1}, \ldots, w_{k+(k *(k-1)) / 2}$ reflect first-order interactions. Notice that from a theoretical viewpoint there is no restriction on the functional relationship between the $w_{k}$ 's and the $z_{k}$ 's; they may even be logarithmically related.

Next the coefficients $a_{0}, \ldots, a_{n}$ in the metamodel are estimated by linear regression, using ordinary least squares, and it is tested whether the metamodel is indeed valid. If not, the metamodel might be improved by adding more terms to (12.2). Now let $Y_{i}$ denote the resulting output in run $i$ where the levels of the factors are $z_{1 i}, \ldots, z_{k i}$ which determine $w_{1 i}, \ldots, w_{n i}$. Let $m$ be the number of runs, $m \geq q=n+1$, where $q$ is the number of constants $a_{j}$, and let $W$ be the matrix

$$
\begin{array}{rrrr}
1 & w_{11} & \ldots & w_{1 n} \\
1 & w_{i 1} & \ldots & w_{i n} \\
1 & w_{m 1} & \ldots & w_{m n}
\end{array}
$$

Then it is well known, that

$$
\hat{\beta}=\left(W^{\prime} W\right)^{-1} W^{\prime} \bar{Y}^{\prime}
$$


is the least squares estimator of the vector of coefficients $\left(a_{0}, a_{1}, \ldots, a_{n}\right)$, where $\vec{Y}=\left(Y_{1}, \ldots, Y_{m}\right)$. Of course in (12.4) it is assumed that $\left(W^{\prime} W\right)$ is a non-singular matrix. Equation (12.4) yields the following estimator (denoted by $\hat{Y}$ ) of $\tilde{Y}$ in (12.2):

$$
\hat{Y}^{\prime}=w\left(W^{\prime} W\right)^{-1} W^{\prime} \bar{Y}^{\prime},
$$

where $w$ is the vector of functionals $\left(w_{0}, w_{1}, \ldots, w_{n}\right)$. Since $\tilde{Y}$ is an approximation of $Y$ it follows that $\hat{Y}$ is also an approximation of $Y$. Two types of errors have been introduced:

1. The choice of $\tilde{Y}$. This choice, determining the metamodel, may lead to a systematic error. The vallidition procedure has to prove the correctness of this choice.

2. The choice of $z_{i 1}, \ldots, z_{i k}$, with $i=1, \ldots, m$ in the estimation procedure of $a_{0}, a_{1}, \ldots, a_{n}$, which can be interpreted as "noise".

This mathematical analysis can be refined if a statistical (sub)model is added for the fitting errors $e=Y-\hat{Y}$ (Rotmans et al (1990), Kleijnen et al. (1990)). If it is assumed that these errors are normally and independently distributed with common variance, say $\sigma^{2}$. Then the least squares algorithm yields the Best Linear Unbiased Estimator (BLUE); The variances of these estimators are on the main diagonal of the variance-covariance matrix of $\hat{B}$ :

$$
\operatorname{cov}(\hat{B})=\left(X^{\prime} X\right)^{-1} \sigma^{2}
$$

Recently a group of Americans statisticians proposed a more general model. They assume that the errors $e$ are not independent but form a stationary process with a specific auto-correlation function, see Sachs et al. (1989), Kleijnen (1990). $\sigma^{2}$ can be estimated by the mean squared residuals:

$$
\hat{\sigma}^{2}=\sum_{i=1}^{m}\left(Y_{i}-\hat{Y}_{i}\right) /(m-n-1)
$$

where $\hat{Y}_{i}$ denotes the predicted observation for run $i$, using (12.5). To test whether a coefficient $a_{k}$ in (12.2) significantly differs from 0 the $t$ statistic

$$
t_{d . k}=\hat{\beta}_{k} / s_{k}, \quad k=0,1, \ldots, n
$$

can be used, where $s_{k}$, the standard deviation of the estimator $\hat{B}_{k}$, equals the corresponding main diagonal element of the covariance matrix of $\hat{\beta}$ : $\left(W^{\prime} W\right)^{-1} \hat{\sigma}^{2}$. Further, $d$ stands for the degrees of freedom of $t$, which equals 
the degrees of freedom of $\hat{\sigma}^{2}: d=m-n-1$. When validating deterministic simulation models, Kleijnen (1987) discourages the application of the studentized deviation $\left(Y_{m+1}-\hat{Y}_{m+1}\right) /\left(\widehat{\operatorname{var}}\left(\hat{Y}_{m+1}\right)+\widehat{\operatorname{var}}\left(Y_{m+1}\right)\right)$ where $m+1$ refers to an extra run. Instead he recommends the use of the relative prediction error

$$
R P_{m+1}=\hat{Y}_{m+1} / Y_{m+1}
$$

where $R P_{m+1}$ is the relative prediction error of the extra run, $\hat{Y}_{m+1}$ is the predicted observation of the extra run, using formula (12.5), and $Y_{m+1}$ is the observed outcome of the simulation program. Though there exists a method of approximating the variance of the ratio of two random variables (Efron and Gong, 1983, pag. 40), a simple statistic for this relative prediction error is not known. In addition the power of such a statistical test becomes small if the model is bad. Therefore Kleijnen (1987) suggests rejecting the regression model if these errors are "too big", for example bigger than $5 \%$ (this number depends on the distribution of the errors throughout the model, on the nature of the simulation model etc.).

\subsection{Experimental Design}

Experimental design is a statistical technique for doing experiments in an effective and efficient way. The input variables are changed in a systematic way to discover the behaviour of the output variable(s). With respect to rnetamodels experimental design involves the setting of factors in each simulation run to estimate $\hat{\beta}$. Here an experimental design is identified by a given set of values for the factors $z_{1}, \ldots, z_{k}$. In experimental designs these factors have only a limited number of levels, mostly two. An experimental design is effective if all relevant coefficients can be estimated, and efficient if variances of the estimators are minimal compared to the estimators of designs with the same number of experiments. Or, in other words, if variances are equal, the method which requires the least number of runs is the most efficient.

In order to minimize the number of runs with the simulation model in estimating the regression coefficients, several well-known experimental designs are used.

Assuming a first-order approximation, with $n=k$ and $w_{j}=z_{j}, j \in$ $\{0, \ldots, k\}$ then $(12.2)$ can be written as:

$$
\tilde{Y}=\sum_{j=0}^{k} a_{j} z_{j}
$$


In this case an experimental design can be based on 2 levels per factor, namely the highest and lowest value of each factor. A complete factorial design, where each combination of values occurs, would take $2^{k}$ experiments or runs. However, by associating $p$ factors with irrelevant interactions (products of factors) the number of experiments needed is reduced to $2^{k-p}$ (Kleijnen, 1987, Rotmans et al., 1988).

By applying a simple linear transformation the factors can be normalized such that the highest and lowest value of each factor is respectively +1 and -1 (Bettonvil and Kleijnen, 1988, Kleijnen, 1987, see section 12.4.3). Such a normalization can be carried out very simply by the substitution:

$$
z_{j}=c_{j} x_{j}+d_{j}
$$

where $c_{j}=\left(H_{j}-L_{j}\right) / 2$ and $d_{j}=\left(H_{j}+L_{j}\right) / 2 ; H_{j}$ and $L_{j}$ refer to the highest and lowest value of factor $z_{j}$, respectively. Then Equation (12.10) transforms into:

$$
\tilde{Y}=\sum_{j=0}^{k} \alpha_{j} x_{j}
$$

where $\alpha_{0}, \ldots, \alpha_{k}$ follow straightforwardly as functions of $a_{0}, \ldots, a_{k}$ by substitution of (12.11) into (12.10). Since each factor in (12.12) can vary between +1 and -1 , the coefficients $b_{j}, j \in\{0, \ldots, k\}$ can be interpreted as $1 / 2$ times the effect of factor $x_{j}$ when this factor changes from its lowest value to its highest one. Moreover $b_{0}$ can be interpreted as the overall (or mean) effect, averaged over all possible combinations of values of the factors. Another advantage of this normalization is that each factor now changes over the same interval $[-1 ;+1]$ allowing the estimatiors of the coefficients to be compared directly in determining the relative importance of the related factors.

To estimate quadratic terms one needs more than two values per factor. In that case 3 values per factor can be used, in a $3^{k-p}$ factorial design, and even five factors per factor, in a central composite design. Both the $3^{k-p}$ and central composite designs are described extensively in Box and Hunter (1978), Montgomery (1984), and Rotmans et al. (1988). Rotmans and Vrieze (1990) conclude that central composite designs are more appropriate than $3^{k-p}$ designs, because the latter imply a number of runs growing inadmissibly when $k-p$ increases. 


\subsection{A Metamodel for the Costs of Dike Raising}

\subsubsection{Introduction}

In this section metamodels and experimental designs are developed for the modules concerning dike raising and the costs of dike raising for the Netherlands. In these modules dike raising as well as the costs of dike raising are calculated given the simulated sea level rise in Chapter 8. In total nine different metamodels have been formulated, calculated with nine experimental designs. Here only the two most relevant designs and metamodels are treated. For each metamodel the parameters, which a priori supposed to be important, are presented.

Subsequently the metamodel and experimental design are formulated. Next the experiments and validation of the metamodel will be carried out; then the results are presented. Finally the results will be evaluated and conclusions will be drawn. Furthermore, in the last metamodel the effect of standardization of the factors is examined.

\subsubsection{Input and output variables}

The cumulative costs of dike raising (in billions of guilders) for a chosen strategy of dike raising with constant safety level (den Elzen and Rotmans, 1988), are chosen as output variable, denoted as $Y$. The costs of dike raising, approximated by the metamodel, is denoted as $\tilde{Y}$. Factors of which the influence on output variables has to be estimated are denoted originally as $z$, and in normalized form as $x$. The estimates of their effects are denoted by $\hat{\alpha}$, see section 12.4 .3 . The costs of dike raising refer to the year 2100 , the chosen end-point of simulation.

\subsubsection{Specification of the First Metamodel for the Costs of Dike Raising}

For the modules of dike raising and the costs of dike raising the following eleven factors are selected (also see Chapter 8, and 9):

$z_{1} \quad$ initial costs of dike raising;

$z_{2}$ : marginal costs of dike raising per meter;

$z_{3}$ : reduced rate of interest, meaning the difference between the real rate of interest and economic growth;

$z_{4}$ : mimimal dike raising;

$z_{5}$ : gradient of flooding frequencies of storm surges, 
where flooding frequency is defined as the probability

of once exceeding a certain height;

$z_{6}$ : natural sea level rise;

$z_{7}$ : melting of the glaciers;

$z_{8}$ : melting of the Greenland ice cap;

$z_{9}$ : net effect at the Antarctics (negative, because of

the accumulation effect);

$z_{10}$ : depth of the mixed layer of the ocean;

$z_{11}$ : delay of the thermal expansion, representing the inertia of the ocean.

The upper and lower bounds of these factors, mainly based on mational and international scientific knowledge are represented in Table 12.4.1. The basic values in this table are the "standard' values of the parameters, as used in the model. By means of a simple linear transformation, described in Equation (12.11), the factors $z_{j}$ are transformed into normalized factors $x_{j}$ with two levels, -1 and +1

Additionally seven two-factor interactions are expected to be important, namely those between the factors $x_{1}$ and $x_{2}$, and between $x_{5}$ and $x_{6}, x_{7}, x_{8}, x_{9}, x_{10}$ and $x_{11}$. So it is assumed that the simulation model can be approximated by the following regression equation:

$$
\begin{aligned}
Y_{m}(i)= & \alpha_{0}+\sum_{j=1}^{11} \alpha_{j} x_{j}(i)+\alpha_{1,2} x_{1}(i) x_{2}(i)+\alpha_{5,6} x_{5}(i) x_{6}(i) \\
& +\alpha_{5,7} x_{5}(i) x_{7}(i)+\alpha_{5,8} x_{5}(i) x_{8}(i)+\alpha_{5,9} x_{5}(i) x_{9}(i) \\
& +\alpha_{5,10} x_{5}(i) x_{10}(i)+\alpha_{5,11} x_{5}(i) x_{11}(i) \quad(i=1, \ldots, m)
\end{aligned}
$$

with:

$Y_{m}(i)$ : estimated costs of dike raising at time 2100 in the $i$-th experiment, or the $i$-th combination of factor levels; $(i=1, \ldots, m)$;

$x_{j}(i)$ : value of factor $x_{j}$ in the $i$ th experiment (or combination); $(j=1, \ldots, 11)$;

$\alpha_{j} \quad:$ main effect of factor $x_{j}$

$\alpha_{0} \quad$ : the 'overall' average value;

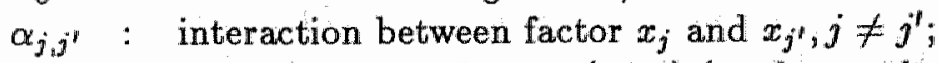

$m$ : number of experiments (runs) (or the number of combinations). 


\begin{tabular}{|l|l|l|l|l|}
\hline factor & $\begin{array}{l}\text { minimum } \\
\text { value }(-)\end{array}$ & $\begin{array}{l}\text { basic } \\
\text { value }\end{array}$ & $\begin{array}{l}\text { maximum } \\
\text { value }(+)\end{array}$ & dimension \\
\hline$z_{1}$ & $1.1 \mathrm{E}+08$ & $2.2 \mathrm{E}+08$ & $16.5 \mathrm{E}+08$ & $\mathrm{fl} / \mathrm{m}$ \\
$z_{2}$ & $4.4 \mathrm{E}+08$ & $15.4 \mathrm{E}+08$ & $26.4 \mathrm{E}+08$ & fl/m \\
$z_{3}$ & 1.0 & 2.0 & 3.0 & $\% /$ year \\
$z_{4}$ & 0.30 & 0.30 & 0.50 & $m$ \\
$z_{5}$ & 2.5 & 3.0 & 3.5 & \\
$z_{6}$ & 0.0015 & 0.0015 & 0.002 & $m /$ year \\
$z_{7}$ & 0.0009 & 0.0011 & 0.0012 & $m /{ }^{\circ} \mathrm{C}$ year \\
$z_{8}$ & 0.000128 & 0.000147 & 0.000166 & $m /{ }^{\circ} \mathrm{C}$ year \\
$z_{9}$ & -0.0003648 & -0.000237 & -0.0001088 & $m /{ }^{\circ} \mathrm{C}$ year \\
$z_{10}$ & 70 & 75 & 100 & $m$ \\
$z_{11}$ & 15 & 25 & 35 & year \\
\hline
\end{tabular}

Table 12.4.1: Factors with their upper and lower bounds.

\subsubsection{Experimental Design for the First Metamodel}

A full factorial experimental design, or a $2^{k}$ design, where $k$ denotes the number of factors, would require $2^{k}$ experiments. Because that is too many, another experimental design is chosen: a $2^{k-p}$ design (Kleijnen, 1987). Taking into account seven particular interactions between the eleven factors (see section 12.4.3), $2^{11-6}=32$ runs must be done in order to estimate the $(1+11+7=19) \alpha s$ in the metamodel. This must be executed as follows: between the eleven factors five factors are selected which occur comparatively rarely in the important interactions (at least the interactions which are supposed to be important, based on the prior knowledge and experience of the model builder $) ;\left(x_{1}, x_{2}, x_{3}, x_{4}\right.$ and $\left.x_{6}\right)$ are selected and for these factors a full experimental design is worked out, requiring $2^{5}$ runs. The remaining six factors $\left(x_{5}, x_{7}, x_{8}, x_{9}, x_{10}\right.$ and $\left.x_{11}\right)$ are written as combinations of the five main factors (Kleijnen, 1987, pp. 295-300):

$$
5=137=148=169=2410=2611=46
$$

Where the notation $5=13$ means $x_{5}(i)=x_{1}(i) x_{3}(i)(i=1, \ldots, m)$. This means that the value of factor 5 in combination $i$ equals the value of factor 1 in combination $i$, multiplied by the value of factor 3 , etc. Therefore the main effect of factor 5 is confounded with the interaction between the factors 1 and 3 , with $\hat{\alpha}_{5}=\hat{\alpha}_{13}$ and $E\left(\hat{\alpha}_{5}\right)=\alpha_{5}+\alpha_{13}$, see Kleijnen (1987), pp. 295-300. Equation (12.14) gives the generators of this experimental design. 


\subsubsection{Results of the First Metamodel}

Table 12.4 .2 contains the estimated effects $\hat{\alpha}$, estimated by using ordinary least squares. In Table 12.4.2 also the values of the Student statistic $t_{v}$ with $v=m-q=32-19=13$ degrees of freedom, where $q$ is the number of effects to be estimated see (12.3). Since we wish a type-I error of $5 \%$, only those factors are significant for which $\left|t_{13}\right|>2.16$. These factors will be denoted by an asterisk.

Consequently the most important factors, next to $x_{0}$ are $x_{2}, x_{4}, x_{5}, x_{6}$, $x_{7}, x_{9}, x_{10}$ and $x_{11}$.

\begin{tabular}{|l|r|r|}
\hline factor & estimated effect & Student $t_{13}$ \\
\hline$x_{0}$ & 2.8904 & $207.00^{*}$ \\
$x_{1}$ & 0.0243 & 1.74 \\
$x_{2}$ & 0.0335 & $2.40^{*}$ \\
$x_{3}$ & -0.0061 & -0.44 \\
$x_{4}$ & -0.7863 & $-56.31^{*}$ \\
$x_{5}$ & -0.0993 & $-7.11^{*}$ \\
$x_{6}$ & -0.0658 & $-4.71^{*}$ \\
$x_{7}$ & -0.0772 & $-5.53^{*}$ \\
$x_{8}$ & -0.0147 & -1.05 \\
$x_{9}$ & -0.0996 & $-7.13^{*}$ \\
$x_{10}$ & -0.0474 & $-3.40^{*}$ \\
$x_{11}$ & 0.0545 & $3.90^{*}$ \\
$x_{1} x_{2}$ & 0.0113 & 0.81 \\
$x_{5} x_{6}$ & 0.0023 & 0.16 \\
$x_{5} x_{7}$ & -0.0075 & -0.54 \\
$x_{5} x_{8}$ & 0.0001 & 0.01 \\
$x_{5} x_{9}$ & -0.0062 & -0.44 \\
$x_{5} x_{10}$ & 0.0002 & 0.01 \\
$x_{5} x_{11}$ & 0.0026 & 0.18 \\
$x_{2}$ & - & \\
\hline & &
\end{tabular}

Table 12.4.2: Factors with estimated effects and $t$-values.

\subsubsection{Further Analysis after the First Metamodel}

From Table 12.4.2. it follows that $\alpha_{6}, \alpha_{7}$ and $\alpha_{9}$ are significant and negative, implying a reduction in the costs of dike raising were the sea level to continue rising. However this is inconsistent with simulation results, showing increasing costs of dike raising with continuing sea level rise. Therefore the metamodel gives no adequate approximation of the simulation model and should be rejected. 
After the first metamodel another seven metamodels have again been specified and calculated. For brevity's sake the results of these metamodels are omitted. Thorougly analysing the simulation model teaches us that the simulation should be split up. Firstly the dike raising at a constant safety level must be calculated, using the dike raising module. Thereafter these dike raising figures are put into the module which calculates the costs of dike raising, whereupon subsequently the costs of dike raising are simulated. So far the costs of dike raising have been calculated without adapting dike raising.

A new factor is introduced, namely the safety factor $\left(x_{12}\right)$, which, multiplied by the "Delta norm", represents the maximal permissible probability of inundation. Since the reduced rate of interest and the economic growth are directly related to each other (economic growth = nominal rate of interest reduced rate of interest), taking only one of these three factors into account will suffice. Henceforth instead of the reduced rate of interest $\left(x_{3}\right)$ only the economic growth will be considered. This factor has a basic value of $2 \%$ per year in the former experiments of Table 12.4.1. Varying this factor, from its lowest value ( $1 \%$ per year) to its highest value ( $3 \%$ per year), it appears to dominate the other factors, which indeed might be expected. The longer one delays dike raising, the more "expensive" a dike raising will be, caused by inflation. In order to estimate the other factors in a better way the economic growth factor $\left(x_{13}\right)$ will be set to zero. In paragraph 12.4.7. a survey of all factors is given.

\subsubsection{Specification of the Final Metamodel for the Costs of Dike Raising}

Considering the conclusions of the last paragraph, a new series of experiments will be executed, once again with a $2^{k-p}$ design, but with restricted bounds, consequently causing a shrinking domain of the metamodel, see Table 12.4.3.

Following Kleijnen (1987, pp. 197-200) restricting the metamodel to a smaller domain, or equivalently, reducing the ranges of the factors is one of the possibilities to improve a false or non-valid metamodel. Once again the factors $z_{j}$ are normalized to $x_{j}$ by means of the linear transformation, described in Equation (12.11). After the previous experiments, it is now assumed that eight interactions are important, namely those between the factors $x_{1}$ and $x_{2}, x_{2}$ and $x_{7}, x_{2}$ and $x_{9}, x_{5}$ and $x_{6}, x_{5}$ and $x_{7}, x_{5}$ and $x_{8}, x_{5}$ and $x_{9}$, and $x_{5}$ and $x_{10}$. The following generators are chosen; 


$$
2=4125=147=169=1810=6811=812
$$

This results in Table 12.4.4 (with $m=32$ and $q=20$ ).

\begin{tabular}{|l|l|l|l|l|}
\hline factor & $\begin{array}{l}\text { minimum } \\
\text { value }(-)\end{array}$ & $\begin{array}{l}\text { basic } \\
\text { value }\end{array}$ & $\begin{array}{l}\text { maximum } \\
\text { value }(+)\end{array}$ & dimension \\
\hline$z_{1}$ & $1.65 \mathrm{E}+08$ & $2.2 \mathrm{E}+08$ & $2.42 \mathrm{E}+08$ & $\mathrm{fl} / \mathrm{m}$ \\
$z_{2}$ & $9.9 \mathrm{E}+08$ & $15.4 \mathrm{E}+08$ & $20.9 \mathrm{E}+08$ & fl $/ \mathrm{m}$ \\
$z_{1}$ & 0.30 & 0.30 & 0.40 & $\mathrm{~m}$ \\
$z_{5}$ & 2.5 & 3.0 & 3.5 & \\
$z_{6}$ & 0.00125 & 0.0015 & 0.00175 & m/year \\
$z_{7}$ & 0.0010 & 0.0011 & 0.0012 & m/ $/{ }^{\circ} \mathrm{C}$ year \\
$z_{8}$ & 0.000128 & 0.000147 & 0.000166 & m/ ${ }^{\circ} C$ year \\
$z_{9}$ & -0.0003648 & -0.000237 & -0.0001088 & m $/{ }^{\circ} \mathrm{C}$ year \\
$z_{10}$ & 65 & 75 & 80 & m \\
$z_{11}$ & 20 & 25 & 30 & year \\
$z_{12}$ & 1.375 & 1.5 & 1.5 & \\
\hline
\end{tabular}

Table 12.4.3: Revised factors and their upper and lower bounds.

\begin{tabular}{|l|r|r|}
\hline factor & estimated effect & Student $t_{12}$ \\
\hline$x_{0}$ & 2.1273 & $144.28^{*}$ \\
$x_{1}$ & 0.1596 & $10.83^{*}$ \\
$x_{2}$ & 0.5693 & $38.61^{*}$ \\
$x_{4}$ & -0.0815 & $-5.53^{*}$ \\
$x_{5}$ & -0.0093 & -0.63 \\
$x_{6}$ & 0.1482 & $10.05^{*}$ \\
$x_{7}$ & 0.0730 & $4.95^{*}$ \\
$x_{8}$ & 0.0415 & $2.81^{*}$ \\
$x_{9}$ & 0.2009 & $13.63^{*}$ \\
$x_{10}$ & 0.0718 & $4.87^{*}$ \\
$x_{11}$ & -0.0323 & $-2.19^{*}$ \\
$x_{12}$ & 0.0052 & 0.35 \\
$x_{1} x_{2}$ & 0.0206 & 1.39 \\
$x_{2} x_{7}$ & 0.0205 & 1.39 \\
$x_{2} x_{9}$ & 0.0794 & $5.39^{*}$ \\
$x_{5} x_{6}$ & 0.0003 & 0.02 \\
$x_{5} x_{7}$ & -0.0306 & -2.07 \\
$x_{5} x_{8}$ & -0.0052 & -0.35 \\
$x_{5} x_{9}$ & -0.0028 & -0.19 \\
$x_{5} x_{10}$ & 0.0155 & 1.05 \\
\hline
\end{tabular}

Table 12.4.4: Factors with estimated effects and $t$-values. 


\subsubsection{Validation of the Final Metamodel}

The estimated effects do now have the right signs. So the metamodel explains reasonably well; the question is, however, whether the metamodel does predict acceptably. To answer this question the metamodel will be validated in four different ways:

1. The estimated costs from the metamodel $(\hat{Y})$ are compared to the costs calculated by the simulation model $(Y)$. Next, for each run the relative residual (in terms of percentage) is calculated:

$$
\begin{aligned}
\text { rel. residual }= & 100 *(\text { simulated costs } \\
& - \text { estimated costs }) / \text { simullated costs } \\
= & 100 *(Y-\hat{Y}) / Y
\end{aligned}
$$

This yields Table 12.4.5. The relative residuals in this table are less than $10 \%$, which is acceptable, in light of the uncertainties involved in these modules.

2. Cross-validation (Kleijnen, 1987, pp. 188-190) is a technique where a number of times (six in this case) one run is left out from the experimental design. Next the whole estimation procedure is executed with the $(m-1)=(32-1)$ remaining runs and $\hat{Y}$ (outcome of a metamodel) of the omitted run is predicted. Thereafter $\hat{Y}$ is compared to $Y$ (outcome of a simulation model) of the omitted run. In Table 12.4.6 the results of cross-validation are given. The results of this cross-validation are satisfactory.

3. A number of extra runs is done, again six. These extra experiments are based upon new combinations of values of the input variables, according to a random experimental design: the + and - values are drawn with chance 0.5. Based on the estimates of the first 32 runs the metamodel can calculate the value $\hat{Y}(m+1)$. This value is compared to the $(m+1)$ th outcome of the simulation model, etc. The extra runs and the results of these experiments are represented in Table 12.4.7. 


\begin{tabular}{|c|c|c|c|}
\hline run & $\begin{array}{l}\text { estimatied } \\
\text { costs }(\hat{Y})\end{array}$ & $\begin{array}{l}\text { simulated } \\
\text { costs }(Y)\end{array}$ & $\begin{array}{c}\text { relative residuals } \\
(100 *(Y-\hat{Y}) / Y)(\operatorname{lin} \%)\end{array}$ \\
\hline 1 & 3.372 & 3.397 & 0.7 \\
\hline 2 & 2.634 & 2.651 & 0.6 \\
\hline 3 & 2.774 & 2.730 & -1.6 \\
\hline 4 & 2.385 & 2.367 & -0.8 \\
\hline 5 & 2.219 & 2.233 & 0.6 \\
\hline 6 & 1.829 & 1.752 & -4.4 \\
\hline 7 & 1.644 & 1.548 & -6.2 \\
\hline 8 & 1.480 & 1.618 & 8.5 \\
\hline 9 & 2.046 & 2.020 & -1.3 \\
\hline 10 & 1.497 & 1.482 & -1.0 \\
\hline 11 & 1.531 & 1.577 & 2.9 \\
\hline 12 & 1.331 & 1.347 & 1.2 \\
\hline 13 & 3.653 & 3.699 & 1.2 \\
\hline 14 & 2.816 & 2.832 & 0.6 \\
\hline 15 & 2.996 & 3.032 & 1.2 \\
\hline 16 & 2.385 & 2.307 & -3.4 \\
\hline 17 & 2.261 & 2.317 & 2.4 \\
\hline 18 & 2.686 & 2.712 & 1.0 \\
\hline 19 & 2.101 & 2.126 & 1.2 \\
\hline 20 & 2.751 & 2.662 & -3.3 \\
\hline 21 & 1.596 & 1.601 & 0.3 \\
\hline 22 & 1.650 & 1.623 & -1.7 \\
\hline 23 & 1.168 & 1.181 & 1.1 \\
\hline 24 & 1.571 & 1.600 & 1.8 \\
\hline 25 & 1.417 & 1.300 & -9.0 \\
\hline 26 & 1.396 & 1.430 & 2.4 \\
\hline 27 & 1.175 & 1.210 & 2.9 \\
\hline 28 & 1.378 & 1.406 & 2.0 \\
\hline 29 & 2.547 & 2.543 & -0.2 \\
\hline 30 & 2.791 & 2.816 & 0.9 \\
\hline 31 & 2.202 & 2.187 & -0.7 \\
\hline 32 & 2.794 & 2.767 & -1.0 \\
\hline
\end{tabular}

Table 12.4.5: Estimated costs and simulated costs and relative residuals. 


\begin{tabular}{|l|c|c|c|}
\hline omitted ruin & $Y$ & $\hat{Y}$ & $100 *(Y-\hat{Y}) / Y(i n \%)$ \\
\hline 1 & 3.397 & 3.329 & 1.97 \\
2 & 2.651 & 2.606 & 1.69 \\
3 & 2.730 & 2.848 & -4.32 \\
4 & 2.367 & 2.416 & -2.04 \\
5 & 2.233 & 2.196 & 1.67 \\
6 & 1.752 & $1.956-$ & -11.63 \\
\hline
\end{tabular}

Table 12.4.6: Cross-validation

\begin{tabular}{|c|c|c|c|}
\hline extra run & $Y$ & $\hat{Y}$ & $100 *(Y-\hat{Y}) / Y(i n \%)$ \\
\hline 33 & 1.5765 & 1.546 & 1.93 \\
34 & 2.6363 & 2.483 & 5.81 \\
35 & 1.6123 & 1.738 & -7.79 \\
36 & 1.8543 & 1.918 & -3.44 \\
37 & 1.3761 & 1.306 & 5.08 \\
38 & 1.3761 & 1.406 & -2.14 \\
\hline
\end{tabular}

Table 12.4.7: Extra runs.

Table 12.4.7 shows that the relative residuals do not deviate much from zero, and are thus acceptable.

4. Finally two extra validation runs are executed, where points are chosen within the empirical area, instead of at the corners. In these runs the basic values from Table 12.4 .3 have been standardized to values between -1 and +1 and substituted in the regression equation, yielding a $\hat{Y}$ value of 2.1969 . The accompanying value $Y$ is 1.7872 . Thus the relative residual $100 *(Y-\hat{Y}) / Y$ is $-22.92 \%$. The same procedure has been adopted for the second run, with values "close" to the basic values:

$x_{1}=2.0 E+08, x_{2}=1.0 E+09, x_{4}=0.350, x_{5}=2.75, x_{6}=0.0012$, $x_{7}=0.00105, x_{8}=0.0014, x_{9}=-0.0003, x_{10}=67.5, x_{11}=22.5$, and $x_{12}=1.4$.

This yields a $\hat{Y}$ of 1.2413 and a $Y$ of 1.1689 ; the relative residual of this run is $-6.19 \%$. Because the relative residuals in the Tables 12.4 .5 , 12.4.6, and 12.4.7 and in the second extra run are less than $10 \%$, except for the sixth run (see Table 12.4.6), this metamodel is accepted. 


\subsubsection{Scaling Effects}

In order to determine the influence of factor standardization on the results, a couple of inverse transformations have been been carried out following Kleijnen (1987, pp. 341-345) and Bettonvil and Kleijnen (1988). Such an inverse transformation involves the conversion of the normalized factors $x_{j}$ back to the original factors $z_{j}$. Considering only the significant factors and interactions (see Table 12.4.4), then the equation of the final metamodel, but now expressed in the original factors $z_{j}$, becomes (see section 12.4.7):

$$
\begin{aligned}
Y= & \beta_{0}+\beta_{1} z_{1}+\beta_{2} z_{2}+\beta_{4} z_{4}+\beta_{6} z_{6}+\beta_{7} z_{7}+\beta_{8} z_{8}+\beta_{9} z_{9}+\beta_{10} z_{10} \\
& +\beta_{11} z_{11}+\beta_{2,9} z_{2} z_{9}
\end{aligned}
$$

An alternative is the "centered" model, where $\bar{z}_{j}=b_{j}=\left(H_{j}+L_{j}\right) / 2$.

$$
\begin{aligned}
Y= & \delta_{0}+\delta_{1}\left(z_{1}-\bar{z}_{1}\right)+\delta_{2}\left(z_{2}-\bar{z}_{2}\right)+\delta_{4}\left(z_{4}-z_{4}\right)+\delta_{6}\left(z_{6}-\bar{z}_{6}\right)+ \\
& \delta_{7}\left(z_{7}-\bar{z}_{7}\right)+\delta_{8}\left(z_{8}-\bar{z}_{8}\right)+\delta_{9}\left(z_{9}-\bar{z}_{9}\right)+\delta_{10}\left(z_{10}-\bar{z}_{10}\right)+ \\
& \delta_{11}\left(z_{11}-\bar{z}_{11}\right)+\delta_{2,9}\left(z_{2}-\bar{z}_{2}\right)\left(z_{9}-\bar{z}_{9}\right)
\end{aligned}
$$

Bettonvil and Kleijnen (1988) treat the general relationship between $\alpha, \beta$ and $\delta$. Table 12.4 .8 gives the results for the different scales. The effects order of the factors, decreasing from high to low effects, is for $\alpha$ :

$x_{2}, x_{9}, x_{1}, x_{6}, x_{4}, x_{7}, x_{10}, x_{8}, x_{11}$; and for $\beta$ and $\delta$ :

$x_{9}, x_{8}, x_{7}, x_{6}, x_{4}, x_{11}, x_{10}, x_{1}, x_{2}$.

The interaction 2,9 appears to be rellatively unimportant. The order for the parameters $\beta$ and $\delta$ is exactly the same; (from Table 12.4.8 it follows that, apart from $\beta_{0}$ and $\delta_{0}, \beta$ and $\delta$ are identical) however the inverse transformation order $(\beta$ and $\delta$ ) deviates from that of the standardized model $(\alpha)$. To determine the correct order, the one-factor-at-a-time procedure (Kleijnen, 1987) has been applied for the factors $x_{2}$ and $x_{8}$. Setting all factors to their basic value, except for factor $x_{2}$, which is set to its maximal value, results in increased costs of dike raising from Df. 1.7872 billion to Df. 2.2684 billion; following the same procedure for $x_{8}$ instead of $x_{2}$ yields an increase in costs of dike raising from Dfl. 1.7872 billion to Dfl. 1.8011 billion. Apparently $x_{2}$ dominates $x_{8}$, so the standardized model gives the correct priority order. This is in line with the general conclusion in Kleijnen (1987) and Bettonvil and Kleijnen (1988). 


\begin{tabular}{|l|r|r|r|}
\hline $\begin{array}{l}\text { index } \\
j\end{array}$ & standardized effect & original effect \\
$\left(\beta_{j}\right)$ & centered effect \\
\hline 0 & 2.1273 & -1.9140 & $\left(\beta_{j}\right)$ \\
1 & 0.1596 & 0.0000 & 2.1273 \\
2 & 0.5693 & 0.0000 & 0.0000 \\
4 & -0.0815 & -1.6300 & 0.0000 \\
6 & 0.1482 & 592.7999 & -1.6300 \\
7 & 0.0730 & 730.0000 & 592.7999 \\
8 & 0.0415 & 2184.2104 & 2184.0000 \\
9 & 0.2009 & 1569.5016 & 1569.5016 \\
10 & 0.0718 & 0.0096 & 0.0096 \\
11 & -0.0323 & -0.0065 & -0.0065 \\
2,9 & 0.0794 & 0.0000 & 0.0000 \\
\hline
\end{tabular}

Table 12.4.8: Three alternative models.

\subsubsection{Conclusions}

The first metamodel, estimated by a $2^{k-p}$ experimental design, has been rejected, because it did not adequately reflect the simulation model of dike raising costs: the signs of a number of estimated parameters were wrong. Next, after a series of nine experiments with various kinds of metamodels, a final metamodel has been specified and worked out, again estimated with a $2^{k-p}$ experimental design, with a smaller domain (the factor bounds have been narrowed). After having validated the metamodel extensively, it has been accepted. The priority order of factors influencing the costs of dike raising is, in decreasing order:

$x_{2}$ : marginal costs of dike raising per meter;

$x_{9}$ : net effect at the Antarctics (negative, because of the accumulation effect);

$x_{1}$ : initial costs of dike raising;

$x_{6}$ : natural sea level rise;

$x_{4}$ : mimimal dike raising;

$x_{7}$ : melting of the glaciers;

$x_{10}$ : depth of the mixed layer of the ocean;

$x_{8}$ : melting of the Greenland ice cap;

$x_{11}$ : delay of the thermal expansion, representing the inertia of the ocean; and the interaction between the factors $x_{2}$ and $x_{9}$. 
The marginal costs of of dike raising per meter appears to be of major importance, which is according to the expectations. The order of the remaining eight significant factors as well as the interaction, contains several surprises. This leads to an increased insight in the simulation model. The parameters of the standardized metamodel give the correct order of ranking of the parameters, in contrast to the non-standardized and centered metamodels, respectively. This means that it is not necessary to carry out the inverse transformation from the standardized $x_{j}$ to the originals $z_{j}$. The only thing that matters is the relative interval width of the corresponding factors. From now on, in the further analysis of simulation models only standardized metamodels will be considered.

\subsection{A Metamodel for the Ocean Module}

\subsubsection{Introduction}

The next module which is subjected to a sensitivity analysis is the carbon cycle module, including the relation between the concentration of carbon dioxide in the atmosphere, terrestrial biosphere, and ocean; see Figure 2.2. The carbon cycle which is analysed is the original version of Goudriaan and Ketner (1984); in the newest version the deforestation module as well as a different stratification of the ocean is included, as described in Chapter 3.

The techniques of metamodelling and experimental design are applied to the ocean and terrestrial biosphere modules. The ocean module is treated first. The chosen output variable is the atmospheric $\mathrm{CO}_{2}$ concentration (in $p p m$ ) in the year 2100 , the end point of simulation. The organization of this section is analagous to that of Section $\mathbb{1 2 . 4}$.

The ocean is divided into the following layers: at lower lattitudes a mixed layer of about 75 meters, and under this mixed layer one of about 325 meters. At higher lattitudes there is a mixed layer of about 400 meters. Under both these mixed layers the deep sea is divided into nine layers of about 378 meters each (in total $3400 \mathrm{~m}$ ). As mentioned in Chapter 3 this stratification of the ocean is somewhat different from the new ocean module described in Chapter 3. Nevertheless the primary processes, determining the carbon concentration in the ocean, are identical:

1. carbon transport by mass flow of water, through deep ocean layers to the equator and back to the polar areas;

2. turbulent mixing between the different layers;

3. precipitation of undissolved $\mathrm{CO}_{2}$ at the bottom of the ocean. 


\subsubsection{First Metamodel for the Ocean Module}

The following ten factors have been selected:

$z_{1}$ : precipitation of undissolved $\mathrm{CO}_{2}$ at the bottom of the ocean;

$z_{2}$ : diffusion coefficient;

$z_{3}$ : thickness of the warmer ocean mixed layer;

$z_{4}$ : thickness of the colder ocean mixed layer

$z_{5}$ : total thickness of the nine deeper ocean layers;

$z_{6}$ : residence time of $\mathrm{CO}_{2}$ in the thin (warmer) ocean surface mixed layer;

$z_{7}$ : residence time of $\mathrm{CO}_{2}$ in the thick (colder) ocean surface mixed layer;

$z_{8}$ : massflow of water;

$z_{9}$ : ocean area; and

$z_{10}$ : atmospheric coefficient, converting $\mathrm{CO}_{2}$ emissions into atmospheric $\mathrm{CO}_{2}$ concentrations

Table 12.5.1 contains the factors with their basic, upper and lower bounds.

\begin{tabular}{|l|l|l|l|l|}
\hline factor & $\begin{array}{l}\text { minimum } \\
\text { value }(-)\end{array}$ & $\begin{array}{l}\text { basic } \\
\text { value }\end{array}$ & $\begin{array}{l}\text { maximum } \\
\text { value }(+)\end{array}$ & dimension \\
\hline$z_{1}$ & 7 & 8 & 9 & $\mathrm{GtC} /$ year \\
$z_{2}$ & 3716 & 4000 & 5984 & $\mathrm{~cm}^{2} / \mathrm{sec}$ \\
$z_{3}$ & 70 & 75 & 85 & $\mathrm{~m}$ \\
$z_{4}$ & 300 & 400 & 500 & $\mathrm{~m}$ \\
$z_{5}$ & 3000 & 3400 & 4000 & $\mathrm{~m}$ \\
$z_{6}$ & 0.05 & 1 & 2 & year \\
$z_{7}$ & 15 & 20 & 25 & year \\
$z_{8}$ & 2.1 & 2.3 & 2.5 & $10^{15} \mathrm{~m}^{3} /$ year \\
$z_{9}$ & 0.32 & 0.36 & 0.40 & $10^{12} \mathrm{~m}^{2}$ \\
$z_{10}$ & 0.469 & 0.471 & 0.472 & $\mathrm{ppm} / \mathrm{GtC}$ \\
\hline
\end{tabular}

Table 12.5.1: Factors with their upper and lower bounds.

Following the same procedure as treated in section 12.4 .3 , the factors $z_{j}$ are transformed to normalized factors $x_{j}$. Eleven interactions are expected to be important, namely between the factors $x_{1}$ and $x_{3}, x_{1}$ and $x_{5}, x_{2}$ and $x_{3}, x_{2}$ and $x_{5}, x_{3}$ and $x_{6}, x_{3}$ and $x_{7}, x_{5}$ and $x_{6}, x_{5}$ and $x_{7}, x_{5}$ and $x_{8}, x_{6}$ 
and $x_{8}$ and between $x_{7}$ and $x_{8}$. The number of effects to be estimated $(q)$ is thus $1+10+11=22$. For a $2^{k-p}$ experimental design it holds that $m=2^{k-p}>q$; thus $m=2^{10-5}=32$. From among the ten factors again five factors are selected which occur comparatively rarely in the important interactions (at least the interactions which are supposed to be important, based on knowledge and experience of the model-builder); $x_{1}, x_{2}, x_{4}, x_{9}$ and $x_{10}$. This leads to the following generators:

$$
3=9105=4106=197=298=124
$$

Executing these 32 runs and analysing the results yields Table 12.5.2.

\begin{tabular}{|l|r|r|}
\hline factor & estimated effect & Student $t_{10}$ \\
\hline$x_{0}$ & 1183.0 & $67.90^{*}$ \\
$x_{1}$ & -32.2 & -1.85 \\
$x_{2}$ & 28.8 & 1.65 \\
$x_{3}$ & 112.5 & $6.45^{*}$ \\
$x_{4}$ & 316.1 & $18.14^{*}$ \\
$x_{5}$ & -453.0 & $-26.00^{*}$ \\
$x_{6}$ & -8.1 & -0.47 \\
$x_{7}$ & 40.5 & $2.33^{*}$ \\
$x_{8}$ & 18.0 & 1.03 \\
$x_{9}$ & -12.8 & -0.73 \\
$x_{10}$ & -72.2 & $-4.15^{*}$ \\
$x_{1} x_{3}$ & -8.0 & -0.46 \\
$x_{1} x_{5}$ & 5.3 & 0.31 \\
$x_{2} x_{3}$ & 29.0 & 1.66 \\
$x_{2} x_{5}$ & -25.9 & -1.49 \\
$x_{3} x_{6}$ & -11.4 & -0.66 \\
$x_{3} x_{7}$ & 10.5 & 0.60 \\
$x_{5} x_{6}$ & 19.2 & 1.10 \\
$x_{5} x_{7}$ & -6.8 & -0.39 \\
$x_{5} x_{8}$ & -14.3 & -0.82 \\
$x_{6} x_{8}$ & -53.9 & $-3.09^{*}$ \\
$x_{7} x_{8}$ & 20.2 & 1.16 \\
\hline
\end{tabular}

Table 12.5.2: Factors with estimated effects and $t$-values.

The estimated $\mathrm{CO}_{2}$ concentration $(\hat{Y})$ can now be determined and compared to the simulated $\mathrm{CO}_{2}$ concentration $(Y)$. The relative residuals $100 *(Y-$ $\hat{Y}) / Y$ appear to be more than $10 \%$ in eight runs (see Table 12.5.3), which 
is not acceptable; so this metamodel is rejected.

\begin{tabular}{|c|c|c|c|}
\hline run & $\begin{array}{c}\text { estimated } \mathrm{CO}_{2} \\
\text { concentration } \\
(\hat{Y})\end{array}$ & $\begin{array}{c}\text { simulated } \mathrm{CO}_{2} \\
\text { concentration } \\
(Y)\end{array}$ & $\begin{array}{c}\text { relative residuals } \\
(100 *(Y-Y) \\
/ Y)(i n \%)\end{array}$ \\
\hline $\mathbb{1}$ & 1084 & 1069 & -1.40 \\
\hline 2 & 1032 & 991 & -4.14 \\
\hline 3 & 1107 & 1079 & -2.59 \\
\hline 4 & 1070 & 1067 & -0.28 \\
\hline 5 & 1406 & 1435 & 2.02 \\
\hline 6 & 1080 & 1108 & 2.53 \\
\hline 7 & 1680 & 1695 & 0.88 \\
\hline 8 & 1224 & 1241 & 1.37 \\
\hline 9 & 1915 & 1845 & -3.79 \\
\hline 10 & 1833 & 1746 & -4.98 \\
\hline 11 & 1900 & 1826 & -4.05 \\
\hline 12 & 1948 & 1890 & -3.07 \\
\hline 13 & 392 & 478 & 17.99 \\
\hline 14 & 297 & 368 & 19.29 \\
\hline 15 & 432 & 491 & 12.02 \\
\hline 16 & 323 & 396 & 18.43 \\
\hline 17 & 821 & 838 & 2.03 \\
\hline 18 & 804 & 819 & 1.83 \\
\hline 19 & 936 & 964 & 2.90 \\
\hline 20 & 935 & 964 & 3.01 \\
\hline 21 & 1057 & 1065 & 0.75 \\
\hline 22 & 1252 & 1212 & -3.30 \\
\hline 23 & 1109 & 1057 & -4.92 \\
\hline 24 & 1174 & 1170 & -0.34 \\
\hline 25 & 2235 & 2317 & 3.54 \\
\hline 26 & 2010 & 2061 & 2.47 \\
\hline 27 & 2224 & 2287 & 2.75 \\
\hline 28 & 2129 & 2224 & 4.27 \\
\hline 29 & 527 & $467-$ & -12.85 \\
\hline 30 & 667 & 595 & -12.10 \\
\hline 31 & 563 & 478 & -17.78 \\
\hline 32 & 688 & 616 & -11.69 \\
\hline
\end{tabular}

Table 12.5.3: Estimated and simulated $\mathrm{CO}_{2}$ concentrations and the relative residuals. 


\subsubsection{Further Analysis after the First Metamodel}

Thereafter five other metamodels have been specified, where the bounds of the factors $x_{3}, x_{4}, x_{5}$ and $x_{10}$ have been varied (the domain has been broadened and narrowed, respectively). The relative residuals, however, appear to be only larger. Scaling up the lower bound of $x_{3}$ and $x_{10}$ is the only remedy to get better results.

Therefore it was decided to carry out a new series of experiments with the help of a central composite experimental design (Rotmans et al., 1988, Kleijnen, 1987). Such a central composite design makes it possible to estimate higher order effects; for instance quadratic effects or some higher order interactions between the factors, dependent on the experimental design (Kleijnen, 1987, pag. 200).

\subsubsection{Final Metamodel for the Ocean Module}

To determine whether there are quadratic effects, and whether the interactions between the factors $x_{3}$ and $x_{4}, x_{3}$ and $x_{5}, x_{4}$ and $x_{5}$ and $x_{4}$ and $x_{7}$ are significant, a new metamodel is specified with the factors $x_{3}, x_{4}, x_{5}, x_{7}$ and $x_{10}$, which were significant (see Table 12.5.2). The starting-point is a $2^{5-1}$ experimental design with levels -1 and +1 , with generator:

$$
4=3710
$$

To complete the central composite design supplementary runs are added to this $2^{5-1}$ design, where the factors in these runs take the values $0,-2$ and +2. The values of -2 and +2 are chosen arbitrarily (Rotmans et al., 1988). This makes a total of 27 runs $(16+2 * 5+1)$, leading to Table 12.5.4, where the degrees of freedom are $27-(1+5+5+4)=12$. 


\begin{tabular}{|l|r|r|}
\hline factor & $\begin{array}{r}\text { estimated } \\
\text { effect }\end{array}$ & Student $t_{12}$ \\
\hline & 1074.66 & $154.08^{*}$ \\
$x_{0}$ & 51.77 & $32.07^{*}$ \\
$x_{3}$ & 158.37 & $98.10^{*}$ \\
$x_{4}$ & -224.95 & $-139.35^{*}$ \\
$x_{5}$ & 18.78 & $11.63^{*}$ \\
$x_{7}$ & -0.24 & -0.15 \\
$x_{10}$ & -0.46 & -0.23 \\
$x_{3}^{2}$ & -3.82 & -1.93 \\
$x_{4}^{2}$ & 27.78 & $14.05^{*}$ \\
$x_{5}^{2}$ & -1.24 & -0.63 \\
$x_{7}^{2}$ & -0.21 & -0.10 \\
$x_{10}^{2}$ & 3.06 & 1.55 \\
$x_{3} x_{4}$ & -8.35 & $-4.22^{*}$ \\
$x_{3} x_{5}$ & -17.65 & $-8.93^{*}$ \\
$x_{4} x_{5}$ & -12.26 & $-6.20 *$ \\
$x_{4} x_{7}$ & & \\
\hline
\end{tabular}

Table 12.5.4: Factors with estimated effects and $t$-values.

In analogy to the validation procedure of section 12.4 .8 , this metamodel is validated in four different ways. The relative residuals of the runs which have already been executed are given in Table 12.5.5, while Table 12.5.6 contains the results of the cross-validation procedure. The random design and the results of the runs with this random design are given in Tables 12.5.7 and 12.5 .8 , respectively. All relative residuals are less than $10 \%$, which is acceptable. The extra validation run with basic values yields a $\hat{Y}$ of 1043.58 ; the corresponding $Y$ is 1055.45 , which results in a relative residual of $1.12 \%$. 


\begin{tabular}{|c|c|c|c|}
\hline run & $\begin{array}{c}\text { estimated } \mathrm{CO}_{2} \\
\text { concentration } \\
(\hat{Y})\end{array}$ & $\begin{array}{c}\text { simulated } \mathrm{CO}_{2} \\
\text { concentration } \\
(Y)\end{array}$ & $\begin{array}{c}\text { relative residuals } \\
100 *((Y-\hat{Y}) \\
/ Y)(2 n \%)\end{array}$ \\
\hline 1 & 1065 & 1074 & 0.85 \\
\hline 2 & 1567 & 1565 & -0.15 \\
\hline 3 & 722 & 719 & -0.40 \\
\hline 4 & 1119 & 1114 & -0.50 \\
\hline 5 & 740 & 741 & 0.16 \\
\hline 6 & 1171 & 1162 & -0.83 \\
\hline 7 & 959 & 963 & 0.40 \\
\hline 8 & 1428 & 1432 & 0.31 \\
\hline 9 & 803 & 803 & 0.06 \\
\hline 10 & 1234 & 1238 & 0.29 \\
\hline 11 & 973 & 974 & 0.16 \\
\hline 12 & 1441 & 1435 & -0.46 \\
\hline 13 & 1053 & 1053 & -0.01 \\
\hline 14 & 1555 & 1550 & -0.31 \\
\hline 15 & 660 & 669 & 1.42 \\
\hline 16 & 1058 & 1054 & -0.37 \\
\hline 17 & 1073 & 1074 & 0.07 \\
\hline 18 & 1074 & 1074 & -0.02 \\
\hline 19 & 1107 & 1108 & -0.01 \\
\hline 20 & 1032 & 1032 & -0.05 \\
\hline 21 & 1176 & 1177 & 0.08 \\
\hline 22 & 969 & 969 & -0.05 \\
\hline 23 & 736 & 724 & -1.62 \\
\hline 24 & 1636 & 1648 & 0.74 \\
\hline 25 & 1376 & 1373 & -0.20 \\
\hline 26 & 743 & 746 & 0.46 \\
\hline 27 & 1075 & 1074 & -0.06 \\
\hline
\end{tabular}

Table 12.5.5: Estimated and simulated $\mathrm{CO}_{2}$ concentrations and the relative residuals. 


\begin{tabular}{|l|r|r|r|}
\hline $\begin{array}{l}\text { omitted } \\
\text { run }\end{array}$ & $Y$ & $\hat{Y}$ & $100 *(Y-\hat{Y})$ \\
\hline 3 & & & $/ Y$ \\
4 & 1113.79 & 1125.15 & -0.80 \\
6 & 1161.79 & 1183.17 & -1.00 \\
11 & 974.41 & 971.06 & -1.84 \\
15 & 669.42 & 650.12 & 0.34 \\
16 & 1053.87 & 1061.79 & 2.88 \\
\hline
\end{tabular}

Table 12.5.6: Cross-validation.

\begin{tabular}{|c|c|c|c|c|c|c|c|c|c|c|c|c|c|c|}
\hline Exun: & 210 & \pm 7 & $x_{a}$ & $x_{5}$ & $x_{4}$ & $x_{10}$ & $x y$ & $x_{3}$ & 虹 5 & 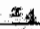 & $x_{3} x^{2}$ & $x_{3} x_{5}$ & $x_{4} x_{5}$ & $x_{4} x_{7}$ \\
\hline 28 & + & - & + & $t$ & 4 & $t$ & $t$ & $t$ & $t$ & + & $t$ & + & $t$ & - \\
\hline 20 & + & + & - & + & + & + & + & + & $t$ & + & - & - & + & $t$ \\
\hline 30 & + & + & + & + & - & + & + & + & + & + & - & + & - & - \\
\hline 31 & + & - & - & - & - & + & $t$ & + & + & + & + & + & + & + \\
\hline 32 & + & + & $t$ & - & - & + & + & + & + & $t$ & - & - & + & - \\
\hline$a 3$ & - & - & + & - & - & + & + & + & + & + & - & - & + & + \\
\hline
\end{tabular}

Table 12.5.7: Random experimental design.

\begin{tabular}{|c|r|r|r|}
\hline $\begin{array}{c}\text { extra } \\
\text { run }\end{array}$ & $Y$ & $\hat{Y}$ & $100 *(Y-\hat{Y})$ \\
\hline 28 & 1052.61 & 1052.2 & 0.04 \\
29 & 974.41 & 972.3 & 0.22 \\
30 & 803.20 & 802.2 & 0.12 \\
31 & 1053.87 & 1057.3 & -0.33 \\
32 & 1237.55 & 1233.5 & 0.33 \\
33 & 1161.79 & 1171.9 & -0.87 \\
\hline
\end{tabular}

Table 12.5.8: Results with the random experimental design of Table 12.5.7.

Finally the regression is carried out once more, omitting the non-significant factors $x_{10}, x_{3}^{2}, x_{4}^{2}, x_{7}^{2}, x_{10}^{2}$ and $x_{3} x_{4}$. The results are presented in Table 12.5.9. It can be concluded that all significant factors of Table 12.5.4. remain significant; no radical changes occur in the point estimators and therefore the metamodel is accepted. 


\begin{tabular}{|l|r|r|}
\hline factor & $\begin{array}{r}\text { estimated } \\
\text { effect }\end{array}$ & Student $t_{18}$ \\
\hline$x_{0}$ & 1068.55 & $503.31^{*}$ \\
$x_{3}$ & 51.77 & $30,85^{*}$ \\
$x_{4}$ & 158.37 & $94.36^{*}$ \\
$x_{5}$ & -224.95 & $-134.02^{*}$ \\
$x_{5}^{2}$ & 28.93 & $18.17^{*}$ \\
$x_{7}$ & 18.78 & $11.19^{*}$ \\
$x_{3} x_{5}$ & -8.35 & $-4.06^{*}$ \\
$x_{4} x_{5}$ & -17.65 & $-8.59^{*}$ \\
$x_{4} x_{7}$ & -12.26 & $-5.97^{*}$ \\
\hline
\end{tabular}

Table 12.5.9: Factors with estimated effects and $t$-values:

\subsubsection{Conclusions}

The relative residuals of the definite metamodel for the ocean module are all less than about $3 \%$. Therefore this metamodel is accepted. The priority order of the factors in the ocean module determining the atmospheric $\mathrm{CO}_{2}$ concentration is, in decreasing order:

$x_{5}$ : total thickness of the nine deep ocean layers;

$x_{4}$ : thickness of the colder ocean mixed layer;

$x_{3}$ : thickness of the warmer ocean mixed layer;

$x_{5}^{2}$ : the squared effect of the total thickness of the nine deep ocean layers

$x_{7}$ : residence time of $\mathrm{CO}_{2}$ in the colder ocean mixed surface layer; and the interactions between the factors $x_{4}$ and $x_{5}$, $x_{4}$ and $x_{7}$, and $x_{3}$ and $x_{5}$.

\subsection{A Terrestrial Biosphere Metamodel}

\subsubsection{Introduction}

This section deals with the application of the techniques of metamodelling and experimental design on the terrestrial biosphere module of IMAGE. In the previous section an adequate metamodel for the ocean module has been developed. The latter module, together with the terrestrial biosphere module, simulates the carbon cycle module according to Goudriaan and Ketner (1984). Through metamodels an attempt has been made to elucidate the relationship between the carbon dioxide concentration in the atmosphere and 
in the terrestrial biosphere. Following the procedure used for the metamodel of the ocean module, the atmospheric $\mathrm{CO}_{2}$ concentration in the year 2100 (in $p p m$ ) is chosen as response variable. The notation is exactly the same as in previous sections.

The terrestrial biosphere is a major reservoir in the carbon cycle. Tremendous amounts of carbon dioxide are exchanged yearly between the atmosphere and the terrestrial biosphere. As stated in Chapter 3, the crucial question with regard to the carbon cycle is whether the terrestrial biosphere is a "source" (net uptake of $\mathrm{CO}_{2}$ ) or a "sink" (net release of $\mathrm{CO}_{2}$ ): this question cannot yet be answered adequately. The simulated version of the terrestrial biosphere acts as a sink, based on Goudriaan and Ketner (1984). The biosphere is horizontally divided into six ecosystems: tropical forest, temperate forest, grassland, agricultural land, human area, and semi-desert area. Vertically leaves, branches, stems, roots, humus and charcoal are distinguished. Within each ecosystem carbon is transported naturally, via leaves to charcoal, in exchange with the atmosphere. Besides this natural flux mutual shifts between various ecosystems induce fluxes of carbon. Additionally human activities like burning and shifting cultivation influence largely the amount of carbon in an ecosystem (Swart and Rotmans, 1989b, Goudriaan and Ketner, 1984).

\subsubsection{Various Metamodels for the Terrestrial Biosphere Module}

The following 62 factors of the carbon cycle module have been selected:

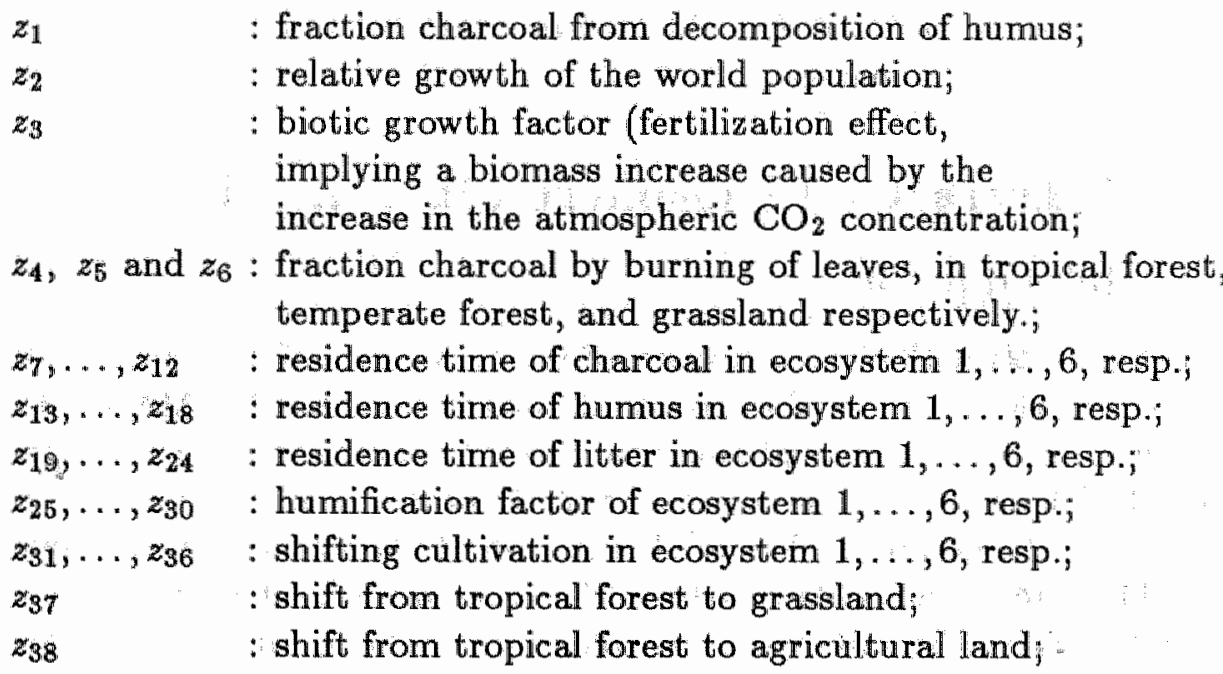


$z_{39}, \ldots, z_{44} \quad$ : life span of leaves in ecosystem $1, \ldots, 6$, resp.;

$z_{45}, \ldots, z_{50} \quad$ : life span of branches in ecosystem $1, \ldots, 6$, resp;

$z_{51}, \ldots, z_{56}:$ life span of stems in ecosystem $1, \ldots, 6$, resp; and

$z_{57}, \ldots, z_{62} \quad$ : life span of roots in ecosystem $1, \ldots, 6$, resp,

where ecosystem 1 is tropical forest, 2 is temperate forest, 3 is grassland, 4 is agricultural land, 5 is human area, and 6 is semi-desert. Initially no interactions are considered in the metamodel, because of its complexity and the many calculations necessary. The 62 main effects of this metamodel are estimated in $\left(2^{62-55} \Rightarrow 128\right.$ runs, by using a so-called $R$ IV design. Such a design yields estimates of main effects without being biased by possible interactions. In this case at least 124 runs are necessary, see Kleijnen et al. (1990). However, it appeared that $\hat{\alpha}_{62}$ was significantly positive, while this parameter was expected to be negative. Hence this metamodel is rejected.

Next the domain of the input variables is narrowed. The basic values and the upper and lower bounds of these factors are given in Table 12.6.1. Besides the 62 main effects 26 important two-factor interactions are now taken into account, namely between the factors $x_{1}$ and $x_{37}, x_{2}$ and $x_{37}, x_{3}$ and $x_{37}, x_{1}$ and $x_{38}, x_{2}$ and $x_{38}, x_{3}$ and $x_{38}, x_{2}$ and $x_{31}, \ldots, x_{36}, x_{3}$ and $x_{31}, \ldots, x_{36}, x_{2}$ and $x_{44}, x_{3}$ and $x_{44}, x_{5}$ and $x_{44}, x_{2}$ and $x_{60}, x_{3}$ and $x_{60}, x_{37}$ and $x_{60}, x_{38}$ and $x_{60}$ and $x_{44}$ and $x_{60}$. The "defining relation" (Kleijnen, 1987, pp. 295-301) is:

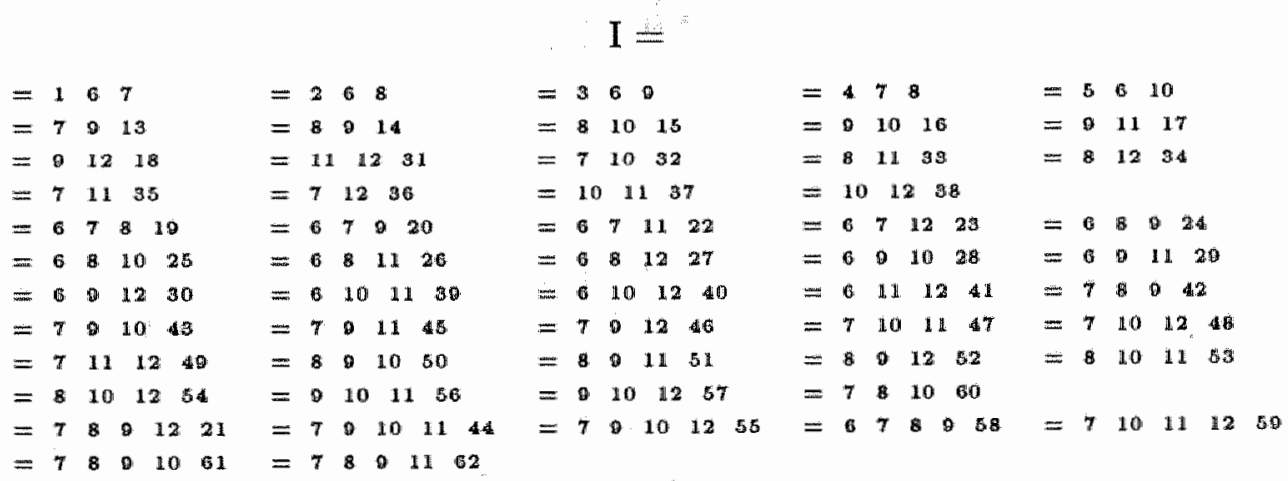




\begin{tabular}{|c|c|c|c|c|}
\hline$\sqrt{\text { fateror }}$ & 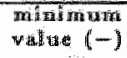 & $\begin{array}{l}\text { botes } \\
\text { val }\end{array}$ & 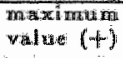 & difation \\
\hline$x$ & 0,0 & $0.0 \%$ & 0.07 & \\
\hline$x_{2}^{2}$ & 0.010 & 0.020 & 0.022 & \\
\hline 2 & 0.28 & $0 \%$ & 0.75 & $\therefore$ \\
\hline$x_{d x}$ & 008 & 9.08 & 0.07 & \\
\hline$x^{3}$ & 0.00 & 0,1 & 0. I 18 & \\
\hline 6 & 0.1 & 0.2 & 0.3 & $\therefore$ \\
\hline 27 & 230 & 500 & 780 & year \\
\hline $\mathrm{B}$ & $\because 280$ & $\$ 00$ & 780 & Yeat \\
\hline$x$ & 250 & 5010 & 750 & yiertr \\
\hline$x_{10}$ & 250 & 500 & 760 & $y$ ter \\
\hline 11 & 250 & $E$ ad & 700 & yex $x$ \\
\hline 12 & $2(x)$ & 800 & 780 & year \\
\hline 213 & $b$ & 10 & 15 & year \\
\hline$=14$ & 24 & 50 & 75 & $y \in \operatorname{arn}$ \\
\hline$x 15$ & 20 & 40 & 60 & yed \\
\hline 16 & 10 & 20 & 35 & $y e x$ \\
\hline$x_{17}$ & 25 & sio & 76 & year \\
\hline 13 & 2.5 & 80 & 78 & yeratre \\
\hline$x 19$ & D. & 1 & 1.5 & year \\
\hline+20 & 1 & 2 & $\mathfrak{3}$ & yrear \\
\hline$x_{21}$ & 1 & 2 & $\$$ & $y e a x$ \\
\hline 222 & 0.8 & $x$ & 1.6 & $y \in$ ar \\
\hline 2 & 1 & 2 & 3 & $y \in a x$ \\
\hline 24 & 1 & 2 & 弯 & year \\
\hline 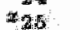 & 0.2 & 0.4 & 0.6 & $\therefore$ \\
\hline 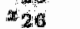 & $0 . \&$ & 0.6 & 0.0 & \\
\hline 27 & $\therefore 0$ & 0.6 & 0.1 & $\because$ \\
\hline 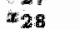 & 0.1 & 0.2 & 0.3 & $\because$ \\
\hline$x 2$ & 0.25 & 0,5 & 0.75 & $\therefore$ \\
\hline 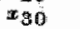 & 0.8 & 0.6 & 0.0 & \\
\hline$* 31$ & 5 & 15 & 25 & mha/yerar \\
\hline 32 & 1 & 2 & $\mathrm{~g}$ & mho/year \\
\hline 政家 & 200 & 400 & 600 & $m h a / y \in a$ \\
\hline 34 & 200 & 400 & 600 & $m h a / y \operatorname{ar}$ \\
\hline 85 & 0 & 田 & 1 & mha/year \\
\hline$x$ & 0 & 0 & 1. & mha/yoar \\
\hline 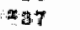 & $\therefore \quad s$ & $6:$ & 0 & mha \\
\hline+38 & 8 & 6 & 0 & mha \\
\hline 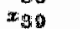 & 0.5 & 1 & L.s & $y \in \mathbf{a r}$ \\
\hline+40 & $\mathbb{I}$ & 2 & 3 & year \\
\hline 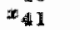 & 0.5 & 1 & 1. 5 & yetar \\
\hline$x_{42}$ & 0.3 & 1 & 1.5 & year \\
\hline$x_{43}$ & 0.5 & 1 & $1+5$ & year \\
\hline$x$ & 0.5 & 1 & 1.5 & year \\
\hline$x 45$ & 亚 & 10 & 15 & year \\
\hline$x+4$ & $\mathfrak{s}$ & 10 & 15 & year \\
\hline$x_{4}^{4}$ & $B$ & 10 & 16 & $y \in a x$ \\
\hline 48 & 8 & 10 & 15 & yentr \\
\hline 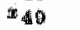 & 息 & 10 & 16 & year \\
\hline$x_{6}$ & 5 & $\mathbf{1 0}$ & 14 & yegr \\
\hline$* 51$ & 38 & 30 & 35 & $y \in x$ \\
\hline$x: 2$ & 80 & 18 & อ0 & $y e n$ \\
\hline 283 & 28 & 150 & 78 & 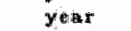 \\
\hline atgia & 25 & 50 & 75 & $y \operatorname{ean} x$ \\
\hline$x+8$ & $2 b^{3}$ & $\$ 0$ & 75 & $y \in a x$ \\
\hline+80 & 28 & 50 & $7 B$ & $y \in x$ \\
\hline$x 57$ & 5 & 10 & 15 & year \\
\hline 56 & $\mathrm{~g}$ & 10 & 15 & yent \\
\hline$x_{B 0}$ & 9.5 & $\|$ & 1.5 & year \\
\hline 40 & 0.5 & 1 & 1.5 & year \\
\hline$G$ & 5 & 10 & 15 & year \\
\hline 82 & $\mathbb{1}$ & 2 & 3 & year \\
\hline
\end{tabular}

Table 12.6.1: Factors with their upper and lower bounds. 
The effects and interactions are estimated in $\left(2^{62-55}=\right) 128$ runs. The results are given in Table 12.6 .2 .

\begin{tabular}{|c|c|c|c|c|c|}
\hline Tactor & $\begin{array}{r}\text { estimated } \\
\text { effect }\end{array}$ & Stual exitt $t: 0$ & factor & $\begin{array}{l}\text { eatinin atted } \\
\text { uffect }\end{array}$ & Studerat t 39 \\
\hline$x_{0}$ & 1333.08 & 477.21 & $x, 5$ & 3.70 & 1.33 \\
\hline \pm 1 & -2.03 & -1.05 & $\begin{array}{l}-40 \\
+46\end{array}$ & 0.67 & 0.24 \\
\hline$* 2$ & 0.8 .3 & 0.30 & $x$ & 0.3 & 0.12 \\
\hline$x$ & -1100.002 & -35.81 & $x_{48}$ & 1. 65 & 0.50 \\
\hline$x_{4}$ & -3.76 & -1.35 & $x_{49}$ & -0.10 & -0.04 \\
\hline$x$ & -11.92 & -4.27 & $x_{50}$ & $=2.17$ & -0.78 \\
\hline$x_{6}$ & -41.78 & -4.2 & $x_{31}$ & -2.50 & -0.89 \\
\hline$z_{7}$ & 4.07 & 1.6 & $\times 52$ & -6.80 & -2.47 \\
\hline 8 & 0.10 & 0.07 & $\times 53$ & 0.13 & 0.05 \\
\hline 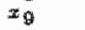 & -3.58 & -1128 & $x_{54}$ & 0.21 & 0.07 \\
\hline \pm 10 & -3.71 & -1.33 & $x 55$ & 4.56 & 1.63 \\
\hline II & -2.52 & -0.00 & $x_{56}$ & -0.07 & -0.35 \\
\hline 12 & -5.21 & -1.86 & $x: 57$ & 1.23 & 0.4 \\
\hline$x_{13}$ & 1.73 & 0.62 & $\begin{array}{l}x_{58} \\
\end{array}$ & -0.05 & -0.02 \\
\hline$x_{14}$ & -0.04 & -0.01 & $x_{50}$ & -0.83 & -0.30 \\
\hline$x_{15}$ & -25.65 & -9.18 & $x_{60}$ & -0.15 & -0.03 \\
\hline$x_{16}$ & -7.05 & -2.85 & $x_{01}$ & -1.22 & -0.44 \\
\hline$x 17$ & -5.28 & -1.89 & $x_{62}$ & -0.56 & -0.20 \\
\hline 18 & -3.98 & -1.43 & $x_{1} x_{37}$ & 0.03 & 0.01 \\
\hline 19 & 1.50 & 0.54 & $x_{2} \times 37$ & 0.10 & 0.04 \\
\hline 20 & 2.01 & 0.72 & $x 3 x_{37}$ & -0.61 & -0.22 \\
\hline$x_{21}$ & 2.98 & 1.07 & $x_{1} x_{38}$ & 1.03 & 0.37 \\
\hline$\times 22$ & -3.23 & -1.15 & $x_{2} x_{38}$ & 2.62 & 0.94 \\
\hline$\times 23$ & -1.15 & -0.41 & $x_{3} \leq x_{38}$ & 2.21 & 0.70 \\
\hline$x_{24}$ & -0.24 & -0.00 & $x_{2} x_{31}$ & 2.52 & 0.00 \\
\hline$x_{25}$ & 7.27 & 2.60 & $x_{2} x_{32}$ & 3.31 & 1.10 \\
\hline$x_{26}$ & -3.82 & -1.37 & $x_{2} x_{33}$ & -0.78 & -0.28 \\
\hline 227 & $-38,88$ & -13.92 & $x_{2}=3.4$ & -1.09 & -0.71 \\
\hline$x_{28}$ & -9.63 & -3.45 & $x_{2}+35$ & 1.098 & 0.30 \\
\hline$x 29$ & -2.88 & -1.03 & $x_{2} x_{36}$ & 0,68 & 0.24 \\
\hline$x_{30}$ & -6.11 & $-2,19$ & $x_{3} x_{3,1}$ & 1.07 & 0.71 \\
\hline$x_{31}$ & 3.45 & $1: 24$ & $x_{3} x_{32}$ & 0.10 & 0.03 \\
\hline$x_{32}$ & 0.53 & 0.10 & $x_{3} x_{33}$ & -0.81 & -0.29 \\
\hline$\pi 33$ & 0.02 & 0.01 & $x_{3} x_{34}$ & -10.42 & -0.15 \\
\hline$x_{3}$ & 0.02 & 0.3 .3 & $x_{3} \times 35$ & -0.11 & $-0,0$. \\
\hline$x 5$ & -0.4 .2 & -0.15 & $x_{3} x_{36}$ & -0.0 .09 & -0.01 \\
\hline$x_{30}$ & -1.68 & -0.610 & $x_{2} x_{44}$ & -0.00 & -0.03 \\
\hline$\$ 37$ & -11.26 & -4.03 & $x_{3} x_{44}$ & 2.03 & 6.73 \\
\hline$x_{3}$ & 18.53 & 6.63 & $x_{5} x_{44}$ & -0.93 & -0.33 \\
\hline$x_{30}$ & -0.60 & -0.22 & $x_{2} x_{60}$ & -1.00 & -0.36 \\
\hline$x_{40}$ & -12.018 & -4.33 & $x^{x} x_{60}$ & 3.00 & 1.31 \\
\hline$x_{41}$ & 3.20 & 1.18 & $x_{37} x_{0,03}$ & 0.35 & 6.13 \\
\hline$x_{12}$ & -1.01 & -0.38 & $\begin{array}{r}38 \times 6 \\
0\end{array}$ & -0.411 & -8.16 \\
\hline$x_{43}$ & 3.04 & 0.73 & $x_{4}^{x} 60$ & -0.10 & $=0.0,04$ \\
\hline$x_{44}$ & 2.57 & 0.92 & & & \\
\hline
\end{tabular}

Table 12.6.2: Factors with estimated effects and $t$-values.

All factors now do have a correct sign. The model is validated in two different ways. The relative residuals of the runs which have already been carried out are presented in Table 12.6.3. The results of 12 extra runs are given in Table 12.6.4. 


\begin{tabular}{|c|c|c|c|c|c|c|c|}
\hline ruin: & $\begin{array}{c}\text { entinged } \\
\mathrm{Co}_{2} \text { concentrition } \\
(\mathrm{Y})\end{array}$ & $\mathrm{OO}_{2}$ & $\begin{array}{l}\text { Arnal ated } \\
\text { coucenturat } \\
(\mathrm{Y})\end{array}$ & ion & 100 & 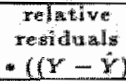 & $(Y)$ \\
\hline 1 & 1115 & & 1104 & & & 1.05 & \\
\hline 2 & 1170 & & $118 \%$ & & & -4.82 & \\
\hline 3 & 2146 & & $118 \mathrm{~T}$ & & & -8.63 & \\
\hline 4 & 1264 & & 1220 & & & 2.33 & \\
\hline 8 & 1103 & $\therefore$ & 1210 & & & $-1.7 t$ & \\
\hline 8 & 1.325 & & $\mathbb{1 1 3 \pi}$ & & & 0.63 & \\
\hline 7 & 1178 & & 1166 & & & $1,0 s$ & \\
\hline 8 & 1:30 & & 1805 & & & -180 & \\
\hline 0 & 2306 & & 1348 & & & 1.40 & \\
\hline 10 & 1420 & & 1450 & & & -2.06 & \\
\hline 11 & 1086 & & 1.400 & & & $-1.60^{\circ}$ & \\
\hline 12 & 1143 & . & 1446 & & & 0.52 & \\
\hline 13 & 1410 & & 1428 & & & -0.64 & \\
\hline 14 & 14811 & & 1463 & & & 1.91 & \\
\hline 15 & 1.82 & & 1363 & & & 1.30 & \\
\hline 10 & 1472 & & 1484 & & & -0.70 & \\
\hline 17 & 1230 & & 1281 & & & -1.20 & \\
\hline 18 & 1149 & & 1140 & & & 0.832 & \\
\hline 10 & 1258 & & 1243 & & & 0.03 & \\
\hline 20 & 1104 & & 12266 & & & -2.61 & \\
\hline 21 & 1268 & & 1246 & & & 1.59 & \\
\hline 22 & 1220 & & 2236 & & & -0.52 & \\
\hline 23 & 1235 & & 1245 & & & -0.81 & \\
\hline 24 & 1238 & & 1215 & & & 1.80 & \\
\hline 25 & 1450 & & 1462 & & & -10.83 & \\
\hline 26 & 1301 & & $136 \mathrm{t}$ & & & 1.71 & 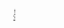 \\
\hline 27 & 1480 & & 1470 & & & 1.10 & \\
\hline 28 & 14.21 & & 1422 & & & -0.00 & \\
\hline 20 & 1453 & & I440 & & & 0.44 & : \\
\hline 30 & 1380 & & 1. 405 & & & -11.80 & \\
\hline 31 & 1431 & & 1448 & & & -1.13 & 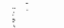 \\
\hline 32 & 1364 & & 1367 & & & 0.60 & \\
\hline $3: 3$ & 1076 & & 1053 & & & 2.18 & 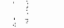 \\
\hline 34 & 1165 & & 1167 & & & -0.19 & \\
\hline 35 & 1120 & & 1138 & & & -1.56 & $\therefore$ \\
\hline 30 & 1263 & & 1240 & & & 1.10 & \\
\hline 37 & 1210 & & 1234 & & & -1.18 & \\
\hline 38 & 1331 & & 1320 & & & 0.13 & \\
\hline 30 & 1200 & & $118: 3$ & & & 1.33 & \\
\hline 40 & 1364 & & 1303 & & & -2.10 & \\
\hline 41 & 1411 & & $140: 9$ & & & 0.58 & \\
\hline 42 & 142 & & 1451 & & & -1.60 & \\
\hline 43 & 1397 & & 14010 & & & -0.00 & \\
\hline 44 & 1435 & & 1493 & & & 0.12 & \\
\hline 45 & 1436 & & 145.2 & & & -1.00 & \\
\hline 40 & 1484 & & 1401 & & & 1.57 & \\
\hline 47 & 1000 & & 1376 & & & 1.03 & \\
\hline 娄的 & I & & 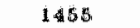 & & & 0.32 & \\
\hline 40 & 1221 & & 1230 & & & -1.41 & \\
\hline 60 & 1130 & & 1142 & & & -0.20 & \\
\hline s1 & 11245 & : & 123 & & & 1.01 & \\
\hline 52 & 1105 & & 1212 & & & -1.50 & \\
\hline 53 & 1279 & & 1288 & & & 1.18 & \\
\hline 84 & 1188 & & 1191. & & : & -0.18 & \\
\hline 58 & 1229 & & 1246 & & & -1.20 & \\
\hline 50 & 1170 & & 1150 & & & 2.57 & \\
\hline 87 & 1480 & & 1503 & & & -0.80 & \\
\hline 8 & 1416 & & 1380 & & & 2.04 & \\
\hline 50 & 1470 & & 1469 & & & 1.23 & \\
\hline 60 & 1404 & & 1411 & & & -0.47 & \\
\hline 61. & 1450 . & & $14: 2$ & $\because$ & & 1.20 & \\
\hline 62 & 1804 & & 1418 & & & -1.71 & \\
\hline 69 & 1412 & & 1428 & & & -1.00 & \\
\hline 6 & 1349 & & 1353 & & & -0.27 & \\
\hline
\end{tabular}

Table 12.6.3: Estimated and simulated $\mathrm{CO}_{2}$ concentration and the relative residuals. 


\begin{tabular}{|c|c|c|c|}
\hline Fun & $\begin{array}{c}\mathrm{OO}_{2} \text { conctinated } \\
(\hat{r}) \\
\end{array}$ & $\begin{array}{c}\text { simulatided } \\
\mathrm{GO}_{2} \text { eoncertination } \\
(Y)\end{array}$ & $\begin{array}{c}\text { rellative } \\
\text { residuals } \\
100-\int(Y-Y) / Y\end{array}$ \\
\hline 65 & $\mathbb{1 1} 469$ & 1491 & -1.51 \\
\hline 66 & 104 & 1828 & 1.10 \\
\hline 67 & 11487 & 1476 & 0.77 \\
\hline 6 & 2345 & 1876 & -2.25 \\
\hline 60 & 1484 & 1400 & 1.66 \\
\hline 70 & 1482 & 1492 & -0.66 \\
\hline$\pi 1$ & 1463 & 1470 & -0.48 \\
\hline 72 & 14.57 & 1430 & 1.29 \\
\hline 73 & 1277 & 1282 & -0.41 \\
\hline$\pi 4$ & 1168 & 1146 & 1.59 \\
\hline 75 & 1300 & 1282 & 1.42 \\
\hline 76 & 1270 & 1125 & -0.43 \\
\hline $\mathrm{TT}$ & 1901 & 1208 & 0.19 \\
\hline 78 & 1282 & 1305 & -1.78 \\
\hline 70 & 1268 & 1289 & -1.68 \\
\hline 80 & 1245 & 1220 & 1.32 \\
\hline B.I & 1507 & 1404 & 0.80 \\
\hline 82 & 1503 & 1500 & -0.42 \\
\hline 8.3 & 1518 & 1520 & -0.13 \\
\hline 84 & 1518 & 1497 & 1.42 \\
\hline $8: 5$ & 1330 & 1350 & -1.45 \\
\hline 80 & 1477 & 1472 & 0.34 \\
\hline 87 & 1310 & 1308 & 0.16 \\
\hline 818 & 1466 & 1480 & -0.012 \\
\hline 80 & 1260 & 1246 & 0.04 \\
\hline 00 & 1290 & 1321 & -1.8 .8 \\
\hline 91 & 1205 & 1320 & -1.88 \\
\hline 92 & 1334 & 1322 & 0.00 \\
\hline 93 & 1158 & 1160 & -0.22 \\
\hline 94 & 1307 & 1280 & 1.82 \\
\hline os & 1135 & 1113 & $1.0 \pi$ \\
\hline 015 & 1302 & 1318 & -1.20 \\
\hline 07 & 1449 & 1472 & -1.58 \\
\hline DS: & 1340 & 1340 & 0.22 \\
\hline 00 & 1406 & 1.484 & 0.82 \\
\hline 1 i & 1387 & 1405 & -1.18 \\
\hline 101 & 1473 & 1456 & 1.20 \\
\hline 102 & : $\quad 1461$ & 1466 & -0.36 \\
\hline 103 & 1465 & 1477 & -0.87 \\
\hline 104 & 1444 & 1417 & 1.88 \\
\hline 105 & 1205 & 1308 & -0.99 \\
\hline 106 & 1142 & 1115 & 2.42 \\
\hline 107 & 1302 & 1280 & 1.79 \\
\hline 108 & 1138 & 1148 & -0.80 \\
\hline 100 & 1296 & 1276 & 1.53 \\
\hline 110 & 1274 & 1300 & -1.08 \\
\hline 111 & 1270 & 1292 & -1.74 \\
\hline 112 & 1230 & 12.37 & 0.20 \\
\hline i1 3 & 1431 & 1402 & 2.05 \\
\hline 114 & 147 & 146 & -0.61 \\
\hline 115 & 1481 & 1400 & -1.21 \\
\hline 116 & 1409 & 1475 & 1.64 \\
\hline 117 & 1330 & 1357 & -1.30 \\
\hline $14: 8$ & 1452 & 1446 & 0.44 \\
\hline 110 & 1333 & 1310 & 1.07 \\
\hline 120 & 1458 & $14: 186$ & $-1.8 \mathrm{~g}$ \\
\hline 121 & 1251 & 1244 & 0.50 \\
\hline 122 & 1270 & 1200 & -1.0 .1 \\
\hline 123 & 1270 & 1286 & -1.25 \\
\hline 124 & 1308 & 13005 & 0.28 \\
\hline 125 & III & 1133 & -11.78 \\
\hline 126 & 1202 & 1206 & 2.07 \\
\hline 127 & 1000 & 1077 & 2.13 \\
\hline 128 & 1200 & 1202 & -0.20 \\
\hline
\end{tabular}

Table 12.6.3 (Continued). 


\begin{tabular}{|l|c|c|c|}
\hline extra run & $Y$ & $\hat{Y}$ & $100 *(Y-Y) / Y(i n \%)$ \\
\hline 129 & 1260.33 & 1268.48 & -0.65 \\
130 & 1128.98 & 1191.01 & -5.49 \\
131 & 1432.58 & 1484.19 & -3.61 \\
132 & 1217.65 & 1218.82 & -0.10 \\
133 & 1232.28 & 1248.99 & -1.36 \\
134 & 1248.88 & 1263.05 & -1.13 \\
135 & 1233.89 & 1244.53 & -0.86 \\
136 & 1216.85 & 1239.17 & -1.83 \\
137 & 1448.75 & 1474.09 & -1.75 \\
138 & 1372.28 & 1405.28 & -2.40 \\
139 & 1466.94 & 1495.61 & -1.95 \\
140 & 1422.69 & 1426.27 & -0.25 \\
\hline
\end{tabular}

Table 12.6.4: Extra runs.

Table 1.2.6.4 shows that for the twelve extra runs, all relative residuals are negative. This might be due to the fact that no random design is used for these extra runs.

\subsubsection{Conclusions}

The relative residuals appear to be less than $6 \%$. Therefore the metamodel is accepted. The priority order of the factors in the terrestrial biosphere module influencing the atmospheric $\mathrm{CO}_{2}$ concentration is, in decreasing order of importance:

$x_{3}$ : biotic growth factor;

$x_{27}$ : humification factor of grassland;

$x_{15}$ : residence time of humus in grassland;

$x_{38}$ : shift from tropical forest to agricultural land;

$x_{40}$ : life span of leaves in temperate forest;

$x_{5}$ : fraction of charcoal by burning of leaves, in temperate forest;

$x_{6}$ : fraction of charcoal by burning of leaves, in grassland;

$x_{37}$ : shift from tropical forest to grassland;

$x_{28}$ : humification factor of agricultural land;

$x_{16}$ : residence time of humus in agricultural land;

$x_{25}$ : humification factor of tropical forest;

$x_{52}$ : life span of stems in temperate forest; and

$x_{30}$ : humification factor of semi-desert area. 


\subsection{General Conclusions}

Specification of a metamodel should be based on internal knowledge of the observed system. Since no statistic (such as Student's $t$ ) is available to support the validation process, doubt about the correctness of the metamodel has to be checked by examining a more complex metamodel.

To calibrate the regression model, many runs can be saved by choosing an experimental design, associating some factors with unused interactions between other factors. It turned out that $2^{k-p}$ designs are appropriate for estimating first-order effects and two-factor interactions, while central composite designs appeared to be suitable for estimating higher order effects, such as quadratic terms.

For the module of the casts of dike raising an adequate metamodel has been found, using a $2^{k-p}$ experimental design. Ignoring the dominant factor of economic growth, particularly the marginal costs of dike raising per meter are of major importance. The net effect of the Antarctic, the initial costs of dike raising, and the natural sea level rise play an equal, although less important role. The other factors, such as the minimal dike raising, melting of the glaciers, depth of ocean mixed layer, melting of the Greenland ice cap, and the thermal expansion delay time, are significant, but clearly of minor importance. Additionally one interaction, namely that between the marginal costs of dike raising per meter and the net effect of the Antarctic, is significant. The use of metamodels compels the user to examine the simulation model thoroughly. In this way errors or misuse of the simulation model can be located, as appeared when analyzing the dike raising model.

For the ocean module an adequate (quadratic) metamodel has been specified as well. The total thickness of the nine deep ocean layers largely influences the atmospheric $\mathrm{CO}_{2}$ concentration. It is remarkable that the quadratic effect of this factor is also significant. Furthermore the thickness of the cold surface layer is of major importance. Less influential are the thickness of the warm ocean surface layer, the residence time of $\mathrm{CO}_{2}$ in the cold surface layer and some interactions, for instance those between the thickness of the cold surface layer and the total thickness of the nine deep ocean layers.

The attempt to find a metamodel for the complicated terrestrial biosphere module also succeeded. This metamodel showed that the biotic growth factor, representing the fertilization effect, dominates the other factors. Amongst the other twelve significant factors especially the humification factor of grassland, the residence time of humus in grassland and the shift 
of land from tropical forest to agricultural land are of substantial importance. No significant interactions between factors have been found in this metamodel.

Summarizing it can be concluded that the techniques of metamodelling and experimental design can serve as a helpful tool in performing sensitivity. analysis on simulation models. Even complex simulation models can be analyzed in this way, although the specification of adequate metamodels is very time-consuming. So far the metamodel for the terratrial biosphere is one of the largest known in the literature. This underlines the underestimation of metamodelling as a helpful tool in analyzing simulation models.

In the near future it is intended to specify metamodels for all modules of IMAGE. These metamodels will then be used for building an interactive version of IMAGE. 


\section{Chapter 13}

\section{Discussion}

Over the last few years the usefulness of an integrated methodology to evaluate different future worlds with respect to climate change has been proved extensively. Demonstrations given for high level Dutch policy officials and in Parliament have proved the integrated greenhouse model IMAGE to be a helpful tool to improve the understanding of the greenhouse problem. Besides this, IMAGE has been used to increase awareness among all kinds of societal groups. IMAGE gives an overview of the complex problem by making explicit long-term relationships between causes and effects of the enhanced greenhouse effect, based on the latest scientific evidence, but without requiring detailed scientific knowledge from the user. With IMAGE it is possible to derive sets of allowable emissions from certain targets for climate impacts. It also enables scientists working in the field of climate change to put their efforts in a wider perspective. The model can easily be adapted to changed or increased knowledge.

In this study four scenario sets have been developed and calculated with IMAGE. Evaluating the results obtained from these scenario calculations leads to interesting results. For $\mathrm{CO}_{2}$ these IMAGE simulations point out that continuation of the recent emissions trend of $\mathrm{CO}_{2}$ leads to a rapid rise of the atmospheric $\mathrm{CO}_{2}$ concentration, and may lead to a doubling of the $\mathrm{CO}_{2}$ concentration around 2060. Even radical measures (scenario D: forced trends scenario) cannot prevent the $\mathrm{CO}_{2}$ concentration from increasing, although in this case a $\mathrm{CO}_{2}$ doubling is not reached before 2100. The role of deforestation within the carbon cycle has been investigated by the development of a separate deforestation module. It appeared that the primary direct cause of deforestation is the demand for agricultural land to satisfy demand for food, feed or debt-resolving export products. Simula- 
tion results with IMAGE show that if present deforestation rates continue a total destruction of the tropical forests will occur halfway through the next century. Although it is difficult to give quantified estimates, IMAGE simulations make clear that soil degradation is a process that, while seldom mentioned in this connection, contributes considerably to the rate of tropical deforestation by decreasing the avalability of land for agriculture and pasture. Although reforestation can play a significant role in a transition period, a gradual shift towards renewables, away from fossil fuels, is a more effective strategy for mitigating climatic change. The contribution of biospheric changes to the greenhouse effect is important but small as compared to that of fossil fuel combustion. Model simulations showed a difference of a maximum of $10 \%$ in $\mathrm{CO}_{2}$ concentrations over the next century between optimistic and pessimistic deforestation cases. The result, that even fast deforestation has only a moderate net effect on the carbon cycle in IMAGE, is primarily caused by an increasing soil carbon pool due to the conversion of organic matter into charcoal during burning, by $\mathrm{CO}_{2}$ fertilization and by a possible underestimation of soil lasses after conversion. To some extent the biospheric $\mathrm{CO}_{2}$ emissions by deforestation will be counteracted by a $\mathrm{CO}_{2}$ fertilization effect. If not for reasons of global climate change, deforestation should be stopped for other reasons, including the combating of erosion, the conservation of species diversity, the threat to the indigenous population and the effects on local and regional climate.

With the help of the developed simulation model for the $\mathrm{CH}_{4}-\mathrm{CO}-\mathrm{OH} \mathrm{cy}-$ cle the importance of methane as a greenhouse gas is underlined. The model shows that there is no sense in forcing back only the methane emissions. Even if the emissions could be stabilized the methane concentrations would still rise, due to the interrelated influence of other trace gases such as carbon monoxide and hydroxyl (by $\mathrm{NO}_{x}$ and $\mathrm{O}_{3}$ ). The sources of $\mathrm{NO}_{x}$ and $\mathrm{CO}_{2}$ are especially important. Nevertheless the relative role of methane is expected to decrease because methane has a relatively short lifetime, the potential development of sources tends to be slower than that of other gases, and emission reduction and recovery measures are possible. However, should potentially important feedback mechanisms induced by wetlands and methane hydrates materialize, methane concentrations might increase considerably.

With respect to $\mathrm{N}_{2} \mathrm{O}$ it is clear that in the long run $\mathrm{N}_{2} \mathrm{O}$ will become a greenhouse gas of great importance. Even the most optimistic $\mathrm{N}_{2} \mathrm{O}$ emission scenario leads to a rise in temperature. Policy measures can probably affect the $\mathrm{N}_{2} \mathrm{O}$ concentrations, but additional research is needed to improve our knowledge of the sources and the validity of measurement techniques. 
According to IMAGE calculations, the effect of the implementation of the Montreal Ozone Protocol will lead to a stabilization of the relative role of CFCs in the greenhouse effect, and is a significant step forward. However under the present Protocol conditions CFC concentrations can still increase. To decrease this role, it seems to be necessary to improve the agreement sharply.

Continuation of the recent trend of emissions of the relevant trace gases leads to a rapid increase of the mean global temperature. IMAGE simulations give an equilibrium temperature range of 2 to 8 degrees Celsius at the end of the next century. Calculations with IMAGE suggest that the rate of global temperature increase can be delayed considerably and limited to walues which do not go beyond past climate experience by the global implementation of $\mathrm{CO}_{2}$ emission reductions of $20 \%$ in 2000 and $50 \%$ in 2025 . These figures are consistent with the recommendations of the Toronto conference on the Changing Atmosphere in 1988, provided these reductions are applied globally and a strong effort is undertaken to control the emissions of the other greenhouse gases, including a near phase-out of CFCs. Most effective are policies towards energy conservation and non-fossil fuels, which are presently unattractive given the low energy prices. Increase of efficiency with low inputs in the agricultural sector also contributes, albeit moderately, to the delay of the greenhouse effect.

Simulation experiments with IMAGE show for the end of the next century a sea level rise range of about 0.45 to 0.95 meter. The simulated increase for the next hundred years falls within the interval of 0.28 to 0.78 meter, which means an increase of about 2 to 5 times that of the past centuries. The dominant causes of this sea level rise will be the thermal expansion of the ocean, and the melting of glaciers and small ice caps. For the next hundred years changes in the mass of polar ice sheets may have a significant effect on sea level, but will be minor components compared to expansion and glaciers.

Simulations with IMAGE suggest that the socio-economic consequences of the greenhouse effect for the Netherlands are far-reaching, involving considerable cumulative costs for the next century. However, the yearly costs will be less than a half percent of the gross national product, indicating that, if policy makers will anticipate in time, the socio-economic costs can be mitigated.

In order to evaluate recent future proposals for the control of greenhouse gas emissions it is recommended to determine long-term environmental or climate goals that would allow for a sustainable development. Both the Tem- 
perature Increasing Potential (TIP) and the Sea level Rise Potential (SRP) can serve as useful tools for setting environmental long-term goals with respect to climate change. The TIP and SRP provide an index to compare the temperature increasing effect and the sea level rise of greenhouse gas emissions, as a greenhouse counterpart to the ozone depleting potential (ODP). These TIPs and SRPs can be used to define quantified environmental targets which can serve as reference values for the development of international response strategies. Although surrounded by many uncertainties it is possible to estimate such indexes with IMAGE. However simulations demonstrate the dynamical element in determining the TIP. Hence it is better to speak of a TIP function rather than a TIP value.

Results based on calculations with IMAGE showed that $\mathrm{CH}_{4}$ and $\mathrm{N}_{2} \mathrm{O}$ in particular, being much more effective than $\mathrm{CO}_{2}$, are currently underestimated. This appeared from the relative contributions of greenhouse gases to the global warming for the year 1985, calculated according to the TIP concept, which showed a considerable share of especially $\mathrm{CH}_{4}$. Based on the TIP estimates it can be concluded that $\mathrm{CH}_{4}$ and $\mathrm{N}_{2} \mathrm{O}$ will have the most threatening greenhouse potential for the future.

The technique of metamodelling might be extremely useful in long-term scenario studies. Up to now this technique has been underestimated as a powerful tool for analyzing sensitivities and uncertainties in simulation models. For different scientific topics, ranging from environmental protection, health care to economics, scenario studies on future developments are marked by high degrees of uncertainties. Living in a world with limited financial means, policy makers have to make choices in initiating projects to reduce these uncertainties. Sensitivity analysis by metamodelling and experimental design deserves more attention, and can provide a method for differentiating between the relative relevance of these uncertainties and can therefore play a decisive role in determining priorities for filling gaps in our scientific knowledge. 


\section{References}

Abrahamse, A.H., Baarnse, G., Beek, E. van (1982a), "Policy analysis of water management for the Netherlands", Volume 11, Rijkswaterstaat, Government printing office, The Hague, The Netherlands.

Abrahamse, A.H., Baarnse, G., Beek, E. van (1982b), "Policy analysis of water management for the Netherlands", Volume 12, Rijkswaterstaat, Government printing office, The Hague, The Netherlands.

Abrahamse, A.H., Baarnse, G., Beek, E. van (1982c), “Policy analysis of water management for the Netherlands", Volume 16, Rijkswaterstaat, Government printing office, The Hague, The Netherlands.

AGGG (1990), "Targets and indicators of climatic change"; Report of Working Group 2 of the Advisory Group on Greenhouse Gases (AGGG).

Aldenberg, T.A. (1988), "Note concerning integrated modelling” (in Dutch), RIVM, Bilthoven, The Netherlands.

Anderson, I.C., and Levine, J.S. (1987), "Simultaneous field measurements of biogenic emissions of nitric oxide and nitrous oxide", Journal of Geophysical Research 92, 965-976.

Atmospheric Ozone (1985), "Assessment of our understanding of the process controlling its present distribution and change", volume 1 ; WMO/ NASA/UNEP/FVA/NOAA/CEC. 
Augustsson, $\mathrm{T}$., Ramanathan, $\mathrm{V}$ (1977), "A radiative-canvective model study of the $\mathrm{CO}_{2}$ climate prablem", Journal of the Atmospheric Sciences $34,448-451$.

Automobile International (1929-1987) World Automotive Market.

Avenhaus, R. and Hartmann, G. (1975), "The carbon cycle of the earth - a material balance approach", Research Report no. RR-75-45, IIASA, Laxenburg, Austria.

Banin, A. (1986), "Global budget of $\mathrm{N}_{2} \mathrm{O}$ : the role of soils and their change", The Science of the Total Environment 55, 27-38.

Barnett, T.P. (1983), "Recent changes in sea level and their possible causes", Climatic Change 5, 15-38.

Barnett, T.P. (1985), in Detecting the climatic effect of increasing carbon dioxide, McCracken, M.C. and Luther, F.M., (eds), US Department of Energy, Washington D.C., 91-107.

Barth, M.C., and Titus, J.G. (1984), "Greenhouse effect and sea level rise: a challenge for this generation", van Nostrand Rheinhold Company Inc., New York.

Bartlett, K.B., Harris, R.C. and Seiler, D.I. (1985), "Methane flux from coastal salt marshes", Journal of Geophysical Research 90, 5710-5720.

Beafort, G.A., Baarse, G., Pluym, M., Roelse, P., and Peerbolte, E.B. (1989), "Beach and dune depletion" (in Dutch), Coastal defence after 1990, Technical Report 11, The Netherlands.

Bettonvil, B. and Kleijnen J.P.C. (1988), "Measurement scales and resolution IV designs: a note", to be published in the Americain Journal of Mathematical and Management Sciences, Catholic University of Brabant, Tilburg, the Netherlands.

Bettonvil, B. (1990), "Detection of important factors by sequential bifurcation", Thesis, Catholic University of Brabant, Tilburg, The Netherlands.

Bettonvil, B. and Rotmans, J. (1990), "Screening designs, applied to the greenhouse simulation model IMAGE , to be published. 
Bingemer, H.G. and Crutzen, P.J. (1987), "The production of methane from solid wastes", Journal of Geophysical Research 92, 2181-2187.

Björkström, A. (1979), "A model of $\mathrm{CO}_{2}$ interaction between atmosphere, oceans, and land biota", in The Global Carbon Cycle, B. Bolin, E. Degens, S. Kempe, and P. Ketner (eds.), SCOPE 13, John Wiley and Sons, New York.

Bolin, B., Björkström, A., Holmen, K., and Moore, B. (1983), "The simultaneous use of tracers for ocean circulation studies", Tellus $35 \mathrm{~B}$, 206-236.

Bolin, B., Döös, B.R., Jäger, J., and Warrick, R.A. (eds) (1986), "The greenhouse effect, climatic change and ecosystems", SCOPE 29, Chichester, UK, John Wiley \& Sons.

Bolin, B. (1986), "How much $\mathrm{CO}_{2}$ will remain in the atmosphere: the carbon cycle and projections for the future", In: "The Greenhouse Effect, Climatic Change and Ecosystems', B.Bolin, B.R. Döös, J.Jäger, R.A.Warrick (eds), SCOPE 29, Chichester, UK, John Wiley and Sons, 93-155.

Bolle, H.J., Seiler,W. and Bolin, B. (1986), "Other greenhouse gases and aerosols: assessing their role for atmospheric radiative transfer". In: The Greenhouse Effect, Climatic Change, and Ecosystems, B. Bolin, B.R. Döös, J. Jäger and R.A. Warrick (eds.), SCOPE 29, Chichester, UK, John Wiley and Sons, 157-203.

Boois, H. de, Rotmans, J., Swart, R.J. (1988), "State of affairs and perspectives of the greenhouse problem: presentation of IMAGE for the Dutch parliament" (in Dutch), Report no. 758471005, RIVM, Bilthoven, the Netherlands.

Bouwman, A.F. (1989a), "Land evaluation for dry farming", working paper, International Soil Reference and Information Centre, Wageningen.

Bouwman, A.F. (1989b), The role of soils and land use in the 'greenhouse effect', Accepted by the Netherlands Journal of Agricultural Science.

Box, G.E.P., Hunter, W.G., and Hunter, J.S. (1978), "Statistics for experimenters", J. Wiley \& Sons Inc., New York. 
Brasseur, G. and Rudder, A. de (1987), "The potential impact on atmospheric ozone and temperature of increasing trace gas concentrations", Journal of Geophysical Research 92, 10903-10920.

Brewer, P.G. (1983), "Carbon dioxide and the oceans", In: Changing Climate, Report of the Carbon Dioxide Assessment Committee, NRC/NAS/NAE/IOM, National Academy Press, Washington D.C.

Brouwer, F.M. (1987), "Integrated environmental modelling: design and tools", Kluwer Academic Publisher Group, Dordrecht-Boston- Lancaster.

Bruggeman, G.A. (1988a), "Notice concerning the salt intrusion in the New Waterway”, RIVM, Bilthoven.

Bruggeman, G.A. (1988b), "Increase in salt seepage along the Dutch coast with a sea level rise (global approach)", RIVM, Bilthoven.

Brühl, Ch., and Crutzen, P.J. (1985), " $A$ time dependent 1-D photochemical climate model", Progress Report to contract CLT-080-D.

Brühl, Ch. and Crutzen, P.J. (1988), "Scenarios of possible changes in atmospheric temperatures and ozone concentrations due to man's activities, estimated with a one-dimensional coupled photochemical model", Climate Dynamics 2, 173-203.

Buringh, P., Heemst, H.D.J. van, and Staring, G.J. (1975), "Computation of the maximum food production of the world", Agricultural University, Wageningen.

Burke, M.K., Houghton, R.A. and Woodwell, G.M. (1990), "Increased emissions of $\mathrm{CH}_{4}$ from wetlands as a consequence of global warming", in Bouwman, A.F. (ed.): Soils and the Greenhouse Effect, Wiley, London, 1990.

Central Planning Bureau (1984), "Dutch economy in the long-term, three scenarios for the period 1985-2010" (in Dutch), The Netherlands.

Cess, R.D., and Goldenberg, S.D. (1981), "The effect of ocean heat capacity upon global warming due to increasing atmospheric carbon dioxide ${ }^{3}$, Journal of Geophysical Research 86, 498-502. 
Chamberlain, J.W., Foley, H.M., MacDonald, G.J., and Ruderman, M.A. (1982) "Climatic effects of minor atmospheric constituents", in Carbon Dioxide Review, W.C. Clark (ed), Oxford University Press, New York, 255-295.

Chemical Manufacturers Association (CMA) (1983), "Production, sales and calculated release of $C F C-11$ and $C F C-12$ through $1982^{\prime \prime}$, News Release of the CMA, Washington D.C.

Chemical Manufacturers Association (CMA) (1987), "Production, sales and calculated release of $C F C-11$ and $C F C-12$ through $1986^{\prime}$, News Release of the CMA, 18 November 1987, Washington DC.

Cheng, H.C., Steinberg, M. and Beller, M. (1986), "Effects of energy technology on global $\mathrm{CO}_{2}$ emissions", US Department of Energy, Report no. TR030, Washington, D.C.

Conrad, R., and Seiler, W. (1980), "Field measurements of the loss of fertilizer nitrogen into the atmosphere as nitrous oxide", Atmospheric Environment 14, 555-558.

Conrad, R., Seiler, W., and Bunse, G. (1983), "Factors influencing the loss of fertilizer nitrogen into the atmosphere as $\mathrm{N}_{2} \mathrm{O}$, Journal of Geophysical Research 88, 6709-6718.

Crutzen, P.J. (1983), "Atmospheric interactions - homogeneous gas reactions of $C, N$, and $S$ containing compounds", in The Major Biogeochemical Cycles and their Interactions, B. Bolin and R.B. Cook (eds), SCOPE 21, John Wiley and Sons, New York, 67-112.

Crutzen, P.J. (1985), "The rale of the tropics in atmospheric chemistry", in Geophysiology of Amazonia, R. Dickinson (ed.), New York.

Crutzen, P.J., Asselmann, I. and Seiler, W. (1986a), "Methane production by domestic animals, wild ruminants, other herbivorous fauna and humans", Tellus 38B, 271-284.

Crutzen, P.J. and Graedel, T.J. (1986b), "The role of atmospheric chemistry in environment-development interactions". In: "Sustainable Development of the Biosphere", W.C.Clark and R.E.Munn (eds), IIASA, Laxenburg. 
Cunnold, D.M., Prinn, R.G., Rasmussen, R.A., Simmonds, P.G., Alyea, F.N., Cardelino, C.A., Crawford, A.J., Fraser, P.J., and Rosen, R.D. (1983a), "The atmospheric lifetime experiment 3. Lifetime methodology and application to three years of $\mathrm{CFCl}_{3}$ data", Journal of Geophysical Research 88, 8379-8400.

Cunnold, D, M., Prinn, R.G., Rasmussen, R.A., Simmonds, P.G., Alyea, F.N., Cardelino, C.A., Crawford, A.J., Fraser, P.J., and Rosen, R.D. (1983b), "The atmospheric lifetime experiment \&. The results for $\mathrm{CF}_{2} \mathrm{Cl}_{2}$ based on three years of data", Journal of Geophysical Research $88,8401-8414$.

Dantzig, D. van (1956), "Economic decision problems for flood prevention", Econometrica 24, 276-287.

Delft Hydraulics (1990), "Sea level rise: a world wide cost estimate of basic coastal defence measures", draft Report for IPCC/Rijkswaterstaat.

Deltacommissie (1960), "Eindverslag en interimadviezen", deel 1 , pp. 56 etc., Government printing office, The Hague.

Derwent, R.G. (1990), "Trace gases and their relative contribution to the greenhouse effect", Modelling and Assessments Group, Environmental and Medical Sciences Division, Harwell Laboratory, Oxfordshire, United Kingdom.

Detwiler, R.P. and Hall, C.A.S. (1985), "Land use change and carbon exchange in the tropics: II. estimates for the entire region ${ }^{n}$, Environmental Management 9, no. 4, 335-344.

Detwiler, R.P. and Hall, C.A.S. (1988), "Tropical forests and the global carbon cycle", Science 239, 42-47.

Dickinson, R.E. (1986), "How will climate change? The climate system and modelling of future climate". In: "The greenhouse effect, climatic change, and ecosystems", B. Bolin, B.R. Döös, J. Jäger, and R.A. Warrick (eds), SCOPE 29, Chichester, UK, John Wiley and Sons, 206-270.

Dillingh, D., Graaf, J. van de, Vellinga, P., Visser, C. (1984), "Leidraad voor de beoordeling van de veiligheid van duinen als waterkering", Technische Adviescommissie voor de Waterkering, Staatsdrukkerij, The Hague, The Netherlands. 
Dover, M. and Talbot, L.M. (1987), "To feed the earth: Agro-ecology for sustainable development", World Resources Institute, Washington D.C.

Dubbeld, M. (1985), "De invloed wan het bewonersgedrag, de bouwhundige en installatietechnische varianten en de regio op het energiegebruik van een eengezinswoning, berekend met een meerkamermodel", IMGTNO, Delft, The Netherlands.

Edmonds, J.A., and Reilly, J.M. (1983), "A long-term global energyeconomic model of carbon dioxide release from fossil fuel use", Energy Economics, April 1983, 283-297.

Edmonds, J.A. and Reilly, J.M. (1985), "Future global energy and carbon dioxide emissions". In: "Atmospheric carbon dioxide and the global carbon cycle', US Department of Energy, Washington D.C.

Edmonds, J.A. and Reilly, J.M. (1986), "The long-term global energy $\mathrm{CO}_{2}$ model: $\mathrm{PC}$-version $\mathrm{A} \& 4 \mathrm{PC}^{\prime}$; Carbon Dioxide Information Center, Oak Ridge.

Efron, B. and Gong, G. (1983), "A leisurely look at the bootstrap, the jacknife and cross-validation", American Statistician 37, 36-48.

Ehhalt, D.H. (1985), "Methane in the global atmosphere", Environment 27 (no. 10), 6-11.

Elshout, A.J. (1989), " $\mathrm{N}_{2} \mathrm{O}$ in the atmosphere", Report of the divison Research and Development of the KEMA no. 80244-MOA 89-3250, Arnhem, the Netherlands (in Dutch).

Elzen, M.G.J. den, and Rotmans, J. (1988), "Simulationmodel for the socio-economic consequences of the greenhouse effect for the Nether. lands", (in Dutch), Report no. 758471008, RIVM, Bilthoven, The Netherlands.

Elzen, M.G.J. den, and Rotmans, J. (1989), "A scenario study on the socio-economic impact of the greenhouse effect for the Netherlands", Report M 89-09, University of Limburg.

Elzen, M.G.J. den, and Rotmans, J. (1990), "A scenario study on the socio-economic consequences of a sea level rise for the Netherlands", accepted by Climatic Change. 
Elzen, M.G.J. den, Rotmans J., and Vrieze, O.J. (1990a), "Mathematical models for strategic dike raising”, in press.

Elzen, M.G.J. den, Rotmans, J., and Swart. R.J. (1990b), "The role of CFCs and substitutes and other halogenated chemicals in climate change”, Report, RIVM, Bilthoven, the Netherlands, in press.

Elzen M.G.J. den, Rotmans, J., and Swart, R.J. (1990c), "The greenhouse effect of halocarbons after the Montreal Protocol", submitted to International Environmental Affairs.

Emanuel, W.R., Killough, G.G., Stevenson, M.P., Post, W.M., and Shugart, H.H. (1984), "Computer implementation of a globally averaged model of the world carbon cycle”, DOE/NBB-0062, U.S. Department of Energy, Washington, D.C.

Emanuel, W.R., Fung, I.Y.S., Killough, G.G., Moore, B., and Peng, T.H. (1985), "Modelling the global carbon cycle and changes in the atmospheric carbon dioxide levels", in "Atmospheric carbon dioxide and the global carbon cycle', J.R. Trabalka (ed.), United States Department of Energy, DOE/ER/-0239-1, Washington D.C.

Environment Canada (1988), "Conference statement: the changing atmosphere: implications for global security", Toronto, Canada.

Environmental Protection Agency (1989), "Policy options for stabilizing global climate”, Draft Report to Congress, Washington, D.C.

EPA (1989), "Policy options for stabilizing global climate", Draft Report to Congress, D.A. Lashof and D.A. Tirpack (eds.), United States Environmental Protection Agency, Office of Policy, Planning and Evaluation, Washington, D.C.

EPA (1989), "Policy options for stabilizing global climate", draft Report to Congress, Washington D.C., 1989.

ESRG (1988) LEAP, "LDC energy alternatives planning system", User's Guide, Energy Systems Research Group and the Beijer Institute, Boston.

Esser, G. (1987), "Sensitivity of global carbon pools and fluxes to human and potential climatic impacts", Tellus 39B, 245-260. 
Eversdijk, P.J. (1989), "Hard coastal defence, sea dikes, harbour areas and beach walls as dams", (in Dutch), Coastal defence after 1990, Technical Report 16, Rijkswaterstaat, The Netherlands.

Fearnside, P.M. (1987), "Causes of deforestation in the brazilan amazon", in: Dickenson, R.E. (ed.): "The Geophysiology of Amazonia", Wiley.

Fisher, C.R., Hales, C., Wang, W.C., Ko, M., and Sze, N. (1990), "Model calculations of the relative effects of CFCs and their replace. ments on global warming", Nature $344,513-516$.

Food and Agricultural Organization (FAO) (1984), "Land, food and people”, Rome, 1984.

Food and Agricultural Organization (FAO) (1986), "Thopical fortst action plan", Rome.

Food and Agricultural Organization (FAO) (1987), "Agricultate: *owards 2000", Rome.

Gamlen, P.H., Lane, B.C., Midgley, P.M., and Steed, $\mathbf{M}$. M. (1086), "The production and release to the atmosphere of $\mathrm{CCl}_{3} \mathrm{~F}^{\text {and }} \mathrm{CCW}_{2} \mathrm{~F}_{\mathrm{z}}$ (Chlorofluorocarbons $C F C-11$ and $C F C-12$ )", Atmospheric Liwwersment 20, 1077-1085.

GEMS Monitory and Assessment Research Center (1989), United Nations Environment Program, Environmental Data Report, London, UK, in cooperation with the World Resource Institute (WRI), and UK Department of the Environment.

Gardner, R.H., Rojder, B., Bergström, U. (1983), "PRISM: a systematic method for determining the effect of parameter uncertainties on model predictions", Studsvik Energiteknik AB, Report Studsvik/NW$83 / 555$, Nykoping, Sweden.

Goodman, M.R. (1974), "Study note in system dynamics", WrightAllen Press inc., Cambridge, Massachussets.

German Enquete Commission (1988), "Zur Sache; schutz der Erdatmosphäre; eine internationale Herausforderung", German Bundestag. 
Gibbs, M.J., Inglis, M.R., Linder, K.P. (1987), "Potential impacts of climate change on electric utilities", New York State Energy Research and Development Authority, New York.

Goldenberg J., Johansson T.B., Reddy A.K.N., Williams R.H. (1987a), "Energy for development", World Resources Institute, Washington D.C.

Goldenberg, J., Johansson, T.B., Reddy, A.K.N. and Williams, R.H. (1987b), "Energy for a sustainable world", World Resources Institute, Washington, D.C.

Gornitz, V., Lebedeff, L., and Hansen, J. (1982), "Global sea level trend in the past century", Science 215, 1611-1614.

Gornitz, V. et. al. (1984), "Global sea level trend in the past century", Science 226, 1418-1421.

Goudriaan, J. (1987), "The biosphere as driving force in the global carbon cycle", Netherlands Journal of Agricultural Science 35, 177187.

Goudriaan, J. (1988a), "Agriculture and climate", Lucht en omgeving, March.

Goudriaan, J. (1988b), "modelling biospheric control of carbon fluxes between atmosphere, ocean and land in view of climatic change", draft, to be published, Wageningen, The Netherlands.

Goudriaan, J. and Ketner, P. (1984), "A simulation study for the global carbon cycle including man's impact on the biosphere", Climatic Change 6, 167-192.

Haan, B. de: (1989), "Note concerning acean modelling", RIVM, Bilthoven, The Netherlands (in Dutch).

Hafkamp, W.A. (1984), "Economic-environmental modelling in a national-regional system", North Holland Publishing Company, Amsterdam, The Netherlands.

Hageman, H. (1988), Personal communication, Rijkswaterstaat, The Netherlands. 
Hahn, J: (1974), "The North Atlantic acean as a source of atmospheric $\mathrm{N}_{2} \mathrm{O}^{\prime}$, Tellus 26, 160-168.

Hahn, J. and Junge, C. (1977), "Atmospheric nitrous oxide: A critical review", Zeitschrift Naturforschung 32, 190-214.

Ham, G. van, Rotmans, J., and Kleijnen, J.P.C. (1990), "Sensitivity analysis by metamodels and experimental designs, applied to the greenhouse simulation model IMAGE", submitted to Kwantitatieve Methoden, Heiloo, the Netherlands.

Ham, J. van, (1987), “Tropospheric chemistry: proposal for a dutch research program in an international framework" (in Dutch), The Council for Environment and Nature Research, The Hague, the Netherlands.

Hameed, S., Pinto, J.P. and Stewart, R.W. (1979), "Sensitivity of the predicted $\mathrm{CO}-\mathrm{OH}-\mathrm{CH}_{4}$ perturbation to tropospheric $\mathrm{NO}_{x}$ concentration", Journal of Geophysical Research 84 (C2), 763-768.

Hammitt, J.K. et. al. (1986), "Product uses and market trends for potential ozone-depleting substances 1985-2000", Rand Corporation.

Hansen, J., Russel, G., Lacis, A., Fung, I., Rind, D., and Stone, P. (1985), "Climate response times: dependence on climate sensitivity and ocean mixing", Science 229, 857-859.

Hansen, J., Fung, I., Lacis, A., Rind, D., Lebedeff, S., Ruedy, R., Russel, G., and Stone, P. (1988), "Global climate changes as forecast by Goddard Institute for Space Studies three-dimensional model", Journal of Geophysical Research 93, 9341-9364.

Hao, W.M., Wofsy, S.C., McElroy, M.B., Beer, J.M., and Toqan, M.A. (1987), "Sources of atmospheric nitrous oxide from combustion", Journal of Geophysical Research 92, 3098-3104.

Harvey, L.D. Danny (1989a), "Transient climatic response to an increase of greenhouse gases", Climatic Change 15, 15-30.

Harvey, L.D. Danny (1989b), "Managing atmospheric $\mathrm{CO}_{2}$ ", Climatic Change 15, 343-381.

Hasselmann, K. (1988), "Climate and development: scientific efforts and assessment the state of the art ${ }^{n}$, paper presented at the World 
Congress, Climate and Development: Climatic Change and Variability and the Resulting Social, Economic and Technological Implications, Hamburg, FRG, 7-10 November, 1988.

Health Council of the Netherlands (1983), "First advice concerning the $\mathrm{CO}_{2}$ problem" (in Dutch), Staatsuitgeverij, The Hague, The Netherlands.

Health Council of the Netherlands (1986), "Second advice concerning the CO-problem: scientific insights and social consequnces" (in Dutch), Staatsuitgeverij, The Hague, The Netherlands.

Hecht, S. (1988), "Livestock expansion in the Brazilian tropics: dynamics and consequences", paper presented at the 46th International Congress of Americanists, Amsterdam.

Henderson-Sellers, A, and McGuffie, K. (1987), "A Climate Modelling Primer", Research and developments in climate and climatology, A. Henderson-Sellers and M.M. Verstraete (eds.), John Wiley \& Sons, Chichester.

Hettelingh, J.P. (1989), "Uncertainty in modelling regional environmental systems: the generalization of a watershed acidification model for predicting broad scale effects", Thesis, Free University of Amsterdam, The Netherlands.

Hewitt, C.N. and Harrison, R.M. (1985), "Tropospheric concentrations of the hydroxyl radical - a review", Atmospheric Environment 19, 545554 .

Hignett, T.P. (1985), "Outlook for the fertilizer industry 1978-2000". In: Fertilizer Handbook, International Fertilizer Development Center, Muscle Shoals, Alabama.

Hill, R.D., Rinker, R.G., Coucouvinos, A. (1984), "Nitrous oxide production by lightning", Journal of Geophysical Research 89, 1411.

Hoffert, M.I., Callegari, A.J., and Hsieh, C.T. (1981), "A box-diffusion carbon cycle model with upwelling, polar bottom water formation and a marine biosphere", In: Carbon cycle modelling, SCOPE 16, B. Bolin (ed.), John Willey and Sons, New York. 
Hoffman, J.S., Keynes, D., and Titus, J.G. (1983), Projecting future sea level rise", Washington, D.C.: Government Printing Office.

Hoffman, J.S., Wells, J.B., and Titus, J.G. (1983), "Projecting future sea level rise: methodology, estimates to the year 2100, and research needs", US GPO No. 055-000-00236-3, Government Printing Office, Washington D.C.

Hoffman, J.S. (1984), "Estimates of future sea level rise", in: Greenhouse Effect and Sea Level Rise: a Challenge for this Generation, M.C. Barth, and J.G. Titus (eds.), van Nostrand Rheinhold Company Inc., New York.

Holzapfel-Pschorn, A. and Seiler, W. (1986), "Methane emission during a cultivation period from an Italian rice paddy", Journal of Geophysical Research 92, 11803-11814.

Houghton, R.A., Hobbie, J.E., Mellillo, J.M., Moore, B. Peterson, B.J., Shaver, G.R. and Woodwell, G.M. (1983), "Changes in the carbon content of terrestrial biota and soils between 1860 and 1980: a net release of $\mathrm{CO}_{2}$ to the atmosphere", Ecological Monographs 53, no. 3, 235-262.

Houghton, R.A., Boone, R.D., Mellillo, J.M., Palm, C.A., Woodwell, G.M., Myers, N., Moore, B. and Skole, D.L. (1985), "Net flux of carbon dioxide from tropical forests in 1980", Nature $316,617-620$.

Houghton, R.A., Boone, R.D., Fruci, J.R., Hobbie, J.E., Mellillo, J.M., Palm, C.A., Peterson, B.J., Shaver, G.R. and Woodwell, G.M. (1987), "The flux of carbon from terrestial ecosystems to the atmosphere in 1980 due to changes in land use: geographic distribution of the global flux", Tellus 39B, 122-139.

Huizinga, P. (1988), Personal communication, Nederlandse Gasunie, Groningen, The Netherlands.

IEA (1989), "World energy outlook", Draft Paper, IEA, Paris.

IPCC (1989), "Emissions scenarios of the response strategies working group of the intergovernmental panel on climate change”, draft Report of the US-Netherlands Expert Group on Emissions Scenarios, Bilthoven, the Netherlands, 7-8 april. 
IPCC (1990), "Scientific assessment of climate change", Report prepared for IPCC by working Group 1, pre-publication copy, June 1990.

Isaksen, I.S.A. and $\mathrm{H} \phi \mathrm{v},(1987)$, "Calculation in trends in the tropospheric concentration of $\mathrm{O}_{3}, \mathrm{OH}, \mathrm{CO}, C \mathrm{H}_{4}$ and $N \mathrm{O}_{x}$, Tellus $39 \mathrm{~B}$, 271-285.

Jackman, C.H., and Guthrie, P.D. (1985), "Sensitivity of $\mathrm{N}_{2} \mathrm{O}, \mathrm{CFCl}_{3}$ and $\mathrm{CF}_{2} \mathrm{Cl}_{2}$; two-dimensional distributions to $\mathrm{O}_{2}$ absorption cross sections", Journal of Geophysical Research 90, 3919-3923.

Jäger, J. (1988), "Developing policies for responding to climatic change". A Summary of the Discussions and Recommendations of the Workshops held in Villach (28 sept-2oct 1987) and Bellagio (9-13 nov 1987), under the Auspices of the Beijer Institute, Stockholm World Climate Program Impact Studies, WMO/UNEP, WMO/TD-No. 225, $53 \mathrm{pp}$.

Jansen, T. (1987), "The terrestrial biospheric carbon cycle and the effect on the atmospheric $\mathrm{CO}_{2}$ concentration", Report of the Energy Study Centre, Petten, The Netherlands (in Dutch).

Jansen, P.H.M., Slob, W, Rotmans, J. (1990), "Uncertainty analysis and sensitivity analysis: an inventory of ideas, methods, and techniques from the literature", Report (in Dutch), forthcoming, Bilthoven, The Netherlands.

Jong, C.H. de (1985), "De gewenste veiligheid tegen overstromingen vanuit economisch oogpunt", Rijkswaterstaat.

Jong, C.H. de (1986), “De veiligheid van Nederland bij grate zeespiegelrijzing (een verkennend onderzoek)", Rijkswaterstaat.

Kavanaugh, M. (1987), "Estimates of future $\mathrm{CO}, \mathrm{N}_{2} \mathrm{O}$ and $\mathrm{NO}_{z}$ emissions from energy combustion", Atmospheric Environment 21, 463-468.

Keeling, C.D., Bacastow, R.B., and Whorf, T.P. (1982), "Measurements of the concentrations of carbon dioxide at Mauna Loa observatory, Hawaii ${ }^{\prime \prime}$, in Carbon Dioxide Review: 1982, 377-385, W.C. Clark (ed.), Oxford University Press, Oxford, United Kingdom. 
Keller, M., Kaplan, W.A. and Wofsy, S.C. (1986), "Emissions of $\mathrm{N}_{2} \mathrm{O}$, $\mathrm{CH}_{4}$ and $\mathrm{CO}_{2}$ from tropical forest soils", Journal of Geophysical Research 91, 11791-11802.

Keller, M., Kaplan, W.A. and Wofsy, S.C. (1987), "Emissions of $\mathrm{N}_{2} \mathrm{O}$, $\mathrm{CH}_{4}$ and $\mathrm{CO}_{2}$ from tropical forest soils", Journal of Geophysical Research $91,11791-11802$.

Kellog, W.W. (1983), "Feedback mechanisms in the elimate system affecting future levels of carbon dioxide", Journal of Geophysical Research $88,1263-1269$.

Kerr, R.A. (1984), "Doubling of methane supported", Science 226, 954955.

Khalil, M.A.K. and Rasmussen, R.A. (1982), "Secular trends of atmospheric methane $\left(\mathrm{CH}_{4}\right)$ ", Chemosphere 11 , no. 9, 877-883.

Khalil, M.A.K, and Rasmussen, R.A. (1983), "Increase and seasonal cycles of nitrous oxides in the earth's atmosphere", Tellus $35 \mathrm{~B}, 161-$ 169.

Khalil, M.A.K. and Rasmussen, R.A. (1984), "Carbon monoxide in the earth's atmosphere: increasing trend", Science 224, 55-56.

Khalil, M.A.K. and Rasmussen, R.A. (1985), "Causes of increasing atmospheric methane: depletion of hydroxyl radicals and the rise of emissions", Atmospheric Environment 19, no. 3, 397-407.

Khalil, M.A.K. and Rasmussen, R.A. (1987), "Atmospheric methane: trends over the last 10,000 year", Atmospheric Environment 21, 24452452.

Kiehl, J.T. and Dickinson, R.E. (1987), "A study of the radiative effects of enhanced atmospheric $\mathrm{CO}_{2}$ and $\mathrm{CH}_{4}$ on early earth surface temperatures", Journal of Geophysical Research 92, 2991-2998.

Kleijnen, J.P.C. (1987), "Statistical tools for simulation practitioners", Marcel Dekker, Inc., New York.

Kleijnen, J.P.C. (1990), "Statistics and deterministic simulation models: why not?", Catholic University of Brabant, Report no. FEW 435, Tilburg, The Netherlands. 
Kleijnen, J.P.C., Ham, G. van, and Rotmans; J. (1990), "Techniques for sensitivity analysis of simulation models: a case study for the greenhouse effect", submitted to Simulation.

Knoester, D. Baarse, G., Kuik, A.J., Louisse, C.J. (1989), "Systematical model" (in Dutch), Coastal defence after 1990, Technical Report 17, The Netherlands.

Kohlmaier, G.H., Kratz, G., Bröhl, H., and Siré, E.O. (1981), "The source-sink function of the terrestrial biota within the global carbon cycle", in Energy and Ecological modelling, W.J. Mitsch, R.W. Bosserman, and J.M. Klopatek (eds.), Elsevier Science Publ. Co., Amsterdam, 57-68.

Kohlmaier, G.H., Janecek, A., and Kindermann, J. (1990), "Positive and negative feedback loops within the vegetation/soil system in response to a $\mathrm{CO}_{2}$ greenhouse warming", in Soils and the greenhouse effect, Bouwman, A.F. (ed.), John Wiley and Sons, Chichester.

Kram, T. and Okken, P.A. (1989), "Integrated assessment of energyoptions for $\mathrm{CO}_{2}$ reduction", in Climate and Energy: the Feasibility of Controlling $\mathrm{CO}_{2}$ Emissions, P.A. Okken, R.J. Swart, and S. Zwerver (eds.), Kluwer Academic Publishers, Dordrecht, The Netherlands.

Kvenvolden, K.A. (1988), "Methane hydrates and global climate", Geobiochemical Cycles, vol. 2, no. 3, 221-229.

Lammerts, I. (1989). "Uncertainty analysis applied to the greenhouse model IMAGE" (in Dutich) University of Utrecht, the Netherlands.

Langeweg, F. (ed.) (1989), "Concern for tomorrow: a national environmental survey 1985-2010", Bilthoven, The Netherlands.

Lanly, J.P. (1982), "Tropical forest resources", FAO, Rome.

Lashof, D.A. (1989), "The dynamic greenhouse: feedback processes that may influence future concentrations of atmospheric trace gases and climatic change", to be published in Climatic Change.

Lashof, D.A., and Ahuja, D.R. (1990), "Relative global warming potentials of greenhouse gas emissions", Nature, 344, 529-531, Washington, D.C. 
Lashof, D.A., and Rotmans, J. (1990), "Evaluation of methods for estimating Global Warming Potentials (GWPs) of greenhouse gases", submitted to Climatic Change.

Levine, J.S, Shaw, E.F. (1983), "In situ aircraft measurements of enhanced levels of $\mathrm{N}_{2} \mathrm{O}$ associated with thunderstorm lightning", Nature 303,312 .

Levine, J.S., Rinsland, G.P. and Tennille, G.M. (1985), "The photochemistry of methane and carbon monoxide in the troposphere in 1950 and $1985^{\circ}$, Nature 318, 254-257.

Logan, J.A., Prather, M.J., Wofsy, S.C. and McElroy, M.B. (1981), "Tropospheric chemistry: a global perspective", Journal of Geophysical Research 86, 5163-5171.

Lowe, D.C., Brenninkmeijer, C.A.M., Manning, M.R., Sparks, R. and Wallaca, G. (1988), "Radiocarbon determination of atmospheric methane at Baring Head, New Zealand", Nature 332, 522-524.

Lugo, A.E., and Brown, S. (1980), "Tropical forest ecosystems: sources or sinks of atmospheric carbon", Unasylva 32 (129), 8-13.

Lugo, A.E., and Brown, S. (1986), "Steady state terrestrial ecosystems and the global carbon cycle", Vegetatio $68,83-90$.

Lyon, R.K., Kramlich, J.C., and Cole, J.A. (1989), "Nitrous oxide: sources, sampling and science policy", Environmental Science and Technology 23, (4), 1989.

Marland, G., and Rotty, R.M. (1984), "Carbon dioxide emissions from fossil fuels: a procedure for estimation and results for 1950-1982", Tellus 36B, 232-261.

Marland, G. and Rotty, R.M. (1985), "Greenhouse gases in the atmosphere: what do we know?", Journal of the Air Pollution Control Association 35, 1033-1038.

McKinsey \& Company, Inc. (1989), "Background paper on funding mechanisms", for the Ministrial Conference on Atmospheric Pollution and Climatic Change, with particular attention to Global Warming 6th and 7th november 1989. 
Meadows, D.L., Randers, J., and Behrens, W. (1972), "The limits to growth", Potomac Associates/Universe Books, New York.

Meier, M.F. (1984), "Contribution of small glaciers to sea level", Science $226,1418-1421$.

Michael, P., Hoffert, M., Tobias, M., and Tichler, J. (1981), "Transient climate response to changing carbon dioxide concentration", Climatic Change 3, 137-153.

Miller, A.S. and Mintzer, I.M. (1986), "The sky is the limit: Strategies for protecting the ozone layer" , World Resources Institute, Washington D.C.

Mintzer, I. (1987), "A matter of degrees: the potential for controlling the greenhouse effect", World Resources Institute, Washington, D.C.

Molofsky, J., Hall, C.A.S. and Meyers, N. (1986), "A comparison of tropical forest surveys", US Department of Energy, Report no. TRO32, Washington D.C.

Montalembert, M.R. de, and Clément, J. (1983), "Fuelwood supplies in the developing countries", FAO, Rome.

Montgomery, D.C. (1984), "Design and analysis of experiments" (second edition), J. Wiley \& Sons Inc., New York.

Mook, W.G., and Engelsman, F.M.R. (1983), "The atmospheric $\mathrm{CO}_{2}$ concentration and the role of the oceans" (in Dutch), Chemical Magazine, December 1983, 669-671.

Myers, N. (1984), "Conversion of tropical moist forests", National Academy of Sciences, Washington, D.C.

OECD: (1983), "Long-term outlook for the world automobile industry", Paris.

Oerlemans, J. (1982), "Response of the Antarctic ice sheet to a climatic warming: a model study", Journal of Climatology 2, 1-11.

Oerlemans, J. (1986a), "Glaciers as indicators of a carbon dioxide warming", Nature 320, no. 6063, 607-609. 
Oerlemans, J. (1986b), "Greenhouse warming and changes in sealevel", Presented at the Technical Workshop: Developing policies for responding to future climatic change, Villach, Australia, 28 Sept. 31 Oct. 1987, 14 pp.

Oerlemans, J. (1987), "Greenhouse warming and changes in sea-level", Presented at the Technical Workshop: Developing policies for responding to future climatic change, Villach, Austria, September $28-$ October 31 1987, $14 \mathrm{pp}$.

Oerlemans, J. (1988), "Simulation of historic glacier variations with a simple climate-glacier model", Journal of Glaciology 34, no. 118.

Oerlemans; J. (1989), "A projection of future sea level rise", Climatic Change.

Oeschger, H., Siegenthaler, U., Schotterer, V., and Gugelmann, A. (1975), "A box diffusion model to study the carbon dioxide exchange in nature", Tellus 27, 168-192.

Olsthoorn, T.N. (1987), "Integrated environmental modelling, definition report", (in Dutch), RIVM, Bilthoven, The Netherlands.

Olsthoorn, T.N., Jaarsveld, J.A. van, Knoop, J.M., Egmond, N.D. van, Mülschlegel, J.H.C., Duijvenboden, W. van (1989), "Integrated modelling in the Netherlands", paper presented at the International Conference on Environmental Models: Emissions and Consequences, Risø, Denmark, 22-25, May 1989.

Peng, T.H., Broecker, W.S., Freyer, H.D., and Trumbore, S. (1983), "A deconvolution of the tree-ring based ${ }^{13} \mathrm{C}$ record", Journal of Geophysical Research 88, 3609-3620.

Pestel, E. (1988), "Beyond the limits to growth" (in Dutch), Report to the Club of Rome, Amsterdam, The Netherlands.

Pugh, A.L. (1983), "DYNAMO User's manual", sixth edition, MIT Press, Cambridge, Massachusetts, and London.

Pulles, J.W. (1985), "Beleidsanalyse voor de waterhüshouding in Nederland (PAWN)", Rijkswaterstaat, Hoofddirectie van de Waterstaat, The Hague. 
Ramanathan, V., Lian, MS, Cess, RD. (1979), "Increased atmospheric $\mathrm{CO}_{2}$ : Zonal and Seasonal Estimates of the Effect on the Radiation Energy Balance and Surface Temperature", Journal of Geophysical Research $84,4949-4958$.

Ramanathan, V., Cicerone, R.J., Singh, H.B. and Kiehl, J.T. (1985), "Trace gas trends and their potential role in climate change", Journal of Geophysical Research-90, 5547-5566.

Repetto, R. (1988), "The forest for the trees? Government Policies and the Misuse of Forest Resources", World Resources Institute, Washingtion.

Response Strategies Working Group (1989a), "Emissions scenarios of the response strategies working group of the intergovernmental panel on climate change", Draft Report of the U.S.-Netherlands Expert Group on Emissions Scenarios, Bilthoven, The Netherlands.

Response Strategies Working Group (1989b), "Emissions scenarios of the response strategies working group of the intergovernmental panel on climate change", Draft Appendix of the U.S.-Netherlands Expert Group on Emissions Scenarios, Bilthoven, The Netherlands.

Revelle, R.R. (1983), "Probable future changes in sea level resulting from increased atmospheric carbon dioxide". In: 'Changing Climate', Report of the Carbon Dioxide Assessment Committee, NRC/NAS/ NAE/IOM, National Academy Press, Washington D.C.

Revelle, R.R. (1983), "Probable future changes in sea level resulting from increased carbon dioxide". In: Changing Climate, National Academy Press, Washington, D.C., 433-448.

Rijkswaterstaat (1989), "Survey technical foundation discussion paper coastal defence" (in Dutch), Coastal defence after 1990, Technical Report 0 , The Netherlands.

Robertson, G.P., and Tiedje, J.M., (1988), "Deforestation alters denitrification in a lowland tropical rain forest", Nature 336, 1988, 756-759.

Robin, G.Q. de (1986), "Changing the sea level: projecting the rise in sea level caused by warming of the atmosphere". In: "The greenhouse effect, climatic change, and ecosystems', B. Bolin, B.R. Döös, J. Jäger, 
R.A. Warrick (eds), SCOPE 29, Chichester, UK, John Wiley and Sons, 323-359.

Robin, G. de Q. (1986), "Changing the sea level, in the greenhouse effect, climatic change and ecosystems", Bolin, B., Döös, B.R., Jäger, J. and Warrick, R.A. (eds), John Wiley and Sons, New York, 323-359.

Ronde, J.G. de (1988), "What will happen to the Netherlands if sea level rise accelerates", Rijkswaterstaat.

Ronde, J.G. de, and Vrees, L. de (1990), Personal communication, Rijkswaterstaat, The Netherlands.

Ronde, J.G. de, and Vogel, J.A. (1989), "Sea level rise, hydro meteo scenario" (in Dutch), Coastal defence after 1990, Technical Report 6, The Netherlands.

Rotmans, J. (1986), "The development of a simulation model for the global $\mathrm{CO}_{2}$ problem", (in Dutch), Report no. 840751001 , RIVM, Bilthoven, The Netherlands.

Rotmans, J. (1989), "A scenario study of the greenhouse effect", In Atmospheric Ozone Research and its Policy Implications, (eds. T. Schneider, S.D. Lee, G.J.R. Wolters, L.D. Grant) 377-384, Elsevier Amsterdam.

Rotmans, J. (1990), "Sea level rise potentials", in Targets and Indicators, Draft Report of Working Group II of the Advisory Group on Greenhouse Gases (AGGG), UNEP/WMO.

Rotmans, J., Boois, H. de, and Swart, R.J. (1990a), "An integrated model for the assessment of the Greenhouse Effect: the Dutch approach", Climatic Change, Vol. 16, no. 3, 331-356; also printed as RIVM Report no. 758471009, Bilthoven 1989, The Netherlands.

Rotmans, J., Swart, R.J., and Vrieze, O.J. (1990b), "The role of the $\mathrm{CH}_{4}-\mathrm{CO}-\mathrm{OH}$ cycle in the greenhouse problem", Science of the Total Environment, Vol. 94, no. 3, 233-252.

Rotmans, J., and Swart, R.J. (1990), "Modelling tropical deforestation and its consequences for global climate", submitted to Ecological Modelling. 
Rotmans, J., and Swart, R.J.(1990), "Should the world phase-out fossil fuels?", to be published in Environmental Management.

Rotmans, J., and Elzen, M.G.J. den, (1990), "Temperature increasing potentials (TIPS) of greenhouse gases", Report no. 222901001, RIVM, Bilthoven, The Netherlands.

Rotmans, J., Lashof, D.A., and Elzen, M.G.J. den, (1990c), "Emissions, concentrations, and temperature", in Targets and Indicators, Draft Report of Working Group II of the Advisory Group on Greenhouse Gases (AGGG), UNEP/WMO.

Rotmans, J. and Eggink, E. (1988), "Methane as a greenhouse gas: a simulation model of the atmospheric chemistry of the $\mathrm{CH}_{4}-\mathrm{CO}-\mathrm{OH}$ cycle", Report no. 758471002, RIVM, Bilthoven, The Netherlands.

Rotmans, J., Ham, G. van, Kleijnen, J.P.C. (1990), "Sensitivity analysis by metamodels and experimental designs, applied on a simulation model of the greenhouse effect", (in Dutch), accepted by Kwantitatieve Methoden.

Rotmans, J., Vrieze O.J., Peek, G.H.J.C., Veraart, W.N.G.M. (1988), "Experimental design and metamadelling appled to a $\mathrm{CO}_{2}$ simulation model", (in Dutch), RIVM-report, Report no. 758471003, Bilthoven, the Netherlands.

Rotmans, J., and Vrieze, O.J. (1990), "Metamodelling and experimental design: case study of the greenhouse effect", to be published in the European Journal of Operations Research, and is also a research report of the University of Limburg, Report M 88-03, Maastricht, the Netherlands.

Rotty, R.M. and Masters, C.D. (1985), "Carbon dioxide from fossil fuel combustion: trends, resources and technological implications"; In: Atmospheric Carbon Dioxide and the Global Carbon Cycle; US Department of Energy, Washington D.C.

Rotty, R.M. (1987), "A look at $1989 \mathrm{CO}_{2}$ emissions from fossil fuels (with preliminary data for 1984)", Tellus 39, 203-208.

Sachs, J., Welch, W.J., Mitchell, T.J., and Wynn, H.P. (1989), “Design and Analysis of computer experiments", Statistical Science 4, no. 4, $409-435$. 
Sassin, W., Jäger, J., Primio, J.C. di, and Fischer, W. (1988), "Das Klimaproblem zwischen Naturwissenschaft und Politik", Kernforschungs-anlage Jährlich.

Schlesinger, M.E. (1985), "Analysis of results from energy balance and radiative-convective models ${ }^{m}$, in Projecting the Climatic Effects of Increasing Carbon Dioxide, US Department of Energy, DOE/ER-0237, Washington D.C.

Schlesinger, M.E. (1986), "Equilibrium and transient climatic warming induced by increased atmospheric $\mathrm{CO}_{2}$ ", Climate Dynamics-1, 35-51.

Schneider, S.H., and Thompson, S.L. (1981), "Atmospheric $\mathrm{CO}_{2}$ and climate: importance of the transient response ${ }^{\$}$, Journal of Geophysical Research 86, 3135-3147.

Schneider, S.H. (1989), "The changing climate", Scientific American, September $1989,38-47$.

Schuurmans, C.J.E., Oerlemans, J , Mureau, R., Dool, H.M., van den (1982), "Fysische aspecten van het $\mathrm{CO}_{2}$ probleem", Energiespectrum, September 1982, 218-227.

Seiler, W. (1984), "Contribution of biological processes to the global budget of $\mathrm{CH}_{4}$ in the atmosphere"; In: Current perspectives in microbiological ecology, Am. Soc. of Microbiology, Washington D.C.

Sheppard, J.C. et al. (1982), "Inventory of global methane sources and their production rates", Journal of Geophysical Research 87, 13051312 .

Shine, K.P., and Henderson-Sellers, A. (1983), "Modelling climate and the nature of climate models: A review", Journal of Climatology 3 , $81-94$.

Siegenthaler, U. and Oeschger, H. (1987), "Biospheric $\mathrm{CO}_{2}$ emissions during the past 200 years, reconstructed by deconvolution of ice core data", Tellus 39B, 140-154.

Soest, J.P. van, Kasteren, J. van, Jansen, F., Groen, A., Hartman, B., and Bakker, J. (1988), "Reality of the model" (in Dutch), Aramith Uitgevers, Amsterdam, The Netherlands. 
Spelman, M.J." and Manabe, S. (1984), "Infiuence of oceanic heat transport upon the sensitivity of a model climate", Journal of Geophysical Research $89,571-586$.

Stewart, R.W., Hameed, S. and Pinto, J.P. (1977), "Photochemistry of tropospheric ozone", Journal of Geophysical Research 82, 3134-3140.

Stive, M.J.F. (1989), "Coastal prediction development coastline 19902090", Coastal defence after 1990, Technical Report 5, Rijkswaterstaat; The Netherlands.

Swart, R.J. (1988), "Global anthropogenic emissions of carbon monoxide and non-methane volatile organic compounds as input for the $\mathrm{CH}_{4}$ CO-OH cycle module; A contribution to IMAGE, the Integrated Model for the Assessment of the Greenhouse Effect", Report no. 758471004, RIVM, Bilthoven, The Netherlands.

Swart, R.J., Boois, H. de, and Rotmans, J. (1989), "Targeting climate change", International Environmental Affairs, A Journal for Research and Policy 1, no 3, 222-234.

Swart, R.J. and Rotmans, J. (1989a), "Food or forest? Can the tropical forests survive along with continuing growth of population and economy?", In: Soils and the greenhouse effect, Bouwman, A.F. (ed.), 431-439, John Wiley and Sons, Chichester.

Swart, R.J. and Rotmans, J. (1989b), "A scenario study on causes of tropical deforestation and effects on the global carbon cycle", RIVM, Report no. 758471007, Bilthoven, The Netherlands.

Swart, R.J., and Rotmans, J. (1989), "IMAGE: a tool for long-term global greenhouse policy analysis", in Climate and Energy: the feasibility of controlling $\mathrm{CO}_{2}$ emissions, P.A. Okken, R.J. Swart, S. Zwerver (eds.), 18-27, Kluwer Academic Publishes, Dordrecht, The Netherlands.

Swart, R.J., and Rotmans, J. (1990a), "Emission scenarios for the Intergovernmental Panel on Climate Change", (in Dutch), Milieu 1990/3.

Swart, R.J., and Rotmans, J. (1990b), "Stabilizing atmospheric concentrations: towards international methane control", submitted to Ambio. 
Sze, N.D. (1977), "Anthropogenic CO emissions: implications for the atmospheric $\mathrm{CO}-\mathrm{OH}-\mathrm{CH}_{4}$ cycle $^{m}$, Science 195, 673-675.

Thissen, W: (1978), "Investigations into the club of Rome's worlds model: lessons for understanding complicated models", Thesis, Krips Repro, Meppel, The Netherlands.

Thissen, W. (1978), "Investigations into the worlds model: lessons for understanding complicated models", IEEE Transactions on Systems, Man, and Cybernetics, vol. smc-8, no. 3 .

Thomas, R.H., and Bentley, C.R. (1978), "A model for holocene retreat of the West Antarctic Ice Sheet", Quartenary Res 10, 150-170.

Thompson, A.M.and Cicerone, R.J. (1986) "Possible perturbations to atmospheric $\mathrm{CO}, \mathrm{CH}_{4}$ and $\mathrm{OH}^{*}$, Journal of Geophysical Research 92, 10853-10864.

Tricot, Ch. and Berger, A. (1987), "modelling the equilibrium and transient responses of glabal temperature to past and future trace gas concentrations", Climate Dynamics 2, 39-61.

United Nations (1986), "World population prospects, estimates and projections as assessed in $1984^{\prime \prime}$, Population Studies 98.

United Nations Environment Program (1987), "Montreal protocol on substances that deplete the ozone layer: final act", Montreal.

United Nations Environment Program, and World Meteorological Organization (1989), "Scientific assessment of stratospheric ozone" ,Chapter 4: ODPs and GWPs.

United States Department of Energy (1985a), "Atmospheric carbon dioxide and the global carbon cycle", J.R. Trabalka (ed.), USDOE, DOE/ER/-0239-1, Washington D.C.

United States Department of Energy (1985b), "Methods of uncertainty analysis for a global carbon dioxide model", R.H. Gardner and J.R. Trabalka (eds.), USDOE, DOE/OR/21400-4, Washington D.C.

United States Department of Energy (1985c), "Glaciers, ice sheets, and sea level: effect of a $\mathrm{CO}_{2}$ induced climatic change", USDOE, DOE/ER/60235-1, Washingtion D.C. 
Veen, C.J. van der, (1986), "Ice sheets, atmospheric $\mathrm{CO}_{2}$ and sea level", Thesis, University of Utrecht, the Netherlands.

Veen, C.J. van der (1986), "Ice sheets, atmospheric $\mathrm{CO}_{2}$ and sea level", Thesis, University of Utrecht, The Netherlands, $184 \mathrm{pp}$.

Volz, A., Ehhalt, D.H. and Derwent, R.G. (1981), "Seasonal and latitudinal variation of $C O$ and the tropospheric concentration of $O H$ radicals", Journal of Geophysical Research $86,5163-5171$.

Vrijling, J.K. (1985), "Enkele gedachten over een aanvaardbaar risiconiveau in Nederland", Technische Adviescommissie van de Waterkering, Government printing office, The Hague.

Wang, W.-C., and Molnar, G. (1985), "A model study of the Greenhouse Effect due to increasing atmospheric $\mathrm{CH}_{4}, \mathrm{~N}_{2} \mathrm{O}, \mathrm{CF}_{2} \mathrm{Cl}_{2}$, and $\mathrm{CFCl}_{3}$ ", Journal of Geophysical Research 90, 12971-12980-12980.

Washington, W.M., and Parkinson, C.L. (1986), "An introduction to three-dimensional climate modelling", Oxford University Press, Oxford, England.

Watts, J.A. (1982), "The carbon dioxide question: data sampler", in the Carbon Dioxide Review, W.C. Clark (ed.), 457-460.

Weiss, R.F. (1981), "The temporal and spatial distribution of tropospheric nitrous oxide", Journal of Geophysical Research 86, 7185-7195.

Wiersurn, K.F., and Ketner, P. (1989), "Reforestation, a feasible contribution to reducing the atmospheric carbon dioxide content", in Climate and Energy, the Feasibility of Controlling $\mathrm{CO}_{2}$ Emissions', P.A. Okken, R.J. Swart, and S. Zwerver (eds.), Kluwer Academic Publishers, Dordrecht, The Netherlands.

Wigley, T.M.L. (1985), "Carbon dioxide, trace gases and global warming", Climate Monitor 13, no. 5, 132-148.

Wigley, T.M.L. (1987), "Relative contributions of different trace gases to the greenhouse effect", Climate monitor-16, no. 1, 14-28.

Wigley, T.M.L. (1988), "Future CFC concentrations under the Montreal Protocol and their greenhouse effect implications", Nature 335, 333-335. 
Wigley, T.M.L., Raper, S.C.B. (1987), "Thermal expansion of sea water associated with global warming", Nature 330, 127-131.

Wigley, T.M.L. and Schlesinger, M.E. (1985), "Analytical solution for the effect of increasing $\mathrm{CO}_{2}$ on global mean temperature", Nature 315 , $649-652$.

Wind, H.G. (1987), "Impact of sea level rise on society", Balkema, Rotterdam, The Netherlands.

Wolman, M.G. and Fournier, F.G.A. (ed.) (1987), "Land transformation in agriculture ${ }^{*}$, SCOPE-report 32 , Wiley.

World Resources Institute/Institute for Environment and Development (1986), "World Resources 1986", Washington D.C.

World Resources Institute/Institute for Environment and Development (1987), "World Resources 1987", Washington D.C.

World Resources Institute/Institute for Environment and Development (1988/1989): “World Resources 1988/1989", Washington D.C.

Wuebbles, D. (1981), "The relative efficiency of a number of halocarbons for destroying stratospheric ozone", Report, UCID-18924, Lawrence Livermore National Laboratory, Livermore.

Wuebbles, D.J. (1983), "Chlorocarbon emission scenarios: potential impact on stratospheric ozone", Journal of Geophysical Research 88, $1433-1443$.

Yearsley, J.R., and Lettenmaier, D.P. (1987), "Model complexity and data worth: an assessment of changes in the global carbon budget", Ecological Modelling 39, 201-226. 
,

1:

: 


\section{Samenvatting}

Dit proefschrift handelt over een computersimulatiemodel voor de broeikasproblematiek. Het broeikaseffect is een van nature voorkomend verschijnsel, dat ervoor zorgt, dat de gemiddelde temperatuur aan het aardoppervlak zo'n $33^{\circ} \mathrm{C}$ warmer is, dan als dit effect er niet zou zijn. De belangrijkste broeikasgassen zijn waterdamp $\left(\mathrm{H}_{2} \mathrm{O}\right)$, kooldioxide $\left(\mathrm{CO}_{2}\right)$, methaan $\left(\mathrm{CH}_{4}\right)$, distikstofoxide $\left(\mathrm{N}_{2} \mathrm{O}\right)$ en chloorfluorkoolwaterstoffen (CFK's). Door een toename van de concentratie van deze gassen wordt verwacht dat een versterkt broeikaseffect zal optreden. In hoofdstuk 1 wordt een beschrijving gegeven van dit mondiale milieuprobleem.

Tevens wordt het simulatiemodel beschouwd in het licht van de school der globale, integrale milieumodellen. Zodoende wordt voor het betreffende model, genaamd IMAGE: an Integrated Model to Assess the Greenhouse Effect, een kader gesteld. Hoofdstuk 2 geeft een algemene beschrijving van IMAGE. Hierin wordt de modulaire opbouw van het model besproken, als ook een ruwe schets gepresenteerd van de afzonderlijke modules en hun onderlinge samenhang.

Vier scenario's zijn ontwikkeld, welke als basis dienen voor alle verdere modelberekeningen. Deze scenario's, $\mathrm{nl}$. ongeremde groei (A), gereduceerde trend (B), veranderende trend (C), en geforceerde trend (D), worden uitgebreid beschreven. Tenslatte wordt IMAGE vergeleken met andere geïntegreerde simulatiemodellen voor het broeikasprobleem.

In hoofdstuk 3 wordt het koolstofcyclus model behandeld. Dot koolstofcyclus model bestaat uit een emissie module, een atmosferische concentratie module, een oceaan module, een terrestrische biosfeer module, en een ontbossingsmodule. Uit tal van experimenten met dit model blijkt onder meer, dat:

- zelfs drastische maatregelen niet kunnen verhinderen, dat de $\mathrm{CO}_{2}$ concentratie de eerste tientallen jaren blijft stijgen;

- wereldwijde ontbossing een rampzalig verschijnsel is; vanwege het verloren gaan van specifieke soorten, toenemende erosie, bedreiging van de autochtone bewolking, en invloeden op lokaal en regionaal klimaat. Echter, het effect van ontbossing op de koolstofcyclus is relatief beperkt. Modelsimulaties tonen aan, dat de invloed op de gemiddelde atmosferische $\mathrm{CO}_{2}$ concentratie hoogstens $10 \%$ is;

- de belangrijkste oorzaak van de ontbossing de almaar toenemende vraag naar landbouwgrond is; 
- volgens modelsimulaties met IMAGE, bij een continuering van de huidige snelheid van ontbossing, het tropisch regenwoud binnen 60 jaar verdwenen kan zijn.

In de hoofdstukken 4, 5, 6 worden de modules van de andere broeikasgassen besproken. Alle onderliggende aannames, vereenvoudigingen, de structuur en methodiek van het modelleringsproces worden toegelicht. In hoofdstuk 4 wordt de $\mathrm{CH}_{4}$ - $\mathrm{CO}-\mathrm{OH}$ cyclus besproken en wordt aangetoond dat het weinig zin heeft alleen de methaan emissies te reduceren. Tevens wordt berekend, dat in potentie positieve terugkoppelingseffecten kunnen leiden tot een versterking van het temperatuurseffect ten gevolge van methaan.

Hoofdstuk 5 behandelt de module van distikstofoxide, met behulp waarmee wordt aangetoond dat op de lange termijn, $\mathrm{N}_{2} \mathrm{O}$ een belangrijk broeikasgas kan worden.

CFK's worden behandeld in hoofdstuk 6. Simulaties met de CFK module tonen aan dat een aanscherping van het Montreal Protocol onontbeerlijk is, teneinde de rol van CFK's in het broeikasprobleem te elimineren.

Hoofdstuk 7 is gewijd aan de klimaat module. Deze module, welke geen reële afspiegeling biedt van de complexe dynamiek van het klimaatsysteem, leent zich uitstekend woor het uitvoeren van gevoeligheidsexperimenten. Een serie van experimenten met deze modules is uitgevoerd. Simulaties met de klimaat module geven aan dat, in weerwil van eventuele ingrijpende maatregelen, niet te ontkomen valt aan een stijging van de gemiddelde temperatuur op aarde.

In hoofdstuk 8 worden de karakteristieken van de zeespiegelstijging module geschetst. Met deze module worden schattingen gepresenteerd van een toekomstige zeesplegelstijging, aan de hand van de reeds eerder gememoreerde scenario's. De schattingen lopen ruwweg uiteen van minimaal een halve tot maximaal één meter zeespiegelstijging aan het eind van de volgende eeuw.

Hoofdstuk 9 vormt de weerslag van een verkennende studie naar de socioeconomische gevolgen van het broeikaseffect voor Nederland. Voor verschillende sectoren van de Nederlandse samenleving (kustverdediging, waterhuishouding en watervoorziening) is getracht via model benaderingen de gevolgen te kwantificeren. De belangrijkste conclusie, welke aan de hand van deze simulaties kan worden getrokken, is dat de gevolgen voor Nederland weliswaar verstrekkend zijn, maar, mits tijdig wordt ingegrepen, de situatie beheersbaar blijft.

In hoofdstuk 10 wordt nader omschreven hoe een beleidswetenschap- 
pelijk milieumodel als IMAGE kan worden gebruikt in het internationale besluitvormingsproces betreffende klimaatveranderingen. Aan de hand van vooraf geformuleerde globale doelstellingen, worden de verschillende wegen geschetst waarlangs deze doelstellingen zouden kunnen worden bereikt, incluis de daarbij horende maatschappijbeelden.

In hoofdstuk 11 wordt getracht een index te ontwikkelen, waarmee lange termijn doelstellingen op het gebied van klimaatveranderingen kunnen worden geformuleerd. Het concept van de 'Temperature Increasing Potential' (TIP) wordt geintroduceerd, als tegenhanger van de 'Ozone Depletion Factor' (ODP). Verschillende methoden worden gepresenteerd om deze TIPs te berekenen. Met deze TIPs kan voor elk broeikasgas het potentiële globale temperatuurseffect worden berekend, en omgekeerd, kan via een te bereiken globale temperatuurstoename, voor elk sporegas de bijbehorende emissiehoeveelheid worden berekend.

Hoofdstuk 12 geeft een uitgebreide beschrijving van de gevoeligheidsanalyse welke is verricht op verschillende onderdelen van het simulatiemodel. Hiervoor zijn de technieken van metamodellering en experimentele proefopzetten gebruikt. Voor verschillende modules van IMAGE zijn adequate metamodellen en experimentele proefopzetten opgesteld. Aangetoond wordt, dat deze technieken bruikbare hulpmiddelen zijn bij het uitwoeren van gevoeligheidsanalyses op complexe simulatiemodellen.

In hoofdstuk 13 tenslotte, worden de bevindingen uit dit proefschrift samengevat en geëvalueerd. 
,

1:

: 


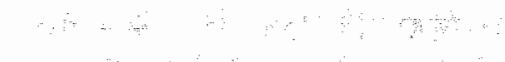




\section{Curriculum vitae}

Jan Rotmans werd op 29 maart 1961 geboren te Rotterdam. In 1979 behaalde hij het diploma VWO aan het Comenius College te Capelle a/d IJssel. Van 1979 tot 1986 studeerde hij Toegepaste Wiskunde aan de Technische Universiteit te Delft. Aldaar werd op 30 mei 1986 het doctoraal-examen wiskunde behaald. In het kader van het afstuderen binnen de vakgroep Operations Research werd gedurende de periode mei 1985 tot april 1986 stage gelopen bij het Rijksinstituut voor Volksgezondheid en Milieuhygiëne (RIVM), toen nog in Leidschendam. Bij het Centrum voor Wiskundige Methoden (CWM) werd een verkennend onderzoek gedaan naar de mathematische modellering van het broeikaseffect. Het resulterende afstudeerverslag vormde de kiem voor het latere promotieonderzoek.

In maart 1986 volgde de aanstelling tot wetenschappelijk medewerker Operations Research van het CWM bij het RIVM te Bilthoven. Bij deze afdeling werd een aanzienlijk deel van het promotieonderzoek verricht. Het onderhavige onderzoek werd sinds november 1989 voortgezet bij de afdeling Mondiale Biosfeer van het RIVM. 